\title{
Interactions between nutrition and medicine in effect and law
}

Citation for published version (APA):

de Boer, A. (2015). Interactions between nutrition and medicine in effect and law. [Doctoral Thesis, Maastricht University]. Maastricht University. https://doi.org/10.26481/dis.20151106ab

Document status and date:

Published: 06/11/2015

DOI:

10.26481/dis.20151106ab

Document Version:

Publisher's PDF, also known as Version of record

\section{Please check the document version of this publication:}

- A submitted manuscript is the version of the article upon submission and before peer-review. There can be important differences between the submitted version and the official published version of record.

People interested in the research are advised to contact the author for the final version of the publication, or visit the DOI to the publisher's website.

- The final author version and the galley proof are versions of the publication after peer review.

- The final published version features the final layout of the paper including the volume, issue and page numbers.

Link to publication

\footnotetext{
General rights rights.

- You may freely distribute the URL identifying the publication in the public portal. please follow below link for the End User Agreement:

www.umlib.nl/taverne-license

Take down policy

If you believe that this document breaches copyright please contact us at:

repository@maastrichtuniversity.nl

providing details and we will investigate your claim.
}

Copyright and moral rights for the publications made accessible in the public portal are retained by the authors and/or other copyright owners and it is a condition of accessing publications that users recognise and abide by the legal requirements associated with these

- Users may download and print one copy of any publication from the public portal for the purpose of private study or research.

- You may not further distribute the material or use it for any profit-making activity or commercial gain

If the publication is distributed under the terms of Article $25 \mathrm{fa}$ of the Dutch Copyright Act, indicated by the "Taverne" license above, 


\section{Interactions between nutrition and medicine in effect and law}

Alie de Boer 
(C) Alie de Boer, Maastricht, 2015

Interactions between nutrition and medicine in effect and law

ISBN: 978-90-9029319-6

Cover design: Karel Klerks

Lay-out: Alie de Boer

Printed by: MultiCopy Parkstad

The research presented in this dissertation was conducted at NUTRIM School of Nutrition and Translational Research in Metabolism which participates in the Graduate School VLAG (Food Technology, Agrobiotechnology, Nutrition and Health Sciences), accredited by the Royal Netherlands Academy of Arts and Science.

This project was partially funded by the Maastricht University Interfaculty Programme 'Eatwell'.

Financial support for printing of this thesis was kindly provided by Natuur- \& gezondheidsProducten Nederland, Yakult Nederland B.V., Augustfood and Spelt NV. 


\title{
Interactions between nutrition and medicine in effect and law
}

\author{
PROEFSCHRIFT \\ ter verkrijging van de graad van doctor aan de Universiteit Maastricht, \\ op gezag van de Rector Magnificus, Prof. dr. L.L.G. Soete, \\ volgens het besluit van het College van Decanen,
}

in het openbaar te verdedigen op vrijdag 6 november 2015 om 16:00 uur

door

\section{Alie de Boer}

geboren te Luinjeberd op 30 maart 1989 


\section{Promotores}

Prof. dr. A. Bast

Prof. dr. E. Vos

\section{Beoordelingscommissie}

Prof. dr. A. Opperhuizen (voorzitter)

Prof. dr. F.J.P.H. Brouns

Prof. dr. mr. B.M.J. van der Meulen (Wageningen UR)

Prof. dr. A.M.W.J. Schols

Prof. dr. R.F. Witkamp (Wageningen UR) 




\section{Contents}

Chapter 1. General introduction ......................................................................................... 9

Chapter 2. Implementation of the nutrition and health claim regulation - the case of

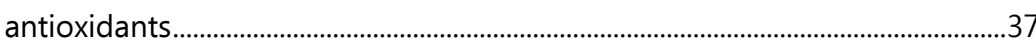

Chapter 3. Stakeholders' perception of the nutrition and health claim regulation ........75

Chapter 4. Enforcement of the nutrition and health claims regulation............................ 103

Chapter 5. International nutrition and health claims legislation ........................................ 125

Chapter 6 . The effect of dietary components on inflammatory lung diseases - a

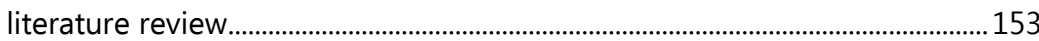

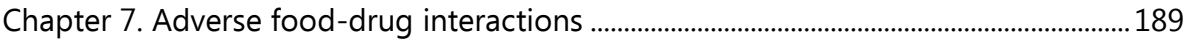

Chapter 8. A bioactive is a bioactive is a bioactive: active ingredients should be leading in health claims on functional foods....................................................215

Chapter 9. Summary and general discussion .....................................................................2. 233

Samenvatting en algemene conclusie ...............................................................247

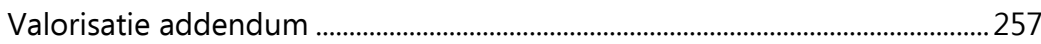

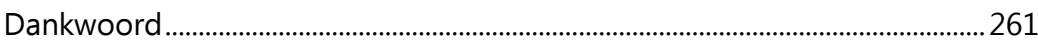

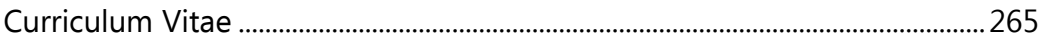

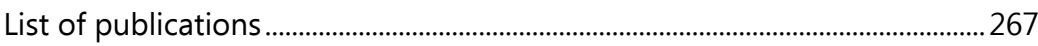





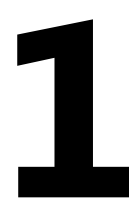

General introduction 
In the past, no distinction was made between food and drugs. All food and healing agents originated from nature. In various cultures practicing traditional medicine there is still no fundamental difference between nutrition and pharmaceutics, although in the Western world both specialisations developed separately ${ }^{(1,2)}$. Where nutrition provides necessary macro-and micronutrients to prevent diseases from occurring and to satisfy hunger, the main focus of pharmaceutics is to cure diseases or to alleviate the symptoms of disease ${ }^{(1,3)}$. This separation is also clearly made in legislation on foods and pharmaceutical products.

\section{The difference between food and drugs}

The strong relationship between food and pharmaceutics is exemplified by the well-known phrase "Let food be your medicine and medicine be your food. Only nature heals, provided it is given the opportunity. "of Hippocrates in $500 \mathrm{BC}^{(1)}$. Where in traditional medicine this connection between food and drugs was acknowledged, in the Western World both specialisations developed separately ${ }^{(1,2)}$. Nutrition and nutritional research first focussed on safety of food and on providing sufficient nutrients to prevent undernourishment ${ }^{(1,4)}$. Pharmacology developed as the study of the effects on organs or body functions elicited by natural or synthetically derived active compounds, focussing on single components and single targets to elicit these effects ${ }^{(1)}$. Due to both technological and economic developments, during the last decades the effects of nutrition in maintaining and improving health became more relevant. Next to the rediscovery of the potential effects of foods in diseases, the adverse effects of overconsumption were acknowledged, leading nutritional science to become a highly multi-disciplinary field including research areas as metabolomics and epidemiology ${ }^{(1,4)}$. In the meantime, in pharmacology it was acknowledged that it is not always possible to cure a disease with one drug affecting one target. Pharmacological research is therefore shifting from studying single, highly selective and potent drugs with a single medicinal product to research into pathways and multitarget pharmacology and the use of 'dirty drugs' affecting more sites of action, thereby lowering risk factors for diseases ${ }^{(1,3)}$. Currently the trend in nutritional and pharmacological 
research is to study the effects of active components with the so-called 'omics' or 'system biology' approach, thereby combining data generated by analysing effects on geneexpression patterns (transcriptomics), protein-expression patterns (proteomics) and on

metabolite profiles (metabolomics) ${ }^{(4-6)}$. By combining such measurements on different levels of complex biological systems, a holistic picture of disease processes and effects of active components can be generated ${ }^{(5-9)}$. These data can be used in new strategies as personalised nutrition and personalised medicine, when the individual genetic makeup is taken into account with advising or administering nutrition and medicinal products ${ }^{(6,7,10)}$.

Subsequent to the development of the separate concepts of nutrition and medicinal products, legislation was developed to regulate both types of products separately.

\section{Development of legislation}

In the Netherlands, the first piece of legislation on pharmaceutical practices and products originates from $1804^{(11)}$. From 1919 food is regulated by law in the Netherlands due to the enactment of the Commodities Act, which was replaced by the new Commodities Act in $1935^{(12)}$. Current legislation concerning medicinal products and foods in the Netherlands is based on European legislation and standards ${ }^{(13)}$. Subsequent to the collaboration started between different West European nations in an attempt to protect peace which was setup in 1949, six nations established the European Economic Community in 1958 to ensure closer collaboration $^{(14)}$. This supra-national organisation evolved to become the European Union, currently comprising 28 Member States which cooperate closely on a political, economic and monetary level ${ }^{(15)}$. In 1992, by signing the Maastricht Treaty, a single market was established throughout the different Member States in which goods, services, people and money can move freely ${ }^{(16)}$.

To create a level playing field within this single market throughout the different Member States, various pieces of legislation have been developed within the EU concerning economic, monetary and political issues ${ }^{(17)}$. Such legislation is developed upon proposal 
of the European Commission (EC), the executive body of the $\mathrm{EU}^{(18)}$. The Council of the European Union and the European Parliament are empowered to develop such legislation ${ }^{(18,19)}$. The EC and the Member States implement and enforce the developed legislation. By becoming a member of the EU, the Member States subscribe to all benefits and commitments of the partnership but remain autonomous states ${ }^{(19,20)}$. To ensure products on the market would be safe and to establish a level playing field in the European Union single market without trade barriers due to unharmonised and local pieces of legislation of Member States, legislation concerning medicinal products and foodstuffs was developed on an European level.

\section{European legislation on food}

One of the main aims of the establishment of free movement of goods due to the Treaty of Rome signed in 1957 was the free movement of foodstuffs throughout the internal market $^{(21,22)}$. The first specific legal act on hygiene of food products ${ }^{i}$ was developed in $1964^{(23)}$. The technological developments on food additives and flavourings led to the development of legislation upon these substances in the 1970s as well as rules upon other ingredients that were specifically prohibited or permitted ${ }^{(21,23)}$. In 1974 the case ruling of the Court of Justice in the Cassis de Dijon case ${ }^{\mathrm{ii}}$ introduced the principle of mutual recognition in food law: Member States could not prohibit food products that are lawfully produced and marketed in another Member State, since these products should be able to move freely through the internal market ${ }^{(21-23)}$. With the Member States not being able to

' Council Directive 64/433/EEC of 26 June 1964 on health problems affecting intra-Community trade in fresh meat. Repealed by Directive 2004/41/EC of the European Parliament and of the Council of 21 April 2004 repealing certain directives concerning food hygiene and health conditions for the production and placing on the market of certain products of animal origin intended for human consumption and amending Council Directives 89/662/EEC and 92/118/EEC and Council Decision 95/408/EC.

ii Rewe-Zentral AG v Bundesmonopolverwaltung für Branntwein, Judgement of the Court of 20 February 1979. Case 120/788. European Court Reports 1979-00649. 
unanimously develop specific legislation on foods, in 1985 a different approach was chosen: food products would be labelled into more detail, to ensure consumers would be able to make a well-informed choice ${ }^{(21)}$.

While from 1987 new legislation on foods was being developed, the different EU-wide food scares in the 1990s led to a call on reforming food law ${ }^{(21,22)}$. The EU's approach to food and food safety was radically reformulated and focussed more on consumer's health ${ }^{(21,24,25)}$. In 1997 the EC presented the Green Paper on the general principles of food law in the European Union, an advisory paper as the first step in developing new European food legislation ${ }^{(26)}$. Following the Green Paper and subsequent proposals described in the White Paper on Food Safety of 2000, in 2002 Regulation (EC) No 178/2002 iii was published $^{(27,28)}$. This Regulation is often referred to as the General Food Law (GFL) and is considered to be the cornerstone of European food law today by providing a framework for national and European legislation on food and all related issues ${ }^{(28,29)}$. Next to describing the general principles, requirements and definitions of food, the GFL also establishes the European Food Safety Authority (EFSA). EFSA is the independent European agency that provides scientific advice as well as scientific and technical support on all aspects concerning food and feed safety ${ }^{(28)}$. Advice from EFSA can be found in opinions and guidance documents which are used by the different EU institutions.

\section{European legislation on pharmaceutics}

European legislation on medicinal products for human use distinguishes two types of medicinal products: a medicinal product by presentation or a medicinal product by function $^{(30)}$. A medicinal product by presentation is defined as a product that presents itself as treatment or prevention for human disease, a medicinal product by function is a product with the function to diagnose or to restore, correct or modify physiological functions

\footnotetext{
iii Regulation (EC) No 178/2002 of the European Parliament and of the Council laying down the general principles and requirements of food law, establishing the European Food Safety Authority and laying down procedures in matters of food safety (Consolidated version 30 June 2014).
} 
following administrations to a human being ${ }^{(30)}$. These definitions are described in Directive 2001/83/ECiv , which forms the main piece of legislation on medicinal products for human use in the EU together with Regulation (EC) No 726/2004 .

Directive 2001/83/EC replaced a variety of Directives, which all dealt with specific aspects of medicinal products. The first relevant Directive in the European Communities, Directive $65 / 65 / E E C^{v i}$, and subsequent rulings following from this Directive were amended multiple times. This led to a complex and diverse situation of different pieces of legislation in the Member States of the European Union ${ }^{(31)}$. To create clarity upon these medicinal products and to harmonise different national procedures, Directive 2001/83/EC was adopted to safeguard public health while eliminating trade barriers ${ }^{(31)}$.

Due to amendments by other directives, Directive 2001/83/EC defines various concepts important in the regulation of these medicinal products, as herbal medicinal products ${ }^{\mathrm{vii}}$

iv Dir 2001/83/EC of the European Parliament and of the Council of 6 November 2001 on the Community code relating to medicinal products for human use (Consolidated version 16 November 2012).

The definitions of medicinal product by function and medicinal product by presentation were amended by Directive 2004/27/EC of the European Parliament and of the Council of 31 March 2004 amending Directive 2001/83/EC on the Community code relating to medicinal products for human use.

${ }^{\vee}$ Regulation (EC) No 726/2004 of the European Parliament and of the Council of 31 March 2004 laying down Community procedures for the authorisation and supervision of medicinal products for human and veterinary use and establishing a European Medicines Agency (Consolidated version 5 June 2013).

${ }^{v i}$ Council Directive 65/65/EEC of 26 January 1965 on the approximation of provisions laid down by Law, Regulation or Administrative Action relating to proprietary medicinal products. Repealed by Directive 2001/83/EC.

vii Directive 2004/24/EC of the European Parliament and of the Council of 31 March 2004 amending, as regards traditional herbal medicinal products, Directive 2001/83/EC on the Community code relating to medicinal products for human use. 
and homeopathic medicinal products ${ }^{\text {viii }}{ }^{(30)}$. Directive 2001/83/EC also describes general principles for the different procedures to obtain marketing authorisation for a medicinal product $^{(30,31)}$. Regulation (EC) No 726/2004 describes the centralised procedure to authorise human and veterinary products, which is one of the potential procedures for authorisation $^{(32)}$. It also defines the supervision of these products following authorisation and establishes the European Medicines Agency (EMA) as the agency that evaluates scientific evidence of medicine that are either produced or used within the $\mathrm{EU}^{(31-33)}$.

\section{The shifting perception of food and drugs}

Due to technical and economic changes in both the society as well as in manufacturing and food processes, the focus of nutrition research shifted during the last decades of the $20^{\text {th }}$ century towards maintaining and improving health ${ }^{(34)}$. Not only nutrition research shifted towards pharmacology, pharmacology is also seen to increasingly rely on expertise gained by nutrition research e.g. with pharmacology gaining insights in metabolic regulation of certain processes and knowledge upon the complexity of pathological disturbances in nutritional science, where pharmacodynamic and pharmacokinetic knowledge is helpful in understanding the fate of nutritional components ${ }^{(1)}$. The increased emphasis on the health enhancing capacities of food and food ingredients clearly depicts that the gap between nutrition and pharmacology is narrowing and both fields of expertise are seen to overlap ${ }^{(1,35)}$. Not only the aims of consuming foods and pharmaceutical products are becoming more alike, increased knowledge on disease development and diagnostics also weaken the boundaries between the concepts of health and disease ${ }^{(1)}$. The process of falling ill is demonstrated to be a continuum between a healthy state and

\footnotetext{
viii Directive 2004/27/EC of the European Parliament and of the Council of 31 March 2004 amending Directive 2001/83/EC on the Community code relating to medicinal products for human use (Consolidated version 30 April 2004).
} 
disease, which is specifically the case in chronic diseases, leading to a less well defined difference ${ }^{(1)}$.

\section{Legal blur}

The movement of nutrition and pharmacology towards each other led to the development of new health enhancing products, of which it is questionable whether these are still foods or become medicinal products ${ }^{(3,36,37)}$. The definitions of food and medicinal products can be found in the General Food Law and in Directive 2001/83/EC (due to amendments by Directive 2004/24/EC): food is defined as any (un)processed substance or product which is intended or can be expected to be ingested by humans; with a medicinal product, as described previously, being defined by its function or by its presentation ${ }^{(28,30,38)}$. Still, various cases were brought to the European Court of Justice (ECJ) when it was not clear under which legal framework a product should fall(36,39). The legal frameworks governing foods and medicinal products are mutual exclusive legal frameworks, causing that a framework does not apply to a product when this product falls within the scope of another legal framework ${ }^{(40)}$. With the definition of a product as a food or a medicinal product the so called 'rule of doubt' (Article 2(2) in Directive 2001/83/EC) is an important factor in the consideration of the applicability of one of these frameworks, which describes that when a product falls both within the definition of a medicinal product and a definition used in other legislation, the classification as medicinal product will prevail ${ }^{(30,36)}$.

The rulings of the ECJ clarified that substances can be used both in foods and medicinal products and thus do not control the determination whether a product is a food or medicinal product ${ }^{(36,40,41)}$. The end-product is therefore leading in this assessment ${ }^{(36,40)}$. Thereby the intended use of a product becomes highly important in this assessment: when the effect of consuming the product as it is intended to be consumed will result in significant changes or modifications of the metabolism, the product is a medicinal product $^{(39)}$. When the effect of consumption is maintaining specific functions, the product will be evaluated as a food product ${ }^{(42)}$. The manufacturer decides under which legal 
framework the product should fall, which is verified by enforcement authorities on a caseby-case basis ${ }^{(3,40)}$.

Highly correlating with the aspect of intended use is the dose of the active substance used in the product. As described previously, when this dose leads to significant effects or modifications of the metabolism, the product will be considered to be a medicinal product $^{(3,36,42)}$. Since various of the presented concepts, as 'significant changes' and the difference between pharmacological and physiological actions are not further specified, they are still under debate ${ }^{(39)}$. Rulings of the ECJ and other courts are used to clarify the legal concepts of foods, (traditional) medicinal products and various related product categories as food supplements ${ }^{(36,40,42)}$. This ongoing discussion intertwines the research presented in this thesis. With the coming to market of functional foods, foods that deliver benefits beyond their normal nutritional value, the notion that there is a grey area between the legal concepts of foods and medicinal products has become more apparent ${ }^{(1)}$.

\section{Functional foods}

The increased focus on health in nutrition research, as well as increased consumer interest in potential health enhancing effects of foods and the ageing population created the opportunity for the development of new food products, aiming to maintain or increase health $(1,37,42,43)$. Around the 1980 s the food industry started with the development of functional foods: foods that deliver benefits going beyond their normal nutritional value $^{(1,44,45)}$. Subsequent to the introduction of functional foods, also other food products focussed on health were brought to market as fortified foods, food supplements, nutraceuticals and superfoods ${ }^{(42)}$. These products have in common that they are foods which have actions that go beyond normal nutritional properties of food consumption due to an ingredient they do not contain (because it is removed in the production process) or due to addition of an ingredient. Ingredients that are added to elicit a health effect following consumption of the specific product are considered active ingredients, and when they come from nature these components are called 'bioactives'(46). 
The different products available on the market often fall within the grey area between the legal definitions of food and medicinal products and do not have their own legal status. The commonly used definitions of these different types of products available on the market are summarised in table 1 .

Table 1. Product categories on the borderline of foods and medicinal products.

\begin{tabular}{|c|c|}
\hline Term & Definition \\
\hline Bioactive & $\begin{array}{l}\text { Component in food or drug originating from nature, which } \\
\text { is able to modulate a biological process. }{ }^{(46,47)}\end{array}$ \\
\hline Cosmetic product & $\begin{array}{l}\text { Any (mixture of) substances intended to be placed in contact } \\
\text { with the external parts of the human membranes with an } \\
\text { exclusive or main view to clean, protect or perfume them. }{ }^{(48)}\end{array}$ \\
\hline Cosmoceuticals & $\begin{array}{l}\text { Commonly defined as cosmetic products with bioactive } \\
\text { ingredients which elicit positive cosmetic effects. }{ }^{(49)}\end{array}$ \\
\hline $\begin{array}{l}\text { Food for special } \\
\text { medical purposes }\end{array}$ & $\begin{array}{l}\text { Food used under medical supervision which are specifically } \\
\text { processed or formulated and intended for the dietary } \\
\text { management of patients, for partial or exclusive feeding of } \\
\text { patients with limited capacity to use ordinary food or } \\
\text { specific nutrients or with other medically-determined } \\
\text { nutrient requirements. }{ }^{(50)}\end{array}$ \\
\hline Food supplement & $\begin{array}{l}\text { Concentrated source of a nutrient or other nutritional or } \\
\text { physiological active substances aimed to supplement the } \\
\text { normal diet, marketed in dose form. }{ }^{(51)}\end{array}$ \\
\hline Functional foods & $\begin{array}{l}\text { Also known as 'health foods'. Commonly defined as food } \\
\text { products which provide health benefits beyond normal } \\
\text { nutritional effects due to biologically active } \\
\text { components. }{ }^{(44,52)}\end{array}$ \\
\hline $\begin{array}{l}\text { Health enhancing } \\
\text { product }\end{array}$ & $\begin{array}{l}\text { Commonly defined as a component/ingredient which can } \\
\text { boost health. }\end{array}$ \\
\hline $\begin{array}{l}\text { Herbal medicinal } \\
\text { product }\end{array}$ & $\begin{array}{l}\text { Any medicinal product which exclusively contains one or } \\
\text { more (combined) herbal substances or preparations as } \\
\text { active ingredient. }^{(38)}\end{array}$ \\
\hline $\begin{array}{l}\text { Homeopathic } \\
\text { medicinal product }\end{array}$ & $\begin{array}{l}\text { Any medicinal product produced from substances called } \\
\text { homeopathic stocks that are produced in accordance with a } \\
\text { homeopathic manufacturing procedure described by either } \\
\text { the European or national Pharmacopoeia. }{ }^{(53)}\end{array}$ \\
\hline
\end{tabular}


Table 1 (cont.). Product categories on the borderline of foods and medicinal products.

\begin{tabular}{|c|c|}
\hline Term & Definition \\
\hline Medical device & $\begin{array}{l}\text { Any article (e.g. instrument or software) intended to be used } \\
\text { for diagnostic and/or therapeutic purposes which may be } \\
\text { assisted but does not principally exert pharmacological, } \\
\text { immunological or metabolic activity. Can be used to } \\
\text { diagnose, prevent, monitor, treat or alleviate a disease; to } \\
\text { diagnose, monitor, treat, alleviate or compensate an injury } \\
\text { or handicap; investigate, replace or modify anatomy or a } \\
\text { physiological process or to control conception. }{ }^{(54)}\end{array}$ \\
\hline $\begin{array}{l}\text { Medicinal product by } \\
\text { function }\end{array}$ & $\begin{array}{l}\text { Any (combination of) substance(s) which may be } \\
\text { administered to humans aimed to make a medical diagnosis } \\
\text { or to restore, correct or modify human physiological } \\
\text { functions. }^{(53)}\end{array}$ \\
\hline $\begin{array}{l}\text { Medicinal product by } \\
\text { presentation }\end{array}$ & $\begin{array}{l}\text { Any (combination of) substance(s) which is presented for } \\
\text { treating or preventing a disease in human beings. }{ }^{(53)}\end{array}$ \\
\hline Nutraceutical & $\begin{array}{l}\text { Commonly defined as food products with bioactive } \\
\text { ingredients which elicit positive, drug-like effects on } \\
\text { health. }{ }^{(49)}\end{array}$ \\
\hline Nutricosmetics & $\begin{array}{l}\text { Commonly defined as food products with bioactive } \\
\text { ingredients which elicit positive cosmetic effects. }{ }^{(49)}\end{array}$ \\
\hline Superfood & $\begin{array}{l}\text { Marketing term for food products with supposedly high } \\
\text { amounts of healthy nutrients, claiming to lead to health } \\
\text { benefits. }{ }^{\left({ }^{2}\right)}\end{array}$ \\
\hline $\begin{array}{l}\text { Traditional herbal } \\
\text { medicinal product }\end{array}$ & $\begin{array}{l}\text { Herbal medicinal product intended for use without medical } \\
\text { supervision that can provide documentation on its } \\
\text { pharmacological use for at least } 30 \text { years and upon safety of } \\
\text { the formulation intended to be used. }{ }^{(38)}\end{array}$ \\
\hline
\end{tabular}

Within this thesis, the confusion leading to the creation of the grey area between both the effects and legal concepts of food and medicinal products is analysed by unravelling the effects of food and pharmaceuticals as well as legislation surrounding these products. By scientifically clarifying both the effects as well as legislation, we expect to elucidate what should be expected of consuming foods or pharmaceutical products as effects and explain how legislation could fit these products and effects. Therefore this thesis describes both 
biochemical and legal research, in order to clarify this grey area surrounding nutrition and medicinal products.

\section{Nutrition and health claims}

Although functional foods as such are not defined in legislation, the potential commercial statements on their effects are regulated by specific European legislation. To ensure the commercial outings on the effects of these functional foods and other food products will not mislead consumers by giving false or inaccurate claims that are not based on scientific evidence, and to improve the free movement of goods throughout the EU by harmonising national requirements, in 2006 the Nutrition and Health Claim Regulation ${ }^{\text {ix }}$ (NHCR) was published $^{(56-58)}$. The NHCR is one of the more specific regulations following from the regulatory framework provided by the GFL. The NHCR regulates all voluntary communications in any form on food products that state, suggest or imply that a food has certain characteristics ${ }^{(56)}$. The scientific evidence on which the claim is based is reviewed by the Panel on Dietetic Products, Nutrition and Allergies (the NDA Panel) of EFSA, to advise the EC on the authorisation of the $\operatorname{claim}^{(59,60)}$.

Within the NHCR, different types of claims are defined: it separates nutrition claims from health claims and subdivides health claims into three main categories ${ }^{(56)}$. Nutrition claims are claims which describe the nutritional properties of the food or functional ingredient. This broad range of claims entails both nutrient content claims and comparative claims. Nutrient content claims are claims describing the specific nutritional properties of a food or functional ingredient ${ }^{(56)}$. Comparative claims are nutrition claims which compare these nutritional properties of one product to another, and can only be made between foods within the same product category ${ }^{(56)}$. Health claims focus on the relationship between the

\footnotetext{
${ }^{\text {ix }}$ Regulation (EC) No 1924/2006 of the European Parliament and of the Council on nutrition and health claims made on foods (Consolidated version 13 December 2014).
} 
food or functional ingredient and a beneficial effect on health ${ }^{(56)}$. Health claims comprise three categories of claims: (i) Article 13.1 claims, general function claims that imply a health benefit which is based on accepted scientific evidence; (ii) Article 13.5 claims, new function claims that imply a health benefit which is based on newly developed scientific evidence (of which specific data can be protected for five years as proprietary data) and (iii) Article 14.1 claims, on (a) the reduction of disease risk by a food or functional ingredient or (b) children's development and health ${ }^{(56)}$. Subsequent to EFSA's review of the scientific substantiation of a claim, the EC decides upon authorising a claim or not by taking into account the recommendations of $\mathrm{EFSA}^{(59,60)}$. The authorised Article 13.1 and 13.5 health claims are published in Commission Regulation (EU) No 432/2012 ${ }^{\mathrm{x}}$, also called the positive list, which currently includes 234 claims $^{(61)}$. The Article 13.5 claims based on proprietary data and Article 14.1(a) and 14.1(b) claims are only publicly available in the online EU Register of Nutrition and Health Claims ${ }^{(62)}$.

\section{Debate on the NHCR}

By January 2008 over 40,000 claims were proposed by Member States, which were clustered to 4,637 claims to be assessed by EFSA on their scientific substantiation ${ }^{(63)}$. Subsequent to the review process of 2,758 claims, 222 general function health claims (Article 13.1 claims) were authorised for use by the EC following a positive assessment of EFSA by publishing Regulation 432/2012 ${ }^{(61)}$. Currently, 234 Article 13.1 and 13.5 claims are authorised for use within the $\mathrm{EU}^{(61,64-69)}$. With very few claims approved in comparison to the amount of potential claims provided to the authorities, a large debate followed on the NHCR as such. The enactment of the NHCR was thought to stimulate the development of healthier foods and food products with functional benefits and to improve the competitiveness of industrials ${ }^{(58,70)}$. Different industrials questioned the stimulating effect, e.g. due to indistinct criteria on the scientific evidence required for substantiating a claim,

\footnotetext{
${ }^{x}$ Commission Regulation (EU) No 432/2012 of 16 May 2012 establishing a list of permitted health claims made on foods, other than those referring to the reduction of disease risk and to children's development and health (Consolidated version 27 January 2015).
} 
while other parties critically following the regulation and its effects felt the guidance offered to applicant was extensive ${ }^{(57,58,70-72)}$. Many opinions and critiques on the NHCR and the used assessment criteria were expressed, but no critical evaluation of the NHCR has been published. We therefore analysed the implementation of the NHCR, taking food products containing antioxidants or claiming antioxidant activity as a case study. Within the field of food products containing antioxidants more than 200 claims were proposed and only eight claims were approved for use ${ }^{(62)}$. Chapter 2 studies which criteria are used to review the scientific substantiation of health claims and whether these criteria are suitable to assess a claim. It is hypothesised that these criteria not fully fit to assess health effects of foods and more specifically antioxidants, leading to the denial of most proposed health claims on antioxidants. In the debate on the effects of the NHCR it became clear that next to industrials and regulators also consumers and scientists are affected by the enactment of the NHCR. The perception of these stakeholders of the NHCR is reviewed in chapter 3, to unravel the ground(s) for disproving the putative health claims of virtual all antioxidants. Various differences in perceiving the implementation of the NHCR are expected, leading to different opinions about the effectiveness of the NHCR.

The NHCR not only aims to protect consumers from misleading, it also aims to establish a level playing field on the market of foods carrying claims ${ }^{(56)}$. Where in the case of developing legislation on a European level via a directive these pieces of legislation have to be implemented in national law, a regulation as the NHCR is immediately effective throughout all Member States ${ }^{(73)}$. Still, the developed regulation has to be enforced by the different national enforcement authorities ${ }^{(28,73-75)}$. Enforcement is here considered to entail both the identification of noncompliance and the corrective actions taken to ensure compliance $^{(74,76-78)}$. From literature it is known that enforcement is important to prevent the opportunity to abuse laws and thereby ensure consumer confidence, but also to ensure laws are effective ${ }^{(77-84)}$. When national enforcement authorities make different choices in their enforcement strategies (as in the amount of controls on nutrition and health claims) or their enforcement actions (e.g. fine immediately or persuade to ensure compliance), the establishment of a level playing field can therefore be questioned. The theoretical concepts 
surrounding enforcement of the NHCR and the actions taken by various Member States are studied in chapter 4, to review whether enforcement of the NHCR influences the establishment of a level playing field. Following from the previous chapter, a level playing field is not expected to be achieved when enforcement varies throughout Europe.

\section{Claims outside Europe}

The NHCR regulates all nutrition and health claims on the European market, whether they are developed or only marketed in Europe ${ }^{(56)}$. Other jurisdictions are also known to regulate these claims, as the National Labeling and Education ACT (NLEA) in the USA in 1990 and Japan in 1991 with the Foods for Specified Health Use (FOSHU) legislation ${ }^{(85,86)}$. These pieces of legislation all regulate the commercial statements made on food products. The Codex Alimentarius Committee on Food Labelling published guidelines to harmonise global rules and regulations on nutrition and health claims in which it described six claims and their requirements to be authorised, to harmonise rules and regulations on claims globally ${ }^{(87)}$. Still, various definitions are used (as depicted in table 2) and different requirements for claims are requested throughout jurisdictions. This gives rise to the question what the exact differences are between the different jurisdictions which regulate nutrition and health claims. Pieces of legislation from different jurisdictions are reviewed in chapter 5, to identify the optimal approach in reviewing and authorising nutrition and health claims from a scientific perspective, When this optimal approach is identified it could be used in building new legislation on nutrition and health claims instead of developing legislation which is later criticised.

Table 2. Definitions of nutrition and health claims.

\begin{tabular}{|l|l|}
\hline Term & Definition \\
\hline Claim (EU) & $\begin{array}{l}\text { Any form of voluntary communication stating, suggesting or } \\
\text { implying specific characteristics on a food product. }\end{array}$ \\
\hline $\begin{array}{l}\text { Claims referring to } \\
\text { children's } \\
\text { development and } \\
\text { health (EU) }\end{array}$ & $\begin{array}{l}\text { Article 14.1(b) claim. Claim on the relationship between a } \\
\text { food or food ingredient and a beneficial effect on the } \\
\text { development or health of children. }{ }^{(56)}\end{array}$ \\
\hline
\end{tabular}


Table 2 (cont.). Definitions of nutrition and health claims.

\begin{tabular}{|c|c|}
\hline Term & Definition \\
\hline FOSHU (Japan) & $\begin{array}{l}\text { Food for specified health uses. Japanese legislation on } \\
\text { functional foods claiming physiological effects on the } \\
\text { human body }{ }^{(88)} \text {. }\end{array}$ \\
\hline $\begin{array}{l}\text { General function claim } \\
\text { (EU) }\end{array}$ & $\begin{array}{l}\text { Article } 13.1 \text { claim. Claim on the relationship between a food } \\
\text { or food ingredient and a beneficial effect on growth, } \\
\text { development or other normal functions; psychological and } \\
\text { behavioural functions; or increasing satiety or reducing } \\
\text { hunger which are based on generally accepted scientific } \\
\text { evidence. }{ }^{(56)}\end{array}$ \\
\hline $\begin{array}{l}\text { Health claim (Codex } \\
\text { Alimentarius } \\
\text { Committee) }\end{array}$ & $\begin{array}{l}\text { Any representation which states, suggests or implies a } \\
\text { relationship between a food or food ingredient and } \\
\text { health. }{ }^{(87)}\end{array}$ \\
\hline Health claim (EU) & $\begin{array}{l}\text { Claim on the relationship between a food or food ingredient } \\
\text { and a beneficial effect on health. Definition used for claims } \\
\text { used on food products in the European Union. }{ }^{(56)}\end{array}$ \\
\hline Health claim (USA) & $\begin{array}{l}\text { Claim describing the role of a nutrient in reducing the risk of } \\
\text { disease. Definition used for claims used on food products in } \\
\text { the United States of America. }{ }^{\left({ }^{89}\right)}\end{array}$ \\
\hline $\begin{array}{l}\text { New function claim } \\
\text { (EU) }\end{array}$ & $\begin{array}{l}\text { Article } 13.5 \text { claim. Claim on the relationship between a food } \\
\text { or food ingredient and a beneficial effect on normal, } \\
\text { psychological or behavioural functions or increased satiety } \\
\text { or reduced hunger which are based on newly and/or } \\
\text { proprietary data. }{ }^{(56)}\end{array}$ \\
\hline Non-addition claim & $\begin{array}{l}\text { Nutrition claim that an ingredient has not been directly or } \\
\text { indirectly added to the food product. }{ }^{(87)}\end{array}$ \\
\hline $\begin{array}{l}\text { Nutrient function } \\
\text { claim }\end{array}$ & $\begin{array}{l}\text { Nutrition claim describing the physiologic role of the } \\
\text { nutrient in growth, development and normal functions of } \\
\text { the body. }{ }^{(87)}\end{array}$ \\
\hline $\begin{array}{l}\text { Nutrition claim (Codex } \\
\text { Alimentarius } \\
\text { Committee) }\end{array}$ & $\begin{array}{l}\text { Any representation which states, suggests or implies a food } \\
\text { has particular nutritional properties. }{ }^{(87)}\end{array}$ \\
\hline $\begin{array}{l}\text { Nutrition comparative } \\
\text { claim }\end{array}$ & $\begin{array}{l}\text { Nutrition claim comparing the nutrient or energy levels of } \\
\text { two or more food products. }{ }^{\left({ }^{7}\right)}\end{array}$ \\
\hline Nutrient content claim & $\begin{array}{l}\text { Nutrition claim describing the level of a nutrient contained } \\
\text { in a food product. }{ }^{(87)}\end{array}$ \\
\hline
\end{tabular}


Table 2 (cont.). Definitions of nutrition and health claims.

\begin{tabular}{|c|c|}
\hline Term & Definition \\
\hline $\begin{array}{l}\text { Qualified health claim } \\
\text { (USA) }\end{array}$ & $\begin{array}{l}\text { Health claim substantiated by emerging scientific evidence, } \\
\text { accompanied by a disclaimer about this lower level of } \\
\text { substantiating evidence. Category of claims used for food } \\
\text { products in the United States of America. }{ }^{(90,91)}\end{array}$ \\
\hline $\begin{array}{l}\text { Qualified FOSHU } \\
\text { (Japan) }\end{array}$ & $\begin{array}{l}\text { Food with health function which is not substantiated on } \\
\text { scientific evidence meeting the level of FOSHU, or having } \\
\text { certain effectiveness without established mechanism of } \\
\text { action. }{ }^{\left({ }^{88)}\right.}\end{array}$ \\
\hline $\begin{array}{l}\text { Reduction of disease } \\
\text { risk claim (Codex } \\
\text { Alimentarius } \\
\text { Committee) }\end{array}$ & $\begin{array}{l}\text { Claim relating the consumption of a food or food ingredient } \\
\text { to the reduction of a major risk factor in the development of } \\
\text { a disease or health-related condition. }{ }^{(87)}\end{array}$ \\
\hline $\begin{array}{l}\text { Reduction of disease } \\
\text { risk FOSHU (Japan) }\end{array}$ & $\begin{array}{l}\text { Food with health function of which it is clinically and } \\
\text { nutritionally established that the ingredient reduces a } \\
\text { disease risk. }{ }^{(88)}\end{array}$ \\
\hline SSA claim (USA) & $\begin{array}{l}\text { Health claim meeting the SSA standard, indicating that the } \\
\text { Food and Drug Agency has determined, 'based on the } \\
\text { totality of the publicly available evidence (including evidence } \\
\text { from well-designed studies conducted in a manner which is } \\
\text { consistent with generally recognised scientific procedures } \\
\text { and principles), that there is significant scientific agreement } \\
\text { among experts qualified by scientific training and experience } \\
\text { to evaluate such claims, that the claim is supported by such } \\
\text { evidence.'(92) }\end{array}$ \\
\hline $\begin{array}{l}\text { Structure-function } \\
\text { claim (USA) }\end{array}$ & $\begin{array}{l}\text { Claim describing the role of a nutrient in maintaining } \\
\text { health. }{ }^{(93)}\end{array}$ \\
\hline Therapeutic claim & $\begin{array}{l}\text { Claim on the relationship between a food or food ingredient } \\
\text { and the treatment or mitigation of a disease or condition or } \\
\text { the restoring or otherwise modifying effects to an existing } \\
\text { function. Following approval before marketing, food } \\
\text { products in Canada are allowed to carry such claims. }{ }^{(85,94)}\end{array}$ \\
\hline
\end{tabular}




\section{Combining nutrition and pharmaceutical products}

Next to shifting towards each other, nutrition and pharmacology are combined more often. With the acknowledgment of the health enhancing potential of nutrition, its use in treating disease is increasing ${ }^{(1,3)}$. This is mainly seen in the treatment of multifactorial, chronic diseases where specific dietary components can be used to complement the pharmacological treatment or to decrease the need for medication ${ }^{(3,95)}$. Since some dietary compounds are expected to positively affect diseases, in chapter 6 we studied the potential effects of different dietary components in chronic inflammatory lung diseases as asthma, chronic obstructive pulmonary disease (COPD) and interstitial lung diseases (ILD) as sarcoidosis and idiopathic pulmonary fibrosis ${ }^{(96-99)}$. This group of diseases is characterised by inflammation, which is commonly treated with glucocorticosteroids $^{(100,101)}$. These glucocorticosteroids are however not effective in all patients and serious side effects are shown to be caused by glucocorticosteroid use ${ }^{(98,100,101)}$. Therefore the use of dietary components to increase the potency of these medicinal products or to decrease their use would be an interesting opportunity. Since the effect of dietary components on inflammatory markers and lung function are tested in many different models with many different outcomes, we scored the studies found through this systematic review to identify the most potent dietary components to be used by patients suffering from chronic inflammatory lung diseases.

Functional foods and other health enhancing food products containing (bio)active ingredients are generally intended for consumers that have slightly higher risk on disease or consumers already using medication to lower these risk factors for chronic diseases ${ }^{(3)}$. Nonetheless, the consumption of functional foods potentially gives rise to the risk that patients will replace their therapy with functional foods, which will not have similar actions as these prescribed medicinal products ${ }^{(3,102)}$. The other way around is also imaginable: when patients will combine prescribed medicinal products with functional foods or other health enhancing products, drugs could become ineffective or the effects could be enhanced $^{(3)}$. Adverse effects due to the combination of prescribed pharmaceuticals with 
health enhancing products containing bioactive substances can be reported to the Netherlands Pharmacovigilance Centre Lareb by patients, health professionals and the pharmaceutical industry ${ }^{(103)}$. Where in chapter 6 the positive effects of interactions between nutrition and medicinal products are studied, in chapter $\mathbf{7}$ the adverse effects resulting from interactions between food and drugs are discussed. We therefore studied the adverse effects reported to Lareb to identify clinically relevant interactions and analyse where these interactions originate from, to identify the situations in which both consumers and health professionals should take such potential interactions into account.

\section{Biochemical knowledge and the NHCR}

Functional foods are the ultimate example of the shifting focus of nutrition towards health enhancing products and the NHCR, by regulating the voluntary information about the effects of food products, is a nice example of how the legislature tries to deal with this shift. The NHCR strictly applies to food products but requires the active components to be completely identified. Whether this requirement is applied fully throughout the assessment of potential health claims is studied in chapter 8 . It is hypothesised that the active ingredient is often based on the food matrix, instead of the specific bioactive component which is responsible for the health effect. We review what the effect would be of assessing the ingredient as bioactive component instead of linking it to the food matrix since these effects can only be fully apprehended by combining toxicological and nutritional science with the legal perspective.

\section{Aim of this thesis}

Nutrition and medicinal products are regulated as separate concepts in European law. The legal definitions and intended effects following consumption of nutrition and pharmaceutics are however shifting. This shift must not only be elucidated in effect, but also the consequences on legislation have to be analysed. In response to the changing concepts of nutrition, a new regulation dealing with the commercial expression of effects 
of food products was developed: the NHCR. As indicated in previous sections, different elements are studied within this thesis.

The European nutrition and health claim regulation is a clear example of legislation interacting with science, since scientific knowledge is a fundamental aspect within the regulation. Therefore the use of scientific knowledge (chapter 2), the implementation (chapter 3) and enforcement of the nutrition and health claim legislation (chapter 4) have been analysed within this thesis. Subsequently, pieces of legislation concerning nutrition and health claims in other jurisdictions have been examined (chapter 5), to identify how science could be used best in this type of legislation.

To clarify the effects combining food and medicinal products, the use of nutrition in disease is reviewed. More specifically, the use of dietary components in chronic inflammatory lung diseases have been studied (chapter 6), since patients suffering from these diseases often develop resistance or do not respond at all to their anti-inflammatory medication. Interactions between nutrition and medicine can however also elicit adverse effects, since both types of products contain bioactive substances. Therefore the adverse events potentially caused due to interacting effects of nutrition and medicine reported to the Dutch Pharmacovigilance Centre Lareb have been studied (chapter 7), to assess where these interactions arise.

Both fields of interest, law and effect, are combined in chapter 8. There the potential use of unravelling the precise active substance, as proposed in chapter 6 and 7, is applied to the nutrition and health claim regulation to review whether this creates more clarity. 


\section{References}

1. Georgiou NA, Garssen J \& Witkamp RF (2011) Pharma-nutrition interface: The gap is narrowing. Eur. J. Pharmacol. 651, 1-8.

2. Boersma HH \& Stolk LML (1999) 'Innemen 2 uur voor of na een menu met spruitjes'. Voeding en het metabolisme van geneesmiddelen. Pharm. Weekbl. 134, 1254-1259.

3. Eussen SRBM, Verhagen $\mathrm{H}$, Klungel $\mathrm{OH}$, et al. (2011) Functional foods and dietary supplements: Products at the interface between pharma and nutrition. Eur. J. Pharmacol. 668, S2-S9.

4. Afman L \& Müller M (2006) Nutrigenomics: from molecular nutrition to prevention of disease. J. Am. Diet. Assoc. 106, 569-576.

5. Van Ommen B \& Stierum R (2002) Nutrigenomics: exploiting systems biology in the nutrition and health arena. Curr Opin Biotechnol 13, 517-521.

6. Van Ommen B, Keijer J, Heil SG, et al. (2009) Challenging homeostasis to define biomarkers for nutrition related health. Mol Nutr Food Res 53, 795-804.

7. Lindon JC, Holmes E \& Nicholson JK (2006) Metabonomics techniques and applications to pharmaceutical research \& development. Pharm. Res. 23, 1075-1088.

8. Mollet B \& Rowland I (2002) Functional foods: at the frontier between food and pharma. Curr. Opin. Biotechnol. 13, 483-485.

9. Nicholson JK, Holmes E \& Lindon JC (2007) Metabonomics and Metabolomics Techniques and Their Applications in Mammalian Systems. In The Handbook of Metabonomics and Metabolomics, pp. 1-34 [Lindon JC, Nicholson JK, Holmes E, editors]. Amsterdam, the Netherlands: Elsevier.

10. Ginsburg G (2001) Personalized medicine: revolutionizing drug discovery and patient care. Trends Biotechnol. 19, 491-496.

11. Verordening omtrent het Geneeskundig Onderzoek en Toevoorzicht binnen de Bataafse Republiek. Known as 'Geneeskundige Staatsregeling'.

12. Warenwet naar Koninklijk Besluit van 28 december 1935. Last amended by Wet van 17 december 2014 tot wijziging van de Wet op bedrijfsorganisatie en andere wetten in verband met de opheffing van de bedrijfslichamen.

13. Van der Meulen B \& van der Velde M (2008) Food law: development, crisis and transition. In European Food Law Handbook, pp. 229-252. Wageningen: Wageningen Academic Publishers.

14. European Union (2015) A peaceful Europe - the beginnings of cooperation. http://europa.eu/about-eu/eu-history/1945-1959/index_en.htm (accessed April 2015).

15. European Union (2015) History 2013. http://europa.eu/about-eu/eu-history/2010today/2013/index_en.htm (accessed April 2015).

16. European Union (2015) Europe without frontiers. http://europa.eu/about-eu/euhistory/1990-1999/index_en.htm (accessed April 2015).

17. European Union (2015) Europa - How the EU works. http://europa.eu/abouteu/index_en.htm (accessed April 2015).

18. European Union (2015) How EU decisions are made. http://europa.eu/eu-law/decisionmaking/procedures/index_en.htm\#40 (accessed June 2015). 
19. Van der Meulen B \& van der Velde M (2008) The institutions of the European Community. In European Food Law Handbook, pp. 161-216. Wageningen: Wageningen Academic Publishers.

20. European Union (2015) EU institutions and other bodies. http://europa.eu/abouteu/institutions-bodies/index_en.htm (accessed April 2015).

21. Leibovitch EH (2007) Food safety regulation in the European Union: Toward an unavoidable centralization of regulatory powers. Tex. Int. Law J. 43, 429-452.

22. Van der Meulen B (2013) The Structure of European Food Law. Laws 2, 69-98.

23. Directorate-General Health and Consumer Protection \& European Commission (2007) 50 years of food safety in the European Union. Luxembourg: Office for Official Publications of the European Communities.

24. Vos E (2000) EU Food Safety Regulation in the Aftermath of the BSE Crisis. J. Consum. Policy 23, 227-255.

25. Chalmers D (2003) 'Food for Thought': Reconciling European Risks and Traditional Ways of Life. Mod. Law Rev. 66, 532-562.

26. European Commission (1997) The general principles of food law in the European Union Commission green paper. COM 176.

27. European Commission (2000) White paper on food safety. COM 719.

28. European Parliament and Council of the European Union (2002) Regulation (EC) No 178/2002 of the European Parliament and of the Council of 28 January 2002 laying down the general principles and requirements of food law, establishing the European Food Safety Authority and laying down procedures in matters of food safety. OJ L 31 45, 1-24.

29. Szajkowska A (2009) From mutual recognition to mutual scientific opinion? Constitutional framework for risk analysis in EU food safety law. Food Policy 34, 529-538.

30. European Parliament and Council of the European Union (2001) Directive 2001/83/EC of the European Parliament and of the Council of 6 November 2001 on the Community code relating to medicinal products for human use. OJ L $31144,67-128$.

31. Shorthose S \& Smillie M (2011) Overview of European Pharmaceutical Regulatory Requirements. In Guid. to EU Pharm. Regul. Law, 2nd editio, pp. 3-32 [Shorthose S, editor]. Alphen aan den Rijn, the Netherlands: Kluwer Law International.

32. European Parliament and Council of the European Union (2004) Regulation (EC) No 726/2004 of the European Parliament and of the Council of 31 March 2004 laying down Community procedures for the authorisation and supervision of medicinal products for human and veterinary use and establishing a European Medicines Agency. OJ L 136 47, 1-33.

33. European Medicines Agency (2015) European Medicines Agency - About Us. http://www.ema.europa.eu/ema/index.jsp?curl=pages/about_us/general/general_content_0 00235.jsp\&mid = (accessed April 2015).

34. Bigliardi B \& Galati F (2013) Innovation trends in the food industry: The case of functional foods. Trends Food Sci. Technol. 31, 118-129.

35. Mark-Herbert C (2004) Innovation of a new product category - functional foods. Technovation 24, 713-719.

36. Melchor SR \& Timmermans L (2009) It's the Dosage Stupid: The ECJ Clarifies the Border between Medicines and Botanical Food Supplements. EFFL 1/2009, 185-191.. 
37. Weenen TC, Ramezanpour B, Pronker ES, et al. (2013) Food-pharma convergence in medical nutrition- best of both worlds? PLoS One 8, e82609.

38. European Parliament and Council of the European Union (2004) Directive 2004/24/EC of the European Parliament and of the Council of 31 March 2004 amending, as regards traditional herbal medicinal products, Directive 2001/83/EC on the Community code relating to medicinal products for human use. OJ L 136 47, 85-90.

39. Lachenmeier DW, Steffen C, El-Atma O, et al. (2012) What is a food and what is a medicinal product in the European Union? Use of the benchmark dose (BMD) methodology to define a threshold for 'pharmacological action'. Regul. Toxicol. Pharmacol. 64, 286-295.

40. Coppens $P$ (2013) Classifying food supplements: determining what are foods vs what is medicine in the European Union. Agro FOOD Ind. High Tech 24, 36-38.

41. Coppens P (2008) The Use of Botanicals in Food Supplements and Medicinal Products: The Co-Existence of Two Legal Frameworks. EFFL 2/2008, 93-100.

42. Gulati OP \& Berry Ottaway P (2006) Legislation relating to nutraceuticals in the European Union with a particular focus on botanical-sourced products. Toxicology 221, 75-87.

43. Menrad K (2003) Market and marketing of functional food in Europe. J. Food Eng. 56, 181188.

44. Katan MB \& Roos NM (2004) Promises and Problems of Functional Foods. Crit. Rev. Food Sci. Nutr. 44, 369-377.

45. Siró I, Kápolna E, Kápolna B, et al. (2008) Functional food. Product development, marketing and consumer acceptance--a review. Appetite 51, 456-467.

46. Biesalski H-K, Dragsted LO, Elmadfa I, et al. (2009) Bioactive compounds: definition and assessment of activity. Nutrition 25, 1202-1205.

47. Mateo Anson N, Hemery YM, Bast A, et al. (2012) Optimizing the bioactive potential of wheat bran by processing. Food Funct. 3, 362-375.

48. European Parliament and Council of the European Union (2009) Regulation (EC) No 1223/2009 of the European Parliament and of the Council of 30 November 2009 on cosmetic products. OJ L 342 52, 59-209.

49. Harrison-Dunn A-R (2015) In the eye of the beholder: Where does the EU stand on beauty claims? http://www.nutraingredients.com/Trends/Health-claims/Where-does-the-EU-standon-beauty-claims (accessed April 2015).

50. European Parliament and Council of the European Union (2013) Regulation (EU) No 609/2013 of the European Parliament and of the Council of 12 June 2013 on food intended for infants and young children, food for special medical purposes, and total diet replacement for weight control and repealing Council Directive 92/52/EEC, Commission Directives 96/8/EC, 1999/21/EC, 2006/125/EC and 2006/141/EC, Directive 2009/39/EC of the European Parliament and of the Council and Commission Regulations (EC) No 41/2009 and (EC) No 953/2009. OJ L 181 56, 35-56.

51. European Parliament and Council of the European Union (2002) Directive 2002/46/EC of the European Parliament and of the Council of 10 June 2002 on the approximation of the laws of the Member States relating to food supplements. OJ L 183 45, 51-57.

52. European Food Information Council (2015) Functional Foods. http://www.eufic.org/article/en/expid/basics-functional-foods/ (accessed June 2015). 
53. European Parliament and Council of the European Union (2004) Directive 2004/27/EC of the European Parliament and of the Council of 31 March 2004 amending Directive 2001/83/EC on the Community code relating to medicinal products for human use. OJ L 136 47, 34-57.

54. Council of the European Union (1990) Council Directive 90/385/EEC of 20 June 1990 on the approximation of the laws of the Member States relating to active implantable medical devices. OJ L 189 33, 17-36.

55. Voedingscentrum

Superfoods. http://www.voedingscentrum.nl/encyclopedie/superfoods.aspx (accessed April 2015).

56. European Parliament and Council of the European Union (2006) Regulation (EC) No 1924/2006 of the European Parliament and of the council of 20 December 2006 on nutrition and health claims made on foods. OJ L 404 49, 9-25.

57. Hoad D (2011) Scientific Method and the Regulation of Health and Nutritional Claims by the European Food Safety Authority. Bull Sci Technol Soc 31, 123-133.

58. Moors EHM (2012) Functional foods: regulation and innovations in the EU. Innovation 25, 424-440.

59. Verhagen H, Vos E, Francl S, et al. (2010) Status of nutrition and health claims in Europe. Arch Biochem Biophys 501, 6-15.

60. European Commission (2011) 2nd Collective Answer on Regulation (EC) No. 1924/2006 http://ec.europa.eu/food/food/labellingnutrition/claims/docs/collective_answer_20052011_ en.pdf (accessed April 2015).

61. European Commission (2012) Commission Regulation (EU) No 432/2012 of 16 May 2012 establishing a list of permitted health claims made on foods, other than those referring to the reduction of disease risk and to children's development and health. OJ L $13655,1-40$.

62. European Commission (2015) EU Register on nutrition and health claims. http://ec.europa.eu/nuhclaims/?event=search\&CFID =335086\&CFTOKEN=bb484f431b227b d1-79366084-B936-26BA-

A093EC372F6F1B31\&jsessionid =9312c835f5666f4342c4403366511152f434TR (accessed June 2015).

63. EFSA (2012) 'General function' health claims under Article 13. http://www.efsa.europa.eu/en/topics/topic/article13.htm (accessed June 2015).

64. European Commission (2013) Commission Regulation (EU) No 536/2013 of 11 June 2013 amending Regulation (EU) No 432/2012 establishing a list of permitted health claims made on foods other than those referring to the reduction of disease risk and to children's development and health. OJ L 160 56, 4-8.

65. European Commission (2013) Commission Regulation (EU) No 851/2013 of 3 September 2013 authorising certain health claims made on foods, other than those referring to the reduction of disease risk and to children's development and health and amending Regulation (EU) No 432/2012. OJ L 235 56, 3-7.

66. European Commission (2014) Commission Regulation (EU) No 40/2014 of 17 January 2014 authorising a health claim made on foods, other than those referring to the reduction of disease risk and to children's development and health and amending Regulation (EU) No 432/2012. OJ L 14 57, 8-10. 
67. European Commission (2015) Commission Regulation (EU) 2015/539 of 31 March 2015 authorising a health claim made on foods, other than those referring to the reduction of disease risk and to children's development and health and amending Regulation (EU) No 432/2012. OJ L 88 58, 7-10.

68. European Commission (2015) Commission Regulation (EU) 2015/7 of 6 January 2015 authorising a health claim made on foods, other than those referring to the reduction of disease risk and to children's development and health and amending Regulation (EU) No 432/2012. OJ L 3 58, 3-5.

69. European Commission (2013) Commission Regulation (EU) No 1018/2013 of 23 October 2013 amending Regulation (EU) No 432/2012 establishing a list of permitted health claims made on foods other than those referring to the reduction of disease risk and to children's development and health. OJ L $28256,43-45$.

70. Flynn A (2012) Symposium 2: Nutrition and health claims: help or hindrance Scientific substantiation of health claims in the EU. Proc Nutr Soc 71, 120-126.

71. Ernst \& Young (2012) External Evaluation of EFSA - Final Report.

72. Gilsenan MB (2011) Nutrition \& health claims in the European Union: A regulatory overview. Trends Food Sci. Technol. 22, 536-542.

73. Van der Meulen B \& van der Velde M (2008) Public powers: official controls, enforcement and incident management. In European Food Law Handbook, pp. 403-420. Wageningen: Wageningen Academic Publishers.

74. European Parliament and Council of the European Union (2004) Regulation (EC) No 882/2004 of the European Parliament and of the Council of 29 April 2004 on official controls performed to ensure the verification of compliance with feed and food law, animal health and animal welfare rules. OJ L 165 47, 1-141.

75. Van der Meulen B \& van der Velde M (2008) International public law. In European Food Law Handbook, pp. 79-118. Wageningen: Wageningen Academic Publishers.

76. Van der Meulen BMJ (2009) The System of Food Law in the European Union. Deakin Law Rev. 14, 305-340.

77. Verbruggen P (2013) Gorillas in the closet? Public and private actors in the enforcement of transnational private regulation. Regul. Gov. 7, 512-532.

78. Hutter BM \& Amodu T (2008) Risk regulation and compliance: Food safety in the UK. London: London School of Economics and Political Science.

79. Becker GS \& Stigler GJ (1974) Law Enforcement, Malfeasance, and Compensation of Enforcers. J. Legal Stud. 3, 1-18.

80. Patel A, Smith C, Knowles T, et al. (2012) Nutrition and health claims: An enforcement perspective. Trends Food Sci. Technol. 28, 15-22.

81. Whitehead AJ (1995) Elements of an effective national food control system. Food Control 6, 247-251.

82. Neeliah SA \& Goburdhun D (2007) National food control systems: a review. Food Rev. Int. 23, 35-51.

83. Goris JM, Petersen S, Stamatakis E, et al. (2010) Television food advertising and the prevalence of childhood overweight and obesity: a multicountry comparison. Public Health Nutr. 13, 1003-1012. 
84. Sharma LL, Teret SP \& Brownell KD (2010) The food industry and self-regulation: standards to promote success and to avoid public health failures. Am. J. Public Health 100, 240-246.

85. Malla S, Hobbs JE \& Sogah EK (2013) Functional Foods and Natural Health Products Regulations in Canada and Around the World: Nutrition Labels and Health Claims. Saskatchewan: Canadian Agricultural Innovation and Regulation Network.

86. Shimizu T (2003) Health claims on functional foods: the Japanese regulations and an international comparison. Nutr. Res. Rev. 16, 241-52.

87. Codex Committee on Food Labelling (2013) Guidelines for Use of Nutrition and Health Claims (CAC/GL 23-1997). Rome: Codex Alimentarius.

88. Ministry of Health Labour and Welfare \& Japan (2015) Food for Specified Health Uses (FOSHU). http://www.mhlw.go.jp/english/topics/foodsafety/fhc/02.html (accessed April 2015).

89. U.S. Food and Drug Administration (2003) Claims That Can Be Made for Conventional Foods and Dietary Supplements. http://www.fda.gov/Food/IngredientsPackagingLabeling/LabelingNutrition/ucm111447.ht m. (accessed April 2015)

90. Hasler CM (2008) Health claims in the United States: an aid to the public or a source of confusion? J. Nutr. 138, 1216S-1220S.

91. U.S. Food and Drug Administration (2003) Consumer Health Information for Better Nutrition Initiative: Task Force Report http://www.fda.gov/Food/IngredientsPackagingLabeling/LabelingNutrition/ucm096010.ht m (accessed April 2015).

92. Food and Drug Administration (2013) Code of Federal Regulations Title 21, Chapter 9, Subchapter IV ( $r$ ) 343. Misbranded Food. Washington D.C.: Federal Government of the United States.

93. Agarwal S, Hordvik S \& Morar S (2006) Nutritional claims for functional foods and supplements. Toxicology 221, 44-49.

94. Health Canada (2015) Health Claim Assessments. http://hc-sc.gc.ca/fn-an/labeletiquet/claims-reclam/assess-evalu/index-eng.php (accessed April 2015).

95. Eussen S, Klungel O, Garssen J, et al. (2010) Support of drug therapy using functional foods and dietary supplements: focus on statin therapy. Br. J. Nutr. 103, 1260-1277.

96. O'Byrne PM \& Postma DS (1999) The many faces of airway inflammation: asthma and chronic obstructive pulmonary disease. Am. J. Respir. Crit. Care Med. 159, S1-S63.

97. Rothkrantz-Kos S, van Dieijen-Visser MP, Mulder PGH, et al. (2003) Potential usefulness of inflammatory markers to monitor respiratory functional impairment in sarcoidosis. Clin. Chem. 49, 1510-1517.

98. King Jr TE (2005) Clinical advances in the diagnosis and therapy of the interstitial lung diseases. Am. J. Respir. Crit. Care Med. 172, 268-279.

99. Moldoveanu $B$, Otmishi $P$, Jani $P$, et al. (2009) Inflammatory mechanisms in the lung. J. Inflamm. Res. 2, 1-11.

100. Barnes PJ, Shapiro SD \& Pauwels RA (2003) Chronic obstructive pulmonary disease: molecular and cellularmechanisms. Eur. Respir. J. 22, 672-688. 
Introduction

101. Barnes PJ \& Adcock IM (2009) Glucocorticoid resistance in inflammatory diseases. Lancet 373, 1905-1917.

102. Weiner K (2010) Configuring users of cholesterol lowering foods: a review of biomedical discourse. Soc. Sci. Med. 71, 1541-1547.

103. Netherlands Pharmacovigilance Centre Lareb (2015) Lareb - Home. http://www.lareb.nl/?lang=en-GB (accessed April 2015). 



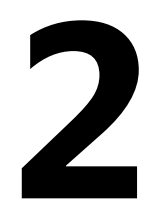

\section{Implementation of the}

nutrition and health claim

regulation - the case of

antioxidants

Alie de Boer, Ellen Vos, Aalt Bast

Regulatory Toxicology and Pharmacology 68 (2014), 475-487 


\section{Abstract}

This article analyses the consequences of the implementation of the nutrition and health claim regulation in the field of food products containing antioxidants or food products claiming antioxidant activity. To this end, it first examines the origin and creation of the regulation and the involvement of EFSA in assessing scientific substantiation of health claims. Three criteria are regarded as critical in EFSA's opinions on the scientific substantiation of a health claim: the claimed effect (i) is well defined; (ii) is a clear beneficial physiological effect; and (iii) shows a cause effect relationship with the consumption of the food or functional ingredient. These criteria have implications for the research requested to substantiate health claims, although these implications do not all seem to fit nutrition research as it is currently executed. Looking at antioxidants, the complexity of the mechanisms and actions of antioxidants is not recognised by the criteria used to evaluate proposed health claims, nor by the methodologies used to assess the effects of antioxidants. These criteria should be adjusted with novel scientific insights after consulting stakeholders. 


\section{Introduction}

After several Europe-wide food scares in the 1990s, there was a call to reform European food law ${ }^{(1-4)}$. Different advisory papers from the European Commission (EC) as the Green Paper (1997) and White Paper on Food Safety (2000), describing the vision on food law, followed ${ }^{(5,6)}$. In 2002 the 'Regulation (EC) No 178/2002 of the European Parliament and of the Council of 28 January 2002 laying down the general principles and requirements of food law, establishing the European Food Safety Authority and laying down procedures in matters of food safety', also called the General Food Law $(G F L)$, entered into force ${ }^{(2,7)}$. This GFL is seen as the cornerstone of the European food law today ${ }^{(8)}$.

In addition to the GFL, the EU has adopted a great number of specific rules dealing with various aspects of the food chain and specific food components, as the use of flavourings ${ }^{(9)}$, microbial criteria for food products ${ }^{(10)}$, or food information to consumers $^{(11)}$. Importantly, one of these specific rules deals with claims and statements made on food products about the effect of the product after intake: 'Regulation (EC) No 1924/2006 of the European Parliament and of the Council of 20 December 2006 on nutrition and health claims made on foods', also known as the Nutrition and Health Claim Regulation $(\mathrm{NHCR})^{(12)}$. This regulation requires the information on the label provided to consumers to be based on scientific evidence, to prevent consumers from being misled by unclear or incorrect information and false claims ${ }^{(1,13)}$. The use of a claim is allowed or refused by the EC, after consulting the expert opinion of the European Food Safety Authority (EFSA) on the submitted claim ${ }^{(14)}$.

The NHCR entered into force on 1 July 2007, regulating all communications about nutritional content and health benefits of a product. All proposed claims were assessed by EFSA and documented in the so-called 'EFSA opinions'. Remarkably, the opinions gave negative advices on almost all suggested health claims in the field of food products or functional ingredients containing antioxidants or claiming antioxidant activity as shown in table 1 below. This table provides an overview of proposed, 
authorised and non-authorised claims on antioxidants. Only eight claims out of 230 on antioxidant activity were assessed positively and subsequently authorised by the EC to be used on products, viz. seven claims on vitamins and minerals, one claim on olive oil polyphenols ${ }^{(15)}$.

Table 1. Claims on antioxidants ${ }^{(15)}$.

\begin{tabular}{|l|l|l|l|}
\hline Claim on $^{\mathbf{a}}$ & $\begin{array}{l}\text { Proposed } \\
\text { claims }\end{array}$ & $\begin{array}{l}\text { Authorised } \\
\text { claims }\end{array}$ & $\begin{array}{l}\text { Non-authorised } \\
\text { claims }\end{array}$ \\
\hline Antioxida*b $^{* \mathbf{b}}$ & 156 & 0 & 156 \\
\hline Phenol* $^{*}$ & 26 & 1 & 25 \\
\hline Oxida* $^{*}$ & 230 & $8^{\mathbf{c}}$ & 222 \\
\hline
\end{tabular}

* = search term entered in database as described

$\mathbf{a}^{\mathrm{a}}$ search term in database

$\mathbf{b}=$ both as substance and effect

c $=$ includes the positive opinions within phenol* as search term

EFSA's negative opinions led to a denial of proposed claims on antioxidants as property, ingredient, protector against oxidative damage or in maintaining the immune system $^{(15)}$. The positive opinions from EFSA on water-soluble tomato concentrate I and II $^{(16,17)}$ and on cocoa flavonoids ${ }^{(18)}$ are not taken into account here. The claimed health benefits of these products are not associated with antioxidant activity, and are not specifically regarded as a consequence of antioxidants as the active ingredient.

As a result of the negative opinions of EFSA on antioxidant related health effects and subsequent declines of proposed health claims by the EC, today no statements about ingredients acting as antioxidants or their health effects are allowed to be made, except for claims based on the previously mentioned positive opinions ${ }^{(15,19)}$. For industrials in this field, who are not able to communicate the benefit of their product, this may be a reason to no longer focus their research on antioxidants ${ }^{(1,20)}$.

The EC as regulator considers the regulation of health claims a stimulation for the industry to innovate and to develop healthier foods or food products with functional benefits, thereby improving their competitiveness ${ }^{(13,21)}$. Nevertheless, several 
industrials view the NHCR suppresses creativity and innovations and notice flaws in the regulation and its implementation, with unclear criteria on the required scientific evidence to substantiate a claim. Other parties, critically following the regulation, however state that extensive guidance is offered to applicants by several guidance documents from $\operatorname{EFSA}^{(1,13,20-22)}$. These parties expect uncertainty on the evidence needed to substantiate a claim certainly will decrease even more with the list of approved claims published in December 2012 as annex to 'Commission Regulation (EU) No 432/2012 of 16 May 2012 establishing a list of permitted health claims made on foods, other than those referring to the reduction of disease risk and to children's development and health ${ }^{\{13,19,22,23)}$. Although many opinions and critiques on the regulation and the used assessment criteria were expressed, no critical evaluation has been written defining the problems that arise from the implementation of the NHCR.

This paper aims to fill that lacuna. Therefore, this paper analyses the implementation of the NHCR, taking food products containing antioxidants or claiming antioxidant activity as a case study. The mechanism of action of antioxidants is currently highly debated, which makes this case study very timely. Two research questions are put forward: (i) which criteria are used to assess the scientific substantiation of health claims; and (ii) whether these criteria are suitable to assess a claim.

In this paper, first the framework of the NHCR is described, followed by the establishment of EFSA and the role of EFSA in the NHCR. Subsequently different opinions on claims of antioxidants are analysed to answer the research questions, which is followed by the conclusions of this paper.

\section{Nutrition and Health Claim Regulation: realisation and definitions}

The Nutrition and Health Claim Regulation entered into force in 2007, and was preceded by scientific projects and advisory papers. 


\section{Creating regulation on claims}

Increasing interest in the concepts of functional foods and health claims led the European Union and International Life Sciences Institute Europe (ILSI Europe) to start the FUFOSE (Functional Food Science) project in 1995, to create an approach for evidence needed to support the development of functional foods, based on science $^{(24,25)}$. This research project also addressed the concept of health claims. The final document in 1999 defined two types of health claims: (i) enhanced function claims, claiming actions of a product going further then their established functions in the body and (ii) reduction of disease risk claims, claiming the consumption of a specific food or functional ingredient will help to decrease the risk of a specific condition ${ }^{(24)}$. To implement the conclusions and principles of the FUFOSE project, the PASSCLAIM (Process for the Assessment of Scientific Support for Claims on Foods) project was started, to define criteria for studies to substantiate both types of claims ${ }^{(25,26)}$. The final document of PASSCLAIM, published in 2005, defined criteria for substantiation of a claim, although it was emphasised these criteria only serve as a template for the evaluation process and could provide guidance for applicants; there was still a need to include expert advice in development of regulation on health claims ${ }^{(26)}$. PASSCLAIM also proposed a third type of health claim, viz. the nutrient function claim closely related to the enhanced function claim. Where enhanced function claims describe functions of the product beyond established functions in the body, a nutrient function claim describes the physiological role of a nutrient in growth, development and normal functions of the body, based on generally accepted and well-established knowledge ${ }^{(26)}$.

In the meantime, introducing specific provisions to manage nutrition and function claims was proposed in the White Paper on Food Safety, to harmonise legislation throughout the European Union and to ensure a high level of consumer protection ${ }^{(6,27)}$. In May 2001 this was followed by the discussion paper on nutrition claims and functional claims, describing issues from invited comments of over 90 stakeholders to take into consideration in upcoming legislative acts. These comments led to the inclusion of health claims in the same proposed regulation as nutrition claims, where 
the first idea was to create separate legislation for the different types of claims ${ }^{(27,28)}$. In 2003 the final proposal to regulate nutrition and health claims in Europe was presented by the $\mathrm{EC}^{(25,28)}$. The development of the NHCR is depicted in figure 1.

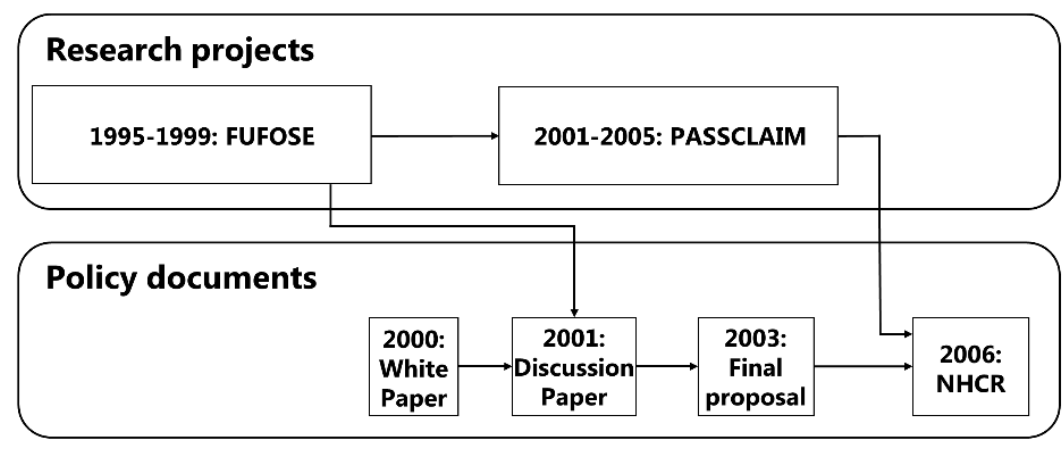

Figure 1. Development of the Nutrition and Health Claim Regulation.

\section{The Nutrition and Health Claim Regulation}

Since 2006, claims on antioxidants and other active ingredients in food products are regulated by 'Regulation (EC) No 1924/2006 of the European Parliament and of the Council of 20 December 2006 on nutrition and health claims made on foods', also called the $\mathrm{NHCR}^{(12)}$. The NHCR is a more specific regulation within the European food law which aims to ensure a high level of protection for consumers and to facilitate their choice by making sure claims are scientifically substantiated, and is intended to improve the free movement of goods in the internal market by harmonising the different national regulations of Member States ${ }^{(13)}$. The regulation deals with all messages voluntarily put on the label in any form including graphic representation, stating, suggesting or implying the food has particular characteristics ${ }^{(12)}$. Thereby, the NHCR prevents consumers from being misled due to unclear or incorrect information and false claims ${ }^{(1,13)}$.

Recital 1 of the preamble of the regulation states why the NHCR was deemed necessary: 'In order to ensure a high level of protection for consumers and to facilitate their choice, products put on the market (...) should be safe and adequately labelled ${ }^{(12)}$. 
The NHCR makes it possible to communicate benefits to consumers about food products, if this claim is substantiated by generally accepted scientific evidence, as described in Article 6: '(1) Nutrition and health claims shall be based on and substantiated by generally accepted scientific evidence. (2) A food business operator making a nutrition or health claim shall justify the use of the claim. ${ }^{\{12,29)}$. A claim is only allowed for use under the general conditions of Article 5(1), making sure the food or functional ingredient is present in a significant quantity, is effective with an amount reasonably consumed in the diet, and leads to a beneficial nutritional or physiological effect $^{(12)}$.

The concept claim is defined in Article 2(2)(1): "Claim' means any message or representation, which is not mandatory under Community or national legislation, including pictorial, graphic or symbolic representation, in any form, which states, suggests or implies that a food has particular characteristics ${ }^{(12)}$. Claims under the NHCR are divided into nutrition claims on the nutritional properties of the ingredient or food product, and health claims on the relationship between the ingredient or food product and a beneficial effect on health ${ }^{(12)}$.

Health claims can be divided in three categories: (i) Article 13.1 claims: general function claims implying a health benefit based on accepted scientific evidence, as 'copper contributes to the protection of cells from oxidative stress ${ }^{\text {(30); }}$; (ii) Article 13.5 claims: new function claims implying a health benefit based on newly developed scientific evidence, giving the option to request protection of proprietary data, as 'water-soluble tomato concentrate I and II helps maintain normal platelet aggregation, which contributes to healthy blood flow ${ }^{(31)}$; and (iii) Article 14 claims: claims on (a) the reduction of disease risk as 'plant sterols and plant stanol esters have been shown to lower/reduce blood cholesterol. High cholesterol is a risk factor in the development of coronary heart disease. 'or on (b) children's development and health as 'essential fatty acids are needed for normal growth and development of children ${ }^{\{12,15,32)}$. 
In Article 13.1 of the NHCR, the list of approved health claims is introduced ${ }^{(12)}$. This list, found in the annex of Regulation 432/2012i, describes all authorised 13.1 and 13.5 health claims (except those based on proprietary data), currently $228^{(15,23,30,33)}$. Since all proposed Article 13.1 claims have been reviewed by EFSA, only Article 13.5 claims can be submitted to be on this list after authorisation by the $\mathrm{EC}^{(34)}$.

\section{European Food Safety Authority: establishment and role in the NHCR}

Next to introducing legal principles and requirements of food law and procedures for food safety matters, the GFL also establishes the European Food Safety Authority $(\mathrm{EFSA})^{(7)}$.

\section{Establishment of EFSA}

The establishment of EFSA as an independent agency was considered necessary to ensure the functional separation of risk assessment (review of scientific evidence to evaluate risks and hazards) and risk management (handling of the identified risks) $)^{(2,8,35,36)}$. The need for improving this separation was suggested by different signalled problems in the use of earlier risk assessments, such as the lack of independence and conflicting outcomes of risk assessments of different expert committees. Also, increasing transparency was needed for all stakeholders in the processes and judgements forming the final expert advice ${ }^{(2)}$. EFSA was founded to regain public confidence through the use of independent, harmonised scientific advice by making sure risk assessment is undertaken in an independent, objective and transparent manner ${ }^{(2,7,13)}$. The establishment of EFSA was seen by the EC as the most

i Regulation 432/2012 is amended by Commission Regulation (EU) No 536/2013 of 11 June 2013 amending Regulation (EU) No 432/2012 establishing a list of permitted health claims made on foods other than those referring to the reduction of disease risk and to children's development and health, adding six Article 13.1 claims to the list found in the Annex. 
effective way to increase consumer confidence and to address the growing need for a solid science-based policy ${ }^{(37)}$. According to European Commissioner Byrne in 2002, the independence of EFSA would make sure the scientific risk assessment would not be overruled by policy considerations or other factors ${ }^{(38)}$.

The establishment of EFSA is described in chapter III of the GFL. Article 22 states the establishment and mission of the authority, by describing EFSA will provide scientific advice and support for all legislation in the European Union relating to food and feed safety and it will provide independent information on and communicate about characterisation and monitoring of risks. Thereby the authority contributes to a high level of protection of human life and health ${ }^{(7)}$. EFSA's tasks are described in Article 23 and entails tasks as providing scientific opinions, identifying and characterising emerging risks and establishing a networking system ${ }^{(7)}$.

Article 29 defines the scientific opinions which can be issued by EFSA: 'The Authority shall issue a scientific opinion: (a) at the request of the Commission, in respect of any matter within its mission, and in all cases where Community legislation makes provision for the Authority to be consulted; (b) on its own initiative, on matters falling within its mission ${ }^{(7)}$. The possibility of diverging opinions and how to resolve such a situation is addressed in Article $30^{(7)}$.

Articles 37 to 42 describe the way EFSA, its staff members and members of the panels ensure independence, transparency and confidentiality. Article 37 states the independence of the authority and members, which became very important after the different food incidents in Europe. External influence of the risk assessment process is hereby reduced as much as possible. Article 38 addresses transparency, by describing in paragraph 1 all items that are made public as the minutes and notes of meetings, declarations of interest and the opinions and the information on which they are based $^{(7)}$. 
Corporate documents of EFSA describe different topics as strategy and independence more thoroughly than illustrated in the GFL, in which these topics are addressed briefly. These corporate documents describe policy and strategy; operating rules; selection of experts and dealing with science; independence; transparency; quality; financial provisions and annual work programme ${ }^{(39,40)}$.

\section{Role of EFSA in the NHCR}

Although the main focus of EFSA was the safety of food, the European Commission and the European Parliament considered EFSA the most suitable agency to review proposed health claims ${ }^{(41)}$.

Within the NHCR, EFSA was given four tasks by the European Commission: (i) give advice on establishment of the positive list of permitted health claims; (ii) give opinions on individual applications for health claims; (iii) provide guidance for applicants on the authorisation process of health claims and (iv) give scientific advice on nutrient profiles $^{(42,43)}$.

The first and second task were combined with assessing Article 13.1 health claims by delivering scientific opinions about the proposed claims ${ }^{(13,14,44)}$. After filtering and clustering by the EC, from the more than 44,000 claims which were proposed by all Member States before 31 January 2008 only 4,637 were left for EFSA to assess ${ }^{(30,34)}$. The assessment procedure is described in Article 13(3) of the NHCR, and a specific informative document on the procedure was published by EFSA in $201{ }^{(12,45)}$. The groups of claims were evaluated by EFSA, taking into account the conditions of use and references provided by associated health claims ${ }^{(42,45)}$.

With these requests to EFSA, the EC formulated Terms of Reference giving EFSA several aspects to consider when issuing opinions on these health claims ${ }^{(42)}$. These aspects followed from the previous research performed on nutrition and health claims, as the PASSCLAIM project ${ }^{(25,26)}$. The final document of PASSCLAIM defined six criteria to be checked for data submitted as scientific substantiation of a claim, on characterisation 
of the food, substantiation of the claim, the use of valid markers, the significance of the effect and the totality of data ${ }^{(26)}$. In the Terms of Reference, this was translated to the following main aspects to be considered by EFSA: (i) if adequate information is provided on characteristics of the food or functional ingredient; (ii) if the beneficial effect is substantiated by generally accepted scientific evidence; and (iii) how important the food is for the claimed effect ${ }^{(42)}$.

With the information provided in the Terms of Reference, EFSA was able to set up an initial screening tool to see if sufficient information was provided to evaluate a claim. Claims were sent back to the EC if clarity or additional information was needed, on: (i) the scope of the claim; (ii) the health relationship of the claim; (iii) the wording of the claim; (iv) characterisation of foods or their conditions of use; (v) definitions of a combination of constituents; or (vi) when claims were written in other languages than English ${ }^{(46)}$.

After finishing this screening procedure and receiving additional information on the proposed claims if necessary, all claims were evaluated by EFSA following the legal framework set by the $\mathrm{NHCR}^{(21)}$. As described, scientific substantiation is considered to be the main aspect for justifying a nutrition or health claim. Provided scientific evidence was used to examine different aspects of the claim, based on the criteria set by the Terms of Reference ${ }^{(47)}$. Scientific data supporting the claims were structured by their relevance to the claim, preferring human intervention studies, human observational studies or other human studies, and with non-human data as supportive evidence ${ }^{(48)}$.

The advices of EFSA on the evaluated scientific data, described in the EFSA opinions, were published in batches in the EFSA Journal. The recommendations of EFSA were discussed by the EC, making the final decision accepting or rejecting a claim. It is also the responsibility of the EC the claim is well understood by consumers ${ }^{(13,14)}$. The full process from the NHCR entering into force to the final decision of the EC is presented in figure 2. 


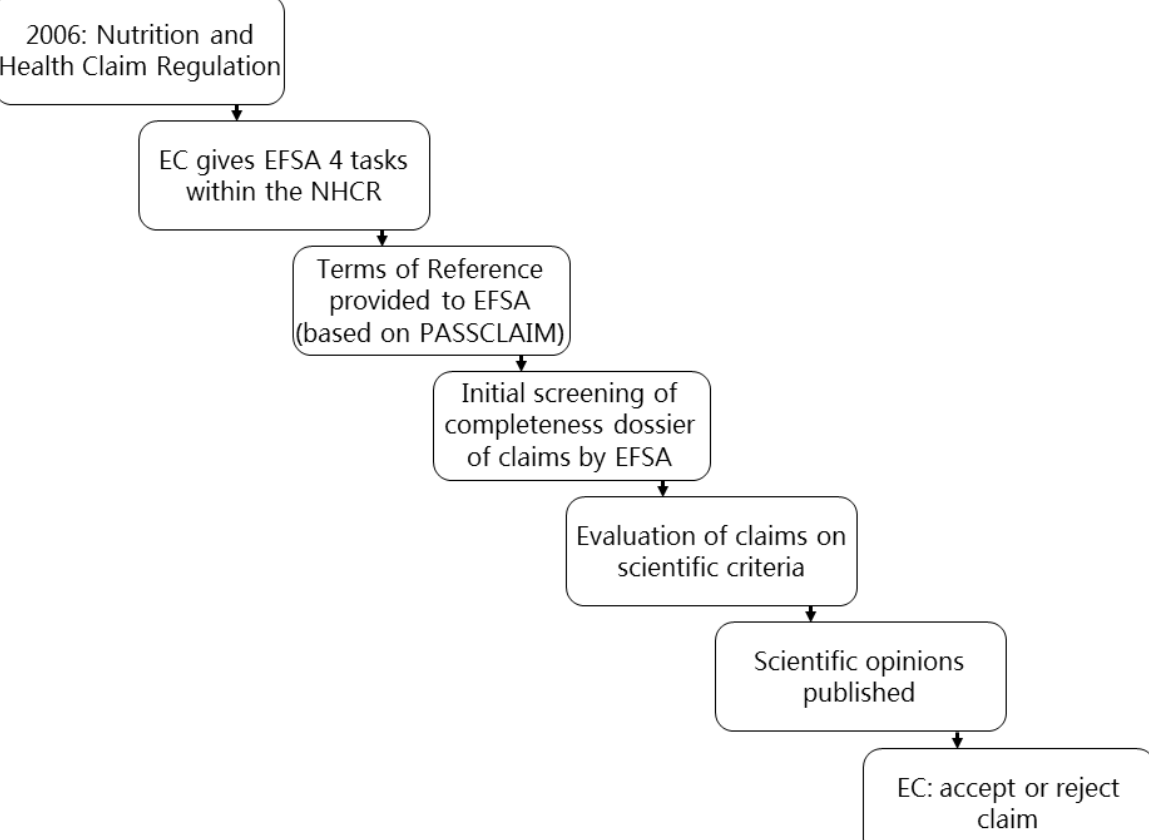

Figure 2. From NHCR to final decisions on claims.

From the 4637 proposed general function claims, 2758 were examined by EFSA. After publishing 341 scientific opinions, the claims on different foods or food ingredients which received a favourable opinion by EFSA and were authorised by the EC, were adopted in Regulation 432/2012, the list of positive Article 13.1 and 13.5 health claims. This left 222 authorised Article 13.1 health claims, entering into force in December $2012^{(23,30,49)}$ with an additional 6 claims put on the list in May $2013^{(33)}$. The procedure starting with 44,000 proposed claims to the 228 claims on the positive list is shown in figure 3. 


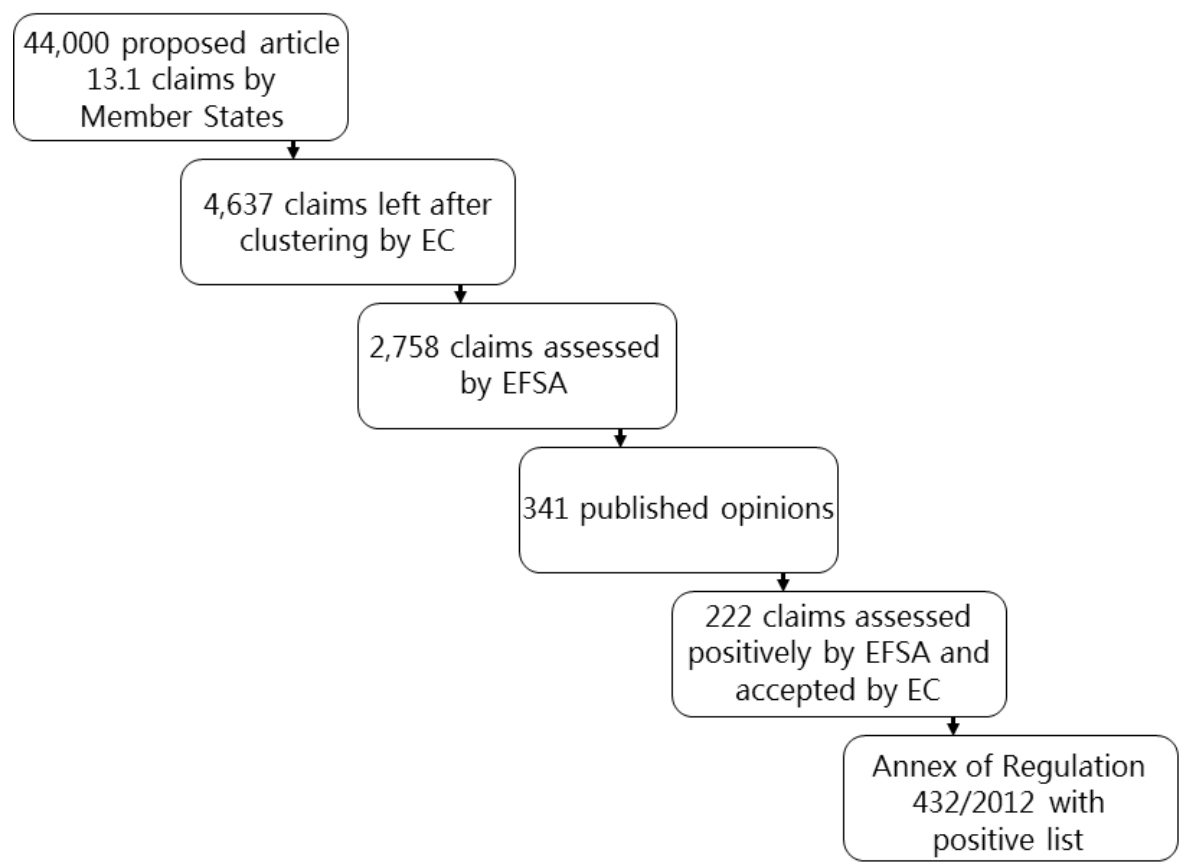

Figure 3. Assessment procedure Article 13.1 claims: proposed claims to accepted claims.

These permitted claims are allowed to be used by all food manufacturers throughout the European Union. Assessment of Article 13.5 and 14 claims, the new function claims and claims on the reduction of disease risk or children's development and health is a continuous process, as food manufacturers are always able to submit new dossiers on these claims. All proposed claims are assessed on a case-by-case basis ${ }^{(13,34,49)}$.

\section{Health claims on antioxidants: assessment and opinions}

As described in the previous section, scientific opinions on health claims under the NHCR are provided by EFSA. These opinions are used by the Commission to decide on permitting or rejecting a claim ${ }^{(14)}$. This section will examine into detail the assessment of health claims concerning antioxidants. To this end, first a brief overview of the actions of antioxidants will be given. 


\section{Mechanisms of action of antioxidants}

In the scientific debate on the actions of antioxidants ranging opinions are given: antioxidants are for example seen as omnipotent life savers or as toxic compounds. New insights in the mechanism of action of antioxidants are important for the substantiation of health claims on antioxidants by EFSA. These insights however are not used yet in the substantiation of health claims on antioxidants where the main focus was only on radical scavenging by antioxidants. In that way, several misconceptions prevail and therefore consensus is not reached ${ }^{(14,50)}$.

Antioxidants, naturally occurring in different food products or produced synthetically, balance reactive species in the human body by acting as a direct or indirect scavenger of reactive species or by inhibiting their production ${ }^{(51,52)}$. The definition of an antioxidant by Halliwell (2007) is: 'any substance that delays, prevents or removes oxidative damage to a target molecule ${ }^{\{53)}$. Some of the reactive oxygen species (ROS) are free radicals, which easily react with other molecules ${ }^{(51,52,54)}$. Their formation is an essential part of normal metabolic processes and has useful functions as to make it possible to use oxygen as electron acceptor in mitochondria and to protect from foreign invading organisms ${ }^{(51-53,55)}$. The classic view is that when production of ROS exceeds the protective antioxidant capacity, oxidative stress occurs. Oxidative stress can be defined as 'a serious imbalance between the generation of ROS and antioxidant protection in favour of the former, causing excessive oxidative damage ${ }^{156,57)}$. During this process reactive species attack healthy cells, especially proteins, DNA and RNA, sugars, and lipids, leading to structural damage of these cells ${ }^{(51,53)}$. Even though the occurrence of oxidative stress is mostly not the primary cause of a disease, it is an important secondary phenomenon linked to several processes as the ageing process, and neurological disorders (Alzheimer disease, Parkinson disease), cardiovascular diseases (ischemia, atherosclerosis), pulmonary diseases (COPD, fibrosis) and metabolic diseases (diabetes) ${ }^{(51,52,54,55,58-60)}$. 
In the current view on the mechanisms of action of antioxidants, it is increasingly recognised that antioxidants not only act as radical scavengers, but that they indirectly influence endogenous ROS protecting enzyme systems through posttranscriptional mechanisms, activated via the antioxidant response elements found in the promoter region of encoding genes ${ }^{(61)}$. Antioxidant response elements influence gene expression, for example via the Nrf2 (nuclear factor (erythroid derived 2)-like 2) mediated transcription. The interaction between antioxidant response elements and Nrf2 is shown by Nrf2 proteins binding to the sequence of the antioxidant response elements, positively regulating its activity. When an inhibiting cofactor as Keap1 (Kelchlike $\mathrm{ECH}$-associated protein 1) binds $\mathrm{Nrf2}$ in the cytoplasm, the translocation of Nrf2 to the nucleus is inhibited and the antioxidant responsive element DNA sequences will not be activated ${ }^{(55,58,60)}$. Oxidative stress activates uncoupling of the inactive Keap1Nrf2 complex through oxidation of cysteine residues of the complex and thereby altering the structure of Keap1, so the binding of Nrf2 in the nucleus can take place. Thus heterodimers of Nrf2 with transcription factors are formed, which bind to the antioxidant response elements and thereby induce the transcription of phase II antioxidant enzymes, as shown in figure $4^{(50,60,62)}$. Moreover, many antioxidants possess anti-inflammatory activity which may contribute to their action ${ }^{(63)}$. Different flavonoids show anti-inflammatory effects by inhibiting the PARP-1 (poly(ADP-ribose) polymerase-1). PARP-1 plays a role in the repair process of oxidatively damaged DNA. Moreover, it is a cofactor in the action of the transcription factor $N f-\kappa B$, which is activated by ROS and produces pro-inflammatory mediators (figure 4). Dietary antioxidants (like flavonoids as quercetin, fisetin and tricetin) prevent the ROS mediated activation of $\mathrm{Nf}-\kappa \mathrm{B}$ and inhibit (via PARP-1 inhibition) the $\mathrm{Nf}-\kappa \mathrm{B}$ induced gene expression ${ }^{(64)}$. In that way antioxidants are anti-inflammatory compounds and display a broad bio-active role. The term 'bioactive' has been suggested ${ }^{(50)}$. 


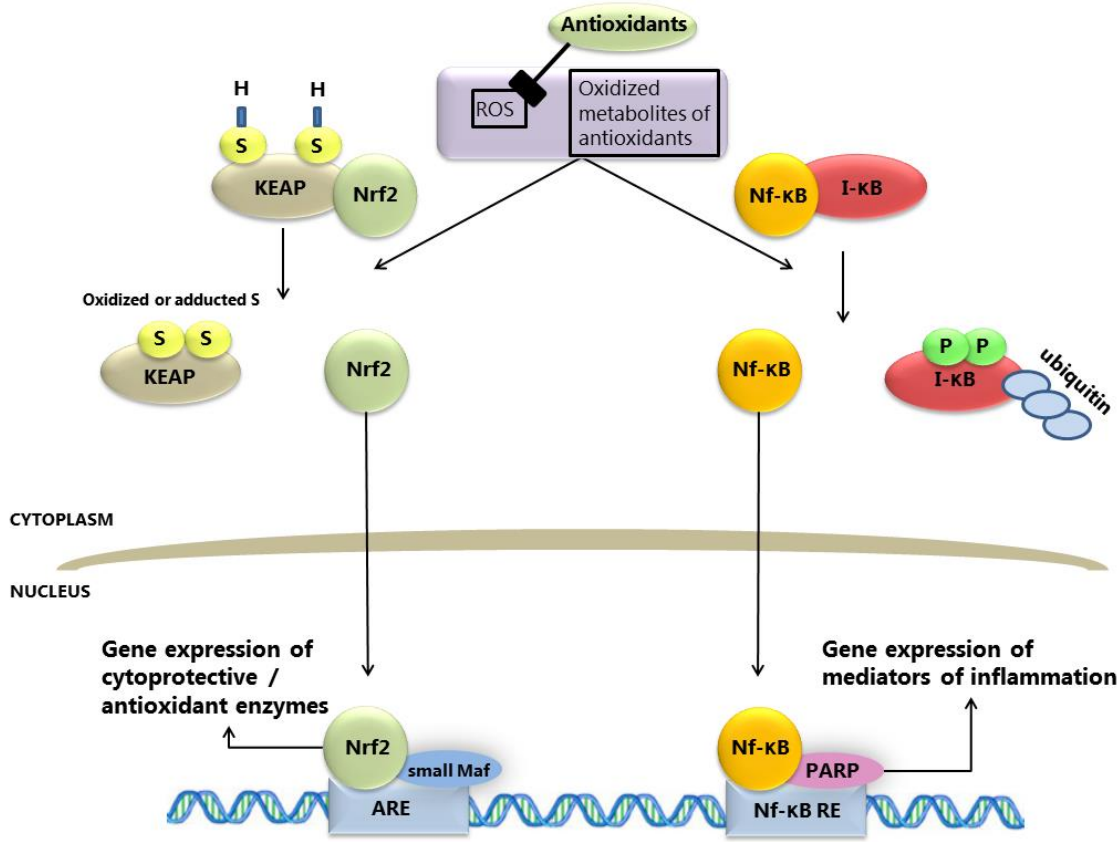

Figure 4. The activation by reactive oxygen species (ROS) and oxidised metabolites of

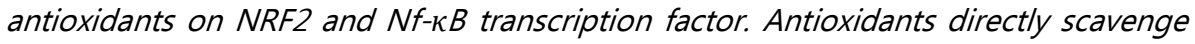
ROS, leading the antioxidants to form electrophilic oxidised metabolites. Thiol oxidation of Keap leads to release of Nrf2 which subsequently induces cytoprotective/antioxidant enzymes via antioxidant response elements (AREs).

Although cells can react to reactive species by up-regulating endogenous antioxidant synthesis, to keep this delicate balance dietary antioxidants are needed. Resilience to stress might be improved by additional antioxidants ${ }^{(50)}$. Dietary antioxidants are naturally found in fruits and vegetables in the forms of flavonoids, vitamins $C$ and $E$ and carotenoids, whilst also phenolic acids, minerals and organosulfur compounds can act as antioxidants ${ }^{(51,65,66)}$. Next to this, several synthetic antioxidants are introduced in foods mostly to prevent food oxidation ${ }^{(51)}$.

Antioxidants can also turn into pro-oxidants when the balance between free radicals and antioxidants shifts. This would lead to oxidative stress, i.e. increasing the risk of onset of disease as Alzheimer disease and inflammatory diseases, as described 
above ${ }^{(51,59)}$. Not only oxidative stress but also oxidised metabolites of antioxidants are shown to uncouple the inactive Keap1-Nrf2 complex. Thereby the endogenous antioxidant system becomes activated ${ }^{(67)}$.

\section{Assessment of health claims on antioxidants}

After the initial screening of over 40,000 proposed claims by the Commission, EFSA assessed each specific food and health relationship forming the basis of a health claim. The three criteria shown to be used for this assessment procedure are based on initiatives as FUFOSE and PASSCLAIM as described in 'Creating regulation on claims', and are found in all opinions published by EFSA (table 2). The criteria were developed by EFSA following the Terms of Reference provided by the EC, and are not only used when reviewing health claims on antioxidants, also assessment procedures of other health claims follow these criteria ${ }^{(47)}$.

Table 2. Assessment criteria scientific opinions(47).

\begin{tabular}{|l|l|}
\hline & Criteria \\
\hline I & The food or functional ingredient is defined and characterised \\
\hline II & $\begin{array}{l}\text { The claimed effect is defined } \\
\text { The claimed effect is a beneficial physiological effect }\end{array}$ \\
\hline III & $\begin{array}{l}\text { A cause and effect relationship is established between the consumption } \\
\text { of the food or functional ingredient and the claimed effect }\end{array}$ \\
\hline
\end{tabular}

Each claimed relationship between a food or functional ingredient and a beneficial physiological effect is assessed separately with these criteria. When the outcome is favourable on all three criteria, the following aspects are reviewed to evaluate the claim:

- If it is reasonable the quantity of the food needed to obtain the claimed effect can be consumed within a balanced diet

- If the proposed wording reflects the scientific evidence;

- If the proposed wording complies with the criteria for use specified in the NHCR (truthful, clear, reliable and useful to the consumer);

- If the proposed conditions and restrictions of use are appropriate (e.g. the presence of certain substances); 
- And in case of an Article 13.5 or 14 claim, if proprietary data is needed for the substantiation ${ }^{(47)}$.

These aspects are assessed for every claim on a case-by-case basis. A favourable outcome on all three criteria leads to a positive opinion on the claim, which will be published in the EFSA Journal. Also negative opinions are published in this journal( ${ }^{(22,47)}$.

\section{Analysis of opinions}

In attempt to understand why most proposed claims on either antioxidants, a type of antioxidants or health effects of antioxidants received negative advices from EFSA, six examples of published negative EFSA opinions and two examples of positive EFSA opinions are analysed. The discussion follows the criteria used by EFSA (table 2).

\section{Criterion I - food defined and characterised}

The first criterion for EFSA to assess a health claim is the characterisation of the food or functional ingredient. Examples of proposed health claims not approved by EFSA due to insufficient characterisation are: honey being an antioxidant and polyphenols from processed fruits, vegetables and juices having antioxidant properties. Subsequently, two positive advices on copper and olive oil polyphenols are discussed.

\section{Negative opinions}

The proposed claim on honey relates to several beneficial properties for honey as a food product, e.g. protecting from oxidative damage and defence against pathogens (68). The definition of honey in five proposed claims is described in the Honey regulations 2003 which takes the definition of the Codex Alimentarius in 1981 into account, defining honey as 'the natural sweet substance produced by bees from the nectar of plants or from secretions of living parts of plants or excretions of plantsucking insects on the living parts of plants, which the bees collect, transform by combining with specific substances of their own, deposit, dehydrate, store and leave in honeycombs to ripen and mature ${ }^{169)}$. However, honey can differ in composition (e.g. in sugar and moisture content) and in botanical sources, with varieties due to the nectar source and the geographical location. Therefore EFSA felt not able to characterise the 
specific honey for which the claim is made, and the opinion on this claim was negative ${ }^{(68)}$.

A second claim declares polyphenols from processed fruits, vegetables and juices have antioxidant properties ${ }^{(70)}$. The term polyphenols, used for this claim and five other proposed claims, describes a large group of secondary plant metabolites including different substances as flavonoids and phenolic acids, all differing in biological activity. The conditions of use of polyphenols are varying widely in the proposed claims and are based either on the non-specific method of spectrophotometric measurement of total polyphenols, or on the use of antioxidant capacity assays. The spectrophotometric measurement measures the reducing capacity of compounds, leading to an overestimation of the actual polyphenol content due to the measurement of other reducing compounds next to the polyphenols. Antioxidant capacity assays as ORAC (oxygen radical absorbance capacity) are also nonspecific for polyphenol activity on oxidation and measure only activity in vitro. The ingredient was therefore not considered to be sufficiently characterised, and the opinion on this claim was negative ${ }^{(70)}$.

\section{Positive opinions}

One of the proposed claims on copper is 'the protection of body tissues and cells from oxidative damage; antioxidant activity ${ }^{k 71)}$. The functional ingredient, copper, is seen as a well-recognised nutrient which is measurable in foods by established methods. As it occurs naturally in foods and is authorised to be added to foods, EFSA considered the ingredient to be sufficiently characterised ${ }^{(71)}$.

The second example is the claim on olive oil polyphenols. Olive oil polyphenols are claimed to have several beneficial health effects due to their antioxidant properties. The dossier firstly describes the characterisation of olive oil polyphenols. Although polyphenols are a wide group of secondary plant metabolites with variable biological activity, the major polyphenols in olive oil as hydroxytyrosol and its derivatives are 
measurable in foods by established methods, and according to EFSA the functional ingredient is thereby characterised ${ }^{(72)}$.

\section{Implications}

The first criterion used by EFSA in evaluating a proposed claim is the definition and characterisation of the food or functional ingredient. The analysis of the opinions described above show that it is important to not only display an explicit characterisation of the food or food ingredient including the active substances of the food, it is also relevant that established methodologies are described which enable measurement of these substances in the food or functional ingredients. The composition of honey is considered to be too variable to characterise its active substances and the measurement methods for polyphenols from processed fruits, vegetables and juices are not considered to be valid methods. Olive oil polyphenols are positively assessed in this regard due to the measurability of hydroxytyrosol and its derivatives (e.g. oleuropein, tyrosol) as the active components in the oil ${ }^{(72)}$.

These implications, summarised in table 3, raise the issue whether a food or functional ingredient can be properly characterised by only measuring one or a limited number of active components, as is currently requested by EFSA. Food does not constitute of only one active component, alike drugs, and therefore this reductionist approach used in nutrition science (the focus of research on the activity of single active components on single effects) is questionable $\mathrm{e}^{(73,74)}$. To assess the full effect of nutrition on health, not only the individual constituents should be researched, also the diet itself with its additional components and different interactions might play a role in health ${ }^{(75,76)}$.

Next to characterising foods or functional ingredients by only single active components, the focus in nutrition science on a single effect is also debatable. The health effect of food is suggested to be the result of multifactorial physiological effects $^{(77)}$. Endpoints capturing these pleiotropic effects of nutrients are needed in nutritional research ${ }^{(78,79)}$. Therefore, although EFSA accurately declines several claims lacking clear characterisation of the active substance, the current approach of EFSA 
requesting scientific substantiation on single components and single effects is problematic, since the multitude of components and effects might elicit different health effects then shown through testing single components and single effects.

\section{Criterion II - claimed effect defined and beneficial}

The second criterion checked by EFSA, after appropriate characterisation of the food or functional ingredient, is the definition of the claimed effect and if this claimed effect can be regarded as a beneficial effect on human health. Antioxidant property and the effect of antioxidants on ageing is an example of an insufficiently defined claimed effect. The proposed claim of glutathione being an antioxidant is an example of such an unclear beneficial effect on human health. This is followed by the analysis of the two positive opinions on copper and olive oil polyphenols. Subsequently, the implications raised in the opinions are discussed.

\section{Negative opinions}

The first claim, that antioxidants included in the diet may help to protect the skin from the effects of ageing is assessed together with 14 other proposed claims on protection of cells from premature ageing ${ }^{(80)}$. The scientific studies supporting the claims however lack definitions on different characteristics as 'premature (skin) ageing', 'healthy ageing', 'oxidation-induced ageing', 'ageing process' or 'cellular ageing'. This led EFSA to consider these claims to be too general and non-specific and gave a negative $\operatorname{advice}^{(80)}$.

The second example involves a claim describing glutathione as antioxidant, contributing to the antioxidant defence system and the body's immune response ${ }^{(81)}$. This claim, along with 25 other claims on antioxidant activity or content and antioxidant properties, was assumed by EFSA to refer to the capacity on scavenging free radicals and/or to their reducing capacity, measured in vitro in model systems. This information was not considered by EFSA to establish a beneficial physiological effect on human health, and the opinion of EFSA on this claim was therefore negative ${ }^{(81)}$. 


\section{Positive opinions}

The proposed claimed effects due to the intake of copper are defined as 'the protection of body tissues and cells from oxidative damage; antioxidant activity'. The effects of oxidative stress, damaging molecules as DNA, proteins and lipids when the reactive oxygen species are not counteracted by the antioxidant network, are seen as negative effects and the claim therefore relates to a beneficial physiological effect according to EFSA, and the claim complies with the second criterion set by $\operatorname{EFSA}^{(71)}$.

The second example of a positive opinion involves the claim on olive oil polyphenols, reducing oxidative stress and having antioxidant activity and antioxidant properties. These proposed health relationships are reviewed in the second criterion. Proposed claims as 'reduces oxidative stress', 'antioxidant properties', 'lipid metabolism', 'antioxidant activity, 'they protect body cells and LDL from oxidative damages', and 'antioxidant properties' are regarded by EFSA to refer to the protection of low-density lipoprotein $(\mathrm{LDL})$ particles from oxidative damage. The effects of oxidative damage, the damage to molecules as DNA, lipids and proteins when reactive oxygen species are not counteracted by the antioxidant network, are seen as harmful to the body. EFSA considered the protection of these biomolecules from oxidative damage to be of possible physiological benefit ${ }^{(72)}$.

\section{Implications}

The second criterion, defining the claimed effect and evaluating if the effect can be considered beneficial to human health, entails that proposed claims are not accepted when they are vague or too general and not explicitly measurable in vivo. The first negative opinion on antioxidants regarded the claims to be too general and too vague. The opinion on glutathione considered the proposed effect, i.e. radical scavenging, not to be beneficial for health. If the effect is connected to health without being a direct treatment for disease, the effect is regarded as a beneficial physiological effect (table 3). EFSA therefore favours effects not directly aiming at treatment or preventing a disease, but rather focuses on effects improving health of the consumer, as described 
in the $\mathrm{NHCR}^{(12)}$. Thus single health effects seem easy to claim, as shown by research on the use of plant sterols and plant stanols. The slight reduction of only one risk factor of coronary heart diseases, LDL cholesterol, is accepted as marker for the reducing the risk of coronary heart diseases ${ }^{(82)}$. However, new insights challenge the use of solitary biomarkers ${ }^{(83)}$. The question is raised whether these secluded effects can always be considered relevant to human health. Research in the field of nutrition suggests that a single clinical biomarker does not reflect health, since these biomarkers imply the use of end-point markers and a link to a disease or condition, which again is not very suitable to measure the subtle effects of nutrition in maintaining health ${ }^{(77,84)}$. Novel markers, developed by clustering different small effects, are needed to measure such subtle effects of nutrition on health in a multi-targeted approach ${ }^{(77)}$.

Next to this, several studies hold that the concept of human health should be redefined, since the rather static definition of health as the absence of disease, defined by the WHO in 1948, does not seem to be accurate anymore. Today health is considered mainly a dynamic ability to adapt to circumstances, and needs a more individual approach $^{(77,79,85-88)}$. Upon redefining the health concept, more accurate test measures should be developed to measure the effect of nutrition on maintaining health ${ }^{(84)}$.

The perceived relevance of the consumer is an important consideration when looking at the relevance of the claimed effect to human health, as well as a consumers' understanding of such a health claim. In the NHCR the average consumer is considered to be 'reasonably well-informed and reasonably observant and circumspect, taking into account social, cultural and linguistic factors ${ }^{\{12)}$. However, in literature the perceived relevance of a health claim is described to be stronger if consumers see the relevance of a product to their own health ${ }^{(89,90)}$. Therefore it is important to consider whether the average consumer, as described in the NHCR, can relate a claim to his or her own health and thereby is able to fully understand a health claim $^{(90)}$. And although in literature the interest of a consumer in nutritional information is shown to be high, understanding of this information and thereby understanding of health claims is hard to test and 
therefore evidence is rare ${ }^{(91,92)}$. Consequently, relevance and understandability of the claim are important concerns when introducing a new health claim, which was seen to be an important consideration for EFSA as well in rejecting vague and general claims.

\section{Criterion III - cause and effect relationship established}

The last criterion in the assessment procedure by EFSA involves a check of the scientific studies provided to substantiate the proposed claim. The evidence can be considered not to be sufficient to result in a positive opinion, as was considered to be the case in the claim on lutein protecting from oxidative damage (vide infra). It might also be that the evidence was considered not to substantiate the proposed claim, as in the case of antioxidant action of beta-carotene (vide infra). The two examples of positive opinions, i.e. on copper and olive oil polyphenols respectively, are also discussed.

\section{Negative opinions}

Lutein was claimed to be a natural antioxidant, and as such to protect the organism from oxidative damage and to act as a natural way to avoid risks caused by oxidation and peroxidation processes ${ }^{(93)}$. Lutein is a carotenoid naturally present in foods and measurable by established methods and therefore sufficiently characterised as functional ingredient. The claim of being a 'natural antioxidant' is considered to refer to the protection of oxidative damage caused by free radicals, which was perceived by EFSA to be a beneficial physiologic effect on human health. Three scientific studies were provided to show the cause and effect relationship of lutein and the protection of oxidative damage. According to EFSA, these studies did not analyse the effects of lutein consumption on markers of oxidative damage in humans, and insufficient scientific evidence was available to establish a cause-effect relationship. This led EFSA to issue a negative opinion on the claim $^{(93)}$.

The claim on beta-carotene states that its antioxidant action helps to neutralise free radicals and counteracts cellular ageing, and the involvement of beta-carotene in body tissue protection from UV rays damage ${ }^{(94)}$. Beta-carotene is sufficiently characterised as a functional ingredient and the ten claims on 'antioxidant activity' and 'protection of 
DNA', including the one described above, may be considered to be a beneficial physiological effect to human health, implying to protect from oxidative damage caused by free radicals. The substantiation of these proposed claims was checked by reviewing the submitted dossier of scientific evidence, including narrative reviews, consensus opinions and human intervention studies. These first documents, narrative reviews and consensus opinions, were not considered to be relevant in substantiating a health claim, because of the lack of original data to evaluate. The other studies provided in the dossier, the human intervention studies, can be divided into two groups. The first group of intervention studies examined the effects of beta-carotene with other carotenoids or antioxidant vitamins on non-related health outcomes for these claims. Therefore these studies are not used in substantiating the claim. The second group of intervention studies are studies on the effect of beta-carotene on oxidative damage. These studies do not include control groups and use markers (as skin erythema as marker of UV-protection and skin malondialdehyde concentrations as a marker of UV-induced photo-oxidative damage), all regarded as unreliable markers of oxidative damage to DNA and lipids. Due to the lack of scientific evidence on the suggested health claim EFSA issued a negative opinion on this claim ${ }^{(94)}$.

\section{Positive opinions}

The proposed claim on copper, claiming to protect from oxidative damage, is scientifically substantiated by different studies. Several papers describe the role of copper in the human body, being a component of enzymes as cytochrome c oxidase (involved in electron transport in the respiratory chain) and ceruloplasmin (involved in iron transport in plasma), cofactors and proteins in the body and thereby having mostly a catalytic role. Many copper metalloenzymes are described to act as oxidases, to reduce molecular oxygen. An example of such an enzyme is the superoxide dismutase (SOD) enzyme. This enzyme in the cytosol of human cells defends against oxidative damage from superoxide radicals. The activity of SOD is, next to other factors, related to copper intake. Therefore a cause and effect relationship was established according to EFSA, and the claim was assessed positively ${ }^{(71)}$. 
To scientifically substantiate the claim of olive oil polyphenols reducing oxidative stress and having antioxidant activity and antioxidant properties, the dossier contains several studies that are not considered to ground the claim. These papers are not seen to be suitable to substantiate the claim, due to testing foods or food ingredients other than olive oil polyphenols and/or study effects different than protection of lipids. Studies that are considered to be relevant to validate the claim are three human intervention studies: (i) a study measuring several significant effects including decreased oxidative damage through plasma-circulating oxidised LDL when consuming higher doses of olive oil polyphenols; (ii) a study showing a significant decrease of concentration of circulating markers of LDL particles with higher phenolic content of the olive oil; and (iii) a double-blind randomised intervention showing both a significant decrease in in vivo plasma-circulating oxidised LDL and a significant increase in ex vivo resistance of LDL to oxidation with a higher phenolic content of the olive oil. Other studies address the bioavailability of the compounds and the possible mechanism of action of olive oil polyphenols on protecting the LDL particles from oxidation, which is thought to be caused by the incorporation of the phenolic compounds in the LDL particles. These studies, along with a short term study and an acute study on the effect of olive oil polyphenols on markers of LDL oxidation, were considered by EFSA to support the claim. Because of the use of appropriate markers of LDL peroxidation and of supportive markers pointing in the same direction, along with evidence for the possible mechanism of action, the claim was assessed positively ${ }^{(72)}$.

\section{Implications}

The third and last criterion in the assessment procedure of a proposed claim used by EFSA is the check on scientific substantiation of the claim. Within this criterion, one very clear condition is shown: the claimed effect has to be tested in vivo in the proposed human target group. This claimed effect has to be caused by the food or functional ingredient. To establish this relationship, a human intervention study is regarded as the most convincing proof in the analysed opinions. Evidence on the probable mechanism of action of the food or functional ingredient has to be in the submitted dossier to 
EFSA, explaining the claimed effect. Supportive evidence can come from reviews, in vitro studies and animal studies, but these studies are never solely used to evoke a positive opinion on a claim. Apparent from the provided examples, not all human intervention trials are accepted as evidence. Not only testing in the proposed target group is important with the appropriate conditions of use, the trials must also have high methodological and statistical quality by e.g. addressing confounding factors, making use of valid biomarkers and having sufficient statistical power ${ }^{(22,47)}$. After analysing the described opinions on scientific substantiation of health claims, it is clear that solely the consumption of the specific food or functional ingredient has to be tested on the claimed effect. A significant beneficial effect shown in different intervention trials performed by independent institutions increases the chance of receiving a positive advice of $\mathrm{EFSA}^{(72)}$.

The implications extracted by analysing the opinions, described in table 3, raise the question whether the physiological effect of the ingredient is the same when it is consumed under experimental conditions or as part of the total diet. Different interventions can have participants consuming different diets, which may influence the observed effects. Also the bioavailability and bioaccessibility are influenced by the composition of the food and the diet possibly leading to different effects with consumption of the food under regular circumstances ${ }^{(77,95)}$. However, since studies for the substantiation of a claim have to use the specific food carrying the proposed claim and mostly attempts are made to control other dietary factors, there currently is no other way to test the effectiveness of the food.

The second issue raised by these implications is the importance of human intervention trials in nutritional research. This study design is currently the only design deemed appropriate to show a strong causal relationship and its suitability to test effects of drugs (evidence-based medicine) has led to the implementation of the design in nutrition research (evidence-based nutrition) ${ }^{(78,96)}$. However, for the evaluation of nutrient effects the design is considered to be less appropriate, due to several issues 
following from the fact that nutrition will not give rise to similar effects as drugs ${ }^{(78)}$. As described in the second characteristic, nutrients have pleiotropic effects on health versus one or few outcome measures with drugs, and the relative small effects over long periods of time expected with the intake of specific nutrients ${ }^{(77,79,96)}$. Therefore suggestions arise in literature to test nutrition in different experimental set-ups as challenge tests where the robustness of a physiological system is put under pressure and the marker for health is the system's ability to resist or to recover from the impact. These challenge tests are reminiscent of oral glucose tolerance test (OGTT) and the oral lipid tolerance test $(\mathrm{OLTT})^{(77,84,87,97)}$. The use of new study designs to substantiate a health claim might be of more relevance to demonstrate the effects of nutrition in health. Table 3 summarises the findings from the opinions published by EFSA as described above in this section.

Table 3. Assessment criteria scientific opinions and their implications for health claims.

\begin{tabular}{|c|c|c|}
\hline & Criteria & Implications \\
\hline I & $\begin{array}{l}\text { The food or functional ingredient is } \\
\text { defined and characterised }\end{array}$ & $\begin{array}{l}\text { - Explicit characterisation of food/ } \\
\text { functional ingredient with active } \\
\text { substances } \\
\text { - Relevant, established measures } \\
\text { for these substances in the food }\end{array}$ \\
\hline II & $\begin{array}{l}\text { The claimed effect is defined } \\
\text { The claimed effect is a beneficial } \\
\text { physiological effect }\end{array}$ & $\begin{array}{l}\text { - Effect measurable in vivo } \\
\text { - Effect connected to a health } \\
\text { outcome, without implying } \\
\text { treatment }\end{array}$ \\
\hline III & $\begin{array}{l}\text { A cause and effect relationship is } \\
\text { established between the } \\
\text { consumption of the food or } \\
\text { functional ingredient and the claimed } \\
\text { effect }\end{array}$ & $\begin{array}{l}\text { - Human trials on claimed effect } \\
\text { with specific substance and its } \\
\text { specific conditions in vivo } \\
\text { - Show evidence for probable } \\
\text { mechanism of action } \\
\text { - Supportive evidence from reviews, } \\
\text { in vitro and animal studies }\end{array}$ \\
\hline
\end{tabular}

Comparing the positively and negatively assessed claims, the evaluation procedure is shown to always follow the same three criteria, as previously described in table 2 . If 
the assessment is not positive in one of these criteria, the other criteria will not be taken into consideration and a negative assessment on the claim follows. This is generally followed by a negative decision by the $\mathrm{EC}$, rejecting authorisation of the claim.

\section{Conclusion}

The White Paper on Food Safety of 2000, developed after different food scares and crises in the 1990s, advised to take different actions on food matters, with the adoption of the GFL as the foundation of European Food Law. Among the many activities on food, in 2006 the EU adopted legislation to regulate nutrition and health claims on food products. Although EFSA was founded in the GFL to perform independent risk assessment, the agency was requested to review proposed health claims under the NHCR. This paper analysed which criteria EFSA uses to undertake this task, specifically in the assessment of claims on antioxidants. Most claims on antioxidant activity were denied while in the meantime new insights on the mechanisms of action of antioxidants arose. Therefore, reviewing the assessment procedure used by EFSA via claims on antioxidants is very timely.

The criteria-implications as displayed in table 3 have consequences for research on and development of health claims. Nutrition research and more specifically antioxidant research methodology seems to require a different approach as pointed out in this paper. Our analysis reveals that not only the current view on health should be redefined, it also questions the use of intervention trials as golden standards, and views that the focus on single-targets in nutrition research needs to shift towards a multitarget approach. The ability to adapt as a definition for health entails that health promoting compounds should be investigated under stress conditions. In that regard adequate challenge models are to be developed to review the multi-factorial effects of dietary compounds. 
New insights arising from research on the mechanisms of action of antioxidants show the lack of usability of the nutrition and health claim regulation. Next to ROS scavenging, the anti-inflammatory actions of antioxidants and their effects on the endogenous antioxidant synthesis could result in health benefits. However, this complexity of the actions of antioxidants is not recognised by the criteria used to evaluate proposed health claims, nor by the methodologies used to assess the effects of antioxidants. At the start of the assessment procedure under the NHCR, EFSA was only provided with Terms of Reference by the EC to base their assessment criteria on. In case of antioxidants the awareness that these compounds have a broader effect than merely their radical scavenging actions might help to position these compounds more clearly. In that regard the term 'bioactive' compounds has been proposed. The current case study shows the need to develop criteria which are more in line with novel scientific insights into the multitude of effects of nutrition, as exemplified with antioxidants. The apparent mismatch in views on how to assess health promoting effects of dietary compounds should be resolved. Therefore, consultative involvement of stakeholders like industrials, advisors of the regulator, scientists and consumer representatives in this respect is pivotal. Improved embedding of nutritional science in these criteria prevails over stringent regulation. 


\section{References}

1. Hoad D (2011) Scientific Method and the Regulation of Health and Nutritional Claims by the European Food Safety Authority. Bull Sci Technol Soc 31, 123-133.

2. Levidow L \& Carr S (2007) Europeanising advisory expertise: The role of 'independent, objective and transparent' scientific advice in agri-biotech regulation. Env. Plann C Gov Policy 26, 880-895.

3. Van der Meulen B \& van der Velde M (2008) Food law: development, crisis and transition. In European Food Law Handbook, pp. 229-252. Wageningen: Wageningen Academic Publishers.

4. Van der Meulen BMJ (2009) The System of Food Law in the European Union. Deakin Law Rev. 14, 305-340.

5. European Commission (1997) The general principles of food law in the European Union - Commission green paper. COM 176.

6. European Commission (2000) White paper on food safety. COM 719.

7. European Parliament and Council of the European Union (2002) Regulation (EC) No $178 / 2002$ of the European Parliament and of the Council of 28 January 2002 laying down the general principles and requirements of food law, establishing the European Food Safety Authority and laying down procedures in matters of food safety.OJ L 31 45, 1-24.

8. Szajkowska A (2009) From mutual recognition to mutual scientific opinion? Constitutional framework for risk analysis in EU food safety law. Food Policy 34, 529-538.

9. European Parliament and Council of the European Union (2008) Regulation (EC) No 1334/2008 of the European Parliament and of the Council of 16 December 2008 on flavourings and certain food ingredients with flavouring properties for use in and on foods and amending Council Regulation (EEC) No 1601/91, Regulations (EC) No 2232/96 and (EC) No 110/2008 and Directive 2000/13/EC. OJ L 354 51, 34-50.

10. European Commission (2010) Commission Regulation (EU) No 365/2010 of 28 April 2010 amending Regulation (EC) No 2073/2005 on microbiological criteria for foodstuffs as regards Enterobacteriaceae in pasteurised milk and other pasteurised liquid dairy products and Listeria monocytoge. OJ L 107 53, 9-13.

11. European Parliament and Council of the European Union (2011) Regulation (EU) No 1169/2011 of the European Parliament and of the Council of 25 October 2011 on the provision of food information to consumers, amending Regulations (EC) No 1924/2006 and (EC) No 1925/2006 of the European Parliament and of the Council, and repealing Commission Directive 87/250/EEC, Council Directive 90/496/EEC, Commission Directive 1999/10/EC, Directive 2000/13/EC of the European Parliament and of the Council, Commission Directives 2002/67/EC and 2008/5/EC and Commission Regulation (EC) No 608/2004. OJ L 304 54, 18-63.

12. European Parliament and Council of the European Union (2006) Regulation (EC) No 1924/2006 of the European Parliament and of the council of 20 December 2006 on nutrition and health claims made on foods. OJ L 404 49, 9-25.

13. Moors EHM (2012) Functional foods: regulation and innovations in the EU. Innovation $25,424-440$. 
14. EFSA (2013) About the NDA Panel and the Nutrition Unit. http://www.efsa.europa.eu/en/nda/aboutnda.htm (accessed October 2013).

15. European Commission (2013) EU Register on nutrition and health claims. http://ec.europa.eu/nuhclaims/?event $=$ search \&CFID $=335086 \&$ CFTOKEN $=b b 484 f 431$ b2 27bd1-79366084-B936-26BA-

A093EC372F6F1B31\&jsessionid $=9312 c 835 f 5666 f 4342 c 4403366511152 f 434 T R$ (accessed October 2013).

16. EFSA NDA Panel (2009) Scientific Opinion on Water-soluble tomato concentrate (WSTC I and II) and platelet aggregation Scientific substantiation of a health claim related to water-soluble tomato concentrate (WSTC I and II) and platelet aggregation pursuant to Article 13(5) of Regulation (EC) No 1924/2006. EFSA Journal 1101, 1-15.

17. EFSA NDA Panel (2010) Scientific Opinion on the modification of the authorisation of a health claim related to water-soluble tomato concentrate and helps to maintain a healthy blood flow and benefits circulation pursuant to Article 13(5) of Regulation (EC) No 1924/2006 following a request in accordance with Article 19 of the Regulation (EC) No 1924/2006. EFSA Journal 1689, 1-9.

18. EFSA NDA Panel (2012) Scientific Opinion on the substantiation of a health claim related to cocoa flavanols and maintenance of normal endothelium-dependent vasodilation pursuant to Article 13(5) of Regulation (EC) No 1924/2006. EFSA Journal 2809, 1-21.

19. Europe Press Releases (2006) Questions and Answers on Health and Nutrition Claims. http://europa.eu/rapid/press-release_MEMO-06-200_en.htm?locale=en (accessed October 2013).

20. Ernst \& Young (2012) External Evaluation of EFSA - Final Report.

21. Flynn A (2012) Symposium 2: Nutrition and health claims: help or hindrance Scientific substantiation of health claims in the EU. Proc Nutr Soc 71, 120-126.

22. Gilsenan MB (2011) Nutrition \& health claims in the European Union: A regulatory overview. Trends Food Sci. Technol. 22, 536-542.

23. European Commission (2012) Commission Regulation (EU) No 432/2012 of 16 May 2012 establishing a list of permitted health claims made on foods, other than those referring to the reduction of disease risk and to children's development and health. OJ L 13655 , $1-40$.

24. Diplock AT, Aggett PJ, Ashwell M, et al. (1999) Scientific Concepts in Functional Foods in Europe: Consensus Document. Br. J. Nutr. 81, S1-S28.

25. European Food Information Council (2015) Functional Foods. http://www.eufic.org/article/en/expid/basics-functional-foods/.

26. Aggett PJ, Antoine J-M, Asp N-G, et al. (2005) PASSCLAIM, Process for the Assessment of Scientific Support for Claims on Foods. Eur J Nutr 44, 5-30.

27. European Commission (2001) Discussion paper on nutrition claims and functional claims. Brussels: SANCO/1341/2001. Prepared by Directorate General Health and Consumer Protection (SANCO D4).

28. European Parliament and the Council of the European Union (2003) Proposal for a regulation of the European Parliament and of the Council on nutrition and health claims made on foods. Brussels: European Commission. 
29. Van der Meulen B \& van der Velde M (2008) Informed choice: presentation of food products. In European Food Law Handbook, pp. 371-402. Wageningen: Wageningen Academic Publishers.

30. EFSA (2013) 'General function' health claims under Article 13. http://www.efsa.europa.eu/en/topics/topic/article13.htm (accessed October 2013).

31. EFSA (2013) 'New function' health claims under Article 13.5. http://www.efsa.europa.eu/en/topics/topic/article13-5.htm (accessed October 2013).

32. EFSA (2013) Claims on disease risk reduction and child development or health under Article 14. http://www.efsa.europa.eu/en/topics/topic/article14.htm (accessed October 2013).

33. European Commission (2013) Commission Regulation (EU) No 536/2013 of 11 June 2013 amending Regulation (EU) No 432/2012 establishing a list of permitted health claims made on foods other than those referring to the reduction of disease risk and to children's development and health. OJ L 160 56, 4-8.

34. Verhagen H, Vos E, Francl S, et al. (2010) Status of nutrition and health claims in Europe. Arch Biochem Biophys 501, 6-15.

35. European Food Safety Authority (2013) EFSA: Risk Assessment. http://www.efsa.europa.eu/en/efsawhat/riskassessment.htm (accessed October 2013).

36. European Food Safety Authority (2013) EFSA: What we do. http://www.efsa.europa.eu/en/aboutefsa/efsawhat.htm (accessed October 2013).

37. Directorate General Health and Consumer Protection (2000) Food law from farm to table - Creating a European Food Authority. Brussels: Directorate General Health and Consumer Protection.

38. Byrne D (2002) EFSA: Excellence, integrity and openness. In Inaugural meeting of the Management Board of the European Food Safety Authority.

39. Van der Meulen B \& van der Velde M (2008) The institutions of the European Community. In European Food Law Handbook, pp. 161-216. Wageningen: Wageningen Academic Publishers.

40. European Food Safety Authority (2013) EFSA corporate documents. http://www.efsa.europa.eu/en/aboutefsa/keydocs.htm (accessed October 2013).

41. Hanekamp JC, Bast A \& Calabrese EJ (2013) Nutrition and health - transforming research traditions. Crititical Rev. Food Sci. Nutr. (in press).

42. European Commission (2007) Terms of Reference.

43. EFSA (2013) EFSA: FAQ on nutrition and health claims. http://www.efsa.europa.eu/en/faqs/faqnutrition.htm?wtrl=01 (accessed October 2013).

44. Silano M \& Silano V (2008) The fifth anniversary of the European Food Safety Authority (EFSA): Mission, organization, functioning and main results. Fitoterapia 79, 149-160.

45. European Food Safety Authority (2010) EFSA's Modus operandi for Article 13(3) Health Claims of Regulation (EC) No 1924/2006. Parma: European Food Safety Authority.

46. European Food Safety Authority (2008) Criteria for the initial screening of Article 13(3) health claims of Regulation (EC) No 1924/2006. Parma: European Food Safety Authority.

47. EFSA NDA Panel (2011) General guidance for stakeholders on the evaluation of Article $13.1,13.5$ and 14 health claims. EFSA Journal 2135, 1-24. 
48. European Commission (2008) Commission Regulation (EC) No 353/2008 of 18 April 2008 establishing implementing rules for applciations for authorisation of health claims as provided for in Article 15 of Regulation (EC) No 1924/2006 of the European Parliement and of the Council. OJ L 109 51, 11-16.

49. European Food Safety Authority (2012) Petition Nutrition and Health Claims. http://ec.europa.eu/food/food/labellingnutrition/claims/docs/petition_nutrition_health_ claims_230712_en.pdf (accessed October 2013).

50. Bast A \& Haenen GRMM (2013) Ten misconceptions about antioxidants. Trends Pharmacol Sci 34, 430-436.

51. Carocho M \& Ferreira ICFR (2013) A review on antioxidants, prooxidants and related controversy: natural and synthetic compounds, screening and analysis methodologies and future perspectives. Food Chem Toxicol 51, 15-25.

52. Halliwell B (1996) Antioxidants in human health and disease. Annu Rev Nutr 16, 33-50.

53. Halliwell B (2007) Biochemistry of oxidative stress. Biochem Soc Trans 35, 1147-1150.

54. Malireddy S, Kotha SR, Secor JD, et al. (2012) Phytochemical antioxidants modulate Mammalian cellular epigenome: implications in health and disease. Antioxid Redox Signal 17, 327-339.

55. Masella R, Di Benedetto R, Varì R, et al. (2005) Novel mechanisms of natural antioxidant compounds in biological systems: involvement of glutathione and glutathione-related enzymes. J Nutr Biochem 16, 577-586.

56. Halliwell B (2011) Free radicals and antioxidants - quo vadis? Trends Pharmacol Sci 32, 125-130.

57. Weseler AR \& Bast A (2010) Oxidative stress and vascular function: implications for pharmacologic treatments. Curr Hypertens Rep 12, 154-161.

58. De Vries HE, Witte M, Hondius D, et al. (2008) Nrf2-induced antioxidant protection: a promising target to counteract ROS-mediated damage in neurodegenerative disease? Free Radic Biol Med 45, 1375-1383.

59. Preiser JC (2012) Oxidative stress. JPEN 36, 147-154.

60. Reuland DJ, McCord JM \& Hamilton KL (2013) The Role of Nrf2 in the Attenuation of Cardiovascular Disease. Exerc Sport Sci Rev 41, 162-168.

61. Nguyen T, Yang CS \& Pickett CB (2004) The pathways and molecular mechanisms regulating Nrf2 activation in response to chemical stress. Free Radic Biol Med 37, 433441.

62. Owuor ED \& Kong A-NT (2002) Antioxidants and oxidants regulated signal transduction pathways. Biochem Pharmacol 64, 765-770.

63. Hazewindus M, Haenen GRMM, Weseler AR, et al. (2012) The anti-inflammatory effect of lycopene complements the antioxidant action of ascorbic acid and $\alpha$-tocopherol. Food Chem 132, 954-958.

64. Geraets L, Moonen HJ, Brauers K, et al. (2007) Dietary flavones and flavonoles are inhibitors of poly(ADP-ribose)polymerase-1 in pulmonary epithelial cells. J Nutr 137, 2007/09/22 ed., 2190-2195.

65. Heim KE, Tagliaferro AR \& Bobilya DJ (2002) Flavonoid antioxidants: chemistry, metabolism and structure-activity relationships. J Nutr Biochem 13, 572-584. 
66. Langseth L (1995) Oxidants, antioxidants, and disease prevention. Brussels: ILSI press.

67. Forman HJ, Davies KJA \& Ursini F (2014) How do nutritional antioxidants really work: Nucleophilic tone and para-hormesis versus free radical scavenging in vivo. Free Radic Biol Med 66, 2013 Jun 6, 24-35.

68. EFSA NDA Panel (2011) Scientific Opinion on the substantiation of health claims related to: dairy products (ID 1140, 1141, 1191), raw or processed food products of animal origin, plus bread and panification products (ID 1193, 1194), herbal yeast plasmolysate (ID 1815, 1816), apple polyphenols (ID 2713), rye flour (ID 1266), tomato juice (ID 1202), whey protein and alphalactalbumin (ID 424, 430, 432, 725, 1433), "brocco shoots", "broccoli sprout powder" and "Brassica oleracea var. italica (broccoli)" (ID 1362, 1481, 2844, 2845), honey (ID 1159, 1160, 1318, 4678, 4679), and Cucurbita pepo L. (pumpkin) seeds and seed extracts (ID 2029, 2365) pursuant to Article 13(1) of Regulation (EC) No 1924/2006. EFSA Journal 2243, 1-33.

69. Codex Alimentarius Committee on Sugar (2001) Revised Codex Standard for Honey (CODEX STAN 12-1981).

70. EFSA NDA Panel (2011) Scientific Opinion on the substantiation of health claims related to flavonoids and ascorbic acid in fruit juices, including berry juices (ID 1186); flavonoids from citrus (ID 1471); flavonoids from Citrus paradisi Macfad. (ID 3324, 3325); flavonoids (ID 1470, 1693, 1920); flavonoids in cranberry juice (ID 1804); carotenoids (ID 1496, 1621, 1622, 1796); polyphenols (ID 1636, 1637, 1640, 1641, 1642, 1643); rye bread (ID 1179); protein hydrolysate (ID 1646); carbohydrates with a low/reduced glycaemic load (ID 476, $477,478,479,602)$ and carbohydrates which induce a low/reduced glycaemic response (ID 727, 1122, 1171); alfalfa (ID 1361, 2585, 2722, 2793); caffeinated carbohydratecontaining energy drinks (ID 1272); and soups (ID 1132, 1133) pursuant to Article 13(1) of Regulation (EC) No 1924/2006. EFSA Journal 2082, 1-38.

71. EFSA NDA Panel (2009) Scientific Opinion on the substantiation of health claims related to copper and protection of DNA, proteins and lipids from oxidative damage (ID 263, 1726), function of the immune system (ID 264), maintenance of connective tissues (ID 265, 271, 1722), ene. EFSA Journal 1211.

72. EFSA NDA Panel (2011) Scientific Opinion on the substantiation of health claims related to polyphenols in olive and protection of LDL particles from oxidative damage (ID 1333, $1638,1639,1696,2865)$, maintenance of normal blood HDL-cholesterol concentrations (ID 1639), maintenance of normal blood pressure (ID 3781), "anti-inflammatory properties" (ID 1882), "contributes to the upper respiratory tract health" (ID 3468), "can help to maintain a normal function of gastrointestinal tract" (3779), and "contributes to body defences against external agents" (ID 3467) pursuant to Article 13(1) of Regulation (EC) No 1924/2006. EFSA Journal 2033, 1-25.

73. Jacobs DRJ \& Steffen LM (2003) Nutrients, foods, and dietary patterns as exposures in research: a framework for food synergy. Am J Clin Nutr 78, 508S-513S.

74. Jacobs DR \& Tapsell LC (2007) Food, not nutrients, is the fundamental unit in nutrition. Nutr Rev 65, 439-450.

75. Hoffmann I (2003) Transcending reductionism in nutrition research. Am J Clin Nutr 78, 514S-516S. 
76. Schneider K \& Hoffmann I (2011) Nutrition Ecology - A Concept for Systemic Nutrition Research and Integrative Problem Solving. Ecol Food Nutr 50, 1-17. Routledge.

77. Weseler AR \& Bast A (2012) Pleiotropic-Acting Nutrients Require Integrative Investigational Approaches: The Example of Flavonoids. J Agric Food Chem 60, 89418946.

78. Heaney RP (2008) Nutrients, endpoints, and the problem of proof. J Nutr 138, 15911595.

79. Van Ommen B \& Stierum R (2002) Nutrigenomics: exploiting systems biology in the nutrition and health arena. Curr Opin Biotechnol 13, 517-521.

80. EFSA NDA Panel (2010) Scientific Opinion on the substantiation of health claims related to various food(s)/food constituent(s) and protection of cells from premature ageing (ID $1668,1917,2515,2527,2530,2575,2580,2591,2620,3178,3179,3180,3181,4329$, 4415), antioxidant activity, antioxidant content and antioxidant properties (ID 857, 1306, $2515,2527,2530,2575,2580,2591,2629,2728,4327,4365,4380,4390,4394,4455,4464$, $4507,4694,4705)$, protection of DNA, proteins and lipids from oxidative damage (ID $1196,1211,1216,1306,1312,1440,1441,1666,1668,1692,1900,1914,1948,2023,2158$, $2517,2522,2527,2575,2591,2620,2637,2639,2663,2860,3079,3276,3564,3818,4324$, 4329, 4351, 4397, 4416, 4424, 4507, 4527, 4528, 4542, 4611,4629, 4659) and bioavailability of anthocyanins in black currants (ID 4220) pursuant to Article 13(1) of Regulation (EC) No 1924/2006. EFSA Journal 1752, 1-34.

81. EFSA NDA Panel (2010) Scientific Opinion on the substantiation of health claims related to various food(s)/food constituent(s) and protection of cells from premature aging, antioxidant activity, antioxidant content and antioxidant properties, and protection of DNA, proteins and lipids from oxidative damage pursuant to Article 13(1) of Regulation (EC) No 1924/2006. EFSA Journal 1489, 1-63.

82. EFSA NDA Panel (2012) Scientific Opinion on the substantiation of a health claim related to $3 \mathrm{~g}$ /day plant sterols/stanols and lowering blood LDL-cholesterol and reduced risk of (coronary) heart disease pursuant to Article 19 of Regulation (EC) No 1924/2006. EFSA Journal 2693, 1-15.

83. Ledford H (2013) Cholesterol limits lose their lustre. Revised guidelines for heart health are set to move away from target-based approach. Nature; http://www.nature.com/news/cholesterol-limits-lose-their-lustre1.12509?WT.ec_id=NATURE-20130228 (accessed October 2013).

84. Elliott R, Pico C, Dommels $Y$, et al. (2007) Nutrigenomic approaches for benefit-risk analysis of foods and food components: defining markers of health. Br J Nutr 98, 10951100.

85. Huber M, Knottnerus JA, Green L, et al. (2011) How should we define health? Br Med J 343.

86. Kussmann M, Raymond F \& Affolter M (2006) OMICS-driven biomarker discovery in nutrition and health. J Biotechnol 124, 758-787.

87. Van Ommen B, Keijer J, Heil SG, et al. (2009) Challenging homeostasis to define biomarkers for nutrition related health. Mol Nutr Food Res 53, 795-804. 
88. WHO (2006) Constitution of the World Health Organization. www.who.int/governance/eb/who_constitution_en.pdf (accessed October 2013).

89. Dean M, Lampila P, Shepherd R, et al. (2012) Perceived relevance and foods with healthrelated claims. Food Qual Prefer 24, 129-135.

90. Nocella G \& Kennedy O (2012) Food health claims - What consumers understand. Food Policy 37, 571-580.

91. Tarabella A \& Burchi B (2012) The Role of Nutrition and Health Claims in Consumers' Perception. Creating Educational Paths to Resolve Information Asymmetries Caused by Promotion and Marketing Activities Regarding Foodstuffs. Procedia Soc Behav Sci 46, 2173-2177.

92. Van Trijp HCM (2009) Consumer understanding and nutritional communication: key issues in the context of the new EU legislation. Eur J Nutr 48, 41-48.

93. EFSA NDA Panel (2011) Scientific Opinion on the substantiation of health claims related to lutein and protection of DNA, proteins and lipids from oxidative damage (ID 3427), protection of the skin from UV-induced (including photo-oxidative) damage (ID 1605, 1779) and maintenance of normal vision (ID 1779, 2080) pursuant to Article 13(1) of Regulation (EC) No 1924/2006. EFSA Journal 2030, 1-16.

94. EFSA NDA Panel (2011) Scientific Opinion on the substantiation of health claims related to beta-carotene and protection of DNA, proteins and lipids from oxidative damage (ID $19,197,1262,1460$ ), protection of the skin from UV-induced (including photo-oxidative) damage (ID 178. EFSA Journal 2021, 1-22.

95. Turgeon SL \& Rioux L-E (2011) Food matrix impact on macronutrients nutritional properties. Food Hydrocoll 25, 1915-1924.

96. Blumberg J, Heaney RP, Huncharek M, et al. (2010) Evidence-based criteria in the nutritional context. Nutr Rev 68, 478-484.

97. Pellis L, van Erk MJ, van Ommen B, et al. (2012) Plasma metabolomics and proteomics profiling after a postprandial challenge reveal subtle diet effects on human metabolic status. Metabolomics 8, 347-359. 


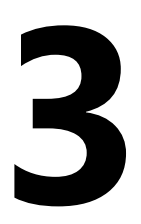

\section{Stakeholders' perception of \\ the nutrition and health claim} regulation

Alie de Boer, Aalt Bast

International Journal of Food Sciences and Nutrition 66(3) (2015), 321-328 
Chapter 3

\section{Abstract}

In 2007, the Nutrition and Health Claim Regulation (NHCR) entered into force, which required scientific substantiation of health claims. In the field of antioxidants, most proposed claims were negatively assessed by the European Food Safety Authority (EFSA). This study reviews the perception of the NHCR of 14 Dutch stakeholders to unravel the grounds for disproving the putative health claims. Most claims are shown to be refused based on the quality of scientific substantiation, due to usage of scientific methods on which no consensus has been reached and the differences in expectations and requirements. Three themes exemplify the need for improvement in applying the NHCR: (i) enforcement; (ii) methodology; and (iii) perceived impact of the NHCR. With highly diverging perceptions of stakeholders, the current effectiveness of the NHCR can be questioned. The views of different stakeholders on these themes help to focus the discussion on the NCHR in capturing health effects. 


\section{Introduction}

Following the reform of European food law in the aftermath of the bovine spongiform encephalopathy (BSE) crisis, a new regulatory framework dealing with nutrition and health claims entered into force in the EU in 2007: the Nutrition and Health Claim Regulation ${ }^{i}(\mathrm{NHCR})^{(1,2)}$. The NHCR aims to protect consumers from misleading by incorrect information and false claims by ensuring that proposed claims are scientifically substantiated. Moreover, the NHCR is intended to improve the free movement of goods in the internal market by harmonising the various national regulations of Member States ${ }^{(1,3,4)}$. The use of a claim is permitted or refused by the European Commission (EC), after consulting the expert opinion of the European Food Safety Authority (EFSA). EFSA is the independent agency advising the EC on the accuracy of the scientific basis of a claim through a set of different criteria ${ }^{(5,6)}$.

The NHCR regulates both nutrition and health claims. Nutrition claims describe the nutritional properties of the ingredient or food product. Health claims state the relationship between the ingredient or food product and a beneficial effect on health ${ }^{(3)}$. Health claims can be divided into three categories: (i) Article 13.1 claims: general function claims, implying a health benefit based on scientific evidence ${ }^{(7)}$; (ii) Article 13.5 claims: new function claims, implying a health benefit based on newly developed scientific evidence ${ }^{(8)}$; and (iii) Article 14 claims: claims on (a) the reduction of disease risk or on (b) children's development and health ${ }^{(3,9,10)}$.

\footnotetext{
' Regulation (EC) No. 1924/2006 of the European Parliament and of the Council of 20 December 2006 on nutrition and health claims made on foods. Regulation (EC) No. 1924/2006 is amended by Regulation (EC) No. 107/2008; Regulation (EC) No. 109/2008; Commission Regulation (EU) No. 116/2010; and Commission Regulation (EU) No. 1047/2012.
} 
Approved Article 13.1 and 13.5 claims are made public in the annex to Regulation 432/2012 ${ }^{\mathrm{ii}}$ (7). New EC-authorised Article 13.5 claims are continuously added to this list ${ }^{(11)}$. Currently, the EC authorised 233 claims $^{(12)}$. EFSA considered nearly all proposed Article 13.1 claims on antioxidants were not substantiated satisfactorily, leading the EC to decline these claims ${ }^{(10,13)}$. Only eight claims on antioxidant activity received a positive advice and were subsequently authorised by the EC, viz. seven claims on vitamins and minerals, one claim on olive oil polyphenols ${ }^{(10)}$. Positive opinions from EFSA on watersoluble tomato concentrate ${ }^{(14,15)}$ and on cocoa flavonoids ${ }^{(16)}$ are not taken into account here, since the claimed health benefits of these products are not regarded as consequence of antioxidants as the active ingredient ${ }^{(13)}$.

Only very few statements about ingredients acting as antioxidant or their health effects are currently allowed ${ }^{(10,17)}$. In order to unravel the ground(s) for disproving the putative health claims of all virtual antioxidants, this study reviews the perception of stakeholders of the NHCR. This was investigated by conducting semi-structured indepth interviews with stakeholders in the Netherlands, working with functional ingredients and specifically antioxidant containing ingredients. Following Freeman's definition of stakeholders (1984): 'any group or individual who can affect or is affected by the achievement of the [organisation's] objectives', for the purpose of this study four groups were identified as stakeholders of the NCHR, viz. industrials (who have to live up to the requirements following the NHCR for current and future claims), regulatory experts (either involved in discussions on the development of the positive list or in enforcing the NHCR), nutritional scientists (affected by the required standards

\footnotetext{
ii Commission Regulation (EU) No. 432/2012 of 16 May 2012 establishing a list of permitted health claims made on foods, other than those referring to the reduction of disease risk and to children's development and health. Regulation 432/2012 is amended by Commission Regulation (EU) No. 536/2013; Commission Regulation (EU) No. 851/2013; Commission Regulation (EU) No. 1018/2013; and Commission Regulation (EU) No. 40/2014, adding seven Article 13.1 and four Article 13.5 claims to the list found in the Annex.
} 
for scientific substantiation) and consumer representatives (serving as spokespersons for consumers, who are facing claims as marketing statements) ${ }^{(18-20)}$.

\section{Methods}

For the purpose of this research a qualitative approach was followed, since qualitative research gives the opportunity to extensively explore the experiences of the involved stakeholders $^{(21)}$. By conducting semi-structured in-depth interviews in person it was possible to review the perception of stakeholders of the NHCR and their attitude about the procedures surrounding this regulation ${ }^{(22)}$.

\section{Theoretical framework}

Through literature research and obtained expert opinions three themes were identified, which are expected to influence a stakeholder's view on the NHCR: (i) the regulatory act itself; (ii) the assessment procedure; and (iii) the impact of the regulation.

Expectations a stakeholder had of the regulatory act during the drafting process of the NHCR are assumed to influence the perception, as expectations prior to the occurrence of an event are described to influence the perception of that event ${ }^{(23,24)}$. In addition, current experience in dealing with the regulation is expected to affect perception. Since the EC decision is based on the scientific opinion of EFSA, the assessment procedure is expected to influence a stakeholder's view of the NHCR. Next to that, the credibility of this assessment process depends partially on transparency and independence of $\operatorname{EFSA}^{(25-29)}$.

The NHCR aims to stimulate innovation through the use of approved health claims, and therefore the impact on innovation is considered in the third variable ${ }^{(3)}$. Since innovation is highly connected to research, a stakeholder is expected to link the effect on innovation to the impact of the NHCR on research ${ }^{(30,31)}$. 


\section{Selection of participants}

In total, 14 Dutch professionals participated in this study (table 1). In line with the theoretical framework set forth above, the four groups of stakeholders that are affected by the NHCR through different positions were approached: industrials, regulatory experts, nutritional scientists and consumer representatives ${ }^{(20)}$. Since this study focuses specifically on the NHCR and processes related to the NHCR and concentrates on food products containing antioxidants, key players were identified and by means of purposive sampling invited to participate in this study ${ }^{(32)}$. Although this type of nonprobability sampling could limit the generalisability of results, the number of experts in the field is very limited and to reach the objective of this study, this methodology is considered to be appropriate ${ }^{(32,33)}$. The identified key players were invited to participate in the study by e-mail. In this invitation e-mail, the aim of the study was explained as follows (translated from Dutch): 'By conducting this research we want to identify how various stakeholders (industrials, regulatory experts, nutritional scientists and consumer representatives) perceive the use of the Nutrition and Health Claim Regulation within the field of food products containing antioxidants, which aspects are considered positive and what could be improved.'

Table 1. Overview of stakeholder participation.

\begin{tabular}{|l|l|l|l|l|}
\hline & Industrials & $\begin{array}{l}\text { Regulatory } \\
\text { experts }\end{array}$ & $\begin{array}{l}\text { Nutritional } \\
\text { scientists }\end{array}$ & $\begin{array}{l}\text { Consumer } \\
\text { representatives }\end{array}$ \\
\hline $\begin{array}{l}\text { Approached } \\
\text { stakeholders }\end{array}$ & $7^{*}$ & 3 & 5 & 2 \\
\hline $\begin{array}{l}\text { Declined } \\
\text { invitations }\end{array}$ & 0 & 1 & 2 & 0 \\
\hline $\begin{array}{l}\text { Participating } \\
\text { stakeholders }\end{array}$ & $7^{*}$ & 2 & 3 & 2 \\
\hline
\end{tabular}

* $=$ includes 3 food supplement industrials and 4 food industrials.

Following the conducted interviews, each interviewee was asked to suggest possible participants to ensure a sufficient amount of stakeholders ${ }^{(32)}$. These individuals were, if not involved in the study already, contacted to participate. Although such snowball 
sampling is suggested to give a higher chance for participation of experts with more social connections, the small amount of experts in the field of antioxidants led to the need to include this type of sampling to ensure sufficient participants to reach the objective of the study ${ }^{(32,33)}$. Even though most interviewees suggested already participating stakeholders, new participants were invited until no new findings were extracted in the data analysis from the conducted interviews and therefore the point of saturation was reached, leading to 14 participants in this study ${ }^{(32,34)}$.

\section{Data collection}

Semi-structured in-depth interviews with the participants were based on the theoretical framework (section 'theoretical framework'). All interviews were individually conducted in person by the first author. This set-up gave the possibility to ask in-depth questions to the interviewees to review their perception of the NHCR and the procedures surrounding this regulation ${ }^{(22)}$. During the interviews, all participating professionals

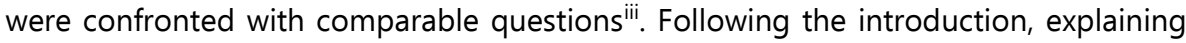
the objective of the interview, the interviewee was asked how he or she came into contact with the regulation, to clarify the position of the interviewee. Secondly, expectations and experience were addressed, and the objectives of the regulation were discussed. Subsequently, the perceived impact on innovation and research was discussed, focusing on the perceived impact within the field of antioxidants. The interview deliberated on the position of EFSA, as well as perceived advantages and disadvantages of the NHCR, again focussing on the field of antioxidants. If there were problems according to the interviewee which were due to this regulation, solutions were asked. Finally, the used standards for scientific substantiation were addressed.

\footnotetext{
iii Due to dynamics of the interviews, three questions were added throughout the interviews and the order of questions was changed.
} 
All interviews, which were conducted in Dutch, lasted 30 to $60 \mathrm{~min}$ and audio recordings were used to transcribe the interviews. All participants were requested to correct transcriptions.

\section{Data analysis}

The transcriptions were analysed through a systematic approach of directed content analysis to identify key concepts, using the existing theoretical framework (section 'theoretical framework' ${ }^{(35)}$. After reviewing the theoretical framework as well as the aim and research questions of the study, transcriptions were read intensively and repeatedly. Since the aim of this study was to identify all relevant issues with the NHCR raised by interviewees, all presented arguments and issues were highlighted. Secondly, the highlighted passages were coded with pre-determined codes, based on the theoretical framework. Thirdly, new codes were given to passages without a predetermined code. Based on these identified concepts and their relationships, the theoretical framework was adjusted. Finally, by comparing the initial theoretical framework to the rebuilt framework and by addressing similarities and differences in theoretical concepts, the final framework was build (depicted in figure 1). All transcriptions were analysed through this systematic approach by two members of the research team to reduce the possibility of the informed bias raised by the use of a directed approach ${ }^{(35)}$. Furthermore, all quotes used in the paper were anonymised by avoiding the use of any names, brand names and industry names.

\section{Results and discussion}

Figure 1 depicts the identified themes influencing a stakeholder's perception of the NHCR. The interviews not only confirmed the themes described in the theoretical framework, but they also identified various additional concepts within these themes. Therefore, the themes comprise the following: (i) the regulatory act itself; (ii) the 
assessment procedure; and (iii) the impact of the NHCR. These themes are discussed below.

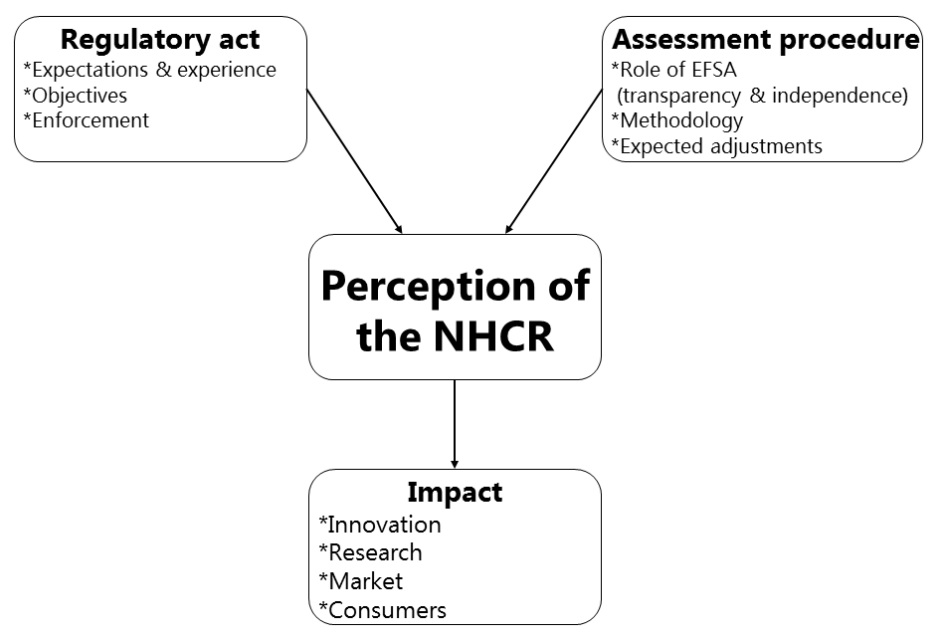

Figure 1. Web of themes.

\section{Regulatory act}

\section{Expectations and experience}

Experiences of various interviewees did not live up to their expectations, leading to disappointment on different aspects of the NHCR, viz. the assessment procedure, the time needed for implementation and the current effectiveness. Various industrials expected, based on publications and presentations previous to the enactment of the $\mathrm{NHCR}$, the possibility to use graded evidence for substantiation with probable, possible and convincing evidence for a claimed effect. This is however not allowed under the NHCR, only generally accepted or newly developed scientific evidence establishing a cause and effect relationship is considered to be sufficient to substantiate a claim $^{(1)}$. The submitted substantiation was varying strongly: some dossiers were not based on scientific evidence where others built on high quality human intervention studies, which exemplifies the different expectations of applicants ${ }^{(10)}$. 
A nutritional scientist mentions debatable claims are still on the market: 'You can still claim almost everything you wanted to claim earlier, if you use one of the nutrients on the positive list'. The consumer representatives also consider the NHCR to be barely effective: although some non-substantiated claims are gone, many possibilities to use claims still exist and consumers can still be misled.

As literature on expectations of performance and consumer satisfaction explains, these disconfirmed expectations (here: positive expectations followed by negative experiences) are shown to result in psychological discomfort and a negative hedonic state $^{(36-39)}$.

\section{Objectives}

The objectives of the NHCR are prioritised differently by the interviewees: although all stakeholder groups feel that harmonisation of national regulatory provisions is an objective of the NCHR, industrials and regulatory experts specifically point out the prevention of medical claims, whereas regulatory experts and nutritional scientists focus also on scientific substantiation of claims. The aim of protecting consumers from being misled is recognised by industrials, nutritional scientists and consumer representatives. These discrepancies between stakeholders in prioritisation of objectives could be counteracted by providing more clarity on the factual objectives of the regulatory act.

Although many stakeholders feel the NHCR effectively protects consumers from being misled, a consumer representative believes that the NHCR does not live up to its objective: 'Consumers are still misled. Antioxidants are a good theme in that case, it is quite clear you cannot claim anything on that. The idea of extra antioxidants in nutrition is actually fully undermined, so you cannot claim anything on it, and still you can easily find these claims'. In contrast, other interviewees (mainly industrials) feel the objective of consumer protection is overreached by enactment of the NHCR. Accomplishment of other objectives is also questioned by interviewees, as nutritional scientists question the stimulation of innovation and competitiveness: 'You see companies are investing 
less in nutrition and health'. To meet the various objectives, the need for more transparency and enforcement is emphasised by many interviewees.

\section{Enforcement}

During the interviews, various issues arise concerning the enforcement of the NHCR. Considerable uncertainty exists on enforcement strategies, priorities and capabilities within the Netherlands as well as in other Member States. Various interviewees consider the establishment of a level playing field in the market of functional foods to depend on comparable enforcement throughout the EU, but the development of such comparable enforcement is questioned. The uncertainties surrounding the use of claims is exemplified by various stakeholders by the case of antioxidants, where mentioning the content of antioxidants is by some considered to be an implicit health claim, but can also be seen as a nutrition claim.

Increasing compliance by traditional enforcement of laws, with punishment as important component, as suggested by various interviewees, is confirmed in literature ${ }^{(40)}$. However, traditional enforcement poses several limitations: monitoring the industry highly increases costs and practical difficulties arise in identifying less visible violations ${ }^{(40)}$. Various stakeholders indicate to perceive that detecting violations of the NHCR is not considered to be a priority for the Netherlands Food and Consumer Product Safety Authority (NVWA). Therefore, due to the apparent lack of traditional enforcement methods, traditional enforcement alone does not seem to be the most suitable way to enforce this act, although punishment of offences could help to set an example and increase compliance to the NHCR.

The development of the self-regulating list by Dutch industrials, in consultation with the Ministry of Health, Welfare and Sports as well as the NVWA, is suggested by several stakeholders to be a good way to cope with the limited enforcement capacity, although various interviewees expect self-regulation not to be sufficient to properly enforce the $\mathrm{NHCR}^{(41,42)}$. Self-regulation is described in literature as a voluntary enforcement mechanism, and this voluntary aspect could decrease the credibility of the 
regulation ${ }^{(43)}$. Due to weak standards, a lack of transparency and ineffective enforcement with mild, non-public punishments, self-regulation is described to fail often, and is therefore considered to serve the industry rather than the public interest $^{(44)}$. Contrary, when used in a form suitable to the regulation, self-regulation is shown to be effective. Setting rules and standards in cooperation with industries and with involvement of the government could lead to an effective form of self-regulation, with more flexibility and lower costs of enforcement ${ }^{(44)}$. Therefore, the use of selfregulation as a tool in enforcing the NHCR is suggested to be helpful.

\section{Assessment procedure}

Several industrials disagree with the current assessment procedure, but do not blame EFSA for the role they were given under the NHCR. Various nutritional scientists agree: 'Considering the vagueness of the texts and what is written in the law, EFSA did everything very well'. Most interviewees consider EFSA as an important organisation in implementing the NHCR, and regulatory experts feel EFSA is also the most appropriate organisation to advise the EC independently and adequately. The quality of work of EFSA is questioned by some stakeholders, due to the high workload.

\section{Transparency and independence}

Transparency and independence are important aspects influencing a stakeholder's view on EFSA. Especially transparency of the assessment procedure was addressed by stakeholders during the interviews. Several supplement industrials question the transparency of EFSA, its procedures and its members, and some industrials feel the issued opinions are based on unclear criteria. A supplement industrial believes claims based on textbook knowledge versus claims based on new evidence are judged differently: 'We know a lot about the mechanism of action of vitamins and minerals because deficiencies will cause disease. But with testing other substances, all patient studies are excluded'. In contrast, a food industrial recognises EFSA as transparent and objective. Also a consumer representative feels that members of EFSA work independently to build good dossiers, and uniformity and transparency of opinions as 
well as handling of the dossiers are increased. Since transparency is shown to influence the credibility of assessments as here the procedure of reviewing scientific substantiation of a health claim, increased transparency of documents as scientific opinions will increase trust and legitimacy of EFSA and the following risk-management decisions of the $\mathrm{EC}^{(26,27,29)}$. It will also decrease uncertainty and will improve the required decision-making time and public confidence in the processes ${ }^{(2,45)}$. EFSA and the EC attempted to improve transparency by developing guidance documents and by publishing various documents as agendas, minutes and opinions of the scientific

committee and all panels ${ }^{(19,27,46-48)}$. Increasing transparency even more could disrupt the stability and credibility of EFSA: publishing minority opinions and expert disagreements could alarm the public or could serve as ammunition for objectors ${ }^{(28,47)}$.

Although a regulatory expert feels the members of panels of EFSA will always be criticised on their independence, since experience in the field of nutrition research or food industry is necessary to evaluate health claims, during the interviews little was commented on the independence of EFSA. The efforts to improve independence of both EFSA and its members, by describing the independent position of board members and scientists involved in EFSA, therefore seem to pay off ${ }^{(26,47)}$.

\section{Methodology}

Some supplement industrials consider the used assessment criteria to be problematic: 'Due to this regulation you, as an entrepreneur, are not allowed to use traditional knowledge to put information on your package'. The nutritional scientists agree that the substantiation criteria are hard to live up to, especially for the industry. However, a regulatory expert feels that EFSA's assessment procedure raised the standards for research: 'EFSA is actually a huge peer review process. (...) EFSA or the regulation instigated the evaluation of a lot of these criteria and made them more explicit'.

The different interviewees do not agree on the effect of antioxidants, but believe antioxidants should not be characterised by antioxidant status of products or plasma. As emphasised by a regulatory expert: 'Most biomarkers in the field of antioxidants are 
not valid. Therefore you should not use them, because if EFSA sees these invalid biomarkers being used in a study, it will be rejected'. This exemplifies the need to discuss used methodologies in nutrition research, as brought up by various stakeholders in the interviews. The high standards used by EFSA in evaluating scientific substantiation of health claims and the explicit need for human data are complimented by most interviewees, although some supplement industrials feel that the standards are too strict and too rigorous. Requiring the substantiation of health effects in an already healthy population is considered to reflect a pharmacological approach, which is also seen by a nutritional scientist and various food industrials. As explained by a nutritional scientist: 'With respect to antioxidants, we should be striving for good tests which are indicative for health. At the same time it should be made clear that a good outcome does not imply five more healthy years'. Another nutritional scientist feels that the current approach highly differs from the set-up of dietary recommendations, where not only scientific evidence but also eminence (the expert opinion) is considered.

The focus of the current assessment procedure on clinical biomarkers in human intervention studies is considered to reflect this pharmacological approach. The possibility to claim that an antioxidant can protect against oxidative stress, as currently allowed for copper, was therefore not expected by an industrial stakeholder: 'Not permitting the use of oxidative stress as a health outcome would not have surprised me, although I myself would not consider it to be a final effect'. This approach, with focussing on one or few outcome measures, is in literature suggested to be more suitable for drug testing than for nutrition research, where pleiotropic effects elicited by food should be studied ${ }^{(49-53)}$. Several industrials and nutritional scientists feel new research methodologies therefore should be developed to test the effect of nutrition on health, which should be based on a revised definition of health. The official WHO definition originates from 1948: 'Health is a state of complete physical, mental and social wellbeing and not merely the absence of disease or infirmity ${ }^{454)}$. Today, health is more about the ability to adapt to specific circumstances and therefore needs a more individual approach ${ }^{(52,55-58)}$. With a more accurate definition of health, proper research 
methodologies can be developed to measure the effect of nutrition on maintaining health ${ }^{(59)}$.

Different methods are proposed in literature to ensure such a personal approach, as using nutrigenomics and phenotyping individuals ${ }^{(60)}$. However, the methodology considered most suitable by various interviewees to test nutritional effects on health is the challenge test: an experimental setup where the system of a subject is put under pressure with a challenge, and the ability to resist or to recover from the impact is the marker for health. Examples of such challenge tests are the oral glucose tolerance test (OGTT), the oral lipid tolerance test (OLTT) and the postprandial challenge test $(P C T)^{(61,62)}$. The influence of a food product or functional ingredient on this disturbance can be studied in this way ${ }^{(53,58,61)}$. These tests are considered to show the short-term effect of nutrition on health more accurately. Therefore, various interviewees expect these tests to be helpful in the future substantiation of health claims.

\section{Suggested adjustments}

Various possible adjustments to the assessment procedure are suggested by several stakeholders, mainly referring to the issue of botanical claims of which scientific substantiation is not reviewed yet. Amongst these botanical claims several antioxidant claims are seen by a stakeholder. These dossiers will not be reviewed before the MS agree upon the required assessment procedure, on which the Commission published a discussion paper in $2012^{(63)}$. Many interviewees are disappointed that these claims are still on hold, and various solutions are offered. Mainly supplement industrials emphasise these claims should be assessed differently under the NHCR, in a procedure more suitable to review the effectiveness of botanicals and which would allow claims to be based on traditional use (alike medicine). This is also the point of view of five of 26 MS in the discussion paper published by the Commission in 2012, which would lead to a different treatment of botanicals requiring new rules for the use of these products in foods ${ }^{(63)}$. However, many other interviewees, as well as seven other MS described in the discussion paper, feel these claims should be assessed via the currently used 
procedure and no exception should be made for botanicals compared to other ingredients in foods ${ }^{(63)}$. These interviewees feel treating botanicals differently would undermine the NHCR. The position of an interviewee and expectations on how this issue will be handled is shown to influence a stakeholder's view of the NHCR.

\section{Impact}

Most interviewees see less innovation is taking place, due to the high demands and costs required to substantiate a claim. As an industrial exemplifies with the case of antioxidants: 'Innovation in and research on antioxidants is not a very interesting field at the moment. I believe it is faded glory, and consumers are fed up with it'. An industrial feels these requirements favour bigger companies while decreasing innovation possibilities for small and medium-sized companies, and a nutritional scientist feels the NHCR hereby leads to an impoverishment of reviewing health effects of products, because when assessing a health claim only one ingredient within a full product is evaluated. Various interviewees see that firms start to work around the regulation. These firms are seen to look for loopholes in the regulation by repositioning their product, e.g. a medicinal product or create mismatch products (products either (i) not regularly connected to health bearing a health claim; or (ii) bearing an approved health claim on one nutrient, but emphasising this effect on another ingredient without an authorised health claim). Other firms are perceived to adopt a defensive position by using different communication strategies than claims or focussing on different unique selling points of their product than health. The number of approved claims is suggested to determine the competitive landscape: rejection of the majority of claims is expected to reduce developments in functional foods ${ }^{(2)}$. With the majority of antioxidant claims being rejected, the perceived reduction in innovation can be explained easily. In order to stimulate innovation after this round of rejection, the focus should rather be on new possibilities to assess health claims more positively ${ }^{(2)}$. Despite the apparent inhibition of innovation, a consumer representative favours the positive effect of the NHCR on reducing consumer misleading. 
Regarding the impact of the NHCR on research, differing opinions are expressed by stakeholders: a consumer representative sees no effect of the NHCR, since research is focussed on dietary patterns and is not targeted at specific components, where other interviewees feel the impact is hardly measureable due to the variance across institutes. Most industrials see less research is taking place, since it is highly connected to innovation. Investments in research are considered to be risky because the probability to get a claim is low, as stated by an industrial: 'When we started questioning the substantiation of antioxidant claims, we decided to lose all of them. They are now prohibited to be used in our company. A regulatory expert emphasises, however, that lower investments in research could also be due to the economic crisis. Other interviewees perceive the NHCR to stimulate research: new research concepts are developed and the established assessment criteria could serve as motive to perform higher quality research.

Several interviewees perceive the NHCR negatively affects the market. A nutritional scientist thinks that companies should stop complaining but develop a strategy together to deal with the required costs and time. Another suggested approach to counteract the negative effect of the NHCR on the market is to reduce the number of mismatch products on the market by providing clarity on the botanicals issue, enforcing the NHCR and introducing nutrient profiles. These nutrient profiles, nutritional requirements which must be met by foods bearing claims, are under development ${ }^{(64)}$. Still, a nutritional scientist believes the market of functional foods is past its prime and although the influence of the NHCR is considered not to be positive, less will be invested in this area.

Many supplement industrials feel the NHCR decreases possibilities to inform consumers about health effects, although in literature health claims are considered to be a tool to educate consumers about health and healthy products, and to stimulate healthy choices in the diet ${ }^{(65-68)}$. Literature however questions this educational effect, since consumers do not seem to believe statements made by industry ${ }^{(69,70)}$. Several 
interviewees notice decreasing interest and trust of consumers in claims, which is confirmed in literature: less exposure decreases the acceptance and interest of consumers $^{(71)}$. Trust is suggested by a supplement industrial to be increased by informing consumers about the authorisation system of claims and the scientific substantiation required, since consumers - unaware of the current situation - request an independent institution to assess and approve a claim ${ }^{(72)}$. Although increased trust in health claims due to the NHCR is expected by various stakeholders, they still question to which extent the permitted claims are understood.

These conflicting ideas on the effect of the NHCR on innovation of functional food products and especially of food products containing antioxidants, as well as the perceived effects on research, the market and consumers, seem to highly influence a stakeholder's perception of the NHCR.

\section{Strengths and limitations}

The interviews, carried out in person by the first author, were conducted with seven industrials, two regulatory experts, three nutritional scientists and two consumer representatives. The industry group was large compared to the other stakeholder groups, but since this group was very diverse and consisted of both supplement industrials and food industrials, they are not overrepresented in this study. Although the number of interviewees was relatively small, in the end no new findings were extracted from the conducted interviews and therefore the point of saturation was reached. Since the amount of experts in the field of antioxidants dealing with the NHCR is very limited, selecting participants via purposive sampling and snowball sampling was considered appropriate as discussed in the method section.

Still, the focus on food products containing antioxidants of this study was not fully reflected in the results, since not all stakeholders focussed solely on food products containing antioxidants. This led to more general answers on the use of the NHCR in the field of functional foods, with the case of antioxidants more often used as an example. However, the participating stakeholders were all experts in the use of the 
NHCR in their organisation and came into contact with products containing antioxidants directly and indirectly. Therefore, all interviews were used for data collection and analysis.

\section{Recommendations for improving the NHCR}

The grounds for disproving all virtual identified antioxidant claims are entailed in figure 1: (i) the regulatory act itself, including (a) expectations and experience, (b) objectives and (c) enforcement; (ii) the assessment procedure, involving (a) transparency and independence, (b) methodology and (c) suggested adjustments; and (iii) the impact of the NHCR, including the impact on (a) innovation, (b) research, (c) the market and (d) consumers.

\section{Strengths of the NHCR}

Most interviewed stakeholders are seen to agree upon the need for the NHCR in protecting consumers from misleading and harmonising regulations throughout Europe. Therefore, the requirement for scientific substantiation of commercial outings on antioxidant containing food products and other functional foods is welcomed. The strengths of the NHCR are considered to be addressing these needs, and similarly the possibility that consumers' trust in claims will be increased due to the NHCR is favourable in the eyes of different stakeholders. Another positive aspect mentioned by some interviewees is that over time the transparency of EFSA in the assessment procedure of proposed claims is highly increased.

\section{Concerns with the NHCR}

The main concerns addressed within the interviews involve the following concepts: (i) enforcement of the NHCR, (ii) methodology of scientific substantiation and (iii) perceived impact. Even though the NHCR entered into force in July 2007 and the list of approved claims was published in May 2012, substantial uncertainty seems to exist on the enforcement of the NHCR. Enforcement is considered to be important for the 
harmonisation throughout Europe, and although no agreement is reached upon the preferred form of enforcement, its implementation is requested by several stakeholders.

The assessment procedure as executed by EFSA is highly debated by various interviewees. The dossiers firstly submitted are shown to be based on evidence highly varying in scientific quality, which exemplifies the differences in expectations of various applicants of the whole procedure. The ideas of stakeholders on methodology used in nutrition research not only differ from each other, but also these views seem to be deviating fundamentally from the use of nutrition research within the NHCR where apparently a more pharmacological approach is used in the assessment procedure. This reveals an underlying issue: how should the effects of nutrition on health be tested; and how should health be defined?

The effects of the NHCR on innovation, research, the market and consumers are experienced differently by various stakeholders. These mostly intuitive effects perceived by a stakeholder are shown to either negatively or positively affect the perception of the NHCR. However, currently no accurate facts about this impact are available.

\section{The case of antioxidants}

The identified issues are helpful in explaining the disproval of the large amount of proposed health claims on antioxidant containing products. Not only the expected quality of scientific substantiation appeared to differ highly from the required scientific substantiation, the methods to study antioxidants are also debated and the health effects of antioxidants might be more subtle than required under the current assessment procedure of health claims.

Antioxidants seem to be an interesting theme in the enforcement of the NHCR, since where content claims are mostly considered to be a nutrition claim, claiming antioxidants in a product can be seen as an implicit - and sometimes prohibited - 
health claim. Also innovation and research on antioxidants, as well as on the market of antioxidant containing products and consumer perception thereof are suggested to be highly influenced by the entry into force of the NHCR, which could explain opinions of stakeholders on the NHCR (either positive or negative, depending on their view on the effects of antioxidants).

\section{Suggestions for improvement}

Next to explaining the disproval of most proposed health claims on antioxidants, the identified strengths and weaknesses give the opportunity to identify specific aspects to improve. Directly related to the regulatory act itself is the enforcement of the NHCR, on which clarification of actions of Member States could shed light. The issue of botanical claims should be resolved by the European Parliament and the Commission, to ensure fair competition on the market of functional foods and to enhance the effectiveness of the NHCR.

However, most improvements do not follow directly from problems with the NHCR itself, but from the public debate about the NHCR as well as from issues with procedures developed under the regulatory act. The perceived impact of the NHCR on innovation, research, the market and consumers is seen to highly influence a stakeholder's perception of the NHCR. Currently, this discussion seems to be driven extremely by instincts and intuition of experts in the field, without being based on facts. To ensure this debate reflects the actual situation, quantitative measurements of the impact of the NHCR are required. These effects could be studied by comparing resources allocated to both innovation and research in different institutes before the entry into force of the NHCR to the current situation, and numbers on the market of antioxidant containing food products and other functional foods can be compared with numbers of the period before the NHCR. Nevertheless, consumer effects are more difficult to measure quantitatively. The impact of the NHCR on consumers could be assessed by reviewing their attitude and willingness to pay towards functional foods carrying specific claims. 
The main issue identified through these interviews with experts in the field of antioxidants is the assessment procedure, with pointing out methodological problems next to the distinct ideas in science about health effects of nutrition. Although antioxidants serve as a good model, these problems do not seem to arise solely in this field. To improve both dossiers building and the assessment procedure, new methodology on how to assess health effects elicited by antioxidants and other nutritional substances should be developed and implemented, following from scientific consensus reached on the definition of health.

\section{Conclusion}

The NHCR was created to regulate commercial outings of health benefits elicited by nutrition. This research was initiated after most proposed antioxidant claims were seen to fail the assessment procedure. To unravel the grounds for disproving the putative health claims, the perception of stakeholders of the NHCR was reviewed by conducting semi-structured in-depth interviews with 14 stakeholders. Most proposed antioxidant claims are seen to be refused based on the quality of scientific substantiation, not only due to the use of scientific methods on which no consensus has been reached, but also due to the differences in expectations of submitters versus requirements of the assessors. Although most stakeholders welcome the NHCR as means to fight consumer misleading and harmonise international regulations, a clear need for improvement in the application of the NHCR is shown. An independent assessment of the impact of the NHCR on innovation, research, the market of antioxidants and functional foods, and consumer acceptance of nutrition and health claims, next to more clarity on enforcement procedures within Member States would help to improve the perception of the NHCR amongst stakeholders. However, most importantly, the need to define health is once more emphasised due to its importance in the assessment procedure of health effects of antioxidants and other functional ingredients. 
Although the current case study focuses on the perception of the NHCR related to food products and functional ingredients containing antioxidants in the Netherlands, it can easily be extrapolated to other fields of functional ingredients and to the situation in other Member States, since the regulation is not only affecting functional foods containing antioxidants or solely Dutch stakeholders but the whole European functional food market. With highly diverging perceptions of stakeholders, the current effectiveness of the NHCR can be questioned. The views of different stakeholders on enforcement, methodology and impact could help to focus the discussion on the NHCR in capturing health effects. 


\section{References}

1. Gilsenan MB (2011) Nutrition \& health claims in the European Union: A regulatory overview. Trends Food Sci. Technol. 22, 536-542.

2. Moors EHM (2012) Functional foods: regulation and innovations in the EU. Innovation 25, 424-440.

3. European Parliament and the Council (2006) Regulation (EC) No 1924/2006 of the European Parliament and of the council of 20 December 2006 on nutrition and health claims made on foods. OJ L 404 49, 9-25.

4. Hoad D (2011) Scientific Method and the Regulation of Health and Nutritional Claims by the European Food Safety Authority. Bull Sci Technol Soc 31, 123-133.

5. EFSA (2014) About the NDA Panel and the Nutrition Unit. http://www.efsa.europa.eu/en/nda/aboutnda.htm (accessed April 2014).

6. EFSA (2014) Nutrition and health claims http://www.efsa.europa.eu/en/topics/topic/nutrition.htm (accessed April 2014).

7. EFSA (2012) 'General function' health claims under Article 13. http://www.efsa.europa.eu/en/topics/topic/article13.htm (accessed April 2014).

8. EFSA (2014) 'New function' health claims under Article 13.5. http://www.efsa.europa.eu/en/topics/topic/article13-5.htm (accessed April 2014).

9. EFSA (2014) Claims on disease risk reduction and child development or health under Article 14. http://www.efsa.europa.eu/en/topics/topic/article14.htm (accessed April 2014).

10. European Commission (2013) EU Register on nutrition and health claims. http://ec.europa.eu/nuhclaims/ (accessed April 2014).

11. Verhagen H, Vos E, Francl S, et al. (2010) Status of nutrition and health claims in Europe. Arch Biochem Biophys 501, 6-15.

12. European Commission (2012) Commission Regulation (EU) No 432/2012 of 16 May 2012 establishing a list of permitted health claims made on foods, other than those referring to the reduction of disease risk and to children's development and health. OJ $L 55,1-40$.

13. De Boer A, Vos E \& Bast A (2014) Implementation of the nutrition and health claim regulation - the case of antioxidants. Regul. Toxicol. Pharmacol. 68, 475-487.

14. EFSA NDA Panel (2009) Scientific Opinion on Water-soluble tomato concentrate (WSTC I and II) and platelet aggregation Scientific substantiation of a health claim related to water-soluble tomato concentrate (WSTC I and II) and platelet aggregation pursuant to Article 13(5) of Regulation (EC) No 1924/2006. EFSA Journal 1101, 1-15.

15. EFSA NDA Panel (2010) Scientific Opinion on the modification of the authorisation of a health claim related to water-soluble tomato concentrate and helps to maintain a healthy blood flow and benefits circulation pursuant to pursuant to Article 13(5) of Regulation (EC) No 1924/2006 following a request in accordance with Article 19 of the Regulation (EC) No 1924/2006. EFSA Journal 1689, 1-9.

16. EFSA NDA Panel (2012) Scientific Opinion on the substantiation of a health claim related to cocoa flavanols and maintenance of normal endothelium-dependent vasodilation pursuant to Article 13(5) of Regulation (EC) No 1924/2006. EFSA Journal 2809, 1-21. 
17. Europe Press Releases (2006) Questions and Answers on Health and Nutrition Claims. http://europa.eu/rapid/press-release_MEMO-06-200_en.htm?locale=en (accessed April 2014).

18. Bremmers HJ, van der Meulen BMJ \& Purnhagen K (2013) Multi-stakeholder responses to the European Union health claims requirements. J. Chain Netw. Sci. 13, 161-172.

19. Ernst \& Young (2012) External Evaluation of EFSA - Final Report.

20. Freeman RE (1984) Strategic Management: A stakeholder approach. Boston, vol. 42. Boston: Pitman.

21. Ritchie J \& Lewis J (2003) Qualitative research practice: A guide for social science students and researchers.

22. DiCicco-Bloom B \& Crabtree BF (2006) The qualitative research interview. Med. Educ. 40, 314-321.

23. Oliver RL (1980) A cognitive model of the antecedents and consequences of satisfaction decisions. J Mark Res, 460-469.

24. Woodruff RB, Cadotte ER \& Jenkins RL (1983) Modeling consumer satisfaction processes using experience-based norms. J Mark Res, 296-304.

25. Jensen KK \& Sandøe P (2002) Food safety and ethics: the interplay between science and values. J Agric Env. Ethics 15, 245-253.

26. Klintman M \& Kronsell A (2010) Challenges to legitimacy in food safety governance? The case of the European Food Safety Authority (EFSA). Eur Integr 32, 309-327.

27. Kobusch A (2010) Linking the levels: Independence and influence in the European two-tiered network of food safety agencies. In Third Biennial Conference "Regulation in the Age of Crises" of the ECPR Standing Group on Regulatory Governance. Dublin: University College Dublin, 17-19 June 2010.

28. Levidow L \& Carr S (2007) Europeanising advisory expertise: The role of 'independent, objective and transparent' scientific advice in agri-biotech regulation. Env. Plann C Gov Policy 26, 880-895.

29. Schreider J, Barrow C, Birchfield N, et al. (2010) Enhancing the credibility of decisions based on scientific conclusions: transparency is imperative. Toxicol Sci 116, 5-7.

30. Mansfield E (1991) Academic research and industrial innovation. Res Policy 20, 1-12.

31. Nelson R (1993) National innovation systems: a comparative analysis. New York: Oxford University Press.

32. Tansey O (2007) Process Tracing and Elite Interviewing: A Case for Non-Probability Sampling. PS Polit. Sci. Polit. 40, 765-772.

33. Lucas SR (2014) Beyond the existence proof: ontological conditions, epistemological implications, and in-depth interview research. Qual. Quant. 48, 387-408.

34. Mason M (2010) Sample Size and Saturation in PhD Studies Using Qualitative Interviews. 2010, vol. 11.

35. Hsieh H-F \& Shannon SE (2005) Three approaches to qualitative content analysis. Qual. Health Res. 15, 1277-1288.

36. Anderson RE (1973) Consumer Dissatisfaction: The Effect of Disconfirmed Expectancy on Perceived Product Performance. J Mark Res 10, 38-44. 
37. Festinger L (1962) A theory of cognitive dissonance. vol. 2. Stanford: Stanford University Press.

38. Greenwald AG \& Ronis DL (1978) Twenty years of cognitive dissonance: Case study of the evolution of a theory. Psychol Rev 85, 53-57.

39. Webb WM \& Worchel S (1993) Prior experience and expectation in the context of crowding. J Pers Soc Psychol 65, 512-521.

40. Malloy TF (2003) Regulation, compliance and the firm. Temple Law Rev. 76, 451.

41. Keuringsraad (2014) Database claimsverordening. http://keuringsraad.nl/Databaseclaimsverordening-en-indicatieve-lijst (accessed April 2014).

42. Nederlandse Voedsel- en Waren Autoriteit (2014) Claims levensmiddelen - Preventief toetsen gezondheidsclaims bij Keuringsraad. http://www.vwa.nl/onderwerpen/regelsvoor-ondernemers-eten-en-drinken/dossier/claims-

levensmiddelen/gezondheidsclaims-correct-gebruik/preventief-toetsengezondheidsclaims-bij-keuringsraad (accessed April 2014).

43. Haufler V (2001) A public role for the private sector: Industry self-regulation in a global economy. Washington D.C.: Carnegie Endowment.

44. Gunningham N \& Rees J (1997) Industry self-regulation: an institutional perspective. Law Policy 19, 363-414.

45. Frewer L \& Salter B (2002) Public attitudes, scientific advice and the politics of regulatory policy: the case of BSE. Sci Public Policy 29, 137-145.

46. European Parliament and the Council (2002) Regulation (EC) No 178/2002 of the European Parliament and of the Council of 28 January 2002 laying down the general principles and requirements of food law, establishing the European Food Safety Authority and laying down procedures in matters of food safety. OJ L 31, 1-24.

47. Finardi C, Pellegrini G \& Rowe G (2012) Food safety issues: From Enlightened Elitism towards Deliberative Democracy? An overview of EFSA's 'Public Consultation' instrument. Food Policy 37, 427-438.

48. Silano M \& Silano V (2008) The fifth anniversary of the European Food Safety Authority (EFSA): Mission, organization, functioning and main results. Fitoterapia 79, 149-160.

49. Bast A, Briggs WM, Calabrese EJ, et al. (2013) Scientism, Legalism and PrecautionContending with Regulating Nutrition and Health Claims in Europe. EFFL 6/2013, 401409.

50. Blumberg J, Heaney RP, Huncharek M, et al. (2010) Evidence-based criteria in the nutritional context. Nutr Rev 68, 478-484.

51. Heaney RP (2008) Nutrients, endpoints, and the problem of proof. J Nutr 138, 15911595.

52. Van Ommen B \& Stierum R (2002) Nutrigenomics: exploiting systems biology in the nutrition and health arena. Curr Opin Biotechnol 13, 517-521.

53. Weseler AR \& Bast A (2012) Pleiotropic-Acting Nutrients Require Integrative Investigational Approaches: The Example of Flavonoids. J Agric Food Chem 60, 89418946. 
54. World Health Organization (1948) Preamble to the Constitution of the World Health Organization as adopted by the International Health Conference. New York: World Health Organization.

55. Editorial (2009) What is health? The ability to adapt. Lancet 373, 781.

56. Huber M, Knottnerus JA, Green L, et al. (2011) How should we define health? Br Med J 343, d:4163.

57. Kussmann M, Raymond F \& Affolter M (2006) OMICS-driven biomarker discovery in nutrition and health. J Biotechnol 124, 758-787.

58. Van Ommen B, Keijer J, Heil SG, et al. (2009) Challenging homeostasis to define biomarkers for nutrition related health. Mol Nutr Food Res 53, 795-804.

59. Elliott R, Pico C, Dommels $Y$, et al. (2007) Nutrigenomic approaches for benefit-risk analysis of foods and food components: defining markers of health. Br J Nutr 98, 10951100.

60. Astley SB \& Elliott RM (2007) The European Nutrigenomics Organisation: linking genomics, nutrition and health research. J Sci Food Agric 87, 1180-1184.

61. Pellis L, van Erk MJ, van Ommen B, et al. (2012) Plasma metabolomics and proteomics profiling after a postprandial challenge reveal subtle diet effects on human metabolic status. Metabolomics 8, 347-359.

62. WHO (1999) Part 1: Diagnosis and Classificaion of Diabetes Mellitus. Geneva: World Health Organization Department of Noncommuncable Disease Surveillance.

63. Mathioudakis B (2013) Presentation International Conference Botanicals in Food Supplements BELFRIT. Rome, 18 April 2013.

64. EFSA (2013) EFSA: FAQ on nutrition and health claims. http://www.efsa.europa.eu/en/faqs/faqnutrition.htm?wtrl=01 (accessed April 2014).

65. Mitra A, Hastak M, Ford GT, et al. (1999) Can the educationally disadvantaged interpret the FDA-mandated nutrition facts panel in the presence of an implied health claim? J Public Policy Mark, 106-117.

66. Roe B, Levy AS \& Derby BM (1999) The impact of health claims on consumer search and product evaluation outcomes: results from FDA experimental data. J Public Policy Mark, 89-105.

67. Van Trijp H \& Van der Lans IA (2007) Consumer perceptions of nutrition and health claims. Appetite 48, 305-324.

68. Williams P (2005) Consumer understanding and use of health claims for foods. Nutr Rev 63, 256-264.

69. Menozzi D, Halawany-Darson R, Mora C, et al (2015). Motives towards traceable food choice: A comparison between French and Italian consumers. Food Control 49, 40-48.

70. Teisl MF \& Levy AS (1997) Does nutrition labeling lead to healthier eating? J Food Distrib Res 28, 18-27.

71. Dean M, Lampila P, Shepherd R, et al. (2012) Perceived relevance and foods with healthrelated claims. Food Qual Prefer 24, 129-135.

72. Gray N (2013) Most consumers don't know what EFSA is, experts find. http://www.nutraingredients.com/Consumer-Trends/Most-consumers-don-t-knowwhat-EFSA-is-experts-find (accessed April 2014). 



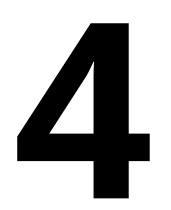

\section{Enforcement of the nutrition and health claims regulation}

Alie de Boer, Miriam J.E. Urlings, Ellen Vos, Aalt Bast

European Food and Feed Law Review 5/2015 (2015) 
Chapter 4

\section{Abstract}

The nutrition and health claim regulation (NHCR) aims to protect consumers against false or incorrect nutrition and health claims by requesting scientific substantiation. It also aims to establish a level playing field in the internal market for all food producers. European regulations as the NHCR require national authorities to enforce these acts. Regulation (EC) No 882/2004 requires national authorities to adopt a risk-based enforcement approach for controls on compliance with feed and food law requirements. Our analysis shows fragmented national enforcement practices. So, 18 Member States have developed 13 different guidance documents on the flexibility of wording and/or compliance with the NHCR, whilst also diverging actions have been taken by Member State authorities. The NHCR is therefore currently unable to establish a level playing field. An EU-wide approach in enforcement should be developed to ensure such fair competition in the internal market. 


\section{Introduction}

Various food scares that the EU witnessed in the 1990s, such as the BSE crisis and the dioxin crisis, led to a radical re-thinking and re-formulation of the EU's approach to food and food safety ${ }^{(1,2)}$. In this manner, the European Commission proposed in total 84 different action points to demonstrate the EU's commitment to establishing 'the highest standards of food safety'(3). The most important instrument hereof was the adoption of 'Regulation (EC) No 178/2002 of the European Parliament and of the Council laying down the general principles and requirements of food law, establishing the European Food Safety Authority and laying down procedures in matters of food safety' in 2002 ${ }^{(3-6)}$. With this so-called 'General Food Law' (GFL) as the cornerstone of European food law, the EU clearly indicated to have food safety as one its key priorities $^{(6,7)}$. The GFL was followed by the adoption of many other legislative actions to ensure food safety and to regain confidence of consumers and public authorities in EU decision-making on food issues, thereby covering the whole of the food chain, including animal feed production and establish a high level of consumer health protection. One of these actions was 'Regulation (EC) No 1924/2006 of the European Parliament and of the Council on nutrition and health claims made on foods', commonly named Nutrition and Health Claim Regulation (NHCR) which, after many years of debate, was adopted in $2006^{(7-10)}$. This article will deal with this instrument.

The NHCR, which entered into force on 1 July 2007, regulates all voluntary communications about the nutritional content and/or health benefits of a product ${ }^{(9,10)}$. It aims not only to ensure a high level of protection of consumers and to facilitate their choice by assuring that claims are scientifically substantiated after a review process by the European Food Safety Authority (EFSA); it also intends to improve the free movement of goods in the internal market by harmonising the different national regulations of Member States ${ }^{(10-12)}$. Importantly, scientific substantiation of a claim is the main aspect to be taken into account for the use of nutrition and health claims according to this regulation. The NHCR defines three types of health claims: Article 13.1 
and 13.5 as function claims (based on either accepted [13.1] or new scientific evidence [13.5]) and Article 14.1 claims, (a) describing the reduction of disease risk as well as (b) claims on children's development and health ${ }^{(9,10,12)}$. The 234 currently approved Article 13.1 and 13.5 claims and their conditions of use can be found in the annex to Regulation (EU) No 432/2012', also referred to as the positive list which entered into force in December 2012 ${ }^{(13)}$. The claims published on this list are phrased scientifically and as long as the meaning of the claim remains similar to consumers, manufacturers have a certain freedom to rephrase these claims ${ }^{(13)}$. After a lengthy and cumbersome process of approval of health claims, today it appears that the enforcement of the NHCR is quite problematic which may hinder the harmonising effect of these claims throughout the $\mathrm{EU}^{(14,15)}$.

The NHCR leaves national authorities with the responsibility for the enforcement ${ }^{(16)}$. To assure enforcement of European food legislation, Article 17(2) of the GFL already obliges Member States to 'enforce food law, and monitor and verify that the relevant requirements of food law are fulfilled' by maintaining a system of official controls next to other appropriate activities. Moreover, it requires Member States to 'lay down the rules on measures and penalties applicable to infringements of food and feed law ${ }^{(5)}$. European Parliament and Council Regulation (EC) No 882/2004 on official controls performed to ensure the verification of compliance with feed and food law, animal health and animal welfare rules further defines this responsibility of Member States in enforcing food law ${ }^{(17,18)}$. With the NHCR being one of the more specific rulings dealing with a specific aspect of the food chain, enforcement of this piece of legislation also falls under the responsibility of Member States. To enforce different food and feed regulations, Member States appoint a national competent authority ${ }^{(18)}$.

\footnotetext{
'Commission Regulation (EU) No 432/2012 of 16 May 2012 establishing a list of permitted health claims made on foods, other than those referring to the reduction of disease risk and to children's development and health (Consolidated version 27 January 2015).
} 
In this study, the enforcement strategy developed in accordance with Regulation $882 / 2004$ of Member States is understood as comprising both the verification of compliance with legal obligations (reviewing whether the law is abided) as well as enforcement of the law referring to detecting infringements of the laws and the formal (as inspections and punishments) and informal actions (as education, advice, persuasion and negotiation) imposed in case of such infringements ${ }^{(6,18-20)}$. Since Member States are responsible for the enforcement of food and feed law, enforcing the NHCR within their territories is also the responsibility of Member States. Where this responsibility is explicitly described in the general framework regulation for food (the GFL), it is only implicated in the NHCR itself in Article 24(1) which describes the options for Member States to remove non-compliant claims from the market, and in Article 26 about the possibilities for Member States to require a model of a label of a newly introduced product on the market ${ }^{(9)}$.

This article will analyse current pitfalls of compliance and the possibilities to ensure compliance with the NHCR by discussing potential strategies and by reviewing the NHCR as well as Regulation 882/2004.

\section{Enforcement explored}

The NHCR is one of the legislative acts depicting the shift of the focus of the EU food law policy towards ensuring food safety and increasing consumer confidence in EUdecision making. In order to conceptualise the enforcement approach under the NHCR we studied literature on enforcement of food safety and consumer protection legislation. As described in the introduction, in this study enforcement is considered to entail both identifying and correcting noncompliance.

\section{Identifying and correcting noncompliance}

Following the entry into force of a legal act, compliance to such act is expected. The need for enforcement to ensure such compliance is repeatedly expressed in 
literature ${ }^{(19-25)}$. Non-enforcement of laws is not only considered to lead to ineffective laws, but also suggested to cause decreased confidence of consumers in legal rules due to the created opportunity to abuse laws ${ }^{(22,24,26)}$.

Even with limited enforcement budgets, governments are expected to ensure a high level of food safety and consumer protection, while simultaneously concerns arise on the burden imposed on businesses in the food system by the increasing number of regulatory acts and the effects these acts have upon freedom of choice and speech ${ }^{(27-}$ 30). In the field of food safety two developments can be observed in an attempt to deal with this contradiction: (i) the use of private mechanisms to respond to the consumer's demand of increased food safety ${ }^{(20,29,31-33)}$; and (ii) the development of risk-based enforcement approaches $(20,22,23,28,34,35)$.

The use of private mechanisms includes self-regulation (involving internal control systems arranged in either individual firms or instituted by trade organisations) and certification schemes (where third parties set and monitor product quality standards $)^{(20,29,31,32)}$. Although research suggests that the high impact of advertising on food choices creates the necessity to regulate advertising on a global scale, often these voluntary agreements and self-regulation are used ${ }^{(33)}$.

With the development of a risk-based enforcement approach, the regulator tries to target enforcement resources efficiently to the highest risks, following a transparent and systematic assessment procedure ${ }^{(20,22,23,28,34,35)}$. This development would ideally result in prioritising attention and enforcement resources efficiently to the highest risks in the eyes of the regulator. Still, the implementation of risk-based approaches is seen to highly vary globally in complexity, institutional structures and strategic choices of the regulator ${ }^{(22,28,36)}$. Moreover, the adoption of a risk-based enforcement approach by an enforcement agency is suggested to extend the possibility of unequal treatment of businesses: accepting some but not other risks may be conflicting with the democratic beliefs of equality ${ }^{(34)}$. In addition, risk-based approaches could induce qualitative judgement and even bias in the decision making process by regulators or could focus on critical points without taking into account new developments ${ }^{(34,37)}$. Next to these 
internal issues within an enforcement agency, the previously mentioned variations between enforcement agencies can result in varying enforcement approaches throughout these (national) agencies ${ }^{(24,38)}$. Such non-uniform approaches in enforcing the NHCR throughout the EU increase uncertainties for businesses and consumers.

The risk-based enforcement approach is in literature seen to be the foundation to enforce European feed and food safety legislation, as described in Regulation $882 / 2004^{(18)}$. Therefore the enforcement actions to ensure compliance or remedy noncompliance with the NHCR should be based on the relative risks to deception or health issues posed by carrying an incorrect or false nutrition or health claim. The incorporation of this risk-based perspective may lead to the question whether such incorrect or false claims would even pose a risk for consumers, concerning their health or safety ${ }^{(39)}$.

Once non-compliance is identified, various corrective actions can be considered. In literature two opposing concepts on how to correct non-compliance are described (as depicted in figure 1): the punitive and the persuasive method ${ }^{(40-44)}$. The punitive style of enforcement, often referred to as the deterrence theory, assumes that players weigh costs and benefits of (non-)compliance. Formal monitoring and sanctions which increase the likelihood and costs of detection are therefore suggested to increase the effectiveness of laws ${ }^{(21,41,45)}$. The persuasive approach on the other hand focusses on increasing capacities of players (e.g. technical knowledge, financial resources and bureaucratic capability), clarifying rules and increasing transparency to enhance the effectiveness of laws ${ }^{(41)}$. Compliance is in this case considered to be the norm and noncompliance the exception, which would not be a deliberate decision but rather the consequence of a lack of capacities and skills ${ }^{(41,44,46)}$.

Although these approaches seem to be contradictory, they are more often seen to coexist and even being merged. This is shown in the current EU approach to induce compliance in various fields, including food law: not only official sanctions are given, informal actions as education and advice are often considered ${ }^{(28,40,41,44,47)}$. By combining 
both the punitive and the persuasive approach, drawbacks of both as decreased efficiency and business' involvement in the case of punitive measures or abuse of lenient rules and enforcers in the persuasive approach, are in literature suggested to be diminished ${ }^{(28,40)}$. This combined approach is known as responsive regulation, wherein enforcement agencies are able to apply a flexible strategy to the specific context of regulatees ${ }^{(28,37,40)}$. To ensure an effective application of responsive regulation three criteria should be met: (i) enforcement officers need to be able to apply enforcement actions and strategies consistently; (ii) the most appropriate enforcement style needs to be applicable to the practical situation; and (iii) unforeseen negative effects following an enforcement officer's behaviour can be controlled ${ }^{(40)}$. It is however doubtful whether these three criteria can be met in every situation ${ }^{(40)}$.

\section{Punitive approach}

\section{Persuasive approach}

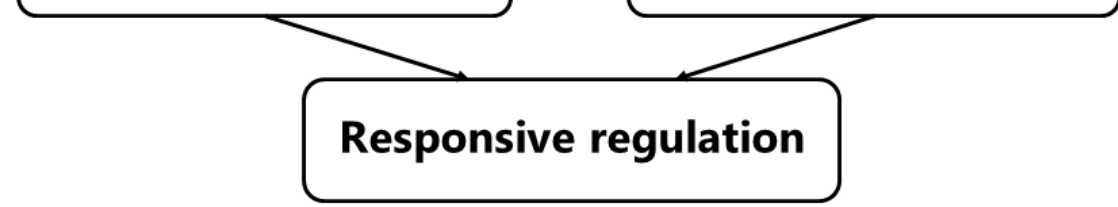

\section{Criteria:}

i) Consistent application of actions and

strategies

ii) Enforcement style applicable to

situation

iii) Control unforeseen negative

consequences of behaviour

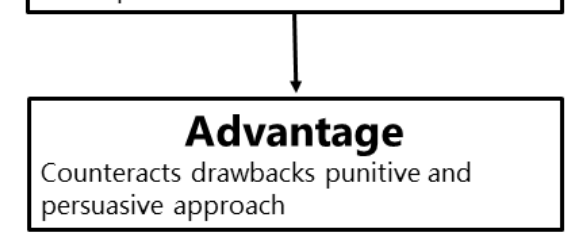

Figure 1. Responsive regulation. 


\section{Enforcement of European food law}

European regulations are not allowed to be incorporated in a modified form into national law, but have a direct effect in Member States ${ }^{(17)}$. The enforcement provisions in various pieces of legislation concerning food stipulate that the enforcement of these regulations is however the responsibility of the Member States themselves ${ }^{(48)}$. Article 1 of Regulation 882/2004 describes the scope of the regulation: it defines general rules on performing official controls within Member States on compliance with feed and food law and includes, as specifically mentioned in Article 1(1)(b), rules on food labelling and other forms of consumer information ${ }^{(18)}$. Thereby the Regulation serves as a harmonised framework of general rules on performing controls on feed and food law. General obligations of Member States in organising the controls on feed and food law compliance include that these controls should be carried out based on risks, introducing the risk-based enforcement approach, as described in Article 3. This riskbased enforcement approach is, as described in the section 'Identifying and correcting noncompliance', a tool to allocate resources efficiently to the highest risks. Articles 4 to 10 define the appointment of competent authorities within Member States who will be responsible for the official controls, and prescribe the use of documented procedures to carry out these official controls by knowledgeable staff. To ensure the staff of these national competent authorities is knowledgeable and is able to assure high quality of the official controls, Article 51 describes that training of control staff might be organised by the Commission. Articles 34 to 40 focus on administrative assistance and cooperation between Member States, Articles 41 to 44 prescribe the establishment and implementation of multiannual national control plans by Member States. Articles 54 and 55 define national enforcement measures, on how to handle in case of noncompliance and determine that defined and implemented sanctions must be 'effective, proportionate and dissuasive'. In case of serious failure in the control system of Member States leading to possible and widespread risks, the EU can take safeguard measures described in Article 53 as coordinated control plans to establish the prevalence of hazards, as outlined in Article $56^{(18)}$. 
Hence, according to Regulation 882/2004, Member States are obliged to enforce feed and food law via enforcement actions and strategies chosen by themselves based on this harmonised framework which, as described in Article 3, focusses on a risk-based approach $^{(17,18,49-51)}$. The introduction of national control plans is in literature believed to be helpful in ensuring safe and high quality food supply ${ }^{(23,24,52)}$. Regulation $882 / 2004$ thereby supports harmonisation of enforcement standards, although non-uniform approaches to the enforcement of certain legislative acts on feed and food, including the NHCR, are still possible between the 28 Member States and their national enforcement agencies ${ }^{(38)}$. As previously mentioned, this could lead to uncertainties for businesses and consumers ${ }^{(24,38)}$.

In combination with the prescribed risk based approach, various Member States cooperate with private initiatives as third party certification and co-regulation in assessing and reducing non-compliance ${ }^{(53,54)}$. These initiatives are suggested to be helpful in focussing enforcement resources as well as in achieving compliance through positively encouraging compliance by increasing access to reliable information and advice ${ }^{(44,47,54-57)}$. Backing up these initiatives by public enforcement actions, as arranged in the Netherlands by acknowledging various private initiatives and incorporation of these in the enforcement plans of the Netherlands Food and Consumer Product Safety Authority (NVWA), is suggested to strengthen the quality and use of private initiatives even more ${ }^{(19,53)}$. Additionally, international private initiatives such as private retailer initiatives and certification schemes for hygiene codes are considered to enhance the harmonising effect of transnational regulatory acts ${ }^{(19,32,55,57)}$.

\section{Enforcement of the NHCR}

Regulation 882/2004 on official controls deals with the control of all feed and food legislation, including those regulations focussed on labelling and consumer information ${ }^{(18)}$. This Regulation therefore also covers the official national controls on nutrition and health claims as described and other controls on feed and food law 
compliance as described in the Multi Annual National Control Plan of a Member State ${ }^{(58)}$.

Within the NHCR itself, little is declared about enforcement of the regulation. Articles 22 to 24 describe the role of Member States: Member States are not allowed to restrict trade by applying national provisions without them being positively received by the Commission and other Member States (in Article 22 and 23) ${ }^{(9)}$. Article 24 describes possible safeguard measures which can be taken by Member States when claims are considered not to comply with the NHCR. Article 26 outlines the possibility for Member States to require notifications to the national competent authority of labels of products placed on the market with nutrition or health claims ${ }^{(9)}$.

Since no specific requirements are described within the NHCR or any other regulatory act, Member States are free to choose their enforcement strategy in relation to the $\mathrm{NHCR}^{(22)}$. As previously indicated, this freedom carries the risk of using non-uniform and inconsistent approaches in enforcing the $\mathrm{NHCR}^{(12,59)}$. The only element, to which all national enforcement agencies can relate to when verifying compliance with the regulation, is the list of approved claims which includes their suggested wording ${ }^{(22)}$. Yet this list cannot prevent interpretation differences. Translation of suggested wordings of claims could still lead to different interpretations of the approved claim or the use of non-textual claims which not have been assessed as such ${ }^{(14,15)}$.

\section{Guidance documents}

To clarify the interpretation of nutrition and health claims by enforcement agencies, various guidance documents have been developed as regards both the flexibility of wording (depicted in figure 2) and the general compliance with the NHCR (figure 3). Not only national enforcement agencies within Member States have developed such documents, also various business associations have issued guidance documents on how to handle the NHCR. 


\section{Guidance on flexibility of wording}

An informal agreement between experts from 17 Member States in 2012 led to a guidance document upon the flexibility of wording with one general and seven specific recommendations ${ }^{(60)}$. The general recommendation is to stick as closely as possible to the authorised wording of a health claim ${ }^{(60)}$. Reflecting the health benefit as described in the claim is advised to ensure the average consumer will expect the effect that is comparable with the effect that is demonstrated in the scientific dossier of a claim. With one of the aims of the NHCR being 'to ensure that health claims are truthful, clear, reliable and useful to the consumer', this is of specific interest to the enforcing authority ${ }^{(13,60)}$. The seven specific recommendations focus on different aspects of the wording of a claim: (i) the adapted wording should have a similar meaning to the consumer as the authorised claim; (ii) the use of 'normal' in a claim; (iii) the claimed effect has to be linked to the ingredient it is authorised for; (iv) the use of health claims on food supplements; (v) presentation of general, non-specific health claims; (vi) use of trade or brand marks; (vii) how to refer to sentences or phrases from EFSA opinions $^{(60)}$.

Next to this informal agreement, the enforcement authorities of both Belgium and Italy published more detailed guidance documents (figure 2). The Belgian documents are published both in Dutch and French and describe 12 principles, which are more in detail compared to the recommendations of the 17 Member States ${ }^{(61,62)}$. The first principles describe how to reformulate the words 'contribute to' and 'normal'. When 'contribute to' is used in an approved health claim, the guidance document emphasises that a reformulated claim should not imply that the health effect connected to intake of the nutrient is contributable to this nutrient alone ${ }^{(61,62)}$. When the approved health claim describes 'normal' in the claim, this cannot only be reformulated to 'good' or 'healthy' when this would imply a broader effect then to which the claim is approved ${ }^{(61,62)}$. The other principles focus on three other aspects: (i) six principles describe issues concerning reformulation of the effect or adding information to the approved claim; (ii) two principles focus on the reformulation of reduction of disease risk claims (Article 
14.1(a) claims); and (iii) the link between the functional ingredient and its effect on health is depicted in two principles ${ }^{(61,62)}$. The Italian guidance document describes nine criteria to take into account when rephrasing claims and includes, similar to the Belgian document, examples of permitted and prohibited formulations of claims ${ }^{(63)}$. The nine criteria focus on the reformulation of the words 'normal', 'contribute to' or 'maintain' in an approved health claim; referring to EFSA opinions; how to deal with health claims on the effects of fibres or calcium; and how health claims on immune function, normal function of a system or organ or the function of the digestive tract can be rephrased ${ }^{(63)}$. The indicative list of claims with permitted and prohibited wording of claims is published by the Dutch Inspection Board Expertise and Advice Health Advertising (KOAG/KAG) and can also be considered as providing guidance, since KOAG/KAG has a non-formal working relationship with the Dutch enforcement authority ${ }^{(64)}$.

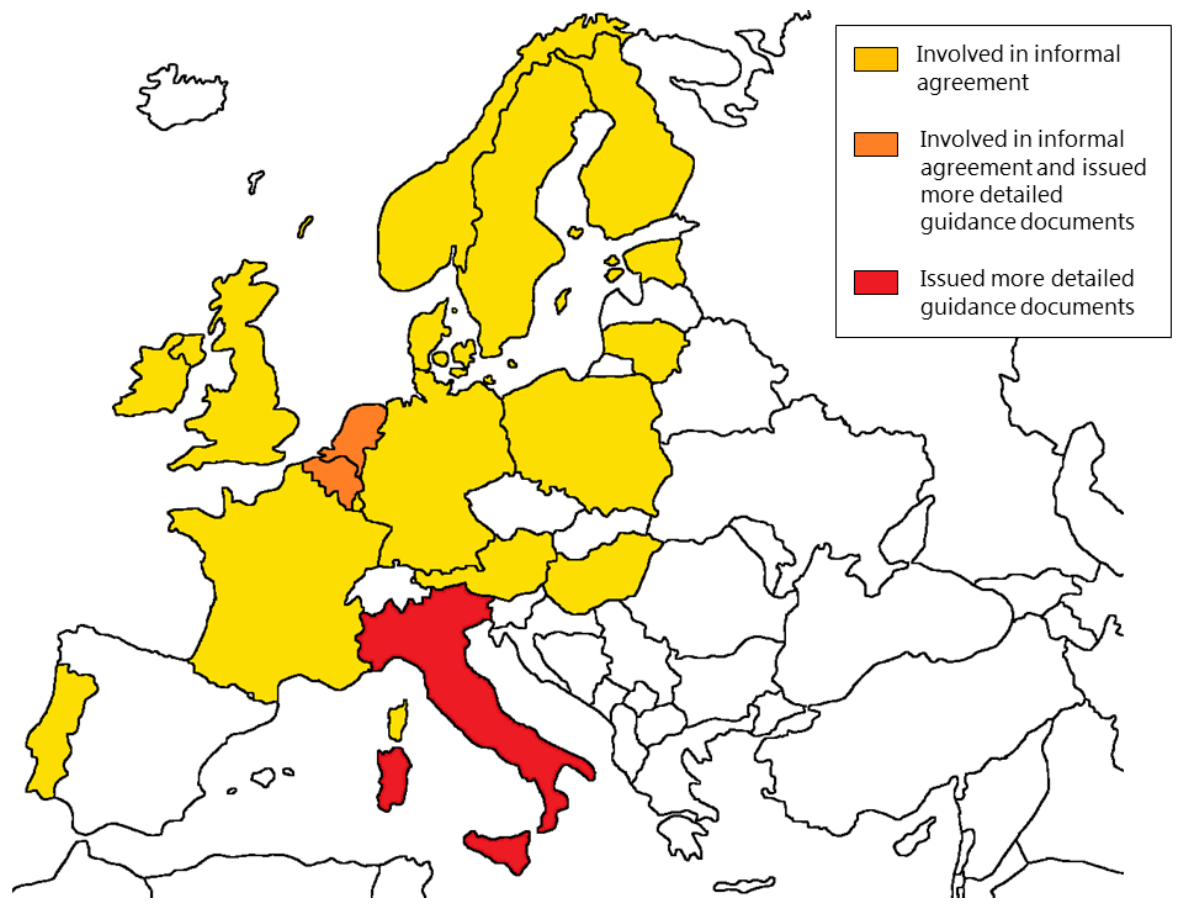

Figure 2. Member states that issued guidance documents on flexibility of wording within the NHCR. 


\section{Guidance on compliance}

General guidance documents on compliance with the NHCR have been developed by eight national authorities throughout the EU (figure 3): Austria, Belgium, Denmark, Finland, Ireland, the Netherlands, Sweden and the United Kingdom issued guidance documents $^{(65-74)}$. In the United Kingdom both the 'Guidance to compliance' and the 'Quick start guide to guidance' was published ${ }^{(73,74)}$. All guidance documents inform on how to approach and comply with the NHCR. Thereby they provide the national interpretation of several aspects of the regulation as flexibility of wording, differences between nutrition claims and health claims and descriptions on allowance to use Article 10.3 or general health claims ${ }^{(65-74)}$.

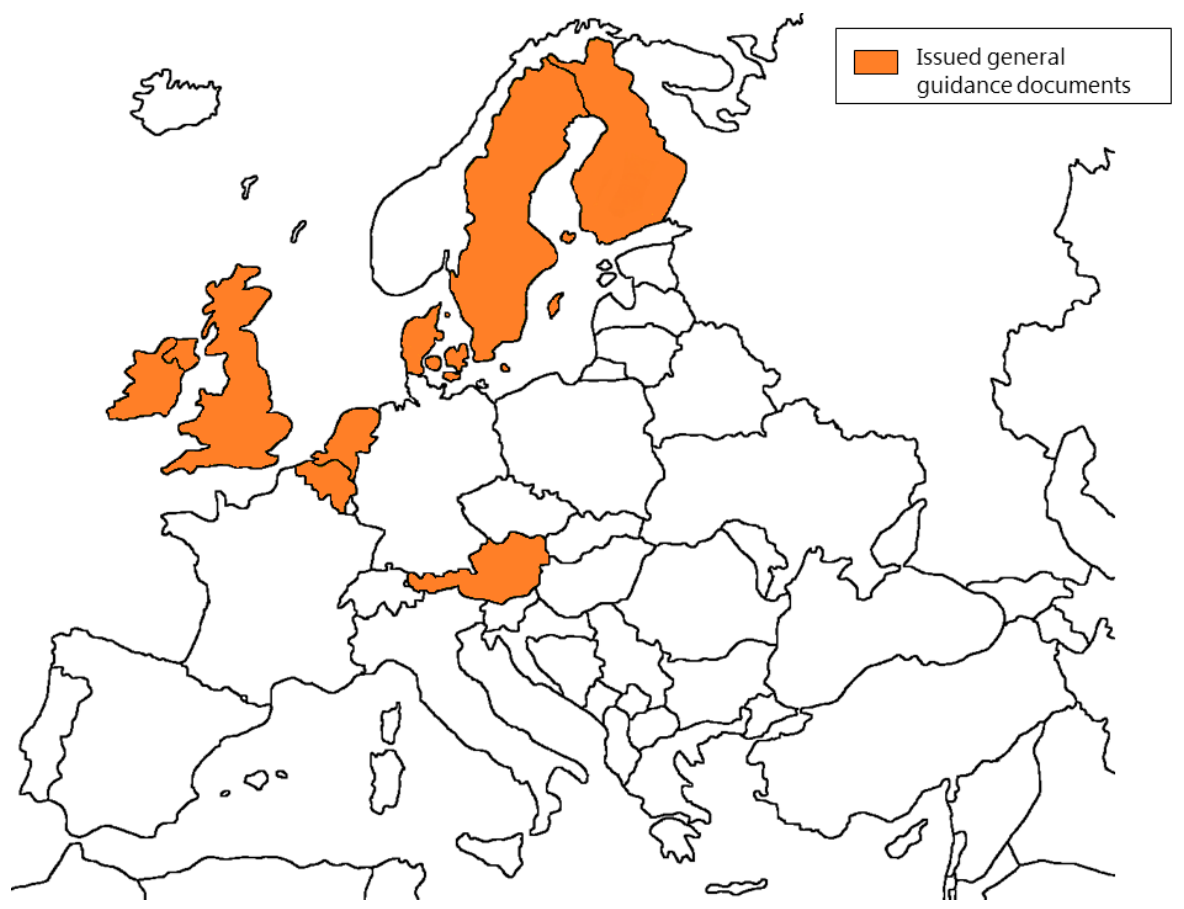

Figure 3. Member states that issued general guidance documents on compliance with the NHCR.

Next to the guidance documents of national authorities, various business organisations as FSE (Food Supplements Europe) and ERNA (European Responsible Nutrition 
Alliance) issued guidance documents. These documents present the interpretation of the NHCR specifically for food business operators ${ }^{(75,76)}$. However, it is important to stress that neither these documents nor the Member State guidance documents are legally binding documents and can only provide an interpretation of the NHCR by these associations or the individual Member State.

\section{Enforcement actions}

As described in the section 'Identifying and correcting noncompliance', the punitive and persuasive approach are more often seen to be combined into responsive regulation in the EU approach to induce compliance in fields as food law ${ }^{(40,41)}$. However, this approach is not fully reflected by the first actions that were issued by national enforcement agencies upon infringement of the NHCR. The highly varying enforcement strategies throughout the $\mathrm{EU}$ are depicted by the differences in penalties: a fine of $€ 250,000$ was recently issued in Italy upon a false claim on a papaya product, where the Advertising Standards Authority in the UK focuses on naming and shaming of offenders ${ }^{(77,78)}$. An infringement of food law in the Netherlands is known to result in a fine ranging from $€ 500$ up to a few thousand euro's, although health claims rephrased as medical claims will be penalised under pharmaceutical law, leading to fines starting from $€ 30.000^{(79,80)}$. In 2012, a fine was issued by the Netherlands Food and Consumer Product Safety Authority (NVWA) to a product bearing a disease risk reduction claim, since this claim was interpreted as a medical claim and thereby an infringement of pharmaceutical law. The fined industrial brought this to the Dutch court, who agreed with the NVWA and assessed that the fine of $€ 152.500$ was justifiable: $€ 2.500$ for violating the pharmaceutical law by not having a marketing authorisation to sell a medicinal product and $€ 150.000$ for advertising of a medicinal product without having marketing authorisation for such product ${ }^{(80)}$. 


\section{Conclusions}

The foundation of enforcing EU feed and food law, therefore including the NHCR, is a risk-based enforcement approach, viz. enforcement resources are focussed on the highest risks. This is an efficient way to deal with limited budgets. The practice of responsive regulation in correcting the identified non-compliance with EU law is considered to be the most effective way to increase compliance. However, both the implementation of risk-based enforcement approaches and the practice of responsive regulation seem to be highly varying throughout the EU. This is depicted by the 13 guidance documents in 18 Member States, all embracing their own focus and principles. Also the actual enforcement actions following from the enforcement strategies of Member States are seen to be highly diverging from persuasive to punitive measures. These variations lead to non-uniform approaches and uncertainties for businesses and consumers. Since the NHCR not only aims to protect consumers from being misled but also intends to create a level playing field, one approach in enforcement throughout the EU should be agreed upon. Such an enforcement approach should include suggestions for guidance, control strategies, interpretation of rephrased wording of claims as well as pictorial claims and finally suggested informal or formal actions to correct infringements of the NHCR. Before implementing such an EU-wide enforcement strategy however, the risks for consumers following a false or incorrect claim should be addressed, to establish a truly risk-based enforcement approach founded upon evidence for these risks. With a uniform enforcement strategy within 28 Member States, the NHCR will be a more effective regulation and establish an actual level playing field throughout Europe. 


\section{References}

1. Vos E (2000) EU Food Safety Regulation in the Aftermath of the BSE Crisis. J. Consum. Policy 23, 227-255.

2. Chalmers D (2003) 'Food for Thought': Reconciling European Risks and Traditional Ways of Life. Mod. Law Rev. 66, 532-562.

3. European Commission (2000) White paper on food safety. COM 719.

4. European Commission (1997) The general principles of food law in the European Union - Commission green paper. COM 176.

5. European Parliament and Council of the European Union (2002) Regulation (EC) No 178/2002 of the European Parliament and of the Council of 28 January 2002 laying down the general principles and requirements of food law, establishing the European Food Safety Authority and laying down procedures in matters of food safety. OJ L 31 45, 1-24.

6. Van der Meulen BMJ (2009) The System of Food Law in the European Union. Deakin Law Rev. 14, 305-340.

7. European Commission (2001) Discussion paper on nutrition claims and functional claims. Brussels: SANCO/1341/2001. Prepared by Directorate General Health and Consumer Protection (SANCO D4).

8. European Parliament and the Council of the European Union (2003) Proposal for a regulation of the European Parliament and of the Council on nutrition and health claims made on foods. Brussels: European Commission.

9. European Parliament and Council of the European Union (2006) Regulation (EC) No 1924/2006 of the European Parliament and of the council of 20 December 2006 on nutrition and health claims made on foods. OJ L 404 49, 9-25.

10. De Boer A, Vos E \& Bast A (2014) Implementation of the nutrition and health claim regulation - the case of antioxidants. Regul. Toxicol. Pharmacol. 68, 475-487.

11. Moors EHM (2012) Functional foods: regulation and innovations in the EU. Innovation $25,424-440$.

12. Gilsenan MB (2011) Nutrition \& health claims in the European Union: A regulatory overview. Trends Food Sci. Technol. 22, 536-542.

13. European Commission (2012) Commission Regulation (EU) No 432/2012 of 16 May 2012 establishing a list of permitted health claims made on foods, other than those referring to the reduction of disease risk and to children's development and health. OJ L 13655 , $1-40$.

14. Lelieveldt H \& Boonen C (2012) EU Health Claims Regulation and the Marketing of Functional Foods: A Regulatory Void? Eur. J. Risk Regul. 4, 577-580.

15. Meisterernst A (2010) A Learning Process-Three Years of Regulation (EC) No. 1924/2006 on Nutrition and Health Claims Made on Foods. EFFL. 2/2010, 59-72.

16. Van der Meulen B \& van der Velde M (2008) Introduction to law. In European Food Law Handbook, pp. 45-78. Wageningen: Wageningen Academic Publishers.

17. Van der Meulen B \& van der Velde M (2008) Public powers: official controls, enforcement and incident management. In European Food Law Handbook, pp. 403-420. Wageningen: Wageningen Academic Publishers. 
18. European Parliament and Council of the European Union (2004) Regulation (EC) No 882/2004 of the European Parliament and of the Council of 29 April 2004 on official controls performed to ensure the verification of compliance with feed and food law, animal health and animal welfare rules. OJ L 165 47, 1-141.

19. Verbruggen P (2013) Gorillas in the closet? Public and private actors in the enforcement of transnational private regulation. Regul. Gov. 7, 512-532.

20. Hutter BM \& Amodu T (2008) Risk regulation and compliance: Food safety in the UK. London: London School of Economics and Political Science.

21. Becker GS \& Stigler GJ (1974) Law Enforcement, Malfeasance, and Compensation of Enforcers. J. Legal Stud. 3, 1-18.

22. Patel A, Smith C, Knowles T, et al. (2012) Nutrition and health claims: An enforcement perspective. Trends Food Sci. Technol. 28, 15-22.

23. Whitehead AJ (1995) Elements of an effective national food control system. Food Control 6, 247-251.

24. Neeliah SA \& Goburdhun D (2007) National food control systems: a review. Food Rev. Int. 23, 35-51.

25. Goris JM, Petersen S, Stamatakis E, et al. (2010) Television food advertising and the prevalence of childhood overweight and obesity: a multicountry comparison. Public Health Nutr. 13, 1003-1012.

26. Sharma LL, Teret SP \& Brownell KD (2010) The food industry and self-regulation: standards to promote success and to avoid public health failures. Am. J. Public Health 100, 240-246.

27. Henson S \& Heasman M (1998) Food safety regulation and the firm: understanding the compliance process. Food Policy 23, 9-23.

28. Black J \& Baldwin R (2010) Really responsive risk-based regulation. Law Policy 32, 181213.

29. Havinga T \& van Waarden F (2013) Enforcing compliance with food regulation: Modalities in the relationship between public enforcement agencies and private parties. Bordeaux: ECPR General Conference 2013.

30. Mello MM, Studdert DM \& Brennan TA (2006) Obesity-the new frontier of public health law. N. Engl. J. Med. 354, 2601-2610.

31. Henson S \& Caswell J (1999) Food safety regulation: an overview of contemporary issues. Food Policy 24, 589-603.

32. Henson S \& Reardon T (2005) Private agri-food standards: Implications for food policy and the agri-food system. Food Policy 30, 241-253.

33. Caraher M, Landon J \& Dalmeny K (2006) Television advertising and children: lessons from policy development. Public Health Nutr. 9, 596-605.

34. King R (2011) The risks of risk-based regulation: the regulatory challenges of the higher education White Paper for England. Oxford: HEPI.

35. Coppens P, Da Silva MF \& Pettman S (2006) European regulations on nutraceuticals, dietary supplements and functional foods: a framework based on safety. Toxicology 221 , 59-74. 
36. Houghton JR, Rowe G, Frewer LJ, et al. (2008) The quality of food risk management in Europe: Perspectives and priorities. Food Policy 33, 13-26.

37. Baldwin R \& Black J (2008) Really responsive regulation. Mod. Law Rev. 71, 59-94.

38. Leibovitch EH (2007) Food safety regulation in the European Union: Toward an unavoidable centralization of regulatory powers. Tex. Int. Law J. 43, 429-452.

39. Hanekamp JC, Bast A \& Calabrese EJ (2015) Nutrition and health - transforming research traditions. Crititical Rev. Food Sci. Nutr. 55, 1074-1080.

40. Mascini P \& Wijk E Van (2009) Responsive regulation at the Dutch food and consumer product safety authority: an empirical assessment of assumptions underlying the theory. Regul. Gov. 3, 27-47.

41. Tallberg J (2002) Paths to Compliance: Enforcement, Management, and the European Union. Int. Organ. 56, 609-643.

42. Polinsky AM \& Shavell S (2000) The economic theory of public enforcement of law. J. Econ. Lit. 38, 45-76.

43. Coglianese C \& Lazer D (2003) Management-Based Regulation: Prescribing Private Management to Achieve Public Goals. Law Soc. Rev. 37, 691-730.

44. Yapp C \& Fairman R (2006) Factors affecting food safety compliance within small and medium-sized enterprises: implications for regulatory and enforcement strategies. Food Control 17, 42-51.

45. Tyran J \& Feld LP (2006) Achieving Compliance when Legal Sanctions are Non-deterrent. Scand. J. Econ. 108, 135-156.

46. Malloy TF (2003) Regulation, compliance and the firm. Temple Law Rev. 76, 451-532.

47. Fairman R \& Yapp C (2005) Enforced Self-Regulation, Prescription, and Conceptions of Compliance within Small Businesses: The Impact of Enforcement. Law Policy 27, 491-519.

48. Van der Meulen B \& van der Velde M (2008) International public law. In European Food Law Handbook, pp. 79-118. Wageningen: Wageningen Academic Publishers.

49. Maudoux JP, Saegerman C, Rettigner C, et al. (2006) Food safety surveillance through a risk based control programme: approach employed by the Belgian Federal Agency for the Safety of the Food Chain. Vet. Q. 28, 140-154.

50. Tähkäpää S, Kallioniemi M, Korkeala H, et al. (2009) Food control officers perception of the challenges in implementing new food control requirements in Finland. Food Control 20, 664-670.

51. Expertisecentrum Europees Recht (2009) Handleiding Wetgeving en Europa - De voorbereiding, totstandkoming en nationale implementatie van Europese regelgeving. Den Haag: Ministerie van Buitenlandse Zaken.

52. Käferstein F \& Abdussalam M (1999) Food safety in the 21st century. Bull. World Health Organ. 77, 347.

53. Nederlandse Voedsel- en Warenautoriteit (2012) Jaarverslag Meerjarenprogramma Nationale Controles. Utrecht: Ministerie van Economische Zaken.

54. Garcia Martinez M, Fearne A, Caswell JA, et al. (2007) Co-regulation as a possible model for food safety governance: Opportunities for public-private partnerships. Food Policy 32, 299-314. 
55. Hatanaka M, Bain C \& Busch L (2005) Third-party certification in the global agrifood system. Food Policy 30, 354-369.

56. Tanner B (2000) Independent assessment by third-party certification bodies. Food Control 11, 415-417.

57. Fulponi $L$ (2006) Private voluntary standards in the food system: The perspective of major food retailers in OECD countries. Food Policy 31, 1-13.

58. Food and Veterinary Office (2013) Work Programme 2014. Grange: Food and Veterinary Office.

59. Coppens P (2007) The Impact of the Nutrition and Health Claims Regulation on the Food Industry. EFFL. 2/2007, 67-75.

60. [Member State experts] (2012) General principles on flexibility of wording for health claims.

61. Federale Overheidsdienst Volksgezondheid Veiligheid van de Voedselketen en Leefmilieu (2012) Richtsnoeren betreffende de flexibiliteit in de toegestane bewoording van gezondheidsclaims. Brussels: Belgian Federal Government.

62. Service Public Fédéral Santé publique Sécurité de la Chaîne alimentaire et Environnement (2012) Lignes directrices concernant la flexibilité du libellé des allégations de santé. Brussels: Belgian Federal Government.

63. Ministero della Salute (2013) Proposte di flessibilità al Regolamento 432/2012 - Criteri di massima [unofficial translation]. Rome: Italian Republic, Ministerio della Salute.

64. Keuringsraad KOAG/KAG (2014) Database Claimsverordening en Indicatieve Lijst. Amsterdam: Keuringsraad KOAG/KAG; http://keuringsraad.nl/Databaseclaimsverordening-en-indicatieve-lijst (accessed April 2015).

65. Wirtschaftskammer Österreich (2013) Informationen zur Verwendung von gesundheitsbezogenen Angaben gemäß der Claims-Verordnung [unofficial translation]. Vienna: Bundesgremium des Lebensmittelhandels.

66. Federale Overheidsdienst Volksgezondheid Veiligheid van de Voedselketen en Leefmilieu (2014) Status en gebruik van de voedings- en gezondheidsclaims. Brussels: Belgian Federal Government.

67. Service Public Fédéral Santé publique Sécurité de la Chaîne alimentaire et Environnement (2014) Statut et utilisation des allégations nutritionnelles et de santé. Brussels: Belgian Federal Government.

68. Molander E (2014) Vejledning om anprisningsforordningen [unofficial translation]. Glostrup: Fødevareministeriet.

69. Product Safety Unit (2011) Nutrition and Health Claim Guide for food supervisors and food business operators. Helsinki: EVIRA.

70. Food Safety Authority of Ireland (2014) Information on Nutrition and Health Claims. Dublin: Food Safety Authority of Ireland.

71. Keuringsraad KOAG/KAG (2013) Richtsnoerdocument betreffende het gebruik van gezondheidsclaims voor levensmiddelen op basis van Verordening (EG) 1924/2006 van 20 december 2006. Amsterdam: Keuringsraad KOAG/KAG.

72. Livsmedels Verket (2013) Vägledning till kontrollmyndigheter m.fl. Näringspåståenden och hälsopåståenden om livsmedel [unofficial translation]. Uppsala: Livsmedels Verket. 
73. Department of Health (2011) Quick start guide to guidance on compliance with Regulation (EC) No. 1924/2006 on nutrition and health claims made on foods. London: Department of Health, United Kingdom Government.

74. Department of Health (2011) Guidance to compliance with Regulation (EC) 1924/2006 on nutrition and health claims made on foods. London: Department of Health.

75. Food Supplements Europe (2013) The application of the Nutrition and Health Claims Regulation 1924/2006. Brussels: Food Supplements Europe.

76. European Responsible Nutrition Alliance (2012) The application of the Nutrition and Health Claims Regulation 1924/2006. Brussels: European Responsible Nutrition Alliance.

77. Starling S (2014) Papaya liar? Italy issues $€ 250,000$ fine over 'distorted' health claims. http://www.nutraingredients.com/Regulation-Policy/Papaya-liar-Italy-issues-250-000fine-over-distorted-health-claims (accessed April 2015).

78. Starling S (2014) Italy cracks whip on health claim abusers - fines couls reach $€ 5 \mathrm{~m}$. http://www.nutraingredients.com/Regulation-Policy/Italy-cracks-whip-on-health-claimabusers-fines-could-reach-5m?nocount (accessed April 2015).

79. Nederlandse Voedsel- en Warenautoriteit (2015) Bestuurlijke boete - De hoogte van de bestuurlijke boete. https://www.vwa.nl/onderwerpen/meest-bezocht-az/dossier/bestuurlijke-boete/de-hoogte-van-de-bestuurlijke-boete (accessed April 2015).

80. Rechtbank Rotterdam (2014) Becel vs NVWA - Boete wegens overtreding van de Geneesmiddelenwet (ROT-12_03898). Rechtbank Rotterdam. 



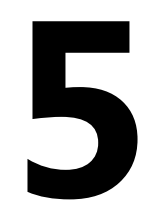

\section{International nutrition and health claims legislation}

Alie de Boer, Aalt Bast

Food Policy 55 (2015), 61-70 
Chapter 5

\section{Abstract}

The increasing public interest in dietary health benefits led to the development of different legislative texts on nutrition and health claims worldwide. Following a review of legislation of 28 jurisdictions, three prominent differences were discerned, concerning (i) the labelling of different types of nutrition and health claims and their permission; (ii) variations arising in the (pre-marketing) authorisation procedures; and (iii) the use of the scientific minority opinion in substantiating claims. By discussing these legal differences with findings from literature concerning consumer and industry effects, this review puts these pieces of legislation into a broader perspective. The studied pieces of legislation show critical differences and although various approaches have positive points, no optimal approach to regulate nutrition and health claims has been implemented yet. It would be preferable to permit similar types of claims throughout jurisdictions, permit claims that have a lower probability of misleading consumers as nutrition claims to use emerging evidence and to require pre-marketing approval of claims with higher impact. International harmonisation of these aspects should globally lead to improved pieces of legislation, stimulate industrial efforts in functional foods and enhance consumers' opportunity to use health-enhancing products. 


\section{Introduction}

The increasing public interest in possible health benefits of foods has created an attractive opportunity for the food industry, i.e. developing functional foods. Functional foods are foods which are consumed within a normal dietary pattern, with healthenhancing properties beyond adequate nutritional effects ${ }^{(1-4)}$. Japan was the first jurisdiction to regulate functional foods and their commercial outings by means of the FOSHU (Foods for Specified Health Use), which was based on research initiated in 1984 on the effects of these foods ${ }^{(3,5,6)}$. FOSHU described the requirements for scientific substantiation of a claim on the health effect elicited by such a functional food product $^{(6)}$. Currently, several pieces of legislation dealing with nutrition and health claims are enforced throughout the world ${ }^{(5)}$.

The international market of functional foods is growing, even though consumers in countries affected by the economic turmoil are less willing to pay premium prices ${ }^{(7)}$. The growth of the market is higher in countries less affected by this economic turmoil: the United States of America (USA) reported a market growth of functional foods of $0.9 \%$ over the years 2008-2013, where the growth reported in China was 21.1\%, 21.3\% in Argentina and even 33.8\% in Venezuela in the same period ${ }^{(8)}$. Growth forecasts show that the market is expected to grow in almost all countries in the upcoming years, but are most optimistic for Asia, varying from an expected growth of $0.6 \%$ in Japan up to $13.4 \%$ in $\mathrm{China}^{(9)}$. Still, the market share of functional foods is rather small in numerous countries ${ }^{(8)}$. This increases the interest of the food industry to operate on an international level. However, global variations in legislative requirements on nutrition and health claims complicate the marketing of functional foods across jurisdictions ${ }^{(5,10-14)}$.

This paper reviews current international pieces of legislation on nutrition and health claims in an attempt to show the diverse approaches and to envision ways to optimise procedures from a scientific perspective. The similarities and differences in required scientific substantiation and their review processes can be found elsewhere (e.g. ${ }^{(11,15)}$ ) and will therefore not be discussed thoroughly in this paper. 


\section{Methods}

The jurisdictions described in the 2004 WHO report on the global regulatory environment of nutrition labels and health claims were the starting point of this review $^{(16)}$. The 22 jurisdictions from this report on which English information was available were included in this research and an additional six jurisdictions were identified where information on nutrition and health claim legislation was available in English.

Information from various sources was used to identify permitted and prohibited types of claims, as well as upon the authorisation procedure and the norm of scientific substantiation for claims by studying legislation of the various jurisdictions and scientific literature describing legislation concerning nutrition and health claims in different jurisdictions. Guidance documents from regulatory bodies dealing with nutrition and health claims were studied. Documents describing the interpretation of pieces of legislation were critically assessed to provide additional information on various jurisdictions. This created the opportunity to compare the different pieces of legislation upon nutrition and health claims and their surrounding procedures.

\section{Results}

Where the 28 identified jurisdictions are all seen to regulate nutrition and health claims, variations were found in the different pieces of legislation: (i) the labelling of different types of nutrition and health claims and their permission; (ii) whether or not authorisation is required and which shape it takes; and (iii) the possibility of using emerging scientific evidence.

\section{Types of claims}

The 'Guidelines for Use of Nutrition and Health Claims' published by the Codex Alimentarius Committee defines two types of claims, viz. nutrition claims and health claims ${ }^{(17)}$. Nutrition claims are defined as 'any representation which states, suggests, or 
implies that a food has particular nutritional properties'. These claims include three categories of claims: (i) nutrient content claims, describing the level of a nutrient contained in a food (e.g. 'contains calcium); (ii) nutrient comparative claims, which compare the nutrient and/or energy levels of two or more foods (e.g. 'light); and (iii) non-addition claims, describing that a specific ingredient has not been added to a food (e.g. 'fat free) ${ }^{(17)}$.

The Codex guidelines define health claims as "any representation that states, suggests, or implies that a relationship exists between a food or a constituent of that food and health", including three types of claims: (i) nutrient function claims, describing the physiological role of the nutrient in growth, development and normal functions of the body (e.g. 'vitamin C contributes to the normal function of the immune system); (ii) other function claims, emphasising specific beneficial effects of the consumption of foods or their constituents, relating to a positive contribution to health or the improvement of a function or to modifying or preserving health ('cocoa flavanols help maintain the elasticity of blood vessels, which contributes to normal blood flow'); and (iii) claims on reduction of disease risk, which relate the consumption of a food or food constituent, in the context of the total diet, to the reduced risk of developing a disease or health-related condition ('Calcium helps to reduce the loss of bone mineral in postmenopausal women. Low bone mineral density is a risk factor for osteoporotic bone fractures. $)^{(17)}$.

Although the studied jurisdictions label the types of claims differently, all claims can be categorised within these six categories. Differences arise between the types of claims permitted for use within the various jurisdictions, as depicted in table 1. Since most pieces of legislation do not further specify the specific types of nutrition claims permitted or prohibited, only the full category is presented in the table. 
Table 1. Types of claims permitted or prohibited per jurisdiction

\begin{tabular}{|c|c|c|c|c|}
\hline \multirow[b]{2}{*}{ Jurisdiction } & \multirow[b]{2}{*}{$\begin{array}{l}\text { Nutrition } \\
\text { claim }\end{array}$} & \multicolumn{3}{|c|}{ Health claims } \\
\hline & & $\begin{array}{l}\text { Nutrient } \\
\text { function }\end{array}$ & $\begin{array}{l}\text { Other } \\
\text { function }\end{array}$ & $\begin{array}{l}\text { Reduction of } \\
\text { disease risk }\end{array}$ \\
\hline Argentina & $V$ & 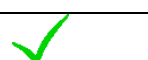 & $V$ & $\gamma$ \\
\hline Australia/New Z & & & & \\
\hline Barbados & 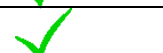 & $\gamma$ & $V$ & \\
\hline Brazil & & & & \\
\hline Brunei Darussal & & & & \\
\hline Canada & $y$ & $\gamma$ & & \\
\hline Central America & & 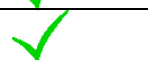 & & \\
\hline Chile & & & & \\
\hline China & $v$ & $V$ & & \\
\hline Colombia & & & & \\
\hline Ecuador & $\gamma$ & & & \\
\hline EU & 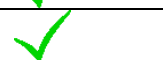 & Y & Y & \\
\hline Hong Kong & & & $n / k$ & \\
\hline India & & & & \\
\hline Indonesia & $x$ & $\gamma$ & $x$ & \\
\hline Japan & & $V$ & & \\
\hline Malaysia & & & & \\
\hline Mexico & 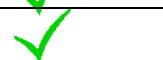 & & & \\
\hline Nigeria & & & & \\
\hline Republic of Kor & & & & \\
\hline Russia & 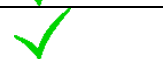 & 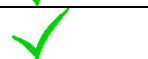 & $y$ & 3 \\
\hline Singapore & $V$ & $V$ & & \\
\hline South-Africa & 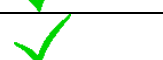 & v & $S$ & \\
\hline Taiwan & $y$ & $y$ & $y$ & \\
\hline Thailand & & & 3 & 3 \\
\hline The Philippines & $v$ & $V$ & $V$ & $\gamma$ \\
\hline USA & $y$ & $\checkmark$ & $V$ & $\checkmark$ \\
\hline Vietnam & $V$ & $V$ & $n / k$ & $n / k$ \\
\hline
\end{tabular}

$\checkmark=$ permitted in legislation; $\mathbf{X}=$ prohibited in legislation; $\mathbf{n} / \mathbf{k}=$ not specified in legislation; ${ }^{\mathbf{a}}=$ including Costa Rica, El Salvador, Guatamala, Honduras, Nicaragua; ${ }^{\mathbf{b}}=$ permitted in draft regulation; ${ }^{c}=$ regarded as nutrition claim; ${ }^{\mathbf{d}}=$ not permitted on food, products with these claims are regulated under drug regulations. 
In all reviewed jurisdictions, nutrition claims are officially permitted for use $\mathrm{s}^{(6,15,18-42)}$. Generally this entails the use of both nutrient content claims and nutrient comparative claims, only legislation in Chile, Japan and Taiwan does not specifically address the use of nutrient comparative claims ${ }^{(6,15,24,29)}$.

The use of nutrient function claims is allowed in almost all evaluated jurisdictions $^{(6,15,18,19,22-25,27-32,34-46)}$. Only Brunei Darussalam and Nigeria prohibit the use of nutrient function claims ${ }^{(21,33)}$. In Nigeria food products bearing health claims are regarded and regulated as drugs and therefore claims are not permitted on regular food products ${ }^{(47)}$. The legislation in most reviewed jurisdictions considers nutrient function claims to be health claims, yet they are judged as nutrition claims in Malaysia and Thailand ${ }^{(15,31,48)}$.

Other or enhanced function claims are prohibited in Brunei Darussalam, India, Nigeria, South-Africa and Thailand, although the new draft regulation on nutrition and health claims in India does permit these claims ${ }^{(21,33,48-50)}$. Legislation in Hong Kong and Vietnam does not specifically describe nor prohibit other or enhanced function claims $^{(39,51)}$. Within the 21 other jurisdictions the use of these claims is permitted $^{(15,18,19,22-25,27,30-32,35,37,38,40-44,52,53)}$.

Brunei Darussalam, Hong Kong, India, Malaysia, Mexico, Nigeria, Russia, South-Africa, Taiwan and Thailand prohibit the use of disease risk reduction claims on food products $^{(15,21,28,29,31-33,36,37,48,50)}$. Additionally the draft regulation in India permits the use of these claims, while Vietnamese legislation does not specifically address these types of claims ${ }^{(39,49)}$. Within the 17 other jurisdictions using a disease risk reduction claim is $\operatorname{permitted}^{(18,19,22-25,27,30,35,38,40-44,52,53)}$.

Canadian legislation goes beyond other pieces of legislation by permitting the use of therapeutic claims after pre-marketing review. These are claims suggesting that the consumption of a nutrient is able to 'treat or mitigate a disease or condition or restore 
or otherwise modify an existing function ${ }^{\{15)}$. Today however no therapeutic claim has been approved for use in Canada(54).

\section{Authorisation procedures}

Different authorisation procedures are defined in different jurisdictions (table 2).

Table 2. Authorisation procedures.

\begin{tabular}{|c|c|c|c|c|}
\hline \multirow[b]{2}{*}{ Jurisdiction } & \multirow[b]{2}{*}{$\begin{array}{l}\text { Nutrition } \\
\text { claim }\end{array}$} & \multicolumn{3}{|c|}{ Health claims } \\
\hline & & $\begin{array}{l}\text { Nutrient } \\
\text { function }\end{array}$ & $\begin{array}{l}\text { Other } \\
\text { function }\end{array}$ & $\begin{array}{l}\text { Reduction of } \\
\text { disease risk }\end{array}$ \\
\hline Argentina & $\mathrm{n} / \mathrm{k}$ & PM & PM & PM \\
\hline Australia/New Zealand & $\mathrm{n} / \mathrm{k}$ & NOT & NOT & PM-N \\
\hline Barbados & $\mathrm{n} / \mathrm{k}$ & PM-N & PM-N & PM-N \\
\hline Brazil & $\mathrm{n} / \mathrm{k}$ & PM & PM & PM \\
\hline Brunei Darussalam & $\mathrm{n} / \mathrm{k}$ & $\mathrm{n} / \mathrm{a}$ & $\mathrm{n} / \mathrm{a}$ & $\mathrm{n} / \mathrm{a}$ \\
\hline Canada & $\mathrm{n} / \mathrm{k}$ & PM-N & PM-N & PM-N \\
\hline Central America $^{a}$ & $\mathrm{n} / \mathrm{k}$ & PM-N & PM-N & PM-N \\
\hline Chile & $\mathrm{n} / \mathrm{k}$ & NN & NN & NN \\
\hline China & $\mathrm{NP}$ & NP & PM & $\mathrm{PM}^{\mathbf{b}}$ \\
\hline Colombia & $\mathrm{n} / \mathrm{k}$ & NN & PM-N & PM-N \\
\hline Ecuador & $\mathrm{n} / \mathrm{k}$ & PM-N & PM-N & PM-N \\
\hline EU & $\mathrm{PM}-\mathrm{N}$ & PM-N & PM & PM-N \\
\hline Hong Kong & $\mathrm{n} / \mathrm{k}$ & $n / k$ & $\mathrm{n} / \mathrm{a}$ & $n / a$ \\
\hline India & NN & NN & $\mathrm{n} / \mathrm{a}$ & $\mathrm{n} / \mathrm{a}$ \\
\hline Indonesia & $\mathrm{PM}-\mathrm{N}$ & PM-N & PM-N & PM-N \\
\hline Japan & $\mathrm{n} / \mathrm{k}$ & NN & PM & PM \\
\hline Malaysia & $\mathrm{n} / \mathrm{k}$ & PM-N & PM-N & $\mathrm{n} / \mathrm{a}$ \\
\hline Mexico & $\mathrm{n} / \mathrm{k}$ & $n / k$ & $n / k$ & $\mathrm{n} / \mathrm{a}$ \\
\hline Nigeria & $\mathrm{n} / \mathrm{k}$ & $\mathrm{n} / \mathrm{a}$ & $\mathrm{n} / \mathrm{a}$ & $\mathrm{n} / \mathrm{a}$ \\
\hline Republic of Korea & $\mathrm{n} / \mathrm{k}$ & PM-N & PM-N & PM-N \\
\hline Russia & $\mathrm{n} / \mathrm{k}$ & PM & PM & $\mathrm{n} / \mathrm{a}$ \\
\hline Singapore & $\mathrm{n} / \mathrm{k}$ & PM-N & PM-N & PM \\
\hline South-Africa & $\mathrm{n} / \mathrm{k}$ & $n / k$ & $\mathrm{n} / \mathrm{a}$ & $\mathrm{n} / \mathrm{a}$ \\
\hline
\end{tabular}


Table 2 (cont.). Authorisation procedures.

\begin{tabular}{|c|c|c|c|c|}
\hline \multirow[b]{2}{*}{ Jurisdiction } & \multirow[b]{2}{*}{$\begin{array}{l}\text { Nutrition } \\
\text { claim }\end{array}$} & \multicolumn{3}{|c|}{ Health claims } \\
\hline & & $\begin{array}{l}\text { Nutrient } \\
\text { function }\end{array}$ & $\begin{array}{l}\text { Other } \\
\text { function }\end{array}$ & $\begin{array}{l}\text { Reduction of } \\
\text { disease risk }\end{array}$ \\
\hline Taiwan & $n / k$ & NP & NP & $\mathrm{n} / \mathrm{a}$ \\
\hline Thailand & $n / k$ & $\mathrm{n} / \mathrm{k}$ & $\mathrm{n} / \mathrm{a}$ & $\mathrm{n} / \mathrm{a}$ \\
\hline The Philippines & $n / k$ & $\mathrm{n} / \mathrm{k}$ & $\mathrm{n} / \mathrm{k}$ & $n / k$ \\
\hline USA & NP & $N N^{c}$ & $N N^{c}$ & PM-N \\
\hline Vietnam & $\mathrm{n} / \mathrm{k}$ & $\mathrm{n} / \mathrm{k}$ & $\mathrm{n} / \mathrm{a}$ & $\mathrm{n} / \mathrm{a}$ \\
\hline
\end{tabular}

$\mathbf{N N}=$ explicitly no pre-marketing approval required, scientific substantiation must be available upon request of the regulatory authority; NOT= pre-marketing notification required for all claims; $\mathbf{N P}=$ no possibility to include additional claims by companies; various claims have been approved by regulatory authority before marketing; $\mathbf{P M}=$ pre-marketing approval required for all claims; PM-N = pre-marketing approval required for claims describing new health effects of nutrients; $\mathbf{n} / \mathbf{a}=$ type of claim prohibited or not described in legislation; $\mathbf{n} / \mathbf{k}=$ authorisation procedure not defined in legislation; ${ }^{\mathbf{a}}=$ including Costa Rica, El Salvador, Guatamala, Honduras, Nicaragua; ${ }^{\mathbf{b}}=$ new claims can only be based on pre-authorised relationships, listed in a register of the SFDA; ${ }^{\mathbf{c}}=$ for dietary supplements pre-marketing notification is required for all claims.

As depicted in table 2 , the authorisation procedure concerning nutrition claims is not explicitly described in most studied jurisdictions. These jurisdictions (except for Brunei Darussalam, Chile, India, Nigeria, Republic of Korea, Russia, Taiwan, the Philippines and Vietnam) list the conditions that nutrition claims have to comply with, but in their pieces of legislation no authorisation procedure for carrying these claims is described ${ }^{(15,18,19,22,23,25,26,28,30-32,35,36,45,48,55-57)}$. Only legislation in China and the USA list the approved claims, without giving the possibility to request approval of new claims $^{(40,41)}$. The requirements for previously approved nutrition claims are listed in legislation or registers of the regulatory bodies. In Europe and Indonesia new nutrition claims (claims which not have been approved for use previously) have to obtain premarketing approval(27,30). Approved nutrient and other function claims are listed in either pieces of legislation or registers of regulatory authorities in Australia/New Zealand, Canada, Central America, Colombia (other function claims only), the EU, Indonesia, Malaysia, Republic of Korea, Singapore and Taiwan ${ }^{(18,22,23,25,27,30,31,35,37,52)}$. These lists do not only describe the conditions the claims have to fulfil, wording of a 
claim is also suggested. These registers are often considered as positive lists, outlining approved claims and their specific conditions ${ }^{(58)}$. In Chile, Ecuador, Hong Kong, Mexico and Thailand, specific conditions for nutrient function claims can be found, but legislation is less explicit upon the suggested wording of claims ${ }^{(24,28,32,44,48)}$. For other function claims such conditions can be found in Chile, Ecuador and Mexico(24,32,44). Other function claims in Europe that are authorised based on proprietary data cannot automatically be used by other companies. A new dossier has to be submitted and authorisation of the claim will be based on the data from this dossier(27).

Most jurisdictions which use a list of claims require pre-marketing approval by the regulatory authority of claims which are not published on the list ${ }^{(22,23,25,27,30,31,35,52)}$. In Australia/New Zealand it is sufficient to notify the regulatory authority about using such a claim, which is also required when using approved claims ${ }^{(18)}$. In the USA, where no requirements for nutrient or other function claims are listed, such notification is requested for claims on dietary supplements only ${ }^{(40)}$. The authority can request to review the scientific substantiation of such a claim, but there is no official pre-marketing approval procedure in place ${ }^{(18,40)}$.

In Argentina, Brazil and Russia, all nutrient function and other function claims have to be approved before use on a food product ${ }^{(15,42,56)}$. This is a specific step in the licensing procedure for these so called 'health foods' in Russia ${ }^{(15,59)}$. Japanese legislation explicitly describes that nutrient function claims do not require pre-marketing approval, where all other function claims have to be approved before use on a product ${ }^{(46,53)}$. The premarketing approval of other function claims in Japan is also part of a licensing system $^{(53)}$. Legislation of Hong Kong, Mexico, South-Africa, Thailand, the Philippines and Vietnam does not describe a specific pre-marketing approval $\left.\right|^{(15,28,32,36,39,48)}$.

Newly established disease risk reduction claims, which are not yet to be found in legislation or registers of the regulatory authority listing positively assessed claims, require pre-marketing approval by the regulatory authority in Australia/New Zealand, Barbados, Canada, Central America, Colombia, Ecuador, Europe, Indonesia, the 
Republic of Korea and the USA ${ }^{(18,19,22,23,25,27,30,40,44,52)}$. In Argentina, Brazil, China, Japan and Singapore all disease risk reduction claims, including previously approved claims, require approval before going on the market ${ }^{(35,42,53,56,60,61)}$. In China, Japan and Singapore, obtaining approval to use a disease risk reduction claim is part of the licensing procedure for so called 'health foods' or 'functional foods'(35,53,60,61). In China and Japan approved claims are found in registers of the regulatory authority, which in China lists the health relationships that can be used for claims which have yet to be approved $^{(53,62)}$. Notification of a disease-risk reduction claim is requested in the USA ${ }^{(40)}$. Legislation of the Philippines does not define the authorisation procedure ${ }^{(38)}$.

The authorisation procedures across the different jurisdictions vary not only in using registers of approved claims or requesting pre-marketing approval, some pieces of legislation explicitly request or prohibit the use of product-specific claims. Productspecific statements (e.g. 'product $X$ helps to maintain normal bone density) imply that a specific food product which carries the claim has a positive physiological effect ${ }^{(11,63)}$. The opposite type of claim is a generic statement (e.g. 'contains calcium, which is needed for the maintenance of normal bone density), based on scientific consensus on a diet-disease or diet-health relationship, which can be used on any product fulfilling specific compositional criteria ${ }^{(11,63)}$. Table 3 outlines whether legislation is sufficiently defined to allow generic statements, product-specific statements or both. 
Chapter 5

Table 3. Generic and product-specific claims.




Table 3 (cont.). Generic and product-specific claims.

\begin{tabular}{|c|c|c|c|c|}
\hline & & Generic claims & Product-specific claims & Not specified \\
\hline $\begin{array}{l}\text { Health } \\
\text { claim }\end{array}$ & $\begin{array}{l}\text { Reduction } \\
\text { of disease } \\
\text { risk }\end{array}$ & $\begin{array}{l}\text { Australia/New Zealand } \\
\text { Brazil } \\
\text { Canada } \\
\text { Central America }{ }^{a} \\
\text { EU } \\
\text { Singapore } \\
\text { The Philippines } \\
\text { USA }\end{array}$ & $\begin{array}{l}\text { China } \\
\text { Japan } \\
\text { Republic of Korea }\end{array}$ & $\begin{array}{l}\text { Argentina } \\
\text { Barbados Chile } \\
\text { Colombia } \\
\text { Ecuador } \\
\text { Indonesia }\end{array}$ \\
\hline
\end{tabular}

${ }^{\mathbf{a}}=$ including Costa Rica, El Salvador, Guatamala, Honduras, Nicaragua; ${ }^{\mathbf{b}}=$ only new health relationships are assessed as product-specific claims, existing/approved health relationships are generic.

All jurisdictions specifying whether product-specific or generic nutrition claims are allowed, require nutrition claims to be generic statements ${ }^{(6,18,22,27,28,31,35,37,38,40,41,48,56,59)}$. It is only in Singapore where product-specific claims are permitted next to generic claims $^{(15)}$.

Russia and Taiwan permit product-specific nutrient function claims and new nutrient function claims in the Republic of Korea are product-specific ${ }^{(15,37,64)}$. The other 12 jurisdictions describing the type of statement permitted authorise generic claims only $(6,18,22,23,27,28,35,37,38,41,48,56)$.

Eight of the reviewed jurisdictions (viz. Australia/New Zealand, Brazil, Canada, Central America, EU, Malaysia, Singapore, The Philippines) approve the use of generic statements for other function claims ${ }^{(18,22,23,27,31,35,38,56)}$. The use of product-specific claims is allowed in China, Japan, Russia and Taiwan ${ }^{(15,37,53,60,61)}$. In the Republic of Korea, claims describing new health effects of nutrients are product-specific claims, whereas other function claims which are already approved for use are generic claims ${ }^{(52)}$.

Australia/New Zealand, Brazil, Canada, Europe, Singapore, the Philippines and the USA require disease risk reduction claims to be generic statements ${ }^{(18,22,27,35,38,40,56)}$. In the Republic of Korea the use of both product-specific and generic claims is allowed, again 
claims describing new health effects are treated as product-specific claims ${ }^{(52)}$. Productspecific reduction of disease risk claims are also permitted in China and Japan ${ }^{(53,60)}$.

\section{Emerging scientific evidence}

In the majority of jurisdictions studied, legislation demands that a health claim must be based on generally accepted scientific evidence. However, in three of the evaluated jurisdictions, i.e. USA, Japan and the Republic of Korea, health claims based on a minority opinion in the scientific community are permitted. Allowing health claims to be based on such a minority opinion or so called 'graded evidence' grants the possibility to use emerging evidence on a health effect induced by a specific food product or component ${ }^{(65)}$. In the USA, emerging scientific evidence is allowed in the substantiation of disease risk reduction claims, which are called qualified or graded health claims $^{(66)}$. The level of scientific evidence substantiating a health claim is indicated by a ranking system with the categories A, B, C and D. Category A may only be used for claims based on generally accepted scientific evidence, thereby reflecting the highest level of evidence. Categories $B, C$ and $D$ reflect the second, third and fourth level of scientific evidence ( $D$ resembling the weakest evidence), and claims must be accompanied by a disclaimer that the claimed effect is substantiated by a lower level of evidence ${ }^{(66-68)}$. In Japan emerging scientific evidence can be used for other function claims, the so-called qualified FOSHU ${ }^{(53)}$. Qualified FOSHU can be approved for an ingredient when the efficacy of the ingredients is suggested but not established yet ${ }^{(6,53)}$. The efficacy is considered to be suggested in different situations, e.g. when the mechanism of action is clear but no randomised controlled trial (RCT) has been performed or no significant effect was shown in an RCT; or when an RCT shows a significant effect without a clarified mechanism of action ${ }^{(6)}$. The statement 'evidence has not necessarily been established' must accompany such a claim ${ }^{(69)}$. Also in the Republic of Korea other function claims can be based on three levels of evidence: convincing, probable and insufficient evidence. The statements of claims based on probable and insufficient evidence must reflect the lower level of evidence for substantiation $^{(70)}$. In other jurisdictions, health claims are required to be based on 
generally accepted scientific evidence or so called consensus in the scientific community upon an effect of consuming an ingredient (e.g. ${ }^{(27,61)}$ ). This requirement resembles the highest level of evidence or the ' $A$ ' rank in the USA.

\section{Discussion}

The growing interest in functional foods has led an increasing number of jurisdictions to propose policies and regulations dealing with these new products and the claims made on effects of these products, to assure both industry and consumer benefits ${ }^{(3,4)}$. Where the evaluated jurisdictions all require the claims to be based on scientific evidence, this paper focusses on the dissimilarities between the reviewed legislation. Differences are shown in the type of claims permitted, the authorisation procedure of claims and use of emerging scientific evidence to substantiate a claim.

\section{Types of claims}

As depicted in table 1 , the studied jurisdictions permit different types of claims. All reviewed legislation permits nutrition claims, where almost half of the jurisdictions do not permit the use of reduction of disease risk claims. Where most jurisdictions do not allow claims to directly refer to diseases, in Canada therapeutic claims are permitted ${ }^{(15)}$. The types of claims permitted throughout the studied jurisdictions are relatively similar, although the definition sometimes differs, e.g. claims labelled as function claims in Canada are considered to be reduction of disease risk claims in other jurisdictions ${ }^{(15)}$.

In spite of the legal differentiation between the types of claims permitted, ranging from nutrition claims, nutrient function claims, other function claims and reduction of disease risk claims, consumers do not always seem to understand this division between claims. Not perceiving these differences between types of claims can be due to cultural differences between consumers, the personal relevance for the consumer, or the fact that all claims describe a link between health and nutrition and such information is processed similarly in the brain ${ }^{(58,71,72)}$. Therefore the effect of legal differentiation 
between the types of claims, as permitted in all studied jurisdictions, can be questioned. Also the effects of prohibiting some claims (as reduction of disease risk claims) when permitting other types of claims can then be challenged. The Codex guidelines to permit nutrition and health claims are seen to be followed closely by newly developed legislation, for example the draft regulation on nutrition and health claims of $\operatorname{India}^{(17)}$. Using Codex guidelines as a basis for legislation should lead to more international harmonisation $^{(5,17)}$. Various other reviewed jurisdictions (as Hong Kong and Thailand) mention following the guidelines, although it is not specified how these recommendations are taken into consideration in the legislative frameworks.

When the guidelines would describe not only the different types of claims with their conditions and recommendations for scientific substantiation, but also include suggestions for application procedures and communication strategies, even more international harmonisation could be attained.

\section{Authorisation procedures}

The studied jurisdictions have various authorisation procedures in place for the different types of claims (table 2), although it is noticeable that not all evaluated jurisdictions explicitly define the authorisation procedures. When defined in legislation, it is shown that for health claims more often pre-market approval of especially newly defined relationships between intake and health outcomes is required. In most jurisdictions however, no approval process is defined for nutrition claims.

\section{Pre-marketing approval}

In most jurisdictions, the conditions which nutrition claims have to fulfil are listed, but no specific approval process to carry a claim on a food product is described. Only US and Chinese legislation explicitly state that no other relationships than the ones listed in specific legislation or registers of the regulatory authority can be used as nutrition claims.

In some jurisdictions nutrient function or other function claims explicitly do not require pre-marketing approval, where in other cases notification of a claim describing a new 
health effect is required (Australia/New Zealand). In most jurisdictions which approve the use of disease risk reduction claims, pre-marketing approval by the regulatory authority is required. Russia, China, Japan and Brazil are therein exceptions by requiring pre-marketing approval for various types of claims, even if similar types of claims are already permitted on the market. This is seen to go hand in hand with the use of a licensing system for functional foods or so called 'health foods' and often with the permission of using product-specific health claims on these products (table 3). Only in Brazil permission is requested for generic claims as well.

When approval of a claim before marketing is requested, the scientific substantiation of a claim is assessed by a regulatory authority or on behalf of such an authority as in Europe by the European Food Safety Authority $(E F S A)^{(27)}$. However, in various jurisdictions not only the scientific substantiation of the claimed effect is considered, but also the safety and efficacy is taken into account. This is explicitly stated in the pieces of legislation of jurisdictions requiring licensing of a product, as in Russia and China. In the USA, the pre-marketing approval process and the need for evidence based on consensus to fully substantiate a claim was considered by the court in Pearson $v$. Shalala to be a violation of an industries' freedom of speech, leading to the possibility of using emerging evidence to substantiate a claim after the following Consumer Health Information for Better Nutrition Initiative in $2003^{(66,73)}$. This issue of qualified health claims is further addressed in the results and the discussion in 'Emerging scientific evidence'.

Requesting pre-marketing approval is seen to be more often required for claims that describe effects more directly related to health outcomes, as disease risk reduction claims. Evidence in literature suggests that claims which have a clearer link with health and preventing diseases are considered to be more persuasive to consumers ${ }^{(71,73,74)}$. Therefore these claims are thought to have a stronger potential to mislead consumers when they are not sufficiently substantiated ${ }^{(71,73,74)}$. As described in the discussion in 'Types of claims' however, consumer research suggests that in spite of a legal differentiation between these claims, consumers are often not capable of 
differentiating between these various types of claims on food products ${ }^{(58,71,72,75)}$. In addition, consumers do not seem to be aware of the approval process for claims prior to marketing, while such an assessment and approval of health claims by an independent organisation is requested by consumers ${ }^{(76)}$. Also, American consumers are sceptical about the truthfulness of nutrition claims, even though these claims are preapproved by the regulatory authority ${ }^{(77)}$. Although the idea of a stricter approval procedure for claims with higher probability to result in consumer misleading when they are not sufficiently substantiated is understandable, the issues that consumers (i) do not distinguish between the different types of claims and (ii) are mostly unaware of the approval procedure, result in the question whether these stricter approval procedures for mostly other function claims and reduction of disease risk claims lead to higher consumer protection.

Another issue arising with the requirement for pre-marketing approval is the burden for both industry and authorities reviewing the proposed claim. Since the approval of a claim is highly uncertain and the substantiation procedure requires much time and resources, the industry has little incentives to request a claim ${ }^{(13,78-81)}$. The competent authorities reviewing claims are shown to have difficulties processing all requests, as exemplified by both the situation in Europe as well as the USA: in Europe, the high amount of proposed claims $(>44,000)$ for EFSA to review, led to a very slow assessment procedure due to an increased workload ${ }^{(58,82)}$. The FDA pre-marketing approval process of health claims in the USA is reduced to a 'policy of non-enforcement' ${ }^{\prime(77)}$.

\section{Positive list}

Several evaluated jurisdictions list the permitted claims or the requirements for claims. The use of such a positive list could stimulate the use of these permitted claims, by giving a clear overview of which claims are permitted and how these claims should be used ${ }^{(58)}$. However, the incentive for the industry to conduct research could be diminished as possibilities to make use of those already approved claims exists ${ }^{(15)}$. 


\section{Generic versus product-specific claims}

Many jurisdictions in this paper are shown to permit generic claims. Only in Russia, Japan, China, Taiwan, Republic of Korea and Singapore some product-specific claims are allowed on food products. In literature the use of generic claims is suggested to be disadvantageous for firms, since the approved claims can not only be used by the industrials performing the research; competitors are also able to use the claim on their product, which creates a free rider problem ${ }^{(15,73,83)}$. Research on nutrition and health claim legislation suggests that using product-specific claims could protect against this free rider problem and could stimulate investments and expenditures on research and development ${ }^{(15,83)}$. For consumers however it could be beneficial to permit the use of generic claims, so more food products will carry a claim and more potential health benefits are visible for consumers ${ }^{(15)}$. Even though the scientific standard is similar for generic and product-specific claims, the type of evidence on which these claims are based can be different ${ }^{(11,14,63)}$. From a theoretical point of view, generic claims are based on generally accepted knowledge and therefore do not require additional studies proving the effect in a human setting, where product-specific claims need scientific substantiation from human intervention studies with the specific product ${ }^{(11,63,84)}$. However, it is shown that in several jurisdictions as the EU, USA and Australia/New Zealand also generic claims require such human studies to substantiate a claim ${ }^{(58,84)}$.

\section{Emerging scientific evidence}

Only three of the twenty-eight reviewed jurisdictions (Japan, the Republic of Korea and the United States of America) allow health claims to be based on emerging scientific evidence or the so-called minority opinion. All claims supported by such a lower level of substantiating evidence must reflect this by carrying some type of disclaimer. These graded health claims are permitted with a view to stimulating firms to perform research and accurately market the benefits of functional ingredients; and to help consumers prevent diseases and improve their health by making informed decisions based on accurate information ${ }^{(75,85)}$. For the industry, the approval of graded health claims decreases the length and strictness of the approval process ${ }^{(75)}$. It gives the opportunity 
to get a product to market more quickly and thereby enhances the possibilities for food industries to grow and compete internationally ${ }^{(3,75)}$. However, the effect of graded health claims on consumers seems to be less positive: various studies show that consumers are not able to distinguish between the graded claims with qualifying language and health claims without qualifying language $\mathrm{e}^{(3,58,67,75,86)}$. It could therefore be interesting to focus on using emerging scientific evidence as substantiation for claims that influence a consumer's perception of health less directly, as is suggested for nutrition claims. Thereby emerging scientific evidence will have a lower probability to mislead consumers. Currently however this emerging evidence is only possible to be used in other function and disease risk reduction claims, claims which can be considered to have a larger effect on consumers since they are more directly related to health effects. Although the use of newly obtained scientific evidence could be beneficial for health by creating the opportunity to inform consumers about health benefits of certain products, consumers should be protected against misleading statements.

\section{Conclusion}

This paper reviews legislation on nutrition and health claims of 28 jurisdictions and puts these findings in a broader perspective by addressing consumer and industry issues. Several differences arise in the approach of the various pieces of legislation, with main differences found in (i) the types of nutrition and health claims permitted, (ii) the approval procedure of claims and (iii) the use of emerging scientific evidence.

Since the different types of nutrition and health claims permitted or prohibited in the various jurisdictions do not seem to elicit differing consumer responses according to consumer studies, it can be questioned whether a strict legal separation between the types of claims is required. 
The approval procedures related to these types of claims are seen to depend upon the use of a licensing system and the use of registers or lists with the permitted claims or requirements for claims published in either legislation or by regulatory bodies. In a licensing system often product-specific claims are permitted following pre-marketing approval, lists with requirements or approved claims often deal with generic statements. In most jurisdictions only claims which describe new relationships between intake of nutrients and a health effect, which have not been published on such lists or in any legislation, are subject to pre-marketing approval by the regulatory authority. The use of a positive list with permitted claims could increase the availability of claims on the market, because companies can easily use a claim from the permitted list on their product. This should be positive for consumers, since they are more exposed to health messages on products.

The allowance of generic claims could stimulate the industry less than product-specific claims to innovate, since a company obtaining the claim is not the only one able to use it. However, it again could lead to an increased use and exposure of claims for consumers. The impact on innovation of these different types of claims should be reviewed to see which approach would have most positive effects. The need for premarketing approval is designed to protect consumers from misleading, by assuring the substantiation of a claim is generally accepted in the scientific community before the product is placed on the market. However, the process creates a high burden for industry and authorities reviewing substantiation which could be disproportionate for claims which are expected to have less effect on a consumer's willingness to buy. Although pre-marketing approval is in most jurisdictions more often required for claims more easily related to health (as other function or disease risk reduction claims), when consumers are not able to perceive differences between the various types of claims and do not realise that these claims are assessed upon their scientific evidence, the effect of such an approval process can be questioned. Therefore, not only more information is required upon the effects of the different types of claims on consumers, also the idea of pre-marketing approval should mainly be used when a false claim could 
have high impact on consumers, so when proposed health benefits have a high probability to result in a positive effect on health. From a scientific perspective, higher probability requires relatively more prove, whereas lower probability (with inherent a lower consumer misleading effect) would require less substantiation. This should be incorporated throughout the different jurisdictions. This is directly related to the use of emerging or graded evidence, which is suggested to be positive for industry, innovation and even consumers. The Japanese system is most transparent in the reasons for allowing specific evidence to substantiate a claim, still requesting some type of evidence to support the communicated effect. The use of emerging evidence is currently possible for other function and reduction of disease risk claims in legislation approving some kind of grading. However, this emerging evidence might be more suitable in the substantiating nutrition claims, since the possibility to mislead consumers could be less and innovation will still be simulated. At this moment however insufficient information is available on the effects on consumers of using emerging scientific evidence in communicating health benefits via claims.

The studied legislative documents show critical differences and although various approaches have positive points, no optimal approach to regulate nutrition and health claims has been implemented yet. Although more consumer research upon the perception of the different types of claims is required, it would be preferable to permit similar types of claims throughout jurisdictions, permit the use of emerging evidence for claims having a lower probability to mislead consumers (as nutrition claims) and to require pre-marketing approval of claims with higher impact. The efforts of the Codex Alimentarius Committee to internationally harmonise the handling of nutrition and health claims should be leading in all developments and improvements of legislation, to stimulate work of the industry in the field of functional foods and to enhance the opportunity for consumers to use health-enhancing products. 


\section{References}

1. Diplock AT, Aggett PJ, Ashwell M, et al. (1999) Scientific Concepts in Functional Foods in Europe: Consensus Document. Br. J. Nutr. 81, S1-S28.

2. Howlett J (2008) Functional foods: from science to health and claims. Brussels: ILSI Europe.

3. Lalor F \& Wall PG (2011) Health claims regulations: Comparison between USA, Japan and European Union. Br. Food J. 113, 298-313.

4. Moors EHM (2012) Functional foods: regulation and innovations in the EU. Innovation 25, 424-440.

5. Jones PJH, Asp N-G \& Silva P (2008) Evidence for health claims on foods: how much is enough? Introduction and general remarks. J. Nutr. 138, 1189S-1191S.

6. Ohama $\mathrm{H}$, Ikeda $\mathrm{H} \&$ Moriyama $\mathrm{H}$ (2006) Health foods and foods with health claims in Japan. Toxicology 221, 95-111.

7. Euromonitor International (2015) Fortified/Functional Packaged Food in the Netherlands.

8. Euromonitor International (2015) Fortified/Functional Packaged Food - Worldwide Historic Growth (2009-2014).

9. Euromonitor International (2015) Fortified/Functional Packaged Food - Worldwide Growth Forecast (2014-2019).

10. Aschemann-Witzel J \& Hamm U (2010) Do consumers prefer foods with nutrition and health claims? Results of a purchase simulation. J. Mark. Commun. 16, 47-58.

11. Jew S, Vanstone CA, Antoine J-M, et al. (2008) Generic and product-specific health claim processes for functional foods across global jurisdictions. J. Nutr. 138, 1228S-1236S.

12. Kwak N \& Jukes DJ (2000) Current international approaches to food claims. Nutr. Rev. 58, 370-377.

13. Lalor F \& Wall PG (2013) Making and justifying health claims. Int. J. Dairy Technol. 66, 321-324.

14. Richardson DP, Affertsholt T, Asp N-G, et al. (2003) PASSCLAIM-Synthesis and review of existing processes. Eur. J. Nutr. 42, 96-111.

15. Malla S, Hobbs JE \& Sogah EK (2013) Functional Foods and Natural Health Products Regulations in Canada and Around the World: Nutrition Labels and Health Claims. Saskatchewan: Canadian Agricultural Innovation and Regulation Network.

16. Hawkes C (2004) Nutrition labels and health claims: the global regulatory environment. Geneva: World Health Organization.

17. Codex Committee on Food Labelling (2013) Guidelines for Use of Nutrition and Health Claims (CAC/GL 23-1997). Rome: Codex Alimentarius.

18. Food Standards Australia New Zealand (2014) Standard 1.2.7 Nutrition, Health and Related Claims. F2013L00054.

19. Global Agricultural Information Network (2011) TCB1126 - Barbados Food and Agricultural Import Regulations and Standards - Narrative. Washington D.C.: United States Department of Agriculture Foreign Agricultural Service.

20. Giudice C (2013) Brazil works on new rules for functional and health claims. http://www.eas.eu/News_Item/3023 (accessed November 2014). 
21. Ministry of Health (2001) Public Health (Food) Act. vol. S80/00. Brunei Darussalam: Negera Brunei Darussalam Government.

22. Government of Canada (2013) Food and Drug Regulations. Ottawa: Government of Canada.

23. Consejo de Ministros de Integración Económica Centroamericana (2012) Reglamento Técnico Centroamericano RTCA 67.01.60:10 - Etiquetado Nutricional de Productos Alimenticios Preenvasados para Consumo Humano para la población a partir de 3 años de edad [unofficial translation]. Guatamala: Consejo de Ministros de Integración Económica Centroamericana.

24. Ministry of Agriculture, Agricultural and Livestock Service (2006) Food Law Chile Title II Food (II): Labelling and Advertising [unofficial translation]. Santiago: Republic of Chile.

25. Ministerio de la Protección Social (2008) Resolucion 288 [unofficial translation]. vol. 46.894. Bogotá: Government of Colombia.

26. Republic of Ecuador (2011) Rotulado de productos alimenticios para consumo humano. Parte 2. Rotulado nutricional. Requisitos [unofficial translation]. Quito: Republic of Ecuador.

27. European Parliament and Council of the European Union (2006) Regulation (EC) No 1924/2006 of the European Parliament and of the council of 20 December 2006 on nutrition and health claims made on foods. OJ L 404 49, 9-25.

28. Centre for Food Safety (2008) Technical Guidance on Nutrition Labelling and Nutrition Claims. Hong Kong: Hong Kong Centre for Food Safety.

29. Zawistowski J (2011) Legislation of functional foods in Asia. In Functional Foods Concept to Product, 2nd ed., pp. 73-108 [Saarela M, editor]. Cambridge: Woodhead Publishing.

30. National Agency of Drug and Food Control (2011) Regulation HK.03.1.23.11.11.09909 (2011) on the Control of Claims on Processed Food Labeling and Advertisements. Jakarta: Republic of Indonesia.

31. Ministry of Health (2013) Malaysian Dietary Guidelines - Key Message 14. Putrajaya: Federal Government Malaysia.

32. Secretaría de Economia (2010) Mexican Official Norm NOM-051-SCFI/SSA1-2010 [unofficial translation]. Mexico City: Federal government of Mexico.

33. National Agency for Food and Drug Administration and Control (2005) Pre-Packaged Food (Labelling) Regulations. Abuja: Ministry of Health Nigeria.

34. Ministry of Food and Drug Safety (2011) Food Sanitation Act. Seoul: Republic of Korea.

35. Agri-Food \& Veterinary Authority of Singapore (2015) A Guide to Food Labelling and Advertisements. Singapore: Agri-Food \& Veterinary Authority of Singapore; http://www.ava.gov.sg/NR/rdonlyres/B96B0EC2-1D1E-4448-9C25-

ABD8470D2BF4/26937/AGuidetoFoodLabellingandAdvertisementsVersionSepte.pdf (accessed April 2015).

36. Department of Health (2010) Regulations relating to the labelling and advertising of foodstuffs. vol. No. R. 146. Cape Town: Republic of South Africa.

37. Food and Drug Administration Taiwan (2012) Regulations for Application of Health Food Permit. 
Taipei:https://consumer.fda.gov.tw/Law/Detail.aspx?nodeID=518\&lang=1\&lawid=160 (accessed April 2015).

38. Bureau of Food and Drugs (1984) Administrative Order No. 88-B s. 1984. Manila: Republic of the Philippines, Ministry of Health.

39. Ministry of Health (2013) Circular on the advertisements for the foods under the management of the Ministry of Health. Hanoi: Socialist Republic of Vietnam.

40. Food and Drug Administration (2013) Code of Federal Regulations Title 21, Chapter 1, Subchapter B - Food for Human Consumption. Washington D.C.: Federal Government of the United States.

41. People's Republic of China (2011) National Food Safety Standard for nutiriton labelling of prepackaged foods (GB 28050-2011). Bejing: People's Republic of China.

42. Ministerio de Salud (2011) Disposición No 7730 [unofficial translation]. Buenos Aires: Government of Argentina.

43. Da Silveira TFV, de Mello Vianna CM \& Mosegui GBG (2009) Brazilian legislation for functional foods and the interface with the legislation for other food and medicine classes: contradictions and omissions. Physis Rev. Saúde Coletiva 19, 1189-1202.

44. Republic of Ecuador (2011) Rotulado de productos alimenticios para consumo humano. Parte 3. Requisitos para declaraciones nutricionales y declaraciones saludables [unofficial translation]. Quito: Republic of Ecuador.

45. Chan P (2011) Regulations and Guidelines Relating to Functional Foods in South-East Asia. New Delhi: ILSI India.

46. Ministry of Health Labour and Welfare \& Japan (2015) Food with Nutrient Function Claims (FNFC). http://www.mhlw.go.jp/english/topics/foodsafety/fhc/01.html (accessed April 2015).

47. Global Agricultural Information Network (2012) Nigeria Food and Agricultural Import Regulations and Standards - Narrative. Washington D.C.: United States Department of Agriculture Foreign Agricultural Service.

48. Ministry of Public Health (1998) Notification of the Ministry of Public Health. Re: Nutrition Labelling. Bangkok: Government of Thailand.

49. Food Safety and Standards Authority of India (2012) Draft 'Regulation on Labelling (Claims)'. New Delhi: Government of India.

50. Gautier C (2012) Food Health Claims: Challenges for ASEAN Manufacturers. http://www.tilleke.com/resources/food-health-claims-challenges-asean-manufacturers (accessed April 2015).

51. Public Health and Municipal Services Ordinance (2008) Food and drugs (composition and labelling) regulation 2008. vol. FH CR 1/18. Hong Kong: Hong Kong Government.

52. Ministry of Food and Drug Safety (2010) Health Functional Foods Act. vol. 101219. Seoul: Republic of Korea.

53. Ministry of Health Labour and Welfare \& Japan (2015) Food for Specified Health Uses (FOSHU). http://www.mhlw.go.jp/english/topics/foodsafety/fhc/02.html (accessed April 2015).

54. Health Canada (2015) Health Claim Assessments. http://hc-sc.gc.ca/fn-an/labeletiquet/claims-reclam/assess-evalu/index-eng.php (accessed April 2015). 
55. Baccino F (2012) Argentina's Case. Food labeling in Latin America: How far is the new boom region when it comes to its own national markets? http://foodlawstrategies.wordpress.com/2012/07/09/argentinas-case-food-labeling-inlatin-america-how-far-is-the-new-boom-region-when-it-comes-to-its-own-nationalmarkets/ (accessed February 2014).

56. Stringueta PC, do Amaral M da PH, Brumano LP, et al. (2012) Public Health Policies and Functional Property Claims for Food in Brazil. In: Structure and Function of Food Engineering [Amer Eissa AH, editor]. InTech.

57. Ministry of Health Labour and Welfare \& Japan (2015) Food with Health Claims, Food for Special Dietary Uses, and Nutrition Labeling http://www.mhlw.go.jp/english/topics/foodsafety/fhc/ (accessed April 2015).

58. Verhagen H, Vos E, Francl S, et al. (2010) Status of nutrition and health claims in Europe. Arch Biochem Biophys 501, 6-15.

59. Global Agricultural Information Network (2011) RS1168 - Russian Federation Food and Agricultural Import Regulations and Standards - Narrative. Washington D.C.: United States Department of Agriculture Foreign Agricultural Service.

60. People's Republic of China (1997) Health Food Standard (Functional Foods) (GB 167401997).

61. State Food and Drug Authority (2005) Interim Regulations on the Registration of Health Foods (SFDA Regulation; Order No.19).

62. China Food and Drug Administration (2015) 27 Categories of health functions claims approved by SFDA. http://www.sfdachina.com/info/86-1.htm (accessed April 2015).

63. Asp N-G (2002) Health claims within the Swedish Code. Generic claims and productspecific physiological claims in relation to current European and international developments. Scand. J. Nutr. 46, 131-136.

64. Kim JY, Kim DB \& Lee HJ (2006) Regulations on health/functional foods in Korea. Toxicology 221, 112-118.

65. U.S. Food and Drug Administration (2003) Claims That Can Be Made for Conventional Foods and Dietary Supplements. http://www.fda.gov/Food/IngredientsPackagingLabeling/LabelingNutrition/ucm111447 .htm (accessed April 2015).

66. U.S. Food and Drug Administration (2003) Consumer Health Information for Better Nutrition Initiative: Task Force Final Report http://www.fda.gov/Food/IngredientsPackagingLabeling/LabelingNutrition/ucm096010 .htm (accessed April 2015).

67. Hasler CM (2008) Health claims in the United States: an aid to the public or a source of confusion? J. Nutr. 138, 1216S-1220S.

68. Kavanaugh CJ, Trumbo PR \& Ellwood KC (2007) The US Food and Drug Administration's evidence-based review for qualified health claims: tomatoes, lycopene, and cancer. J. Natl. Cancer Inst. 99, 1074-1085.

69. Yamada K, Sato-Mito N, Nagata J, et al. (2008) Health claim evidence requirements in Japan. J. Nutr. 138, 1192S-1198S. 
70. Food and Drug Administration (2007) Regulation on Approval of Functional Ingredient for Health Functional Food. Seoul: Republic of Korea.

71. Verbeke W, Scholderer J \& Lähteenmäki L (2009) Consumer appeal of nutrition and health claims in three existing product concepts. Appetite 52, 684-692.

72. Williams $P$ (2005) Consumer understanding and use of health claims for foods. Nutr Rev 63, 256-264.

73. Silverglade BA (1996) The Nutrition Labeling and Education Act: Progress to date and challenges for the future. J. Public Policy Mark. 15, 148-150.

74. Katan MB (2004) Health claims for functional foods: regulations vary between countries and often permit vague claims. Br. Med. J. 328, 180.

75. Hooker NH \& Teratanavat R (2008) Dissecting qualified health claims: evidence from experimental studies. Crit. Rev. Food Sci. Nutr. 48, 160-176.

76. Gray N (2013) Most consumers don't know what EFSA is, experts find. http://www.nutraingredients.com/Consumer-Trends/Most-consumers-don-t-knowwhat-EFSA-is-experts-find (accessed April 2015).

77. DeVeau TM (2012) Naturally Confusing Consumers: Express Federal Preemption of State Claims regarding False and Misleading Food Product Labels. Kentucky J. Equine, Agric. Nat. Resour. Law.

78. Bremmers HJ, van der Meulen BMJ \& Purnhagen K (2013) Multi-stakeholder responses to the European Union health claims requirements. J. Chain Netw. Sci. 13, 161-172.

79. Coppens P (2007) The Impact of the Nutrition and Health Claims Regulation on the Food Industry. EFFL. 2/2007, 67-75.

80. De Boer A \& Bast A (2015) Stakeholders' perception of the nutrition and health claim regulation. Int. J. Food Sci. Nutr. 66(3), 321-328.

81. Hagenmeyer M (2006) Health Claims meet Bureaucracy. EFFL. 4/2006, 233-240.

82. Ernst \& Young (2012) External Evaluation of EFSA - Final Report.

83. Urala N, Arvola A \& Lähteenmäki L (2003) Strength of health-related claims and their perceived advantage. Int. J. Food Sci. Technol. 38, 815-826.

84. Asp N-G \& Bryngelsson S (2008) Health claims in Europe: new legislation and PASSCLAIM for substantiation. J. Nutr. 138, 1210S-1215S.

85. Crowe KM \& Francis C (2013) Position of the academy of nutrition and dietetics: functional foods. J. Acad. Nutr. Diet. 113, 1096-1103.

86. Kapsak WR, Schmidt D, Childs NM, et al. (2008) Consumer perceptions of graded, graphic and text label presentations for qualified health claims. Crit. Rev. Food Sci. Nutr. 48, 248256. 



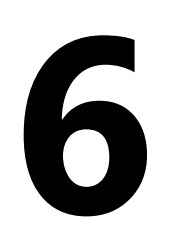

The effect of dietary

components on inflammatory

lung diseases - a literature

review

Alie de Boer, Wouter R.P.H. van de Worp, Geja J.

Hageman, Aalt Bast 
Chapter 6

\section{Abstract}

Anti-inflammatory treatment in chronic inflammatory lung diseases usually involves glucocorticosteroids. With patients suffering from serious side effects or becoming resistant, new treatment options are required and nutrition is suggested to positively influence disease progression. We used the dietary inflammatory index to calculate effects of dietary components on inflammation and lung function in order to identify most potent dietary components. 162 articles describing the effects of dietary intake on asthma, COPD, sarcoidosis or IPF or models reflecting these diseases were included. The intake of EGCG, n-3 PUFAs, probiotics and vitamin E intake showed most convincing evidence of beneficial effects on inflammatory and immunological markers, caffeine, n-3 PUFAs, vitamin $C$ and vitamin $E$ intake most positively affected lung function in chronic inflammatory lung diseases. The effects of $n-3$ PUFAs and vitamin $E$ on lung function can at least partially be explained by their anti-inflammatory effect. This allocation is also suggested for the effects of probiotics and vitamin C, but is less obvious for caffeine and EGCG intake. Many other dietary components showed only small or no effects on inflammation and/or lung function, although the number of weighted studies was often too small for a reliable assessment. We conclude that optimal beneficial dietary elements might reduce the required amounts of antiinflammatory treatments, thereby decreasing both side effects and development of resistance as to improve quality of life of patients suffering from chronic inflammatory lung diseases. 


\section{Introduction}

Lung diseases including asthma, chronic obstructive pulmonary disease (COPD) and interstitial lung diseases (ILD) such as sarcoidosis and idiopathic pulmonary fibrosis (IPF) are characterised by chronic inflammation ${ }^{(1-4)}$. Glucocorticosteroids are considered to be the mainstay in anti-inflammatory treatment for various inflammatory diseases, including these lung diseases ${ }^{(5,6)}$. However, some patients show no response to these drugs and the use of glucocorticosteroids was shown to cause serious side effects $^{(3,5,6)}$. Preventing such resistance and enhancing the effectiveness of glucocorticosteroids with nutrition presents an interesting opportunity for treatment of these chronic inflammatory lung diseases.

Inflammation, the immediate response in tissue to injury, pathogen infiltration or irritants, is characterised by redness, swelling, heat, pain and loss of function ${ }^{(4,7,8)}$. When tissue is affected, chemical signals initiate activation and migration of leukocytes (neutrophils, monocytes and eosinophils) from the venous system to the damaged site and extracellular matrix. Following activation of adhesion molecules within the vascular endothelium, leukocyte integrins are triggered to be activated and upregulated. On the surface of the vascular endothelium the attracted neutrophils are immobilised, which are enabled to transmigrate to sites of injury ${ }^{(7)}$. The progress of inflammation is shaped by chemotactic cytokines (chemokines) as TNF- $\alpha$ and TGF- $\beta 1$, which stimulate monocyte migration to the injured tissue. These monocytes are involved in tissue repair, and defence mechanisms involve phagocytosis, the production of reactive oxygen species, and elimination of the pathogen as well as of cellular and tissue debris $^{(7-9)}$. The inflammatory response may also affect healthy tissue and is therefore tightly controlled by the production of anti-inflammatory cytokines to terminate the process when the injury is repaired ${ }^{(7,9,10)}$. When the process is not ended correctly due to either persistence of pro-inflammatory cytokines, failure or incomplete actions of anti-inflammatory cytokines or even persistence of these anti-inflammatory cytokines, inflammation can result in chronic inflammation ${ }^{(4,7,9,10)}$. 
With inflammation being a key factor in the aetiology of asthma, COPD, sarcoidosis and IPF, other aspects distinguish these diseases. COPD is characterised by a poorly reversible and usually progressive airflow limitation as a result of fixed narrowing of small airways, emphysema and luminal obstruction ${ }^{(5,11)}$. In COPD, the parenchymal cells of the lungs are affected by inflammation, resulting in decreased airflow ${ }^{(4,5)}$. Asthma is typified by chronic inflammation of the airways only, with variable and widespread episodes of airway hyper-responsiveness leading to shortness of breath, wheezing, chest tightness and coughing due to chronic inflammation ${ }^{(4,5,12)}$. ILD refers to a group of over 200 pulmonary diseases which are characterised by inflammation and fibrosis of the septal interstitium of the lungs, next to inflamed alveoli and distal airways ${ }^{(3,13)}$. Two of the more common diseases of this group are sarcoidosis and idiopathic pulmonary fibrosis (IPF) ${ }^{(3)}$. Sarcoidosis is characterised by granuloma in multiple organs following from inflammation, but most frequently affects the lungs and the lymphatic system $^{(14)}$. IPF is a chronic disorder where fibrotic tissue accumulates in the lungs ${ }^{(3,15,16)}$. Following inflammation, injury in the lungs results in progressive collagen accumulation, leading to breathing difficulties and finally resulting in respiratory failure $\mathrm{e}^{(3,15-17)}$.

Since inflammation is a key factor in chronic lung diseases as described above, antiinflammatory therapies have been widely explored. Glucocorticoids are the mainstay in anti-inflammatory therapy. Glucocorticosteroids bind to the glucocorticosteroid receptor (GR) in the cytoplasm after diffusion across the cell membrane, which is translocated to the nucleus following activation by ligand binding ${ }^{(6)}$. Glucocorticosteroids bind to the glucocorticoid response element (GRE) in the promotor region of glucocorticoid-responsive genes. This results in gene transcription leading to the inactivation of numerous activated inflammatory genes ${ }^{(6)}$. The antiinflammatory effect of GRs is also thought to be caused by various indirect effects, such as the interference with inflammatory transcription factors which normally activate gene expression through binding to their promotor sites, or by inducing inhibitors of transcription factors ${ }^{(1)}$. Studies into resistance to glucocorticosteroids in mainly asthma 
patients have led to the identification of six possible molecular mechanisms contributing to this resistance: (i) genetic susceptibility; (ii) GR modification due to phosphorylation, nitrosylation or ubiquitination altering their binding affinity; (iii) increased GR $\beta$ expression or disruption of $G R \alpha$; (iv) increased activation of proinflammatory transcription factors (e.g. AP1, JNK), preventing interaction of GR with GRE and other transcription factors due to binding to the GR; (v) abnormal histone acetylation leading to no transactivation of genes; or (vi) increased P-glycoprotein transporting drugs out of cells ${ }^{(6)}$.

Since oxidative stress is one of the factors affecting histone acetylation, it is suggested to contribute to glucocorticosteroid resistance by suppressing the anti-inflammatory effect of the drug ${ }^{(6,18)}$. Antioxidants can prevent this resistance, as was demonstrated in vitro with cocoa-derived epicatechin which was able to reduce cortisol resistance and protect the anti-inflammatory effects of dexamethasone ${ }^{(18,19)}$. The role of nutrition in inflammatory diseases has been indicated more often in research: a diet rich in fruit, vegetables, cereals and fish (the so called prudent dietary pattern) was associated with a lower risk on COPD whereas a higher risk was associated with consumption of a Western diet (rich in refined grains, preserved meat, potatoes and sweets) ${ }^{(20,21)}$. Other studies showed a protective effect on oxidative processes and inflammation by different dietary components as fruit and vegetables, flavonoids, vitamin C, vitamin $E_{\text {, }}$ $\beta$-carotene, fatty acids and various minerals ${ }^{(22-24)}$. The link between oxidative stress and several inflammatory lung diseases suggests a pivotal role for nutrition in their treatment $^{(22)}$.

This study therefore focussed on the effects of dietary components (including nonnutrients, nutrients, food items and diets) on inflammatory and immunological markers and respiratory function in chronic inflammatory lung diseases described above. Since this study aims to stimulate further research into dietary components which affect inflammation and/or function, all types of research - ranging from in vitro experiments to human trials - were included. Following the dietary inflammatory index as described 
by Shivappa et al. in 2014, an inflammatory and respiratory effect score was calculated to identify potent dietary components in the treatment of chronic inflammatory lung diseases $^{(25)}$.

\section{Methods}

The dietary inflammatory index developed by Cavicchia et al. (2009) and optimised by Shivappa et al. (2014) measures the inflammatory effect of nutrients, relating it to the total dietary intake based on food consumption data ${ }^{(25,26)}$. The dietary inflammatory index was developed to score the overall effect of diet on inflammation ${ }^{(25,26)}$. With the index, the diet of an individual can be scored on a scale from maximally antiinflammatory (with a score of -1 ) up to maximally pro-inflammatory (with a score of +1 ) by taking into account all potential dietary components affecting inflammation ${ }^{(25,26)}$. In the optimised dietary inflammatory index developed by Shivappa et al., the individual intake was compared with referent intakes provided by different food consumption data sets ${ }^{(25)}$.

The dietary inflammatory index and its scoring system were the starting point for this literature review focussing on the effects of dietary components on inflammatory lung diseases. With the aim of this study being to identify components which can influence chronic inflammatory lung diseases and their underlying inflammatory processes, different experimental setups (such as in vitro studies, animal studies, observational studies and intervention trials) with potential varying quality of studies were required. The dietary inflammatory index provided a tool to score the effects found in these different studies.

\section{Literature review strategy}

Various search engines were used (Google Scholar $\AA$, Pubmed $\AA$, Science Direct ${ }^{\circledR}$ ) to identify peer-reviewed studies published in English on the effects of single (non)nutrients or whole diet on lung function or inflammatory markers in chronic 
inflammatory lung diseases. In the search strategy the four diseases were combined with terms for nutrition (nutrients, diet, whole diet, nutrition) and 'anti-inflammatory'. Cancer was explicitly excluded in the search strategy, as well as reviews since only original research was used to calculate the effects of nutrition on these lung diseases.

In total, 1206 articles were screened (figure 1). Studies were included when they studied one of the four diseases or models resembling these diseases and when studying either markers of lung function (forced expiratory volume in 1 second (FEV 1 ), forced vital capacity (FVC), $\mathrm{FEV}_{1} / \mathrm{FVC}$ ratio, forced expiratory flow (FEF) peak expiratory flow (PEF)) or inflammatory and immunological markers (pro-inflammatory: Interleukin (IL)-1 $\beta$, IL4 in asthma, IL-5, IL-6, IL-8, tumour necrosis factor (TNF)- $\alpha$, Leukotriene (LT) $B_{4}$ and/or C-reactive protein (CRP); anti-inflammatory: IL-4 and IL-10) and models (type 1 helper T cells $\left(\mathrm{Th}_{1}\right) /$ type 2 helper $\mathrm{T}$ cells $\left(\mathrm{Th}_{2}\right)$ ratio; influx of immune/inflammatory cells in lung). Studies were excluded when they studied: (i) other inflammation-associated diseases (such as CVD); (ii) other lung diseases (e.g. cystic fibrosis, rhinitis); (iii) effects of intake or exposure to substances other than well-defined dietary components (as drugs, environmental agents, herbal extracts); and (iv) nutrition status or plasma levels of dietary components instead of intake (as vitamin D status). Last, articles focussing on disease prevalence, incidence or occurrence were excluded leading to 162 included articles. 


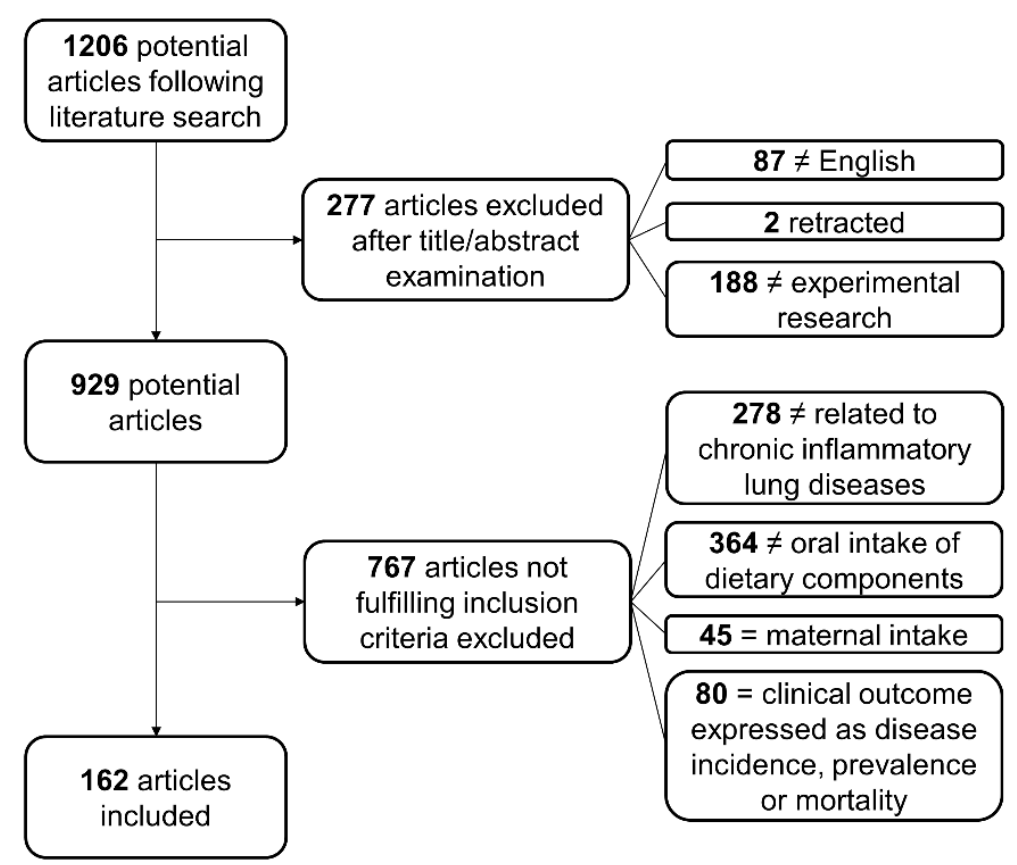

Figure 1. Flow chart literature review.

\section{Scoring algorithm}

Included articles were scored based on (i) the outcome and (ii) the design of the study. Following the set-up of the dietary inflammatory index, the outcomes were labelled as ' +1 ' when showing a pro-inflammatory effect or a decrease in lung function, ' -1 ' with anti-inflammatory effects or improved lung function and ' 0 ' when no significant effect of the dietary component was reported ${ }^{(25)}$. Scores were checked for consistency by all authors. When more effects (as independent intake of different dietary components) were described in one study or multiple methods were used (as in vitro and animal models), all effects were taken into consideration in the calculation of the final effect by weighing the study more than once. The second step was weighing the studies based on their design, which resulted in a specific amount of credits (table 1). 
Table 1. Study design weights (adapted from ${ }^{(25)}$ ).

\begin{tabular}{|l|l|l|}
\hline Type of study & Study design & Credits \\
\hline Human & Experimental & 10 \\
\hline & Prospective cohort & 8 \\
\hline & Case-control & 7 \\
& Ex vivo experimental & 7 \\
\hline & Cross-sectional & 6 \\
\hline Animal & Experimental & 5 \\
\hline Cell culture & Experimental & 3 \\
\hline
\end{tabular}

Subsequently, the dietary component-specific effect score was calculated as follows: (i) the credits attributed to the weighted pro- and anti-inflammatory studies were divided by the weighted number of studies and (ii) the anti-inflammatory fraction was subtracted from the pro-inflammatory fraction (as exemplified in figure 2). As previously done in calculating the dietary inflammatory index, the median of the total credits across all dietary components was used as a cut-off point to indicate the literature pool ${ }^{(25)}$. When the number of weighted articles was below the cut-off point of 15 (inflammation) or 10 credits (lung function), the score was adjusted: the credits were divided by 15 or 10 and subsequently multiplied by the dietary componentspecific effect score following from the first two steps ${ }^{(25)}$. 


\begin{tabular}{|c|c|c|c|c|}
\hline Effect & Study design & Number of articles & Credits & Fraction \\
\hline \multirow{8}{*}{$\begin{array}{l}\text { Anti- } \\
\text { inflammatory }\end{array}$} & Experimental & $8 \times 10=$ & 80 & $91: 119$ \\
\hline & Cohort & 0 & 0 & $=0.723$ \\
\hline & Case-control & 0 & 0 & \\
\hline & Ex vivo & 0 & 0 & \\
\hline & Cross-sectional & $1 \times 6=$ & 6 & \\
\hline & Animal & $1 \times 5=$ & 5 & \\
\hline & In vitro & 0 & 0 & \\
\hline & Total & 10 & 91 & \\
\hline \multirow{8}{*}{\begin{tabular}{|l|} 
Pro- \\
inflammatory
\end{tabular}} & Experimental & 0 & 0 & 5:119 \\
\hline & Cohort & 0 & 0 & $=0$ \\
\hline & Case-control & 0 & 0 & \\
\hline & Ex vivo & 0 & 0 & \\
\hline & Cross-sectional & 0 & 0 & \\
\hline & Animal & $1 \times 5=$ & 5 & \\
\hline & Cell & 0 & 0 & \\
\hline & Total & 1 & 5 & \\
\hline \multirow[t]{8}{*}{ No effect } & Experimental & 0 & 0 & \\
\hline & Cohort & 0 & 0 & \\
\hline & Case-control & $1 \times 7=$ & 7 & \\
\hline & Ex vivo & 0 & 0 & \\
\hline & Cross-sectional & $1 \times 6=$ & 6 & \\
\hline & Animal & $2 \times 5=$ & 10 & \\
\hline & Cell & 0 & 0 & \\
\hline & Total & 4 & 23 & \\
\hline \multirow[t]{2}{*}{ Overall total } & & 15 & 119 & \\
\hline & $\begin{array}{l}\text { Score }= \\
0-0.723\end{array}$ & $=-0.732$ & (step 2) & \\
\hline
\end{tabular}

Figure 2. Example of the calculation of the nutrient-specific effect score for n3 PUFAs in two steps: (i) calculation of the pro- and anti-inflammatory fraction and (ii) the nutrient specific raw inflammatory effect score (adapted from ${ }^{(25)}$ ).

\section{Results}

Since various of the 162 articles measured both inflammatory markers and respiratory function and some studies focussed on multiple dietary components, 101 articles were included in calculating the inflammatory effect scores of dietary components and 88 articles were included to calculate the respiratory function effect scores. 
Table 2. Nutrient specific inflammatory effect score.

\begin{tabular}{|c|c|c|c|c|}
\hline Food item & Credits & $\begin{array}{l}\text { Raw effect } \\
\text { score }\end{array}$ & $\begin{array}{l}\text { Inflammatory } \\
\text { effect score }^{a}\end{array}$ & References \\
\hline EGCG & 34 & -1.000 & -1.000 & $(27-34)$ \\
\hline vitamin D & 18 & -1.000 & -1.000 & $(35-38)$ \\
\hline vitamin $E^{\mathbf{b}}$ & 49 & -1.000 & -1.000 & $(39-45)$ \\
\hline resveratrol & 27 & -0.889 & -0.889 & $(46-50)$ \\
\hline quercetin & 22 & -0.864 & -0.864 & $(48,51-53)$ \\
\hline soy isoflavone & 12 & -1.000 & -0.800 & $(54,55)$ \\
\hline n-3 PUFAs & 109 & -0.743 & -0.743 & $(56-67)$ \\
\hline flavonoids & 35 & -0.714 & -0.714 & $(23,68-71)$ \\
\hline $\begin{array}{l}\text { fatty acid } \\
\text { supplementation }\end{array}$ & 15 & -0.667 & -0.667 & $(72,73)$ \\
\hline prebiotics & 10 & -1.000 & -0.667 & $(74,75)$ \\
\hline vitamin C & 10 & -1.000 & -0.667 & (76) \\
\hline $\operatorname{vitamin} C+\operatorname{vitamin} E$ & 10 & -1.000 & -0.667 & (77) \\
\hline zinc & 10 & -1.000 & -0.667 & $(78,79)$ \\
\hline probiotics & 130 & -0.538 & -0.538 & $(80-94)$ \\
\hline$n-3+n-6$ PUFAs & 20 & -0.500 & -0.500 & $(95,96)$ \\
\hline fruits $\&$ vegetables & 18 & -0.444 & -0.444 & $(97,98)$ \\
\hline synbiotics & 17 & -0.412 & -0.412 & (99) \\
\hline $\begin{array}{l}\text { blackcurrant poly- } \\
\text { phenolic extracts }\end{array}$ & 9 & -0.667 & -0.400 & $(100,101)$ \\
\hline conjugated linoleic acid & 15 & -0.333 & -0.333 & $(72,102,103)$ \\
\hline dietary fibre & 5 & -1.000 & -0.333 & (104) \\
\hline ellagic acid & 5 & -1.000 & -0.333 & (105) \\
\hline lycopene & 5 & -1.000 & -0.333 & (106) \\
\hline naringenic chalcone & 5 & -1.000 & -0.333 & (107) \\
\hline selenium & 5 & -1.000 & -0.333 & (108) \\
\hline sesame & 8 & -0.625 & -0.333 & $(109,110)$ \\
\hline vitamin $A$ & 15 & -0.333 & -0.333 & $(111-113)$ \\
\hline $\begin{array}{l}\text { vitamin } C+\text { vitamin } E \\
+ \text { selenium }\end{array}$ & 5 & -1.000 & -0.333 & (114) \\
\hline retinoic acid & 8 & -0.375 & -0.200 & $(115,116)$ \\
\hline high fat & 5 & 0.000 & 0.000 & (117) \\
\hline Mediterranean diet & 18 & 0.000 & 0.000 & $(98,118)$ \\
\hline
\end{tabular}


Table 2 (cont.). Nutrient specific inflammatory effect score.

\begin{tabular}{|l|l|l|l|l|}
\hline Food item & Credits & $\begin{array}{l}\text { Raw effect } \\
\text { score }\end{array}$ & $\begin{array}{l}\text { Inflammatory } \\
\text { effect score }\end{array}$ & References $^{\text {Rem }}$ \\
\hline n-6:n-3 PUFA ratio & 6 & 0.000 & 0.000 & $(58)$ \\
\hline caffeine & 3 & 0.000 & 0.000 & $(119)$ \\
\hline creatine & 18 & 0.111 & 0.111 & $(120-122)$ \\
\hline fish & 17 & 0.294 & 0.294 & $(61,73,123)$ \\
\hline n-6 PUFAs & 31 & 0.677 & 0.677 & $(58,60,65,124)$ \\
\hline
\end{tabular}

${ }^{a}=$ corrected for literature robustness (cut off point $=15$ ).

$\mathbf{b}=$ including studies assessing the effect of specifically $\alpha$ - and $\gamma$-tocopherol.

As shown in table 2, various dietary components showed an anti-inflammatory effect when consumption occurred during chronic inflammatory lung diseases. EGCG (epigallocatechin gallate), n-3 PUFAs (polyunsaturated fatty acids with a double bond at the third carbon atom from the $\omega$-end of the carbon chain), probiotics and vitamin E have been studied most thoroughly and have an inflammatory effect score of -1 , $0.743,-0.538$ and -1 respectively. This indicates that these dietary components gave rise to an anti-inflammatory effect in most of the included studies. Other components eliciting high anti-inflammatory effects were prebiotics $(-0.667)$, quercetin $(-0.864)$, resveratrol (-0.889), vitamin $C(-0.667)$ and vitamin $D(-1)$, although the number of weighted articles studying these dietary components in chronic inflammatory lung diseases was lower and sometimes fell below the cut-off point of literature robustness of 15 credits. No significant anti-inflammatory effects were found following intake of caffeine, high fat, the Mediterranean diet and an adjusted n-6:n-3 PUFA ratio. A proinflammatory effect was found in chronic inflammatory lung diseases with fish consumption (0.294) and n-6 PUFA (polyunsaturated fatty acids with a double bond at the sixth carbon atom from the $\omega$-end of the carbon chain) intake (0.677). 
Table 3. Nutrient specific respiratory effect score.

\begin{tabular}{|c|c|c|c|c|}
\hline Food item & Credits & $\begin{array}{l}\text { Raw effect } \\
\text { score }\end{array}$ & $\begin{array}{l}\text { Function } \\
\text { effect score }^{a}\end{array}$ & References \\
\hline soy isoflavone & 11 & -1.000 & -1.000 & $(54,125)$ \\
\hline synbiotics & 10 & -1.000 & -1.000 & (99) \\
\hline theophyline & 10 & -1.000 & -1.000 & (126) \\
\hline bread & 8 & -1.000 & -0.800 & (127) \\
\hline white wine & 8 & -1.000 & -0.800 & $(128)$ \\
\hline fruit & 33 & -0.758 & -0.758 & $(129-133)$ \\
\hline fruit \& vegetables & 36 & -0.722 & -0.722 & $(97,98,127,134)$ \\
\hline probiotics & 35 & -0.714 & -0.714 & $(81,92,94,135)$ \\
\hline$n-3+n-6$ PUFAs & 30 & -0.667 & -0.667 & $(63,64,96)$ \\
\hline$\beta$-carotene & 22 & -0.636 & -0.636 & $(127,136,137)$ \\
\hline catechins & 6 & -1.000 & -0.600 & (138) \\
\hline dietary fibre & 6 & -1.000 & -0.600 & (139) \\
\hline total protein & 6 & -1.000 & -0.600 & $(140)$ \\
\hline EGCG & 5 & -1.000 & -0.500 & (27) \\
\hline ellagic acids & 5 & -1.000 & -0.500 & $(105)$ \\
\hline fisetin & 5 & -1.000 & -0.500 & (70) \\
\hline lycopene & 20 & -0.500 & -0.500 & $(141,142)$ \\
\hline prebiotics & 5 & -1.000 & -0.500 & (74) \\
\hline vitamin $C+$ vitamin $E$ & 20 & -0.500 & -0.500 & $(143,144)$ \\
\hline vitamin D & 43 & -0.488 & -0.488 & $\begin{array}{l}(145-149) \\
\end{array}$ \\
\hline caffeine & 110 & -0.455 & -0.455 & $(126,150-157)$ \\
\hline Mediterranean diet & 18 & -0.444 & -0.444 & $(98,118)$ \\
\hline fish & 28 & -0.429 & -0.429 & $(127,136,148,158)$ \\
\hline resveratrol & 13 & -0.385 & -0.385 & $(50,128)$ \\
\hline vitamin C & 185 & -0.378 & -0.378 & $\begin{array}{l}(76,127,130, \\
131,136,137 \\
139,148,159-170)\end{array}$ \\
\hline n-3 PUFAs & 115 & -0.374 & -0.374 & $\begin{array}{l}56,57,60,65 \\
139,148,153 \\
161,171-175)\end{array}$ \\
\hline magnesium & 56 & -0.357 & -0.357 & $\begin{array}{l}(136,162,166, \\
176-178)\end{array}$ \\
\hline
\end{tabular}


Chapter 6

Table 3 (cont.). Nutrient specific respiratory effect score.

\begin{tabular}{|c|c|c|c|c|}
\hline Food item & Credits & $\begin{array}{l}\text { Raw effect } \\
\text { score }\end{array}$ & $\begin{array}{l}\text { Inflammatory } \\
\text { effect score }^{a}\end{array}$ & References \\
\hline ginger & 3 & -1.000 & -0.300 & (179) \\
\hline vitamin $\mathrm{E}^{\mathbf{b}}$ & 113 & -0.283 & -0.283 & $\begin{array}{l}(39,40,127, \\
131,136,137, \\
139,148,159,161 \\
166,180-182)\end{array}$ \\
\hline vitamin $A$ & 26 & -0.231 & -0.231 & $(111,148,161,166)$ \\
\hline apples & 8 & 0.000 & 0.000 & (136) \\
\hline calcium & 7 & 0.000 & 0.000 & $(183)$ \\
\hline carotenoids & 6 & 0.000 & 0.000 & (139) \\
\hline conjugated linoleic acid & 10 & 0.000 & 0.000 & $(184)$ \\
\hline creatine & 10 & 0.000 & 0.000 & $(120)$ \\
\hline dairy & 6 & 0.000 & 0.000 & $(148)$ \\
\hline dietary salt & 13 & 0.000 & 0.000 & $(185,186)$ \\
\hline flavanols & 6 & 0.000 & 0.000 & $(138)$ \\
\hline flavones & 6 & 0.000 & 0.000 & (138) \\
\hline iron & 17 & 0.000 & 0.000 & $(183,187)$ \\
\hline margarine $\&$ oils & 8 & 0.000 & 0.000 & (127) \\
\hline meat & 6 & 0.000 & 0.000 & (139) \\
\hline monosodium glutamate & 10 & 0.000 & 0.000 & $(188)$ \\
\hline n-9 PUFAs & 7 & 0.000 & 0.000 & $(161)$ \\
\hline sodium + potassium & 6 & 0.000 & 0.000 & $(189)$ \\
\hline olive oil & 8 & 0.000 & 0.000 & $(131)$ \\
\hline phosphorus & 7 & 0.000 & 0.000 & $(183)$ \\
\hline potassium & 7 & 0.000 & 0.000 & $(183)$ \\
\hline potatoes & 8 & 0.000 & 0.000 & $(127)$ \\
\hline red wine & 8 & 0.000 & 0.000 & (128) \\
\hline selenium & 13 & 0.000 & 0.000 & $(148,183)$ \\
\hline sodium & 7 & 0.000 & 0.000 & (183) \\
\hline tea & 6 & 0.000 & 0.000 & $(138)$ \\
\hline total energy & 14 & 0.000 & 0.000 & $(136,140)$ \\
\hline vegetables & 14 & 0.000 & 0.000 & $(130,131)$ \\
\hline
\end{tabular}


Table 3 (cont.). Nutrient specific respiratory effect score.

\begin{tabular}{|l|l|l|l|l|}
\hline Food item & Credits & $\begin{array}{l}\text { Raw effect } \\
\text { score }\end{array}$ & $\begin{array}{l}\text { Inflammatory } \\
\text { effect score }\end{array}$ & References $^{\text {Rem }}$ \\
\hline $\begin{array}{c}\text { vitamin C + vitamin E } \\
+ \text { selenium }\end{array}$ & 5 & 0.000 & 0.000 & $(114)$ \\
\hline n-6 PUFAs & 43 & 0.162 & 0.162 & $\begin{array}{l}(60,65,161,172, \\
190)\end{array}$ \\
\hline
\end{tabular}

$\mathbf{a}=$ corrected for literature robustness (cut off point $=10$ ).

$\mathbf{b}_{=}$including studies assessing the effect of specifically $\alpha$-tocopherol.

Several dietary components were shown to elicit positive effects on respiratory function in chronic inflammatory lung diseases (table 3). Most studied were the effects of intake of caffeine (-0.455), n-3 PUFAs (-0.374), vitamin C (-0.378) and vitamin $E(-0.238)$. Consumption of bread (-0.800), fruit (-0.758), fruit and vegetables $(-0.722), n-3$ and $n-$ 6 PUFAs (-0.667), probiotics (-0.714), soy isoflavone (-1), synbiotics (-1), theophylline (1) and white wine $(-0.800)$ were suggested to result in the most significant improvements in respiratory function, although the weighted number of studies showing these effects is only ranging from 8 up to 36 credits. No effect was found following intake of calcium, carotenoids, conjugated linoleic acid, creatine, dairy, dietary salt, flavanols, flavones, iron, margarine and oils, meat, monosodium glutamate, n-9 PUFAs, sodium and potassium, olive oil, phosphorus, potassium, potatoes, red wine, selenium, sodium, tea, total energy intake, vegetables as well as vitamin C combined with vitamin $\mathrm{E}$ and selenium. A decline in function was observed in studies assessing the effects of n-6 PUFAs (0.162).

\section{Discussion}

This study summarises the effects of intake of dietary components on chronic inflammatory lung diseases based on 162 studies in an attempt to identify components which should be studied into more detail, to review their exact effect on these diseases. The scores calculated with the dietary inflammatory index of these dietary components 
provide an indication of their effect on chronic inflammatory lung diseases. The scores were corrected for literature robustness by taking into account the median of credits attributed to the evidence by weighing the articles. This resulted in a cut-off point of 15 credits for inflammatory and immunological markers and a cut-off point of 10 credits for respiratory function. When the number of credits attributed to a dietary component was falling below the cut-off point, the effect found was divided by this cut-off point, as described in the method section, to correct for literature robustness. When a health benefit of a food product is reviewed however by agencies (as the European Food Safety Authority or the US Food and Drug Administration) to advice on their legal status, multiple human intervention studies demonstrating the beneficial effect are required ${ }^{(191-193)}$. Translating this into a number of credits, a cut-off point of 20 could be recommended, below which the outcome should be corrected for literature robustness. Although this number of 20 credits is not necessarily based on two intervention studies but could also be reached by comparing seven in vitro studies (table 1), a number of 20 credits could already establish a more reliable indication of an effect.

\section{Effects of dietary components on markers and function}

Taking into account the number of credits, most convincing evidence has been found for the positive effects following intake of EGCG, n-3 PUFAs, probiotics and vitamin $E$ on inflammatory and immunological markers in chronic inflammatory lung diseases (table 2). The calculated effects of these dietary components range from -0.538 up to -1. The effects on lung function have been studied most for caffeine, n-3 PUFAs, vitamin $C$ and vitamin $E$ (table 3 ). With scores ranging from -0.238 to -0.455 , their beneficial effects on respiratory function appeared to be less explicit than the effects of the most thoroughly studied dietary components on inflammatory and immune markers.

The calculated scores for the effects of $n-3$ PUFAs and vitamin $E$ on chronic inflammatory lung diseases suggest that improvements in respiratory function are at least partially attributable to improvement of inflammatory and immunological 
markers. Intake of n-3 PUFAs may result in decreased inflammation and improved lung function by (i) competition with $n-6$ PUFAs for metabolism by specific enzymes (cyclooxygenase, lysyl oxidase or chytochrome P450 oxygenase), resulting in alternative, less pro-inflammatory and even anti-inflammatory eicosanoids (metabolites); (ii) binding to and activation of receptors bound to the plasma membrane or found in the cytosol as G-protein coupled receptors (mediating the antiinflammatory effects of n-3 PUFAs) and PPAR (peroxisome proliferator-activated receptor) transcription factors (inhibiting NF- $\mathrm{kB}$ (nuclear factor kappa-light-chainenhancer of activated B cells) activation and thereby pro-inflammatory gene transcription); and (iii) inducing the anti-inflammatory pathways by resolvins and protectins derived from n-3 PUFAs ${ }^{(194)}$. The effect on the eicosanoid metabolisation was observed to be crucial in chronic inflammatory lung diseases: various leukotrienes derived from arachidonic acid (n-6 PUFAs) are important mediators in asthma and are associated with inflammation in COPD ${ }^{(65,194)}$. N-3 PUFAs suppress the generation of $\mathrm{LTB}_{4}$, which promotes the production of inflammatory cytokines, and reduce production of IL-1, IL- 6 and TNF- $\alpha$ by leukocytes ${ }^{(8,65)}$. This mechanism of action could also explain both the pro-inflammatory effects (0.667) and negative effects on respiratory function (0.162) following from n-6 PUFA intake, due to the formation of more pro-inflammatory metabolites resulting from the ingestion of n-6 PUFAs.

For vitamin $E$ intake a calculated inflammatory effect score of -1 and a respiratory function score of -0.283 were found, indicating a beneficial effect on chronic inflammatory lung diseases. Vitamin $E$ can be found in eight isoforms, with $\alpha$ tocopherol and $\gamma$-tocopherol being the most abundant ${ }^{(195)}$. Human tissue concentrations of $\alpha$-tocopherol are ten times higher than $\gamma$-tocopherol concentrations due to the higher preference of HDL (high-density lipoprotein) and LDL (low-density lipoprotein) particles for $\alpha$-tocopherol and a higher rate of degradation of $\gamma$ tocopherol $^{(195)}$. The specific effects of the different isoforms are highly debated $^{(41,43,44,195,196)}$. A total of 113 credits were taken into account for the function score, of which 108 credits were based on studies assessing total vitamin E 
intake $\mathrm{e}^{(39,127,131,136,137,139,148,159,161,166,180-182)}$ and five credits focussed on the effect of $\alpha$ tocopherol resulting in a significant improvement of respiratory function in mice ${ }^{(40)}$. Inflammatory and immune responses were mainly studied with $\gamma$-tocopherol administration (39 of the 49 credits) ${ }^{(41-45)}$, where five credits originated from studies focussed on total vitamin $E$ intake ${ }^{(39)}$ and five from studies on $\alpha$-tocopherol intake ${ }^{(40)}$. Vitamin E can affect the metabolism of arachidonic acid by decreasing cyclooxygenase enzymes and lowering leukotriene synthesis, next to decreasing the serum levels of immunoglobulin $\mathrm{E}$ which is typically elevated in asthmatics ${ }^{(40,197)}$. Both $\alpha$ - and $\gamma$ tocopherol scavenge reactive oxygen species, although the clinical relevance of this antioxidant effect is questioned and the positive effects of vitamin E supplementation are attributed to other mechanisms of action such as (i) upregulating PPAR $\gamma$, (ii) inhibiting cyclooxygenase and lysyl oxidase, and (iii) inhibiting nitration reactions by $\gamma$ tocopherol $^{(44)}$. Both isoforms show similar inhibiting capacities of protein kinase $B$, which induces production of pro-inflammatory cytokines and activates NF- $\mathrm{KB}^{(195)}$. But whereas $\alpha$-tocopherol showed anti-inflammatory effects and reduced airway hyperreactivity in mice, $\gamma$-tocopherol was observed in mice to induce pro-inflammatory effects and enhanced airway hyper reactivity during eosinophilic airway inflammation ${ }^{(195)}$. On the other hand, $\gamma$-tocopherol was observed to react with reactive nitrogen species (found in eosinophils and neutrophils) and blocked acute neutrophil inflammation ${ }^{(43,195,198)}$. Therefore $\gamma$-tocopherol is suggested to exert a broader antiinflammatory profile than $\alpha$-tocopherol ${ }^{(43)}$. Consequently, both isoforms are considered to contribute to the anti-inflammatory effects of vitamin E on chronic inflammatory lung diseases.

Although the effects of probiotics on respiratory function have been assessed in relatively few studies (35 credits), the calculated anti-inflammatory effects (-0.538) are reflected in a positive effect on respiratory function (-0.714). Probiotics is the collective term for 400-500 species of live bacteria which survive digestion and are consequently colonised in the gastrointestinal tract, providing a health benefit to the host ${ }^{(199,200)}$. Since probiotics do not all influence the immune system similarly, the elicited health 
benefits can differ per bacterial strain and metabolites ${ }^{(201)}$. The differences in effectiveness of strains also influenced the calculated score in this study: where some tested bacteria strains showed anti-inflammatory properties (e.g. Lactobacillus rhamnosus $G G$ and Lactobacillus reuteri) ${ }^{(81-83,86)}$, other strains did not affect inflammation significantly (e.g. Bifidobacterium longum and Lactobacillus casel) ${ }^{(89,90)}$. The beneficial effects found following probiotic administration appear to be triggered via different mechanisms, which are still poorly understood ${ }^{(201)}$. Various aspects as dendritic cells, epithelial cells, T regulatory cells, effector lymphocytes, natural killer T cells and $B$ cells seem to be influenced by consumption of probiotics, resulting in reduced inflammation ${ }^{(85,201,202)}$.

A link between the calculated improved function (-0.378) and the anti-inflammatory and immunological effect $(-0.667)$ of vitamin $C$ is complicated to assess due to the limited number of credits. Vitamin $C$ intake is suggested to reduce inflammation due to its antioxidant capacity, by lowering the oxidative damage in the lungs and by blocking activation of the NF- $\kappa B$ pathway by inhibiting TNF- $\alpha$ formation ${ }^{(76,203)}$. Other suggested mechanisms are the antiviral properties of vitamin C or its potency to alter the arachidonic acid pathway ${ }^{(160,203)}$.

The relationship between improvement of inflammatory and immunological markers and resulting respiratory function appeared less evident for many other studied dietary components, such as caffeine and EGCG. With a score of -0.455 based on 110 credits, caffeine intake was shown to result in an improvement in lung function. Still, only one in vitro study (assigned 3 credits) assessed the inflammatory and immunological effects caused by caffeine consumption, and found no significant improvements ${ }^{(119)}$. The positive effect of caffeine on lung function is attributed to its bronchodilating effect $^{(153,154,156,204)}$. Caffeine, as one of the methylxanthines, can affect various cellular processes and thereby instigate bronchodilation: it is an inhibitor of cyclic nucleotide phsophodiesterases, of intracellular translocation of calcium, it can increase the intracellular accumulation of cyclic nucleotides, block the adenosine receptor as competitive antagonist and it is able to directly decrease the binding of actin to 
phosphorylated myosin heads of muscles ${ }^{(204-206)}$. These cellular actions lead to bronchodilation, the widening of the airways, and thereby to improved lung function ${ }^{(204)}$.

The inflammatory effect score of EGCG of -1.000 indicated an anti-inflammatory potential, although the positive effect on respiratory function $(-0.500)$ has only been established in one animal study so $\operatorname{far}^{(27)}$. The polyphenol EGCG is not only an antioxidant but can also enhance endothelial-type and neuronal-type nitric oxide synthase enzymes ${ }^{(27)}$. A decline in these enzymes is a feature of inflammation, leading to decreased nitric oxide which is required to prevent activation of $\mathrm{NF}-\kappa \mathrm{B}$ and thereby pro-inflammatory gene transcription ${ }^{(27,29,33)}$. In different animal and in vitro studies a negative effect of EGCG on chemokines as well as matrix metalloproteinases, (extracellular matrix proteins) has been observed, suppressing collagen production in fibroblasts $^{(28,30-32)}$.

Still, many of the studied dietary components showed no effect on either inflammatory markers and/or respiratory function. With using the median as cut-off point, the number of weighted articles fell below this established cut-off point. However, the calculated effects of many dietary components were only just above the cut-off points not reaching the 'ideal amount' of 20 credits. This shows the need for more welldesigned studies to assess the effects of dietary intake on patients suffering from chronic inflammatory lung diseases, with determining not only inflammatory and immunological markers but also the effect on respiratory function.

\section{Limitations}

The number of studies exploring the effects of the different dietary components and food items on chronic inflammatory lung diseases was limited and conflicting results were found. Ideally, the number of weighed articles would be above 20 credits. In our study the cut-off points were established by calculating the median of credits assigned to the group of dietary components, in total 15 credits and 10 credits. For many dietary components with credits ranging between the cut-off point and the ideal number of 
20 credits, the effects might be more reliable when they would be corrected for literature robustness as well. To interpret the results of this study that showed possible health enhancing effects for specific components, some further limitations have to be taken into account.

The calculated inflammatory and respiratory effect scores give an indication of the effect of consuming specific dietary components when suffering from chronic inflammatory lung diseases. The calculation is based on the dietary inflammatory index, to measure the inflammatory effect of dietary components ${ }^{(25,26)}$. Shivappa et al. (2014) related the calculated effect to the total dietary intake based on food consumption data. This was not done in the present study since our main interest was to identify potent nutrients or food items affecting chronic inflammatory lung diseases. Not the amounts consumed by the general population, but intake resulting in a positive effect for patients was the main point of interest. Including a variety of experimental setups and abstaining from a quality control of these included studies could introduce an additional bias to this research. However, with the main aim being to identify dietary compounds potent to affect inflammation and/or function, the scores described in this study should serve as a starting point for future research rather than provide a calculation of an effect that can be reached.

By studying the effect of intake of single dietary components, the components most capable of positively influencing the progress of chronic inflammatory lung diseases were identified. However, methods to measure nutrient intake such as food questionnaires can result in measurement errors and bias by under- or overestimation of consumption ${ }^{(207)}$. Conflicting results between studies on similar ingredients can also be explained by heterogeneity, resulting from: (i) variations in the intake of the active ingredient (due to different compositions of the matrix of the active ingredient, the dosage regimen or duration of intake); (ii) set-up and quality of the study; and (iii) variations between patients (in genetics, dietary status, physical activity and dietary intake). 
Following food consumption, not only single dietary components potentially affect health but all bioactive components are able to influence disease progress. Therefore the whole diet should be taken into consideration: absorption of bioactive ingredients can be influenced, but more importantly the intake of various bioactive ingredients could result in synergistic effects as suggested with adherence to the Mediterranean diet, a diet high in fruit, vegetable and fibre intake $\mathrm{e}^{(98,208-210)}$.

Finally, publication and selection bias could have influenced the inclusion of 162 articles from the over 1000 articles uncovered by the literature review strategy. With many studies showing significant anti-inflammatory or positive function effects, the question can be raised whether studies showing no or negative effects on inflammation or respiratory function are published to a similar extent as studies showing these positive effects, the so-called publication bias. Furthermore, the search strategy and inclusion criteria for this study could have led to selection bias of dietary components or models, although the possibility of this bias was reduced by conducting various searches by different authors and thorough discussion of inclusion and exclusion criteria.

\section{Conclusion}

The calculated inflammatory and respiratory function effect scores showed predominantly beneficial influences of various dietary components and food items on inflammatory and immunological responses as well as on lung function in patients suffering from chronic inflammatory lung diseases. Although inflammatory and immunological markers are not the only factors influencing disease progress, the positive effects of $n-3$ PUFAs and vitamin $E$ on these markers were accompanied by improved lung function scores. Therefore, the consumption of these components could improve quality of life of patients and reduce the need for pharmaceutical antiinflammatory therapies, thereby reducing both side effects and development of resistance. 


\section{References}

1. O'Byrne PM \& Postma DS (1999) The many faces of airway inflammation: asthma and chronic obstructive pulmonary disease. Am. J. Respir. Crit. Care Med. 159, S1-S63.

2. Rothkrantz-Kos S, van Dieijen-Visser MP, Mulder PGH, et al. (2003) Potential usefulness of inflammatory markers to monitor respiratory functional impairment in sarcoidosis. Clin. Chem. 49, 1510-1517.

3. King Jr TE (2005) Clinical advances in the diagnosis and therapy of the interstitial lung diseases. Am. J. Respir. Crit. Care Med. 172, 268-279.

4. Moldoveanu B, Otmishi $P$, Jani $P$, et al. (2009) Inflammatory mechanisms in the lung. J. Inflamm. Res. 2, 1-11.

5. Barnes PJ, Shapiro SD \& Pauwels RA (2003) Chronic obstructive pulmonary disease: molecular and cellularmechanisms. Eur. Respir. J. 22, 672-688.

6. Barnes PJ \& Adcock IM (2009) Glucocorticoid resistance in inflammatory diseases. Lancet 373, 1905-1917.

7. Coussens LM \& Werb Z (2002) Inflammation and cancer. Nature 420, 860-867.

8. Calder PC (2006) $n-3$ polyunsaturated fatty acids, inflammation, and inflammatory diseases. Am. J. Clin. Nutr. 83, S1505-1519S.

9. Pawelec G, Goldeck D \& Derhovanessian E (2014) Inflammation, ageing and chronic disease. Curr. Opin. Immunol. 29, 23-28.

10. Fullerton JN, O'Brien AJ \& Gilroy DW (2013) Pathways mediating resolution of inflammation: when enough is too much. J. Pathol. 231, 8-20.

11. Rabe KF, Hurd S, Anzueto A, et al. (2007) Global strategy for the diagnosis, management, and prevention of chronic obstructive pulmonary disease: GOLD executive summary. Am. J. Respir. Crit. Care Med. 176, 532-555.

12. Bateman ED, Hurd SS, Barnes PJ, et al. (2008) Global Strategy for Asthma Management and Prevention. Eur. Respir. J. 31, 143-178.

13. Bourke SJ (2006) Interstitial lung disease: progress and problems. Postgrad. Med. J. 82, 494-499.

14. Baughman RP, Lower EE \& du Bois RM (2003) Sarcoidosis. Lancet 361, 1111-1118.

15. Gross TJ \& Hunninghake GW (2001) Idiopathic pulmonary fibrosis. N. Engl. J. Med. 345, 517-525.

16. Patel RB, Kotha SR, Sauers LA, et al. (2012) Thiol-redox antioxidants protect against lung vascular endothelial cytoskeletal alterations caused by pulmonary fibrosis inducer, bleomycin: comparison between classical thiol-protectant, $\mathrm{N}$-acetyl-L-cysteine, and novel thiol antioxidant, N, N'-bis-2-merca. Toxicol. Mech. Methods 22, 383-396.

17. Selman M, King JTE \& Pardo A (2001) Idiopathic Pulmonary Fibrosis: Prevailing and Evolving Hypotheses about Its Pathogenesis and Implications for Therapy. Ann. Intern. Med. 134, 136-151.

18. Ruijters EJB, Haenen GRMM, Weseler AR, et al. (2014) The cocoa flavanol (-)-epicatechin protects the cortisol response. Pharmacol. Res. 79, 28-33.

19. Ruijters EJB, Haenen GRMM, Weseler AR, et al. (2014) The anti-inflammatory efficacy of dexamethasone is protected by (-)-epicatechin. PharmaNutrition 2, 47-52. 
20. Varraso R, Fung TT, Hu FB, et al. (2007) Prospective study of dietary patterns and chronic obstructive pulmonary disease among US men. Thorax 62, 786-791.

21. Varraso R, Willett WC \& Camargo CA (2010) Prospective study of dietary fiber and risk of chronic obstructive pulmonary disease among US women and men. Am. J. Epidemiol. $171,776-784$.

22. Romieu I (2005) Nutrition and lung health [State of the Art]. Int. J. Tuberc. Lung Dis. 9, 362-374.

23. Geraets L, Haegens A, Brauers K, et al. (2009) Inhibition of LPS-induced pulmonary inflammation by specific flavonoids. Biochem Biophys Res Commun 382, 598-603.

24. Hazewindus M, Haenen GRMM, Weseler AR, et al. (2014) Protection against Chemotaxis in the Anti-Inflammatory Effect of Bioactives from Tomato Ketchup. PLoS One 9.

25. Shivappa N, Steck SE, Hurley TG, et al. (2014) Designing and developing a literaturederived, population-based dietary inflammatory index. Public Health Nutr. 17, 16891696.

26. Cavicchia PP, Steck SE, Hurley TG, et al. (2009) A new dietary inflammatory index predicts interval changes in serum high-sensitivity C-reactive protein. J. Nutr. 139, 2365-2372.

27. Bani D, Giannini L, Ciampa A, et al. (2006) Epigallocatechin-3-gallate reduces allergeninduced asthma-like reaction in sensitized guinea pigs. J. Pharmacol. Exp. Ther. 317, 1002-1011.

28. Chan $\mathrm{KH}$, Chan $\mathrm{SCH}$, Yeung SC, et al. (2012) Inhibitory effect of Chinese green tea on cigarette smoke-induced up-regulation of airway neutrophil elastase and matrix metalloproteinase-12 via antioxidant activity. Free Radic. Res. 46, 1123-1129.

29. Chen PC, Wheeler DS, Malhotra V, et al. (2002) A green tea-derived polyphenol, epigallocatechin-3-gallate, inhibits IkappaB kinase activation and IL-8 gene expression in respiratory epithelium. Inflammation 26, 233-241.

30. Kim S-H, Park H-J, Lee C-M, et al. (2006) Epigallocatechin-3-gallate protects toluene diisocyanate-induced airway inflammation in a murine model of asthma. FEBS Lett. 580, 1883-1890.

31. Lee I-T, Lin C-C, Lee C-Y, et al. (2013) Protective effects of (-)-epigallocatechin-3-gallate against TNF- $\alpha$-induced lung inflammation via ROS-dependent ICAM-1 inhibition. J. Nutr. Biochem. 24, 124-136.

32. Qin S, Alcorn JF, Craigo JK, et al. (2011) Epigallocatechin-3-gallate reduces airway inflammation in mice through binding to proinflammatory chemokines and inhibiting inflammatory cell recruitment. J. Immunol. 186, 3693-3700.

33. Wheeler DS, Catravas JD, Odoms K, et al. (2004) Epigallocatechin-3-gallate, a green teaderived polyphenol, inhibits IL-1 beta-dependent proinflammatory signal transduction in cultured respiratory epithelial cells. J. Nutr. 134, 1039-1044.

34. You H, Wei L, Sun W-L, et al. (2014) The green tea extract epigallocatechin-3-gallate inhibits irradiation-induced pulmonary fibrosis in adult rats. Int. J. Mol. Med. 34, 92-102.

35. Agrawal T, Gupta GK \& Agrawal DK (2013) Vitamin D supplementation reduces airway hyperresponsiveness and allergic airway inflammation in a murine model. Clin. Exp. Allergy 43, 672-683. 
36. Dimeloe S, Richards DF, Urry ZL, et al. (2012) 1 1,25 -dihydroxyvitamin D3 promotes CD200 expression by human peripheral and airway-resident T cells. Thorax 67, 574-581.

37. Kuo Y-T, Jan R-L, Kuo C-H, et al. (2012) Effects of Vitamin D3 on the Expression of GrowthRelated Oncogene- $\alpha$ in THP-1 Cells and Human Primary Monocytes. J. Food Sci. 77, H47H52.

38. Zhong H, Zhou XJ \& Hong JG (2013) The Effects of Vitamin D on Allergen-Induced Expression of Interleukin-13 and Interleukin-17 in Cord Blood CD4+T Cells. Iran. J. Allergy, Asthma Immunol. 13, 93-97.

39. Mabalirajan U, Aich J, Leishangthem GD, et al. (2009) Effects of vitamin E on mitochondrial dysfunction and asthma features in an experimental allergic murine model. J. Appl. Physiol. 107, 1285-1292.

40. Okamoto N, Murata T, Tamai H, et al. (2006) Effects of alpha tocopherol and probucol supplements on allergen-induced airway inflammation and hyperresponsiveness in a mouse model of allergic asthma. Int. Arch. Allergy Immunol. 141, 172-180.

41. Geiser M, Lay JC, Bennett WD, et al. (2013) Effects of ex vivo $\gamma$-tocopherol on airway macrophage function in healthy and mild allergic asthmatics. J. Innate Immun. 5, 613624.

42. Hernandez ML, Wagner JG, Kala A, et al. (2013) Vitamin E, $\gamma$-tocopherol, reduces airway neutrophil recruitment after inhaled endotoxin challenge in rats and in healthy volunteers. Free Radic. Biol. Med. 60, 56-62.

43. Wagner JG, Jiang Q, Harkema JR, et al. (2007) Ozone enhancement of lower airway allergic inflammation is prevented by gamma-tocopherol. Free Radic. Biol. Med. 43, 1176-1188.

44. Wagner JG, Jiang Q, Harkema JR, et al. (2008) Gamma-tocopherol prevents airway eosinophilia and mucous cell hyperplasia in experimentally induced allergic rhinitis and asthma. Clin. Exp. Allergy 38, 501-511.

45. Wiser J, Alexis NE, Jiang $Q$, et al. (2008) In vivo gamma-tocopherol supplementation decreases systemic oxidative stress and cytokine responses of human monocytes in normal and asthmatic subjects. Free Radic. Biol. Med. 45, 40-49.

46. Birrell MA (2005) Resveratrol, an extract of red wine, inhibits lipopolysaccharide induced airway neutrophilia and inflammatory mediators through an NF- B-independent mechanism. FASEB J. 19, 840-841.

47. Culpitt S V (2003) Inhibition by red wine extract, resveratrol, of cytokine release by alveolar macrophages in COPD. Thorax 58, 942-946.

48. Donnelly LE, Newton R, Kennedy GE, et al. (2004) Anti-inflammatory effects of resveratrol in lung epithelial cells: molecular mechanisms. Am. J. Physiol. Lung Cell. Mol. Physiol. 287, 774-783.

49. Knobloch J, Sibbing B, Jungck D, et al. (2010) Resveratrol impairs the release of steroidresistant inflammatory cytokines from human airway smooth muscle cells in chronic obstructive pulmonary disease. J. Pharmacol. Exp. Ther. 335, 788-798.

50. Lee M, Kim S, Kwon O-K, et al. (2009) Anti-inflammatory and anti-asthmatic effects of resveratrol, a polyphenolic stilbene, in a mouse model of allergic asthma. Int. Immunopharmacol. 9, 418-424. 
51. Boots AW, Drent M, Swennen ELR, et al. (2009) Antioxidant status associated with inflammation in sarcoidosis: a potential role for antioxidants. Respir. Med. 103, 364-372.

52. Boots AW, Drent M, de Boer VCJ, et al. (2011) Quercetin reduces markers of oxidative stress and inflammation in sarcoidosis. Clin. Nutr. 30, 506-512.

53. Verma R, Kushwah L, Gohel D, et al. (2013) Evaluating the Ameliorative Potential of Quercetin against the Bleomycin-Induced Pulmonary Fibrosis in Wistar Rats. Pulm. Med. 2013, 921724.

54. Bao Z-S, Hong L, Guan Y, et al. (2011) Inhibition of airway inflammation, hyperresponsiveness and remodeling by soy isoflavone in a murine model of allergic asthma. Int. Immunopharmacol. 11, 899-906.

55. Kalhan R, Smith LJ, Nlend MC, et al. (2008) A mechanism of benefit of soy genistein in asthma: inhibition of eosinophil p38-dependent leukotriene synthesis. Clin. Exp. allergy 38, 103-112.

56. Arm JP, Horton CE, Mencia-Huerta JM, et al. (1988) Effect of dietary supplementation with fish oil lipids on mild asthma. Thorax 43, 84-92.

57. Broughton K, Johnson C, Pace B, et al. (1997) Reduced asthma symptoms with n-3 fatty acid ingestion are related to 5- series leukotriene production. Am J Clin Nutr 65, 10111017.

58. De Batlle J, Sauleda J, Balcells E, et al. (2012) Association between $\Omega 3$ and $\Omega 6$ fatty acid intakes and serum inflammatory markers in COPD. J. Nutr. Biochem. 23, 817-821.

59. Jang H-Y, Lim K, Lee S-M, et al. (2014) Effects of $n-3$ PUFA on the CD4 $4^{+}$type 2 helper Tcell-mediated immune responses in Fat-1 mice. Mol. Nutr. Food Res. 58, 365-375.

60. Hodge L, Salome CM, Hughes JM, et al. (1998) Effect of dietary intake of omega-3 and omega- 6 fatty acids on severity of asthma in children. Eur. Respir. J. 11, 361-365.

61. Kunitsugu I, Okuda M, Murakami N, et al. (2012) Self-reported seafood intake and atopy in Japanese school-aged children. Pediatr. Int. 54, 233-237.

62. Matsuyama W, Mitsuyama H, Watanabe M, et al. (2005) Effects of omega-3 polyunsaturated fatty acids on inflammatory markers in COPD. Chest 128, 3817-3827.

63. Mickleborough TD, Murray RL, Ionescu AA, et al. (2003) Fish oil supplementation reduces severity of exercise-induced bronchoconstriction in elite athletes. Am. J. Respir. Crit. Care Med. 168, 1181-1189.

64. Mickleborough TD, Lindley MR, Ionescu AA, et al. (2006) Protective effect of fish oil supplementation on exercise-induced bronchoconstriction in asthma. Chest 129, 39-49.

65. Okamoto M, Mitsunobu F, Ashida K, et al. (2000) Effects of dietary supplementation with n-3 fatty acids compared with n-6 fatty acids on bronchial asthma. Intern. Med. 39, 107111.

66. Payan DG, Wong MY, Chernov-Rogan T, et al. (1986) Alterations in human leukocyte function induced by ingestion of eicosapentaenoic acid. J. Clin. Immunol. 6, 402-410.

67. Schuster GU, Bratt JM, Jiang X, et al. (2014) Dietary Long-Chain Omega-3 Fatty Acids Do Not Diminish Eosinophilic Pulmonary Inflammation in Mice. Am. J. Respir. Cell Mol. Biol. $50,626-636$.

68. Kim H-H, Bae Y \& Kim S-H (2013) Galangin attenuates mast cell-mediated allergic inflammation. Food Chem. Toxicol. 57, 209-216. 
69. Park S-J, Shin W-H, Seo J-W, et al. (2007) Anthocyanins inhibit airway inflammation and hyperresponsiveness in a murine asthma model. Food Chem. Toxicol. 45, 1459-1467.

70. Wu M-Y, Hung S-K \& Fu S-L (2011) Immunosuppressive effects of fisetin in ovalbumininduced asthma through inhibition of NF- $\mathrm{KB}$ activity. J. Agric. Food Chem. 59, 1049610504.

71. Xie Y-C, Dong X-W, Wu X-M, et al. (2009) Inhibitory effects of flavonoids extracted from licorice on lipopolysaccharide-induced acute pulmonary inflammation in mice. Int. Immunopharmacol. 9, 194-200.

72. Kanwar RK, Macgibbon AK, Black PN, et al. (2008) Bovine milk fat enriched in conjugated linoleic and vaccenic acids attenuates allergic airway disease in mice. Clin. Exp. allergy 38, 208-218.

73. Wood LG, Hazlewood LC, Foster PS, et al. (2010) Lyprinol reduces inflammation and improves lung function in a mouse model of allergic airways disease. Clin. Exp. allergy 40, 1785-1793.

74. Vos AP, van Esch BC, Stahl B, et al. (2007) Dietary supplementation with specific oligosaccharide mixtures decreases parameters of allergic asthma in mice. Int. Immunopharmacol. 7, 1582-1587.

75. Yasuda A, Inoue K-I, Sanbongi $\mathrm{C}$, et al. Dietary supplementation with fructooligosaccharides attenuates airway inflammation related to house dust mite allergen in mice. Int. J. Immunopathol. Pharmacol. 23, 727-735.

76. Tecklenburg SL, Mickleborough TD, Fly AD, et al. (2007) Ascorbic acid supplementation attenuates exercise-induced bronchoconstriction in patients with asthma. Respir. Med. $101,1770-1778$

77. Sienra-Monge JJ, Ramirez-Aguilar M, Moreno-Macias H, et al. (2004) Antioxidant supplementation and nasal inflammatory responses among young asthmatics exposed to high levels of ozone. Clin. Exp. Immunol. 138, 317-322.

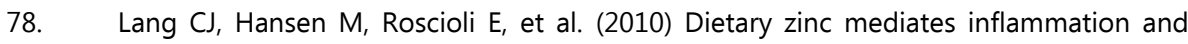
protects against wasting and metabolic derangement caused by sustained cigarette smoke exposure in mice. BioMetals 24, 23-39.

79. Lu H, Xin Y, Tang Y, et al. (2012) Zinc Suppressed the Airway Inflammation in Asthmatic Rats: Effects of Zinc on Generation of Eotaxin, MCP-1, IL-8, IL-4, and IFN- $\gamma$. Biol. Trace Elem. Res. 150, 314-321.

80. Charng Y-C, Lin C-C \& Hsu C-H (2006) Inhibition of allergen-induced airway inflammation and hyperreactivity by recombinant lactic-acid bacteria. Vaccine $24,5931-$ 5936.

81. Feleszko W, Jaworska J, Rha R-D, et al. (2007) Probiotic-induced suppression of allergic sensitization and airway inflammation is associated with an increase of $T$ regulatorydependent mechanisms in a murine model of asthma. Clin. Exp. Allergy 37, 498-505.

82. Forsythe $P$, Inman MD \& Bienenstock J (2007) Oral treatment with live Lactobacillus reuteri inhibits the allergic airway response in mice. Am. J. Respir. Crit. Care Med. 175, 561-569. 
83. Harb $H$, van Tol EAF, Heine $H$, et al. (2013) Neonatal supplementation of processed supernatant from Lactobacillus rhamnosus GG improves allergic airway inflammation in mice later in life. Clin. Exp. allergy 43, 353-364.

84. Hougee S, Vriesema AJM, Wijering SC, et al. (2010) Oral Treatment with Probiotics Reduces Allergic Symptoms in Ovalbumin-Sensitized Mice: A Bacterial Strain Comparative Study. Int. Arch. Allergy Immunol. 151, 107-117.

85. Jan R-L, Yeh K-C, Hsieh M-H, et al. (2012) Lactobacillus gasseri suppresses Th17 proinflammatory response and attenuates allergen-induced airway inflammation in a mouse model of allergic asthma. Br. J. Nutr. 108, 130-139.

86. Karimi K, Inman MD, Bienenstock J, et al. (2009) Lactobacillus reuteri-induced regulatory T cells protect against an allergic airway response in mice. Am. J. Respir. Crit. Care Med. 179, 186-193.

87. Kim H-J, Kim Y-J, Lee S-H, et al. (2013) Effects of Lactobacillus rhamnosus on asthma with an adoptive transfer of dendritic cells in mice. J. Appl. Microbiol. 115, 872-879.

88. Kukkonen AK, Kuitunen M, Savilahti E, et al. (2011) Airway inflammation in probiotictreated children at 5 years. Pediatr. Allergy Immunol. 22, 249-251.

89. Lim LH, Li HY, Huang CH, et al. (2009) The effects of heat-killed wild-type Lactobacillus casei Shirota on allergic immune responses in an allergy mouse model. Int. Arch. Allergy Immunol. 148, 297-304.

90. Lyons A, O'Mahony D, O'Brien F, et al. (2010) Bacterial strain-specific induction of Foxp3+ T regulatory cells is protective in murine allergy models. Clin. Exp. Allergy 40, 811-819.

91. MacSharry J, O'Mahony C, Shalaby $\mathrm{KH}$, et al. (2012) Immunomodulatory effects of feeding with Bifidobacterium longum on allergen-induced lung inflammation in the mouse. Pulm. Pharmacol. Ther. 25, 325-334.

92. Miraglia Del Giudice M, Maiello N, Decimo F, et al. Airways allergic inflammation and L. reuterii treatment in asthmatic children. J. Biol. Regul. Homeost. Agents 26, S35-S40.

93. Moreira A, Kekkonen R, Korpela R, et al. (2007) Allergy in marathon runners and effect of Lactobacillus GG supplementation on allergic inflammatory markers. Respir. Med. 101, 1123-1131.

94. Zhang B, An J, Shimada T, et al. (2012) Oral administration of Enterococcus faecalis FK23 suppresses Th17 cell development and attenuates allergic airway responses in mice. Int. J. Mol. Med. 30, 248-254.

95. Surette ME, Koumenis IL, Edens MB, et al. (2003) Inhibition of leukotriene biosynthesis by a novel dietary fatty acid formulation in patients with atopic asthma: a randomized, placebo-controlled, parallel-group, prospective trial. Clin. Ther. 25, 972-979.

96. Broekhuizen R, Wouters EFM, Creutzberg EC, et al. (2005) Polyunsaturated fatty acids improve exercise capacity in chronic obstructive pulmonary disease. Thorax 60, 376-382.

97. Baldrick FR, Elborn JS, Woodside J V, et al. (2012) Effect of fruit and vegetable intake on oxidative stress and inflammation in COPD: a randomised controlled trial. Eur. Respir. J. 39, 1377-1384.

98. Romieu I, Barraza-Villarreal A, Escamilla-Núñez C, et al. (2009) Dietary intake, lung function and airway inflammation in Mexico City school children exposed to air pollutants. Respir. Res. 10, 122. 
99. Van de Pol MA, Lutter R, Smids BS, et al. (2011) Synbiotics reduce allergen-induced Thelper 2 response and improve peak expiratory flow in allergic asthmatics. Allergy 66 , 39-47.

100. Hurst SM, McGhie TK, Cooney JM, et al. (2010) Blackcurrant proanthocyanidins augment IFN-gamma-induced suppression of IL-4 stimulated CCL26 secretion in alveolar epithelial cells. Mol. Nutr. Food Res. 54, S159-S170.

101. Nyanhanda T, Gould EM, McGhie T, et al. (2014) Blackcurrant cultivar polyphenolic extracts suppress CCL26 secretion from alveolar epithelial cells. Food Funct. 5, 671-677.

102. Böcking C, Harb H, Ege MJ, et al. (2014) Bioavailability and allergoprotective capacity of milk-associated conjugated linoleic acid in a murine model of allergic airway inflammation. Int. Arch. Allergy Immunol. 163, 234-242.

103. Jaudszus A, Krokowski M, Möckel P, et al. (2008) Cis-9,trans-11-conjugated linoleic acid inhibits allergic sensitization and airway inflammation via a PPARgamma-related mechanism in mice. J. Nutr. 138, 1336-1342.

104. Trompette A, Gollwitzer ES, Yadava K, et al. (2014) Gut microbiota metabolism of dietary fiber influences allergic airway disease and hematopoiesis. Nat. Med. 20, 159-166.

105. Zhou E, Fu Y, Wei Z, et al. (2014) Inhibition of allergic airway inflammation through the blockage of NF- $\mathrm{KB}$ activation by ellagic acid in an ovalbumin-induced mouse asthma model. Food Funct. 5, 2106-2112.

106. Hazlewood LC, Wood LG, Hansbro PM, et al. (2011) Dietary lycopene supplementation suppresses Th2 responses and lung eosinophilia in a mouse model of allergic asthma. J. Nutr. Biochem. 22, 95-100.

107. Iwamura C, Shinoda K, Yoshimura M, et al. (2010) Naringenin chalcone suppresses allergic asthma by inhibiting the type-2 function of CD4 T cells. Allergol. Int. 59, 67-73.

108. Jeong D-W, Yoo M-H, Kim TS, et al. (2002) Protection of mice from allergen-induced asthma by selenite: prevention of eosinophil infiltration by inhibition of NF-kappa B activation. J. Biol. Chem. 277, 17871-17876.

109. Hsieh C-C, Kuo C-H, Kuo H-F, et al. (2014) Sesamin suppresses macrophage-derived chemokine expression in human monocytes via epigenetic regulation. Food Funct. 5, 2494-2500.

110. Hsu D-Z, Liu C-T, Chu P-Y, et al. (2013) Sesame oil attenuates ovalbumin-induced pulmonary edema and bronchial neutrophilic inflammation in mice. Biomed Res. Int. 2013, 905670.

111. Hisada T, Adcock IM, Nasuhara Y, et al. (1999) Inhibition of ozone-induced lung neutrophilia and nuclear factor-kappaB binding activity by vitamin $A$ in rat. Eur. J. Pharmacol. 377, 63-68.

112. Sauer JM, Hooser SB \& Sipes IG (1995) All-trans-Retinol Alteration of 1Nitronaphthalene-Induced Pulmonary and Hepatic Injury by Modulation of Associated Inflammatory Responses in the Male Sprague-Dawley Rat. Toxicol. Appl. Pharmacol. 133, 139-149.

113. Schuster GU, Kenyon NJ \& Stephensen CB (2008) Vitamin A deficiency decreases and high dietary vitamin $\mathrm{A}$ increases disease severity in the mouse model of asthma. J. Immunol. 180, 1834-1842. 
114. Kirschvink N, Fiévez L, Bougnet $V$, et al. (2002) Effect of nutritional antioxidant supplementation on systemic and pulmonary antioxidant status, airway inflammation and lung function in heaves-affected horses. Equine Vet. J. 34, 705-712.

115. Fujita $\mathrm{M}, \mathrm{Ye} \mathrm{Q}$, Ouchi $\mathrm{H}$, et al. (2004) Retinoic acid fails to reverse emphysema in adult mouse models. Thorax 59, 224-230.

116. Takamura K, Nasuhara Y, Kobayashi M, et al. (2004) Retinoic acid inhibits interleukin-4induced eotaxin production in a human bronchial epithelial cell line. Am. J. Physiol. Lung Cell. Mol. Physiol. 286, L777-L785.

117. De Vries A, Hazlewood L, Fitch PM, et al. (2009) High-fat feeding redirects cytokine responses and decreases allergic airway eosinophilia. Clin. Exp. Allergy 39, 731-739.

118. Sexton $P$, Black $P$, Metcalf $P$, et al. (2013) Influence of mediterranean diet on asthma symptoms, lung function, and systemic inflammation: a randomized controlled trial. J. Asthma 50, 75-81.

119. Geraets L, Moonen HJJ, Wouters EFM, et al. (2006) Caffeine metabolites are inhibitors of the nuclear enzyme poly(ADP-ribose)polymerase-1 at physiological concentrations. Biochem Pharmacol 72, 902-910.

120. Fuld JP, Kilduff LP, Neder JA, et al. (2005) Creatine supplementation during pulmonary rehabilitation in chronic obstructive pulmonary disease. Thorax 60, 531-537.

121. Nomura A, Zhang M, Sakamoto T, et al. (2003) Anti-inflammatory activity of creatine supplementation in endothelial cells in vitro. Br. J. Pharmacol. 139, 715-720.

122. Vieira RP, Duarte ACS, Claudino RC, et al. (2007) Creatine supplementation exacerbates allergic lung inflammation and airway remodeling in mice. Am. J. Respir. Cell Mol. Biol. 37, 660-667.

123. Yin H, Liu W, Goleniewska K, et al. (2009) Dietary supplementation of omega-3 fatty acidcontaining fish oil suppresses F2-isoprostanes but enhances inflammatory cytokine response in a mouse model of ovalbumin-induced allergic lung inflammation. Free Radic. Biol. Med. 47, 622-628.

124. Muehlmann LA, Zanatta AL, Farias CLA, et al. (2010) Dietary supplementation with soybean lecithin increases pulmonary PAF bioactivity in asthmatic rats. J. Nutr. Biochem. 21, 532-537.

125. Bime C, Wei CY, Holbrook J, et al. (2012) Association of dietary soy genistein intake with lung function and asthma control: a post-hoc analysis of patients enrolled in a prospective multicentre clinical trial. Prim. Care Respir. J. 21, 398-404.

126. Becker AB, Simons KJ, Gillespie CA, et al. (1984) The Bronchodilator Effects and Pharmacokinetics of Caffeine in Asthma. N. Engl. J. Med. 310, 743-746.

127. Tabak C, Smit HA, Räsänen L, et al. (1999) Dietary factors and pulmonary function: a cross sectional study in middle aged men from three European countries. Thorax 54, 10211026.

128. Siedlinski M, Boer JMA, Smit HA, et al. (2012) Dietary factors and lung function in the general population: wine and resveratrol intake. Eur. Respir. J. 39, 385-391.

129. Carey IM, Strachan DP \& Cook DG (1998) Effects of changes in fresh fruit consumption on ventilatory function in healthy British adults. Am. J. Respir. Crit. Care Med. 158, 728733. 
130. Cook DG, Carey IM, Whincup PH, et al. (1997) Effect of fresh fruit consumption on lung function and wheeze in children. Thorax 52, 628-633.

131. De Batlle J, Barreiro E, Romieu I, et al. (2010) Dietary modulation of oxidative stress in chronic obstructive pulmonary disease patients. Free Radic. Res. 44, 1296-1303.

132. Strachan DP, Cox BD, Erzinclioglu SW, et al. (1991) Ventilatory function and winter fresh fruit consumption in a random sample of British adults. Thorax 46, 624-629.

133. Tabak C, Smit HA, Heederik D, et al. (2001) Diet and chronic obstructive pulmonary disease: independent beneficial effects of fruits, whole grains, and alcohol (the MORGEN study). Clin. Exp. Allergy 31, 747-755.

134. Keranis E, Makris D, Rodopoulou P, et al. (2010) Impact of dietary shift to higherantioxidant foods in COPD: a randomised trial. Eur. Respir. J. 36, 774-780.

135. West CE, Hammarström M-L \& Hernell O (2013) Probiotics in primary prevention of allergic disease--follow-up at 8-9 years of age. Allergy 68, 1015-1020.

136. Butland BK, Fehily AM \& Elwood PC (2000) Diet, lung function, and lung function decline in a cohort of 2512 middle aged men. Thorax 55, 102-108.

137. Grievink L, Smit HA, Ocké MC, et al. (1998) Dietary intake of antioxidant (pro)-vitamins, respiratory symptoms and pulmonary function: the MORGEN study. Thorax 53, 166-171.

138. Tabak C, Arts IC, Smit HA, et al. (2001) Chronic obstructive pulmonary disease and intake of catechins, flavonols, and flavones: the MORGEN Study. Am. J. Respir. Crit. Care Med. $164,61-64$.

139. Kan H, Stevens J, Heiss G, et al. (2008) Dietary fiber, lung function, and chronic obstructive pulmonary disease in the atherosclerosis risk in communities study. Am. J. Epidemiol. 167, 570-578.

140. Yazdanpanah L, Shidfar F, Moosavi AJ, et al. (2010) Energy and protein intake and its relationship with pulmonary function in chronic obstructive pulmonary disease (COPD) patients. Acta Med. Iran. 48, 374-379.

141. Falk B, Gorev R, Zigel L, et al. (2005) Effect of lycopene supplementation on lung function after exercise in young athletes who complain of exercise-induced bronchoconstriction symptoms. Ann. Allergy, Asthma Immunol. 94, 480-485.

142. Neuman I, Nahum H \& Ben-Amotz A (2000) Reduction of exercise-induced asthma oxidative stress by lycopene, a natural antioxidant. Allergy 55, 1184-1189.

143. Hernandez M, Zhou H, Zhou B, et al. (2009) Combination treatment with high-dose vitamin $C$ and alpha-tocopherol does not enhance respiratory-tract lining fluid vitamin C levels in asthmatics. Inhal. Toxicol. 21, 173-181.

144. Trenga CA, Koenig JQ \& Williams P V Dietary antioxidants and ozone-induced bronchial hyperresponsiveness in adults with asthma. Arch. Environ. Health 56, 242-249.

145. Agarwal S, Hordvik S \& Morar S (2006) Nutritional claims for functional foods and supplements. Toxicology 221, 44-49.

146. Arshi S, Fallahpour M, Nabavi M, et al. (2014) The effects of vitamin D supplementation on airway functions in mild to moderate persistent asthma. Ann. Allergy. Asthma Immunol. 113, 404-409. 
147. Lehouck A, Mathieu C, Carremans C, et al. (2012) High doses of vitamin D to reduce exacerbations in chronic obstructive pulmonary disease: a randomized trial. Ann. Intern. Med. 156, 105-114.

148. Ng TP, Niti M, Yap KB, et al. (2014) Dietary and supplemental antioxidant and antiinflammatory nutrient intakes and pulmonary function. Public Health Nutr. 17, 20812086.

149. Shaheen SO, Jameson KA, Robinson SM, et al. (2011) Relationship of vitamin D status to adult lung function and COPD. Thorax 66, 692-698.

150. Bukowskyj M \& Nakatsu K (1987) The bronchodilator effect of caffeine in adult asthmatics. Am. Rev. Respir. Dis. 135, 173-175.

151. Colacone A, Bertolo L, Wolkove N, et al. (1990) Effect of caffeine on histamine bronchoprovocation in asthma. Thorax 45, 630-632.

152. Crivelli M, Wahlländer A, Jost $G$, et al. (1986) Effect of dietary caffeine on airway reactivity in asthma. Respiration 50, 258-264.

153. Duffy P \& Phillips YY (1991) Caffeine consumption decreases the response to bronchoprovocation challenge with dry gas hyperventilation. Chest 99, 1374-1377.

154. Gong H, Simmons MS, Tashkin DP, et al. (1986) Bronchodilator effects of caffeine in coffee. A dose-response study of asthmatic subjects. Chest 89, 335-342.

155. Henderson JC, O'Connell F \& Fuller RW (1993) Decrease of histamine induced bronchoconstriction by caffeine in mild asthma. Thorax 48, 824-826.

156. Kivity S, Ben Aharon Y, Man A, et al. (1990) The effect of caffeine on exercise-induced bronchoconstriction. Chest 97, 1083-1085.

157. Yurach MT, Davis BE \& Cockcroft DW (2011) The effect of caffeinated coffee on airway response to methacholine and exhaled nitric oxide. Respir. Med. 105, 1606-1610.

158. Schwartz J \& Weiss ST (1994) The relationship of dietary fish intake to level of pulmonary function in the first National Health and Nutrition Survey (NHANES I). Eur. Respir. J. 7, 1821-1824.

159. Britton JR, Pavord ID, Richards KA, et al. (1995) Dietary antioxidant vitamin intake and lung function in the general population. Am. J. Respir. Crit. Care Med. 151, 1383-1387.

160. Cohen HA (1997) Blocking Effect of Vitamin C in Exercise-Induced Asthma. Arch. Pediatr. Adolesc. Med. 151, 367-370.

161. De Luis DA, Armentia A, Aller R, et al. (2005) Dietary intake in patients with asthma: a case control study. Nutrition 21, 320-324.

162. Fogarty A, Lewis SA, Scrivener SL, et al. (2003) Oral magnesium and vitamin C supplements in asthma: a parallel group randomized placebo-controlled trial. Clin. Exp. Allergy 33, 1355-1359.

163. Hu G, Zhang X, Chen J, et al. (1998) Dietary vitamin C intake and lung function in rural China. Am. J. Epidemiol. 148, 594-599.

164. Kordansky DW, Rosenthal RR \& Norman PS (1979) The effect of vitamin C on antigeninduced bronchospasm. J. Allergy Clin. Immunol. 63, 61-64.

165. Malo JL, Cartier A, Pineau L, et al. (1986) Lack of acute effects of ascorbic acid on spirometry and airway responsiveness to histamine in subjects with asthma. J. Allergy Clin. Immunol. 78, 1153-1158. 
166. McKeever TM, Scrivener S, Broadfield E, et al. (2002) Prospective study of diet and decline in lung function in a general population. Am. J. Respir. Crit. Care Med. 165, 1299-1303.

167. Nadi E, Tavakoli F, Zeraati F, et al. (2012) Effect of vitamin C administration on leukocyte vitamin C level and severity of bronchial asthma. Acta Med. Iran. 50, 233-238.

168. Schachter EN \& Schlesinger A (1982) The attenuation of exercise-induced bronchospasm by ascorbic acid. Ann. Allergy 49, 146-151.

169. Schertling M (1989) Einfluss von Ascorbinsäure auf den klinischen Verlauf des infektbedingten Asthma bronchiale und die Bildung von reaktiven Sauerstoffmetaboliten durch BAL-Zellen [unofficial translation]. Z. Klin. Med. 45, 1770-1774.

170. Ting S, Mansfield LE \& Yarbrough J (1983) Effects of ascorbic acid on pulmonary functions in mild asthma. J. Asthma 20, 39-42.

171. Kirsch CM, Payan DG, Wong MY, et al. (1988) Effect of eicosapentaenoic acid in asthma. Clin. Allergy 18, 177-187.

172. McKeever TM, Lewis SA, Cassano PA, et al. (2008) The relation between dietary intake of individual fatty acids, FEV1 and respiratory disease in Dutch adults. Thorax 63, 208-214.

173. Moreira A, Moreira P, Delgado L, et al. (2007) Pilot study of the effects of $n-3$ polyunsaturated fatty acids on exhaled nitric oxide in patients with stable asthma. J. Investig. Allergol. Clin. Immunol. 17, 309-313.

174. Thien FC, Mencia-Huerta JM \& Lee TH (1993) Dietary fish oil effects on seasonal hay fever and asthma in pollen-sensitive subjects. Am. Rev. Respir. Dis. 147, 1138-1143.

175. Villani F, Comazzi R, De Maria P, et al. (1998) Effect of dietary supplementation with polyunsaturated fatty acids on bronchial hyperreactivity in subjects with seasonal asthma. Respiration 65, 265-269.

176. Gontijo-Amaral C, Ribeiro MAGO, Gontijo LSC, et al. (2006) Oral magnesium supplementation in asthmatic children: a double-blind randomized placebo-controlled trial. Eur. J. Clin. Nutr. 61, 54-60.

177. Hill J, Micklewright A, Lewis S, et al. (1997) Investigation of the effect of short-term change in dietary magnesium intake in asthma. Eur. Respir. J. 10, 2225-2229.

178. Kazaks AG, Uriu-Adams JY, Albertson TE, et al. (2010) Effect of oral magnesium supplementation on measures of airway resistance and subjective assessment of asthma control and quality of life in men and women with mild to moderate asthma: a randomized placebo controlled trial. J. Asthma 47, 83-92.

179. Ghayur MN, Gilani AH \& Janssen LJ (2008) Ginger attenuates acetylcholine-induced contraction and $\mathrm{Ca} 2+$ signalling in murine airway smooth muscle cells. Can. J. Physiol. Pharmacol. 86, 264-271.

180. Daga MK, Chhabra R, Sharma B, et al. (2003) Effects of exogenous vitamin E supplementation on the levels of oxidants and antioxidants in chronic obstructive pulmonary disease. J. Biosci. 28, 7-11.

181. Nadeem A, Raj HG \& Chhabra SK (2008) Effect of vitamin E supplementation with standard treatment on oxidant-antioxidant status in chronic obstructive pulmonary disease. Indian J. Med. Res. 128, 705-711.

182. Pearson PJK, Lewis SA, Britton J, et al. (2004) Vitamin E supplements in asthma: a parallel group randomised placebo controlled trial. Thorax 59, 652-656. 
183. Hirayama F, Lee AH, Oura A, et al. (2010) Dietary intake of six minerals in relation to the risk of chronic obstructive pulmonary disease. Asia Pac. J. Clin. Nutr. 19, 572-577.

184. Stickford JL, Mickleborough TD, Fly AD, et al. (2011) Conjugated linoleic acid's lack of attenuation of hyperpnea-induced bronchoconstriction in asthmatic individuals in the short term. Int. J. Sport Nutr. Exerc. Metab. 21, 40-47.

185. Demissie K, Ernst P, Gray Donald K, et al. (1996) Usual dietary salt intake and asthma in children: a case-control study. Thorax 51, 59-63.

186. Pistelli R, Forastiere F, Corbo GM, et al. (1993) Respiratory symptoms and bronchial responsiveness are related to dietary salt intake and urinary potassium excretion in male children. Eur. Respir. J. 6, 517-522.

187. Shaheen SO, Newson RB, Rayman MP, et al. (2007) Randomised, double blind, placebocontrolled trial of selenium supplementation in adult asthma. Thorax 62, 483-490.

188. Yoneda J, Chin K, Torii K, et al. (2011) Effects of oral monosodium glutamate in mouse models of asthma. Food Chem. Toxicol. 49, 299-304.

189. Zoia MC, Fanfulla F, Bruschi C, et al. (1995) Chronic respiratory symptoms, bronchial responsiveness and dietary sodium and potassium: a population-based study. Monaldi Arch. chest Dis. 50, 104-108.

190. Morris A, Noakes M \& Clifton PM (2001) The role of n-6 polyunsaturated fat in stable asthmatics. J. Asthma 38, 311-9.

191. U.S. Food and Drug Administration (2014) Guidance for Industry: Evidence-Based Review System for the Scientific Evaluation of Health Claims - Final. http://www.fda.gov/food/guidanceregulation/guidancedocumentsregulatoryinformatio n/ucm073332.htm (accessed April 2015).

192. EFSA NDA Panel (2011) General guidance for stakeholders on the evaluation of Article 13.1, 13.5 and 14 health claims. EFSA J. 2135, 1-24.

193. Ellwood KC, Trumbo PR \& Kavanaugh CJ (2010) How the US Food and Drug Administration evaluates the scientific evidence for health claims. Nutr. Rev. 68, 114-121. The Oxford University Press.

194. Yates CM, Calder PC \& Ed Rainger G (2014) Pharmacology and therapeutics of omega-3 polyunsaturated fatty acids in chronic inflammatory disease. Pharmacol. Ther. 141, 272282.

195. Cook-Mills JM \& Avila PC (2014) Vitamin E and D regulation of allergic asthma immunopathogenesis. Int. Immunopharmacol. 23, 364-372.

196. Van Acker SABE, Koymans LMH \& Bast A (1993) Molecular pharmacology of vitamin E: Structural aspects of antioxidant activity. Free Radic. Biol. Med. 15, 311-328.

197. Fogarty A, Lewis S, Weiss S, et al. (2000) Dietary vitamin E, IgE concentrations, and atopy. Lancet 356, 1573-1574.

198. Patel A, Liebner F, Netscher T, et al. (2007) Vitamin E chemistry. Nitration of non-alphatocopherols: products and mechanistic considerations. J. Org. Chem. 72, 6504-6512.

199. Heller F \& Duchmann R (2003) Intestinal flora and mucosal immune responses. Int. J. Med. Microbiol. 293, 77-86.

200. Osborn DA \& Sinn JK (2007) Probiotics in infants for prevention of allergic disease and food hypersensitivity. Cochrane database Syst. Rev., CD006475. 
201. Frei R, Akdis M \& O'Mahony L (2015) Prebiotics, probiotics, synbiotics, and the immune system: experimental data and clinical evidence. Curr. Opin. Gastroenterol. 31, 153-158.

202. Strickland DH \& Holt PG (2011) T regulatory cells in childhood asthma. Trends Immunol. 32, 420-427.

203. Milan SJ, Hart A \& Wilkinson M (2013) Vitamin C for asthma and exercise-induced bronchoconstriction. Cochrane database Syst. Rev. 10, CD010391.

204. Welsh EJ, Bara A, Barley E, et al. (2010) Caffeine for asthma. Cochrane database Syst. Rev., CD001112.

205. Tazzeo T, Bates G, Roman HN, et al. (2012) Caffeine relaxes smooth muscle through actin depolymerization. Am. J. Physiol. Lung Cell. Mol. Physiol. 303, L334-L342.

206. Chawla J \& Suleman A (2013) Neurologic effects of caffeine. http://emedicine.medscape.com/article/1182710-overview\#aw2aab6b4 (accessed April 2015).

207. Freedman LS, Schatzkin A, Midthune D, et al. (2011) Dealing with dietary measurement error in nutritional cohort studies. J. Natl. Cancer Inst. 103, 1086-1092.

208. Jacobs DRJ \& Steffen LM (2003) Nutrients, foods, and dietary patterns as exposures in research: a framework for food synergy. Am J Clin Nutr 78, 508S-513S.

209. Jacobs DR \& Tapsell LC (2007) Food, not nutrients, is the fundamental unit in nutrition. Nutr Rev 65, 439-450.

210. Liu RH (2003) Health benefits of fruit and vegetables are from additive and synergistic combinations of phytochemicals. Am J Clin Nutr 78, 517S-520S. 



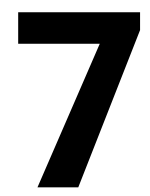

Adverse food-drug

interactions

Alie de Boer, Florence van Hunsel, Aalt Bast 


\section{Abstract}

Food supplements and herbal products are increasingly popular amongst consumers. This increases the risk of interactions between prescribed drugs and these healthenhancing products containing bioactive ingredients. From 1991 up to 2014, 55 cases of suspected adverse drug reactions due to concomitant intake of health-enhancing products and drugs were reported to Lareb, the Netherlands Pharmacovigilance Centre. An overview of these suspected interactions is presented and their potential mechanisms of action are described. Mainly during the metabolism of xenobiotics and due to the pharmacodynamics effects interactions seem to occur, which may result in adverse drug reactions. Where legislation is seen to distinct food and medicine, legislation concerning these different bioactive products is less clear-cut. This can only be resolved by increasing the molecular knowledge on bioactive substances and their potential interactions. Thereby potential interactions can be better understood and prevented on an individual level. By considering the dietary pattern and use of bioactive substances with prescribed medication, both health professionals and consumers will be increasingly aware of interactions and these interactive adverse effects can be prevented. 


\section{Introduction}

With a growing population in the economically instable Western world in the $20^{\text {th }}$ century, the main focus of food consumption was to alleviate hunger and to provide for necessary macro- and micronutrients ${ }^{(1,2)}$. Together with the increased possibilities to chemically produce drugs, this instigated the separate study of pharmaceutics and nutrition, where both were highly connected fields traditionally with their foundation in nature ${ }^{(3)}$. Pharmaceutical products concentrated on curing diseases or alleviating symptoms of disease ${ }^{(3)}$. The potential of food (ingredients) to affect health is recognised both in science and by consumers during the last few decades. Food intake currently not only aims to relieve hunger but is also used to enhance health, thereby shifting more towards the function of pharmaceutical products ${ }^{(1)}$. This increased interest in the health effects of foods pushes sales of products as functional foods, health foods and food supplements ${ }^{(4-6)}$. The active ingredients of these products, the components which are shown to affect human health, are called 'bioactives' ${ }^{(7)}$. These products are considered to be foodstuffs, but consumers also seem to get more interested in products at the interface between nutrition and pharmaceuticals as foods for special groups, (traditional) herbal medicinal products and cosmoceuticals $(5,6,8)$. With more health conscious consumers using products with bioactive ingredients, the risk of serious adverse reactions due to interactions between prescribed medication and potentially bioactive compounds is increasing. Various drug-food interactions (e.g. drugs interacting with the fat content of the meal), drug-nutrient interactions (e.g. with grapefruit juice or soy) and herb-drug interactions (e.g. with ginkgo biloba or St John's wort) have been described and reviewed ${ }^{(9-12)}$.

The Netherlands Pharmacovigilance Centre Lareb receives reports of health professionals, consumers and the pharmaceutical industry on experienced adverse reactions to medicines and vaccines ${ }^{(13)}$. Amongst these suspected adverse reactions also interactive effects of drugs ingested with xenobiotics, as food supplements and herbal products are reported to Lareb. This paper discusses the received reports on 
suspected adverse effects following xenobiotics intake collected by Lareb and describes several other potential interactions between such substances with drugs and their mechanisms of action. This study thereby gives an overview of clinically relevant interactions and can help to focus the attention of health professionals and consumers on the possibility of interactions between prescribed medication with bioactive products as consumed supplements or herbal extracts.

\section{Legal perspective}

The Softenon $₫$-affair in the 1960 s, where the consumption of thalidomide by pregnant women caused birth defects in children, increased public awareness of potential adverse effects of drugs. As a result, two global measures were taken: (i) medicines must meet requirements for efficacy, quality and safety; and (ii) a system was introduced to report adverse drug reactions ${ }^{(14)}$. Hereby all legislation concerning drugs was drastically changed ${ }^{(15)}$. This was the start of pharmacovigilance: all activities related to monitoring, understanding and preventing medicine-related problems including the occurrence of adverse effects(16). In the Netherlands, these adverse effects are

monitored by the Netherlands Pharmacovigilance Centre Lareb. Lareb is an independent foundation and works in close collaboration with the Medicines Evaluation Board (MEB) to maintain the spontaneous reporting system and collects and assesses reports of adverse drug reactions ${ }^{(17)}$. Reports collected are from health care professionals, consumers and marketing authorisation holders ${ }^{(13)}$. 


\section{Pharmacovigilance}

Pharmacovigilance is regulated on an EU level by means of Regulation 1235/2010 and Directive 2010/84/EUii. Directive 2010/84/EU amends Directive 2001/83/ECiii by laying down rules for pharmacovigilance. The general provisions on pharmacovigilance are described, next to the organisation of the pharmacovigilance system in Member States, the responsibilities of the marketing authorisation holder and the tasks of the Commission $^{(18,19)}$.

Regulation 1235/2010 amends Regulation (EC) No 726/2004 ${ }^{\text {iv }}$ by including pharmacovigilance as an aspect to be taken into consideration with the authorisation and supervision of medicinal products ${ }^{(20)}$. Pharmacovigilance is therefore added to the responsibilities of the EMA's Committee for Medicinal Products for Human Use. The tasks of the marketing authorisation holder and competent authorities of Member States are also further clarified ${ }^{(20,21)}$.

\footnotetext{
i Regulation (EU) No 1235/2010 of the European Parliament and of the Council of 15 December 2010 amending, as regards pharmacovigilance of medicinal products for human use, Regulation (EC) No 726/2004 laying down community procedures for the authorisation and supervision of medicinal products for human and veterinary use and establishing a European Medicines Agency, and Regulation No 1394 on advanced therapy medicinal products (Consolidated version 1 January 2011).
}

ii Directive 2010/84/EU of the European Parliament and of the Council of 15 December 2010 amending, as regards pharmacovigilance, Directive 2001/83/EC on the Community code relating to medicinal products for human use (Consolidated version 20 January 2011).

iii Directive 2001/83 of the European Parliament and of the Council of 6 November 2001 on the Community code relating to medicinal products for human use (Consolidated version 16 November 2012).

iv Regulation (EC) No 726/2004 of the European Parliament and of the Council of 31 March 2004 laying down Community procedures for the authorisation and supervision of medicinal products for human and veterinary use and establishing a European Medicines Agency (Consolidated version 5 June 2013). 


\section{Food and drugs}

Next to regulating pharmacovigilance, EU law also defines concepts as food and drugs. Food is defined by the General Food Law ${ }^{v}$ as any substance or product that is intended or can be expected to be ingested by humans, directly listing various exemptions in Article $2^{(22)}$. Following the amendments made by Direction $2004 / 27 / \mathrm{EC}^{\mathrm{vi}}$ to Directive 2001/83/EC, drugs can be defined as either medicinal products by presentation (substance(s) presented for treating or preventing diseases in human beings) or medicinal products by definition (substance(s) administered to human beings to make a medical diagnosis or to restore, correct or modify physiological functions ${ }^{(19,23)}$. Next to Directive 2001/83/EC, Regulation (EC) No 726/2004 is one of the main EU legislation on medicinal products for human use, by establishing the EMA and describing procedures to authorise and supervise drugs ${ }^{(21)}$.

The products at the interface of food and medicine are defined by and regulated under different directives and regulations. Food supplements are defined as concentrated food ingredients aiming to supplement the normal diet ${ }^{(24)}$. Herbal medicinal products are drugs with only herbal substances or preparations as active ingredients ${ }^{(19,25)}$. Following amendments to Directive 2001/83/EC by the Herbal Directive vii $^{\text {, traditional }}$ herbal medicinal products have to fulfil specific conditions laid down in Directive

\footnotetext{
${ }^{\vee}$ Regulation (EC) No 178/2002 of the European Parliament and of the Council of 28 January 2002 laying down the general principles and requirements of food law, establishing the European Food Safety Authority and laying down procedures in matters of food safety (Consolidated version 30 June 2014).

${ }^{v i}$ Directive 2004/27/EC of the European Parliament and of the Council of 31 March 2004 amending Directive 2001/83/EC on the Community code relating to medicinal products for human use (Consolidated version 30 April 2004).

vii Directive 2004/24/EC of the European Parliament and of the Council of 31 March 2004 amending, as regards traditional herbal medicinal products, Directive 2001/83 on the Community code relating to medicinal products for human use.
} 
2001/83/EC (19,25). The Directive also defines homeopathic medicinal products due to the amendment by Directive 2004/27/EC, as medicinal products prepared from homeopathic stocks in accordance with manufacturing procedures described in either the European or a Member States' Pharmacopoeia ${ }^{(19,23)}$. Anthroposophical medicinal products are treated equally to homeopathic medicinal products ${ }^{(19)}$.

Newly developed legislation on food for special medical purposes defines this category as 'food specifically processed or formulated and intended for the dietary management of patients, including infants, to be used under medical supervision ${ }^{(26)}$. Medical devices form the last category of health-enhancing products, instruments which are used for diagnostic and/or therapeutic purposes in human beings ${ }^{(27)}$. Although the European Commission proposed new legislation as well as recommendations on audits and assessments next to a unique identification system, currently three directives deal with medical devices: Directive 90/385/EEC viii on active implantable medical devices; Directive 98/79/EC ${ }^{\text {ix }}$ on in vitro diagnostic medical devices and Directive 93/42/EEC ${ }^{x}$ on other medical devices ${ }^{(27-29)}$.

Where these categories are all defined in legislation, in the health and wellness category a wide variety of other terms is also used for products at the interface of food and drugs: cosmoceuticals, nutraceuticals, superfoods and functional foods. Cosmoceuticals are known as cosmetic products with bioactive ingredients which elicit positive cosmetic effects, for example on the $\mathrm{skin}^{(30)}$. A nutraceutical is a bioactive food derived ingredient in a pharmaceutical formulation. Various anciently used food

viii Council Directive of 20 June 1990 on the approximation of the laws of the Member States relating to active implantable medical devices (90/385/EEC) (Consolidated version 11 October 2007).

${ }^{\text {ix }}$ Directive 98/79/EC of the European Parliament and of the Council of 27 October 1998 on in vitro diagnostic medical devices (Consolidated version 11 January 2012).

${ }^{x}$ Council Directive 93/42/EEC of 14 June 1993 concerning medical devices (Consolidated version 11 November 2007). 
products, to which health enhancing properties are ascribed, are marketed as superfoods. Functional foods, sometimes referred to as 'health foods', are commonly defined as food products that provide health benefits beyond their normal nutritional effects, due to biologically active components ${ }^{(31,32)}$. These products show that food and drugs are becoming more alike. Before legislating can be developed to deal with this shift, more knowledge upon bioactive components in nutrition and all products in this grey area is required.

\section{Adverse interactions}

Several interactions between bioactive components and drugs are well-known in literature and practice, as the interactive effects of grapefruit juice with various drugs. Grapefruit juice is known to affect the isoenzyme 3A4 of the enzyme cytochrome P450 $(\text { CYP3A4) })^{(12)}$. This enzyme is responsible for the metabolism of various drugs to their metabolites, resulting often in the inactivation of the active substance. When grapefruit juice is consumed, this enzyme is inhibited, leading to higher blood plasma concentrations of the non-metabolised form of such drugs. This can lead to overdosing when the drug is required to be metabolised to become inactive, but when the active substance needs to be metabolised to become active too low dosages can become problematic $^{(12)}$.

\section{Data collection}

From 1991 up to 2014 Lareb received 55 reports on suspected interactive effects of food supplements or herbal (medicinal) products with prescribed drugs. These suspected interactive effects are reported by health professionals, consumers and the pharmaceutical industry based on experienced adverse reactions to medicines and vaccines $^{(13)}$. All reported interactions between prescribed drugs and bioactive compounds were analysed to review in which stage these interactions take place and 
whether these interactive effects can be explained by the properties of the specific (bio)active components.

\section{Reported adverse interactions}

The 55 reported adverse interactions are described in table 1 . The bioactive component from the health enhancing product is followed by the description of the active substance of the medicinal product. Next, the reported clinical manifestation of an interaction is described and potential phase where this interaction occurs is defined in the last column of table 1.

Table 1. Reported adverse drug reactions due to interactions with prescribed medicines and health enhancing products.

\begin{tabular}{|c|c|c|c|}
\hline $\begin{array}{l}\text { Active substance } \\
\text { health-enhancing } \\
\text { product }\end{array}$ & $\begin{array}{l}\text { Active substance } \\
\text { prescribed } \\
\text { medicinal product }\end{array}$ & $\begin{array}{l}\text { Clinical manifestation } \\
\text { of interaction }\end{array}$ & $\begin{array}{l}\text { Potential } \\
\text { phase of } \\
\text { interaction }\end{array}$ \\
\hline $\begin{array}{l}\text { Homeopathic } \\
\text { product containing } \\
\text { Antimonium } \\
\text { sulphuratum } \\
\text { auratum, Bryonia } \\
\text { cretica, Drosera } \\
\text { rotundifolia, } \\
\text { Eucalyptus globulus } \\
\text { and Ipecacuanha }\end{array}$ & $\begin{array}{l}\text { Pantoprazole } \\
\text { (proton pump } \\
\text { inhibitor) }\end{array}$ & $\begin{array}{l}\text { Oedema; dyspnoea; } \\
\text { chest discomfort; } \\
\text { angioedema }\end{array}$ & Unknown \\
\hline $\begin{array}{l}\text { Homeopathic } \\
\text { product containing } \\
\text { Arnica montana }\end{array}$ & $\begin{array}{l}\text { Insuline aspart } \\
\text { (insulin analogue) }\end{array}$ & $\begin{array}{l}\text { Blood glucose } \\
\text { increased }\end{array}$ & Unknown \\
\hline $\begin{array}{l}\text { Homeopathic } \\
\text { product containing } \\
\text { Avena sativa* }\end{array}$ & $\begin{array}{l}\text { Paroxetine } \\
\text { (antidepressant) }\end{array}$ & $\begin{array}{l}\text { Psychomotor } \\
\text { hyperactivity }\end{array}$ & Unknown \\
\hline
\end{tabular}


Table 1 (cont.). Reported adverse drug reactions due to interactions with prescribed medicines and health enhancing products.

\begin{tabular}{|c|c|c|c|}
\hline $\begin{array}{l}\text { Active substance } \\
\text { health-enhancing } \\
\text { product }\end{array}$ & $\begin{array}{l}\text { Active substance } \\
\text { prescribed } \\
\text { medicinal product }\end{array}$ & $\begin{array}{l}\text { Clinical manifestation } \\
\text { of interaction }\end{array}$ & $\begin{array}{l}\text { Potential } \\
\text { phase of } \\
\text { interaction }\end{array}$ \\
\hline Cannabis Sativa & $\begin{array}{l}\text { Baclofen (muscle } \\
\text { relaxant) }\end{array}$ & $\begin{array}{l}\text { Hypotension; increased } \\
\text { heart rate; } \\
\text { anticholinergic } \\
\text { syndrome; } \\
\text { gastrointestinal motility } \\
\text { disorder; peripheral } \\
\text { coldness; coma }\end{array}$ & Unknown \\
\hline Chrome & $\begin{array}{l}\text { Levothyroxine } \\
\text { (thyroid agent) }\end{array}$ & Dizziness & Absorption \\
\hline Cranberry extract & $\begin{array}{l}\text { Azathioprine } \\
\text { (immune } \\
\text { suppressant) }\end{array}$ & Pyrexia; alopecia & Unknown \\
\hline $\begin{array}{l}\text { Diet product with } \\
\text { cassein }\end{array}$ & $\begin{array}{l}\text { Valsartan/hydrochlo } \\
\text { rothiazide } \\
\text { (antihypertensive } \\
\text { drug) }\end{array}$ & Hypokalaemia & Absorption \\
\hline Fish oil & $\begin{array}{l}\text { Lithium carbonate } \\
\text { (lithium) }\end{array}$ & $\begin{array}{l}\text { Potentiating drug } \\
\text { interaction }\end{array}$ & Unknown \\
\hline Fish oil tablets & $\begin{array}{l}\text { Enalapril } \\
\text { (antihypertensive } \\
\text { drug) }\end{array}$ & Hypertension & Unknown \\
\hline $\begin{array}{l}\text { Folic acid; vitamin } \\
\text { B6 }\end{array}$ & $\begin{array}{l}\text { Phenprocoumon } \\
\text { (vitamin } \mathrm{K} \\
\text { antagonist, } \\
\text { anticoagulant) }\end{array}$ & INR increased & Unknown \\
\hline Ginkgo biloba & $\begin{array}{l}\text { Carbamazepine; } \\
\text { lamotrigine } \\
\text { (antiepileptic drug) }\end{array}$ & Epilepsy & $\begin{array}{l}\text { Metabolism } \\
\text { or dynamic }\end{array}$ \\
\hline Ginkgo biloba & $\begin{array}{l}\text { Emtricitabine; } \\
\text { tenofovir disoproxil } \\
\text { fumarate; efavirenz } \\
\text { (anti-viral medicine) }\end{array}$ & Virological failure & Metabolism \\
\hline
\end{tabular}


Table 1 (cont.). Reported adverse drug reactions due to interactions with prescribed medicines and health enhancing products.

\begin{tabular}{|c|c|c|c|}
\hline $\begin{array}{l}\text { Active substance } \\
\text { health-enhancing } \\
\text { product }\end{array}$ & $\begin{array}{l}\text { Active substance } \\
\text { prescribed } \\
\text { medicinal product }\end{array}$ & $\begin{array}{l}\text { Clinical manifestation } \\
\text { of interaction }\end{array}$ & $\begin{array}{l}\text { Potential } \\
\text { phase of } \\
\text { interaction }\end{array}$ \\
\hline Ginkgo biloba & $\begin{array}{l}\text { Phenprocoumon } \\
\text { (vitamin } \mathrm{K} \\
\text { antagonist, } \\
\text { anticoagulant) }\end{array}$ & $\begin{array}{l}\text { Coagulation time } \\
\text { prolonged }\end{array}$ & Metabolism \\
\hline $\begin{array}{l}\text { Ginkgo biloba } \\
\text { extract } 761\end{array}$ & $\begin{array}{l}\text { Acenocoumarol } \\
\text { (vitamin K } \\
\text { antagonist, } \\
\text { anticoagulant) }\end{array}$ & $\begin{array}{l}\text { Therapeutic response } \\
\text { decreased }\end{array}$ & $\begin{array}{l}\text { Metabolism; } \\
\text { dynamic }\end{array}$ \\
\hline $\begin{array}{l}\text { Ginkgo biloba } \\
\text { extract } 761\end{array}$ & $\begin{array}{l}\text { Phenprocoumon } \\
\text { (vitamin } \mathrm{K} \\
\text { antagonist, } \\
\text { anticoagulant) }\end{array}$ & $\begin{array}{l}\text { Coagulation time } \\
\text { prolonged; haematoma }\end{array}$ & $\begin{array}{l}\text { Metabolism; } \\
\text { dynamic }\end{array}$ \\
\hline $\begin{array}{l}\text { Ginkgo biloba } \\
\text { extract } 761\end{array}$ & $\begin{array}{l}\text { Acenocoumarol } \\
\text { (vitamin } \mathrm{K} \\
\text { antagonist, } \\
\text { anticoagulant) }\end{array}$ & Haematuria & Metabolism \\
\hline Glucosamine & $\begin{array}{l}\text { Acenocoumarol } \\
\text { (vitamin } \mathrm{K} \\
\text { antagonist, } \\
\text { anticoagulant) }\end{array}$ & INR increased & Unknown \\
\hline Glucosamine & $\begin{array}{l}\text { Acenocoumarol } \\
\text { (vitamin K } \\
\text { antagonist, } \\
\text { anticoagulant) }\end{array}$ & INR fluctuation & Unknown \\
\hline Glucosamine & $\begin{array}{l}\text { Metformine } \\
\text { hydrochloride (oral } \\
\text { antidiabetic agent) }\end{array}$ & $\begin{array}{l}\text { Blood glucose } \\
\text { increased }\end{array}$ & Dynamic \\
\hline Glucosamine & $\begin{array}{l}\text { Simvastatin (lipid- } \\
\text { lowering agent) }\end{array}$ & $\begin{array}{l}\text { Blood glucose } \\
\text { increased }\end{array}$ & Dynamic \\
\hline Glucosamine & $\begin{array}{l}\text { Phenytoin } \\
\text { (antiepileptic drug) }\end{array}$ & Drug ineffective & Unknown \\
\hline
\end{tabular}


Table 1 (cont.). Reported adverse drug reactions due to interactions with prescribed medicines and health enhancing products.

\begin{tabular}{|c|c|c|c|}
\hline $\begin{array}{l}\text { Active substance } \\
\text { health-enhancing } \\
\text { product }\end{array}$ & $\begin{array}{l}\text { Active substance } \\
\text { prescribed } \\
\text { medicinal product }\end{array}$ & $\begin{array}{l}\text { Clinical manifestation } \\
\text { of interaction }\end{array}$ & $\begin{array}{l}\text { Potential } \\
\text { phase of } \\
\text { interaction }\end{array}$ \\
\hline $\begin{array}{l}\text { Glucosamine; } \\
\text { chondroitin }\end{array}$ & $\begin{array}{l}\text { Acenocoumarol } \\
\text { (vitamin } \mathrm{K} \\
\text { antagonist, } \\
\text { anticoagulants) }\end{array}$ & INR increased & Unknown \\
\hline $\begin{array}{l}\text { Glucosamine; } \\
\text { chondroitin }\end{array}$ & $\begin{array}{l}\text { Acenocoumarol } \\
\text { (vitamin K } \\
\text { antagonist, } \\
\text { anticoagulant) }\end{array}$ & INR increased & Unknown \\
\hline $\begin{array}{l}\text { Glucosamine } \\
\text { polymer chitosan }\end{array}$ & $\begin{array}{l}\text { Valproic acid } \\
\text { (antiepileptic drug) }\end{array}$ & Epileptic seizures & Unknown \\
\hline Hop & $\begin{array}{l}\text { Levothyroxine } \\
\text { natrium-X-water } \\
\text { (thyroid agent) }\end{array}$ & Hypothyroidism & Absorption \\
\hline Melatonin & $\begin{array}{l}\text { Acenocoumarol } \\
\text { (vitamin K } \\
\text { antagonist, } \\
\text { anticoagulant) }\end{array}$ & INR decreased & Unknown \\
\hline Melatonin & $\begin{array}{l}\text { Dexamfetamine } \\
\text { (amphetamine } \\
\text { isomer) }\end{array}$ & Syncope & Unknown \\
\hline Melatonin & $\begin{array}{l}\text { Sodium valproate } \\
\text { (antiepileptic drug) }\end{array}$ & Convulsion; insomnia & Dynamic \\
\hline Multivitamin & $\begin{array}{l}\text { Acenocoumarol } \\
\text { (vitamin K } \\
\text { antagonist, } \\
\text { anticoagulant) }\end{array}$ & $\begin{array}{l}\text { Inhibitory drug } \\
\text { interaction }\end{array}$ & Dynamic \\
\hline Multivitamin & $\begin{array}{l}\text { Ethinylestradiol/levo } \\
\text { norgestrel (oral } \\
\text { contraceptive) }\end{array}$ & Nausea & Unknown \\
\hline
\end{tabular}


Table 1 (cont.). Reported adverse drug reactions due to interactions with prescribed medicines and health enhancing products.

\begin{tabular}{|c|c|c|c|}
\hline $\begin{array}{l}\text { Active substance } \\
\text { health-enhancing } \\
\text { product }\end{array}$ & $\begin{array}{l}\text { Active substance } \\
\text { prescribed } \\
\text { medicinal product }\end{array}$ & $\begin{array}{l}\text { Clinical manifestation } \\
\text { of interaction }\end{array}$ & $\begin{array}{l}\text { Potential } \\
\text { phase of } \\
\text { interaction }\end{array}$ \\
\hline Multivitamin & $\begin{array}{l}\text { Levetiracetam; } \\
\text { fluoxetine } \\
\text { hydrochloride } \\
\text { (antiepileptic drug } \\
\text { and antidepressant) }\end{array}$ & Insomnia; hallucination & Unknown \\
\hline Plant sterols & $\begin{array}{l}\text { Acenocoumarol } \\
\text { (vitamin } \mathrm{K} \\
\text { antagonist, } \\
\text { anticoagulant) }\end{array}$ & $\begin{array}{l}\text { Potentiating drug } \\
\text { interaction }\end{array}$ & Absorption \\
\hline $\begin{array}{l}\text { Plantago ovata } \\
\text { pericarp }\end{array}$ & $\begin{array}{l}\text { Candesartan } \\
\text { cilexetil } \\
\text { (antihypertensive } \\
\text { drug) }\end{array}$ & Allergic rhinitis & Unknown \\
\hline $\begin{array}{l}\text { Homeopathic } \\
\text { product containing } \\
\text { Rhus } \\
\text { toxicodendron; } \\
\text { gum* }\end{array}$ & $\begin{array}{l}\text { Carbamazepine; } \\
\text { oxazepam } \\
\text { (antiepileptic drug } \\
\text { and anxiolytic } \\
\text { agent) }\end{array}$ & Drug level decreased & $\begin{array}{l}\text { Unknown, } \\
\text { for gum } \\
\text { potentially } \\
\text { absorption. }\end{array}$ \\
\hline $\begin{array}{l}\text { Homeopathic } \\
\text { product containing } \\
\text { Rhus } \\
\text { toxicodendron* }\end{array}$ & $\begin{array}{l}\text { Digoxin (cardiac } \\
\text { glycosides) }\end{array}$ & Palpitations & Unknown \\
\hline Saw palmetto* & $\begin{array}{l}\text { [unknown, } \\
\text { potentially } \\
\text { anticoagulant] }\end{array}$ & INR increased & Unknown \\
\hline $\begin{array}{l}\text { Homeopathic } \\
\text { product containing } \\
\text { St. John's wort* }\end{array}$ & $\begin{array}{l}\text { Desogestrel/ethinyl } \\
\text { estradiol (oral } \\
\text { contraceptive) }\end{array}$ & Metrorrhagia & Metabolism \\
\hline $\begin{array}{l}\text { Homeopathic } \\
\text { product containing } \\
\text { St. John's wort* }\end{array}$ & $\begin{array}{l}\text { Desogestrel/ethinyl } \\
\text { estradiol (oral } \\
\text { contraceptive) }\end{array}$ & Metrorrhagia & Metabolism \\
\hline
\end{tabular}


Table 1 (cont.). Reported adverse drug reactions due to interactions with prescribed medicines and health enhancing products.

\begin{tabular}{|c|c|c|c|}
\hline $\begin{array}{l}\text { Active substance } \\
\text { health-enhancing } \\
\text { product }\end{array}$ & $\begin{array}{l}\text { Active substance } \\
\text { prescribed } \\
\text { medicinal product }\end{array}$ & $\begin{array}{l}\text { Clinical manifestation } \\
\text { of interaction }\end{array}$ & $\begin{array}{l}\text { Potential } \\
\text { phase of } \\
\text { interaction }\end{array}$ \\
\hline St. John's wort & $\begin{array}{l}\text { Ethinylestradiol/gest } \\
\text { odene (oral } \\
\text { contraceptive) }\end{array}$ & Metrorrhagia & Metabolism \\
\hline St. John's wort & $\begin{array}{l}\text { Ethinylestradiol/levo } \\
\text { norgestrel (oral } \\
\text { contraceptive) }\end{array}$ & Metrorrhagia & Metabolism \\
\hline St. John's wort & $\begin{array}{l}\text { Ethinylestradiol/levo } \\
\text { norgestrel (oral } \\
\text { contraceptive) }\end{array}$ & Metrorrhagia & Metabolism \\
\hline St. John's wort & $\begin{array}{l}\text { Sertraline } \\
\text { hydrochloride } \\
\text { (antidepressant) }\end{array}$ & Mania & Metabolism \\
\hline St. John's wort & $\begin{array}{l}\text { Clozapine } \\
\text { (antipsychotic drug) }\end{array}$ & $\begin{array}{l}\text { Psychotic disorder; anti- } \\
\text { psychotic drug levels } \\
\text { below therapeutic; } \\
\text { scizophrenia } \\
\text { aggrevated }\end{array}$ & Metabolism \\
\hline St. John's wort & $\begin{array}{l}\text { Imipramine } \\
\text { hydrochloride } \\
\text { (antidepressant) }\end{array}$ & $\begin{array}{l}\text { Anticholinergic } \\
\text { syndrome; dehydration }\end{array}$ & Metabolism \\
\hline St. John's wort & $\begin{array}{l}\text { Enalapril/hydrochlor } \\
\text { othiazide } \\
\text { (antihypertensive } \\
\text { drug) }\end{array}$ & Drug ineffective & Dynamic \\
\hline St. John's wort & $\begin{array}{l}\text { Exemestane } \\
\text { (hormone) }\end{array}$ & $\begin{array}{l}\text { Blood creatine } \\
\text { phosphokinase } \\
\text { increased; myalgia; joint } \\
\text { swelling }\end{array}$ & Metabolism \\
\hline St. John's wort & $\begin{array}{l}\text { Insulin detemir } \\
\text { (insulin analogue) }\end{array}$ & $\begin{array}{l}\text { Blood glucose } \\
\text { fluctuation }\end{array}$ & Unknown \\
\hline
\end{tabular}


Table 1 (cont.). Reported adverse drug reactions due to interactions with prescribed medicines and health enhancing products.

\begin{tabular}{|l|l|l|l|}
\hline $\begin{array}{l}\text { Active substance } \\
\text { health-enhancing } \\
\text { product }\end{array}$ & $\begin{array}{l}\text { Active substance } \\
\text { prescribed } \\
\text { medicinal product }\end{array}$ & $\begin{array}{l}\text { Clinical manifestation } \\
\text { of interaction }\end{array}$ & $\begin{array}{l}\text { Potential } \\
\text { phase of } \\
\text { interaction }\end{array}$ \\
\hline St. John's wort & $\begin{array}{l}\text { Metronidazole } \\
\text { (antimicrobial } \\
\text { medicine) }\end{array}$ & $\begin{array}{l}\text { Confusional state; } \\
\text { influenza like illness; } \\
\text { body temperature } \\
\text { increased }\end{array}$ & Unknown \\
\hline St. John's wort & $\begin{array}{l}\text { Quetiapine } \\
\text { (antipsychotic drug) }\end{array}$ & $\begin{array}{l}\text { Panic attack; insomnia; } \\
\text { dyspepsia; dizziness }\end{array}$ & Metabolism \\
\hline Valerian root & $\begin{array}{l}\text { Acenocoumarol } \\
\text { (vitamin K } \\
\text { antagonist, } \\
\text { anticoagulant) }\end{array}$ & INR disrupted & Metabolism \\
\hline Valerian root & $\begin{array}{l}\text { Oxazepam, } \\
\text { diazepam (anxiolytic } \\
\text { agents) }\end{array}$ & $\begin{array}{l}\text { Agitation, tremor, } \\
\text { tension, insomnia }\end{array}$ & Dynamic \\
\hline Vitamin B complex & $\begin{array}{l}\text { Clomipramine } \\
\text { hydrochloride } \\
\text { (antidepressant) }\end{array}$ & Panic reaction & Dynamic \\
\hline Weight loss \\
coffee**
\end{tabular}

* = Causality questioned.

** = Potentially caused by the illegal ingredient sibutramin.

Of the 55 reported interactions to Lareb, 13 reports described the concomitant use of St. John's wort. This included five reports concerning interactive effects with contraceptives. Liver enzyme inducing substances as St. John's wort (inducing CYP3A4 and the P-glycoprotein pump) are seen to lower oestrogen and progestogen levels, making the contraceptive less reliable ${ }^{(33)}$. Other reports concerned interactions with anti-depressants, which are also metabolised (at least partially) via CYP3A4, an ACEinhibitor which requires metabolisation before being active and an insulin mimicking substance, which is metabolised to inactive metabolites via the liver and in muscles ${ }^{(33)}$. 
With St. John's wort affecting metabolism, some of the different drugs will be activated too fast and others will be excreted too quickly, possibly resulting in severe adverse effects. Combining anti-depressants with St. John's wort can also lead dynamic interactions due to the synergistic effects these products elicit, known as the serotonergic syndrome ${ }^{(34)}$.

Ginkgo biloba intake, either as registered medicine or supplement, resulted in six reports of adverse drug reactions: four interactions with vitamin $\mathrm{K}$ antagonists, one with an antiviral medicine and one with anti-epileptic drugs. Vitamin $\mathrm{K}$ antagonists are anticoagulants, which inhibit synthesis of coagulation factors and thereby decrease blood clotting. Where the actions of vitamin $\mathrm{K}$ antagonists can be inhibited by a substance as St. John's wort, it can be intensified by other substances as antibiotics and salicylates ${ }^{(33)}$. The active substances of Ginkgo biloba are known to be flavonoids and terpenoids, of which Ginkgolide B is shown to inhibit platelet aggregation ${ }^{(35,36)}$. Ginkgo biloba extracts are also seen to inhibit P-glycoprotein and various CYP450 enzymes, including CYP2C9 and CYP3A4. Thereby Ginkgo biloba supplementation could increase the risk of bleeding ${ }^{(36,37)}$. The interaction with a non-nucleoside reverse transcriptase inhibitor, an anti-viral agent which is metabolised via CYP3A4 can thereby also be explained by the inhibiting effects of Ginkgo of CYP3A4 ${ }^{(37)}$. The neurotoxic component of Ginkgo, ginkgotoxin, is believed to cause the interactive effect of Ginkgo consumption with anti-epileptic medication. This ginkgotoxin could lead to decreased GABA levels, although the metabolism via CYP3A4 of the drugs could also be inhibited by Ginkgo biloba $^{(33)}$.

Eight reports concerning interactions with glucosamine supplements (containing at least $1500 \mathrm{mg}$ glucosamine) were received, including four interactions with vitamin $\mathrm{K}$ antagonists (acenocoumarol), two with oral antidiabetic drugs and two with antiepileptic drugs. The anti-epileptic drugs in the reports are: (i) valproic acid, metabolised for $50 \%$ via glucuronidation, $30-40 \%$ via $\beta$-oxidation and the other $10 \%$ by metabolisation in the liver via CYP2C9, CYP2C19 and CYP2A6; and (ii) fenytoine, which 
is metabolised for approximately $90 \%$ by CYP2C9 and CYP2C19 in the liver ${ }^{(33)}$. A known adverse effect of glucosamine is impaired glucose tolerance, possibly due to lowering insulin secretion by $\beta$-cells of the pancreas or by affecting peripheral glucose uptake, which could explain the possible interactive effects with oral antidiabetic drugs ${ }^{(33)}$. The increased effects of vitamin $\mathrm{K}$ antagonists following combined intake with glucosamine is described more often in literature, although the exact mechanism is not known ${ }^{(33,35,38)}$. In two of the reports concerning glucosamine and vitamin K antagonists, glucosamine is combined with chondroitin. Chondroitin is associated with increased bleeding, which could explain the reported adverse effects ${ }^{(35)}$.

Interactions following vitamin supplements consumed with drugs were reported in six cases. Two reports concerned the intake of vitamin $\mathrm{K}$ antagonists, one with folic acid and vitamin B6 and one with a multivitamin tablet containing vitamin $\mathrm{K}$, although in a normally non-problematic dosage. However, this intake of vitamin $\mathrm{K}$ when consuming the multivitamin tablet could be inhibiting the actions of vitamin $\mathrm{K}$ antagonists, leading to the reported adverse drug reactions. The effects of folic acid or vitamin B6 on vitamin $\mathrm{K}$ antagonists cannot be explained. Other reports concerned nicotine interacting with vitamin $\mathrm{C}$ and an anti-epileptic and an anti-depressant drug with a multivitamin tablet, of which the interactive effect cannot be explained. The interaction between an antidepressant with vitamin B complex intake could result from potential effects of vitamin B6 and B11 on the central nervous system, or potential interactive effects of the metabolism of the anti-depressant via CYP450 enzymes. The last report concerned the interactive effect following multivitamin supplementation during contraceptive intake, leading to nausea. Although the use of oral contraceptives can increase the need of vitamins, there is no interaction known which could explain this adverse event.

Other reported interactions concerned combined intake of various drugs with different herbal or food supplements, including valerian extract affecting benzodiazepines and a vitamin $\mathrm{K}$ antagonist. Valerian root is shown to inhibit CYP3A4 and possibly other isoenzymes ${ }^{(39)}$. With acenocoumarol being metabolised by mainly CYP2C9 and partially 
CYP1A2 and CYP2C19, valerian root could be affecting these enzymes as well which would lead to an interaction on the level of metabolism ${ }^{(33)}$. The adverse drug reactions occurring when valerian root is used concomitantly with benzodiazepines can be explained by the sedative effects of valerian extract itself. Combining it with an antidepressant can result in a dynamic interaction of these synergistic effects ${ }^{(39)}$.

Table 1 also describes melatonin intake to interact with (i) anti-epileptic drugs, (ii) amphetamines or (iii) vitamin $\mathrm{K}$ antagonists which currently cannot be explained by either the pharmacokinetics or pharmacodynamics of melatonin. Cranberry extract is described to result in the increased metabolism of a purine-antagonist. It is also suggested to affect corticosteroids and benzodiazepines by potentially inducing liver enzymes. An anti-epileptic drug is suggested to interact with either a homeopathic medicinal product or gum, which could increase absorption ${ }^{(33)}$.

\section{Discussion}

The 55 suspected reported interactions between drugs and herbal or food supplements vary in severity of adverse effects. These 55 reports are however thought to be only a very small share of the interactions occurring due to concomitant consumption of these health enhancing products with medication. Generally speaking underreporting is a reality for spontaneous reporting systems and probably the level of underreporting is even higher for herbals or food supplements because the use of these products is often unknown to a patient's healthcare professional.

As described in table 1 , of 26 of the 55 reported adverse drug reactions the stage where the interaction occurs is not known. It is inherit to the method of spontaneous reporting in pharmacovigilance that the causality is not certain for all reported reactions. Causality of the interactive effect due to the intake of both drugs and the bioactive cannot always be validated. 
The interactions which can be explained mostly occur in the phase of pharmacokinetics, more specifically in the metabolism stage of the active substance of the drug. Metabolism is one of the four stages of pharmacokinetics (ADME), the process describing the distribution of a pharmacological compound, in which enzymes oxidise and subsequently conjugate the active substance. Metabolism (M) is preceded by absorption ( $A$, focussing on the concentration or amount of a substance which is absorbed into the bloodstream) and distribution ( $D$, stage describing the transfer of the active substance to different locations), and followed by excretion ( $E$, removing the substance out of the body). Within the absorption and metabolism phases, most interactions are known to occur, although also the distribution and excretion of drugs and its metabolites can be altered due to specific herbal or dietary compounds ${ }^{(40,41)}$.

\section{Potential interactions during phase of absorption}

Various examples can be given of interactions that can occur between food components or other bioactive products and drugs. Bisphosphonates and several antibiotics are known to interact with foods rich in minerals as cheese and milk. These drugs form complexes with the calcium from these foods, decreasing their absorption up to $60 \%^{(41)}$. Fibres can interact in the absorption phase with digoxin and levothyroxine, decreasing the absorbed amount of the active substances. This could be an explanation for the reported interaction between hop and levothyroxine described in table $1^{(41,42)}$. Food products are not only able to interact with drugs, drugs can also influence the absorption of dietary components. Drugs aimed to reduce fat absorption, as litramine (a dietary fibre derived from Opuntia ficus indica) binding fat in the gastro intestinal tract or orlisat as a reversible inhibitor of lipases in the GI tract reducing fat absorption, could lead to decreased absorption of lipophilic components ${ }^{(43-45)}$. These can be vitamins A, D, E or K, but also the absorption of other lipophilic components as pharmaceutical substances could be reduced. Where these examples all stipulate the potential of reduced absorption, other products are known to be absorbed in an increased amount as nitrofurantoin combined with milk or a meal, increasing the bioavailability with 200 up to $400 \%^{(41)}$. 


\section{Potential interactions during phase of metabolism}

When interactions occur during the metabolism phase, the metabolising enzymes (involved in biotransformation of endogenous and exogenous compounds) or transport proteins are either inhibited or induced. This seems to occur in various reported interactions (table 1). When the enzymes are induced, their activity is increased due to increased mRNA transcription. Thereby the enzyme is metabolising the substance more quickly, leading to altered plasma concentrations of the prescribed drug $^{(40)}$. With inhibition, the most well understood is the inhibition due to competition of a bioactive with another substance to become the substrate of the CYP450 enzyme. This leads to concentration dependent decreased action of the enzymes, resulting in increased plasma levels of the substrate ${ }^{(40,46)}$.

As described in 'Adverse interactions', the interactions between grapefruit and various drugs are well-known examples of these types of interactions ${ }^{(12,41,47)}$. The inhibitory effects are partly attributed to the flavonoids found in grapefruits ${ }^{(12,40,47)}$. Also other flavonoids are known to affect CYP enzymes, including rotenone and resveratrol ${ }^{(40)}$. Functional changes (in phase I) are mostly followed by conjugation (phase II), which can also be affected by flavonoids ${ }^{(40)}$. This is exemplified by curcumin, increasing the activity of glutathione S-transferase and valerian that decreases the activity of uridine diphosphoglucoronosyl transferase ${ }^{(40)}$. By affecting these enzymes, the plasma levels of drugs might alter which potentially causes adverse effects.

The metabolism of xenobiotics is highly influenced by individual differences, as polymorphisms of certain CYP isoenzymes or lifestyle. This can lead to idiosyncratic drug reactions, rare adverse reactions which occur due to a combination of risk factors in an individual ${ }^{(48)}$. These idiosyncratic reactions could explain some of the unexpected interactions between bioactive compounds and drugs. These individual differences can have considerable influences on the effects elicited by drugs. This could explain the occurrence of more clinically relevant interactions when (sudden) serious changes in the diet are made ${ }^{(41)}$. 


\section{Potential interactions during pharmacodynamics stage}

Interactions do not only occur in the pharmacokinetic stage. Also the effects of the active substances can be influenced due to concomitant intake of other bioactive substances, the pharmacodynamic stage. This is exemplified by the adverse effects reported with St. John's wort combined with anti-hypertensive medication (table 1), in which case St. John's wort could result in increased blood pressure. Other examples include the decreased effectiveness of oral contraceptives when combined with vitamin B6 or the increased efficacy of acetylsalicylic acid when it is taken together with vitamin $\mathrm{E}^{(41)}$.

\section{The distinction is diffuse}

As described in the legal perspective, legally the definitions of food and drugs are substantially separated. An increased amount of health-enhancing products however can be found on the market, which do not seem to be fully covered by the definitions of food and drugs. To deal with these products as food supplements, medical foods and even medical devices, new legislation is developed in an attempt to ensure consumer safety and truthful advertisement on their effects.

Yet, the use of these health-enhancing products is also diffuse: consumers do not only use prescribed drugs to combat diseases or symptoms of diseases, also herbal medicinal products, homeopathic medicinal products, food supplements and food items are used in an attempt to remain healthy or increase health. With the bioactive components as main reason to use these products, the artificial separation of food and drugs in law does not seem to be applicable anymore.

\section{Conclusion}

The growing interest of consumers in using health enhancing products as food supplements and herbal preparations increases the risk of interactions between these bioactives and prescribed drugs. Although we focussed on the adverse reactions 
caused by these interactions, it is known that combining these products can result in positive effects as well. Bioactive compounds can reduce the toxicity or improve the actions of drugs: epicatechin derived from cocoa was shown to prevent cortisol resistance and protect the anti-inflammatory effects of dexamethasone, which is relevant for their use in chronic inflammatory lung diseases ${ }^{(49,50)}$. Flavonoids are also known to prevent the cardiotoxic adverse effects of the antitumor agent doxorubicin ${ }^{(51)}$. With the reported suspected interactions between bioactive components and prescribed drugs we tried to outline that the combination of these products can result in serious adverse reactions. This emphasises the need for more knowledge upon bioactive substances and the effects that can result from combining these products.

Currently, legislation does not fit the landscape of health enhancing products. The wide variety of bioactive compounds is being regulated by many different rules and regulations. With a food product being clearly defined to be a food due to its intended use, a bioactive can be considered to be a drug due to its presentation. The grey area created by these definitions is already depicted by the case of food supplements: would it become a drug due to its dosage or presented from or is it a food due to its intended use? The created legal dilemma can only be resolved by defining and characterising the bioactive substance and its interactions by studying molecular nutrition, instead of developing more legislation on new product categories. By understanding the molecular mechanisms of bioactive compounds, potential interactions can be better understood and prevented. In this respect even individual differences can be taken into account. By considering the dietary pattern and use of bioactive substances with prescribed medication, both health professionals and consumers will be increasingly aware of interactions and these interactive adverse effects can be prevented. 


\section{References}

1. Georgiou NA, Garssen J \& Witkamp RF (2011) Pharma-nutrition interface: The gap is narrowing. Eur. J. Pharmacol. 651, 1-8.

2. Menrad K (2003) Market and marketing of functional food in Europe. J. Food Eng. 56, 181-188.

3. Eussen SRBM, Verhagen $\mathrm{H}$, Klungel $\mathrm{OH}$, et al. (2011) Functional foods and dietary supplements: Products at the interface between pharma and nutrition. Eur. J. Pharmacol. 668, S2-S9.

4. Euromonitor International (2015) Fortified/Functional Packaged Food - Worldwide Historic Growth (2009-2014).

5. Euromonitor International (2013) Health and wellness: functionality, naturalness and stevia key to developing beverages to fit today's trends.

6. Alissa EM (2014) Medicinal herbs and therapeutic drugs interactions. Ther. Drug Monit. 36, 413-422.

7. Biesalski H-K, Dragsted LO, Elmadfa I, et al. (2009) Bioactive compounds: definition and assessment of activity. Nutrition 25, 1202-1205.

8. Euromonitor International (2011) Female Breadwinners - How the Rise in Working Women is Influencing Spending Patterns.

9. Boullata JI \& Hudson LM (2012) Drug-Nutrient Interactions: A Broad View with Implications for Practice. J. Acad. Nutr. Diet. 112, 506-517.

10. Cheng TO (2006) Food-drug interactions. Int. J. Cardiol. 106, 392-393.

11. Fugh-Berman A (2000) Herb-drug interactions. Lancet 355, 134-138.

12. Pirmohamed M (2013) Drug-grapefruit juice interactions. BMJ 346, f1.

13. Netherlands Pharmacovigilance Centre Lareb (2015) Lareb - Home. http://www.lareb.nl/?lang=en-GB (accessed April 2015).

14. Netherlands Pharmacoviglance Centre Lareb (2015) Lareb - History. http://www.lareb.nl/Over-Lareb/Geschiedenis (accessed April 2015).

15. Lachmann PJ (2012) The penumbra of thalidomide, the litigation culture and the licensing of pharmaceuticals. QJM 105, 1179-1189.

16. World Health Organization (2015) Pharmacovigilance. http://www.who.int/medicines/areas/quality_safety/safety_efficacy/pharmvigi/en/ (accessed April 2015).

17. Netherlands Pharmacoviglance Centre Lareb (2015) Lareb - FAQ's. http://www.lareb.nl/Over-Lareb/Veel-gestelde-vragen (accessed April 2015).

18. European Parliament and Council of the European Union (2010) Directive 2010/84/EU of the European Parliament and of the Council of 15 December 2010 amending, as regards pharmacovigilance, Directive 2001/83/EC on the Community code relating to medicinal products for human use. OJ L 348 53, 74-99.

19. European Parliament and Council of the European Union (2001) Directive 2001/83/EC of the European Parliament and of the Council of 6 November 2001 on the Community code relating to medicinal products for human use. OJ L $31144,67-128$. 
20. European Parliament and Council of the European Union (2010) Regulation (EU) No 1235/2010 of the European Parliament and of the Council of 15 December 2010 amending, as regards pharmacovigilance of medicinal products for human use, Regulation (EC) No 726/2004 laying down Community procedures for the authorisation and supervision of medicinal prouducts for human and veterinary use and establishing a European Medicines agency, and Regulation (EC) No 1394/2007 on advanced therapy medicinal products. OJ L 348 53, 1-16.

21. European Parliament and Council of the European Union (2004) Regulation (EC) No $726 / 2004$ of the European Parliament and of the Council of 31 March 2004 laying down Community procedures for the authorisation and supervision of medicinal products for human and veterinary use and establishing a European Medicines Agency. OJ L 136 47, $1-33$.

22. European Parliament and Council of the European Union (2002) Regulation (EC) No 178/2002 of the European Parliament and of the Council of 28 January 2002 laying down the general principles and requirements of food law, establishing the European Food Safety Authority and laying down procedures in matters of food safety. OJ L $3145,1-24$.

23. European Parliament and Council of the European Union (2004) Directive 2004/27/EC of the European Parliament and of the Council of 31 March 2004 amending Directive 2001/83/EC on the Community code relating to medicinal products for human use. OJ L 136 47, 34-57.

24. European Parliament and Council of the European Union (2002) Directive 2002/46/EC of the European Parliament and of the Council of 10 June 2002 on the approximation of the laws of the Member States relating to food supplements. OJ L 183 45, 51-57.

25. European Parliament and Council of the European Union (2004) Directive 2004/24/EC of the European Parliament and of the Council of 31 March 2004 amending, as regards traditional herbal medicinal products, Directive 2001/83/EC on the Community code relating to medicinal products for human use. OJ L 13647 , 85-90.

26. European Parliament and Council of the European Union (2013) Regulation (EU) No 609/2013 of the European Parliament and of the Council of 12 June 2013 on food intended for infants and young children, food for special medical purposes, and total diet replacement for weight control and repealing Council Directive 92/52/EEC Commission Directives 96/8/EC, 1999/21/EC, 2006/125/EC and 2006/141/EC, Directive 2009/39/EC of the European Parliament and of the Council and Commission Regulations (EC) No 41/2009 and (EC) No 953/2009. OJ L 181 56, 35-56.

27. Council of the European Union (1990) Council Directive 90/385/EEC of 20 June 1990 on the approximation of the laws of the Member States relating to active implantable medical devices. OJ L 189 33, 17-36.

28. European Parliament and Council of the European Union (1998) Directive 98/79/EC of the European Parliament and of the Council of 27 October 1998 on in vitro diagnostic medical devices. OJ L 331 41, 1-37.

29. Council of the European Union (1993) Council Directive 93/42/EEC of 14 June 1993 concerning medical devices. OJ L 169 36, 1-43. 
30. Harrison-Dunn A-R (2015) In the eye of the beholder: Where does the EU stand on beauty claims? http://www.nutraingredients.com/Trends/Health-claims/Where-doesthe-EU-stand-on-beauty-claims (accessed April 2015).

31. Katan MB (2004) Health claims for functional foods: regulations vary between countries and often permit vague claims. Br. Med. J. 328, 180.

32. European Food Information Council (2015) Functional Foods. http://www.eufic.org/article/en/expid/basics-functional-foods/ (accessed April 2015).

33. Commissie Farmacotherapeutisch Kompas Zorginstituut Nederland (2015) Farmacotherapeutisch Kompas. https://www.farmacotherapeutischkompas.nl/ (accessed April 2015).

34. Izzo AA (2004) Drug interactions with St. John's Wort (Hypericum perforatum): a review of the clinical evidence. Int. J. Clin. Pharmacol. Ther. 42, 139-148.

35. Baxter K (2008) Stockley's Drug Interactions. 8th ed. [Baxter K, editor]. London: Pharmaceutical Press.

36. Barnes J, Anderson LA \& Philipson JD (2007) Ginkgo. In Herbal Medicines, 3rd ed., pp. 299-314. London: Pharmaceutical Press.

37. Wiegman D-J, Brinkman K \& Franssen EJF (2009) Interaction of Ginkgo biloba with efavirenz. AIDS 23, 1184-1185.

38. Knudsen JF \& Sokol GH (2008) Potential glucosamine-warfarin interaction resulting in increased international normalized ratio: case report and review of the literature and MedWatch database. Pharmacotherapy 28, 540-548.

39. Barnes J, Anderson LA \& Philipson JD (2007) Valerian. In Herbal Medicines, 3rd ed., pp. 580-590. London: Pharmaceutical Press.

40. Fasinu PS, Bouic PJ \& Rosenkranz B (2012) An Overview of the Evidence and Mechanisms of Herb-Drug Interactions. Front. Pharmacol. 3, 69.

41. Sissingh-Blok L Voeding \& Geneesmiddelen - Weerzijdse interacties. Numansdorp: Natura Foundation.

42. Liel Y, Harman-Boehm I \& Shany S (1996) Evidence for a clinically important adverse effect of fiber-enriched diet on the bioavailability of levothyroxine in adult hypothyroid patients. J. Clin. Endocrinol. Metab. 81, 857-859.

43. Grube B, Chong P-W, Lau K-Z, et al. (2013) A natural fiber complex reduces body weight in the overweight and obese: a double-blind, randomized, placebo-controlled study. Obesity 21, 58-64.

44. Chong P-W, Lau K-Z, Gruenwald J, et al. (2014) A Review of the Efficacy and Safety of Litramine IQP-G-002AS, an Opuntia ficus-indica Derived Fiber for Weight Management. Evid. Based. Complement. Alternat. Med., 943713.

45. McClendon KS, Riche DM \& Uwaifo GI (2009) Orlistat: current status in clinical therapeutics. Expert Opin. Drug Saf. 8, 727-744.

46. Zhang Z-Y \& Wong YN (2005) Enzyme kinetics for clinically relevant CYP inhibition. Curr. Drug Metab. 6, 241-257.

47. Boersma HH \& Stolk LML (1999) 'Innemen 2 uur voor of na een menu met spruitjes'. Voeding en het metabolisme van geneesmiddelen. Pharm. Weekbl. 134, 1254-1259. 
Chapter 7

48. Ulrich RG (2007) Idiosyncratic toxicity: a convergence of risk factors. Annu. Rev. Med. 58, 17-34.

49. Ruijters EJB, Haenen GRMM, Weseler AR, et al. (2014) The cocoa flavanol (-)-epicatechin protects the cortisol response. Pharmacol. Res. 79, 28-33.

50. Ruijters EJB, Haenen GRMM, Weseler AR, et al. (2014) The anti-inflammatory efficacy of dexamethasone is protected by (-)-epicatechin. PharmaNutrition 2, 47-52.

51. Bast A, Kaiserová $H$, Hartog GJM, et al. (2006) Protectors against doxorubicin-induced cardiotoxicity: Flavonoids. Cell Biol. Toxicol. 23, 39-47. 


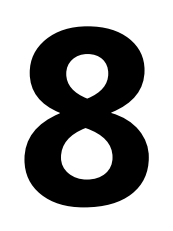

A bioactive is a bioactive is a bioactive: active ingredients should be leading in health claims on functional foods Alie de Boer, Miriam J.E. Urlings, Aalt Bast 
Chapter 8

\section{Abstract}

The first criterion in reviewing scientific substantiation of health claims by the European Food Safety Authority is the definition and characterisation of the active ingredient responsible for the claimed health effect. This study analyses three health claim dossiers in which the active ingredient responsible for the health effect is directly connected to the food item containing the bioactive, either in the claim or in the conditions of use. Since the bioactive itself is held responsible for the health effect, this association of the food item and the bioactive is not always justifiable. Two elements influence whether the bioactive ingredient can be linked to a specific food component: (i) the type of claim considered and (ii) the substantiating evidence available and delivered in the dossier. We argue that it would be preferable to chemically define the active ingredients for subsequent use in standardising the real bioactive substance in the claim. Health claims then become more transparent and therefore more relevant to both the industry and consumers. In this manner claims can be based on a bioactive constituent without the necessity to connect the claim to a specific matrix. Therefore characterisation and defining the active ingredient should be central in the health claim. 


\section{Introduction}

Following various food scares in the 1990s such as the BSE crisis and the dioxin crisis, the EU's approach to food and food safety was radically transformed from an economic perspective to a more consumer-centred policy ${ }^{(1,2)}$. One of the 84 proposed actions described in the European Commission (EC)'s White Paper on Food Safety, to achieve 'the highest possible level of health protection', resulted in the development of the Nutrition and Health Claim Regulation $(\mathrm{NHCR})^{i}$ in $2006^{(3,4)}$. Next to improving the functioning of the internal market by harmonisation of laws, the NHCR aims to protect consumers from being misled ${ }^{(4)}$. It therefore regulates communication about the nutritional content and/or health benefits of a product ${ }^{(4,5)}$. Scientific substantiation of proposed health claims is assessed by the European Food Safety Authority (EFSA). When deciding upon authorisation of a health claim, the EC takes into account the scientific opinion of EFSA ${ }^{(2)}$.

EFSA considers three criteria in reviewing the scientific substantiation for a health claim:

(i) definition and characterisation of the food or functional ingredient; (ii) definition of the (beneficial physiological) claimed effect; and (iii) establishment of a cause and effect relationship between consumption of the food or functional ingredient and the claimed effect $^{(2,6)}$. Subsequent to these criteria, other issues are considered for a claim, e.g. whether the proposed wording of a claim reflects the provided scientific evidence and whether specific conditions to use a claim on a food product are appropriate ${ }^{(6)}$. Following authorisation by the EC, the claim and its accompanying conditions for use can be found in the so-called positive list in the Annex of Regulation 432/2012 ${ }^{\text {ii }}$ (7).

\footnotetext{
i Regulation (EC) No 1924/2006 of the European Parliament and of the Council of 20 December 2006 on nutrition and health claims made on foods (Consolidated version 13 December 2014).

ii Commission Regulation (EU) No 432/2012 of 16 May 2012 establishing a list of permitted health claims made on foods, other than those referring to the reduction of disease risk and to children's development and health (Consolidated version 27 January 2015).
} 
These specific conditions for use focus on different aspects as the required consumed amount of the food containing the active substance to see the effect, the source of the active ingredient, as well as the matrix in which the active ingredient is presented ${ }^{(7)}$.

In this study three health claim dossiers of approved health claims are analysed. We review how the first assessment criterion of defining and characterising the food or functional ingredient for a health claim has been applied by studying these three dossiers.

\section{Olive oil polyphenols}

In 2011 the EC authorised an Article 13.1 health claim on the effect of polyphenols in olive oil. The claim states that 'olive oil polyphenols contribute to the protection of blood lipids from oxidative stress'. Although the claim names olive oil polyphenols as active component, the polyphenol content is standardised as hydroxytyrosol and its derivatives $^{(8)}$. As a consequence, the claim is exclusively valid for olive oil that contains at least $5 \mathrm{mg}$ of hydroxytyrosol and its derivatives per 20 grams of olive oil ${ }^{(8)}$. When these polyphenols are standardised as 'hydroxytyrosol and its derivatives' without defining them in the claim, consumers will not be made aware about the active component nor why this component is related to the matrix.

Polyphenols, a group of secondary metabolites, are known to protect against oxidative stress and to elicit cardio protecting and anti-inflammatory activity ${ }^{(9,10)}$. The main sources of polyphenols are fruits, vegetables, cocoa, tea and olive oil ${ }^{(10)}$. Olive oil has been associated with a decreased incidence of cardiovascular disease and lower blood pressure $^{(11)}$. As such, the health effects of the Mediterranean diet have been attributed to the high consumption of olive oil(12,13). 


\section{Hydroxytyrosol}

The main phenolic compound present in olive oil is hydroxytyrosol ${ }^{(14)}$, together with oleuropein and tyrosol ${ }^{(10)}$ and has been considered as a good natural antioxidant ${ }^{(15)}$. As part of olive oil, hydroxytyrosol is the most abundant and most potent antioxidant, which can be present in several forms ${ }^{(16,17)}$. During the maturation of olives and storage of olive oil, oleuropein is hydrolysed into hydroxytyrosol, which is therefore mostly present in olive oil and olive mill waste waters ${ }^{(10)}$. In addition, hydroxytyrosol can be present both in the free form and as hydroxytyrosol acetate ${ }^{(16)}$. Hydrolysis of oleuropein into hydroxytyrosol continues after ingestion of the olive oil, increasing the proportion of hydroxytyrosol in olive oil even more inside the body ${ }^{(18)}$. Hydroxytyrosol is not only abundant in olive oil, but it can be easily obtained from olive leaves and mill waste water, which is a by-product of olive oil production ${ }^{(14,19,20)}$. Via these routes, consumption of hydroxytyrosol can be enhanced by using it as a preservative or as active ingredient in functional foods, pharmaceuticals or cosmetics to prevent oxidation $^{(14)}$. The free radical scavenging capacity of hydroxytyrosol can be attributed to its molecular structure, i.e. two phenolic hydroxyl groups. These hydroxyl groups are known for their ability to donate hydrogen atoms to the free radical and thereby terminate the oxidation process ${ }^{(17)}$. Currently, hydroxytyrosol and its derivatives as present in olive oil, and related products, is the only phenol recognised by EFSA as a protector of blood lipids from oxidative damage ${ }^{(15)}$.

\section{Chemically produced hydroxytyrosol}

Where hydroxytyrosol in this claim is directly connected to olive oil and related products, hydroxytyrosol is found in other natural sources and can even be produced synthetically ${ }^{(15,16)}$.

Because of its antioxidant capacity, hydroxytyrosol is an interesting food preservative in other products than olives. Research into the production of a chemical form of hydroxytyrosol, as a cheap and more convenient alternative to be used as preservative, has led to the development of hydroxytyrosol acetate (figure 1$)^{(21,22)}$. As depicted in 
figure 1 , hydroxytyrosol in its free form and hydroxytyrosol acetate are very much alike and are both present in olive oil and related products(10). In the digestive tract, hydroxytyrosol acetate is easily converted into hydroxytyrosol, similar to the form in olive oil, and acetic acid.

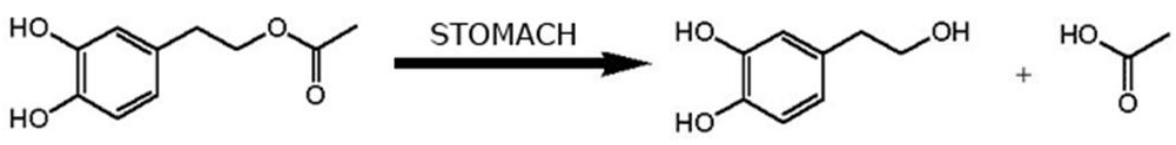

Figure 1. Hydroxytyrosol acetate is converted in the stomach to hydroxytyrosol and acetic acid.

\section{The claim}

The health effect of olive oil polyphenols as described in the claim involves the protection of low-density lipoprotein (LDL) particles from oxidative damage, which can be attributed to the potency of hydroxytyrosol to scavenge free radicals. Still the active ingredient in the claim is defined as 'olive oil polyphenols', which is later standardised by the content of hydroxytyrosol and its derivatives. The potency of hydroxytyrosol to scavenge free radicals is not limited to its activity in olive oil. By emphasising in the opinion the importance of hydroxytyrosol and its derivatives, from a chemical perspective it would be more accurate to define these specific components in the claim instead of defining them as 'olive oil polyphenols'.

\section{Cocoa flavanols}

The health claim 'cocoa flavanols help maintain the elasticity of blood vessels, which contributes to normal blood flow' was authorised for use in 2013 by the EC, as an Article 13.5 claim on the effects of cocoa flavanol consumption ${ }^{(23)}$. Flavanols (figure 2 ) are one of the eight subclasses of flavonoids ${ }^{(24)}$. Various compounds belong to this group of active substances, varying in their degree of polymerisation from monomeric structures to polymers ${ }^{(25,26)}$. 
<smiles>OC1=C(c2ccccc2)Oc2ccccc2C1</smiles>

Figure 2. Chemical structure of a flavanol.

\section{Epicatechin}

In characterising cocoa flavanols, the bioactive components are considered to be the monomeric catechins (primarily epicatechin) and oligomeric flavanols (procyanidins) $^{(27)}$. In the opinion only monomers and rarely dimers are considered to be absorbed after oral consumption, attributing the effect to those components and not to the unabsorbed procyanidins ${ }^{(27)}$. The potential health effects of these procyanidins are highly debated, suggesting procyanidins are degraded by the gut microbiota, which results in new bioactive components possibly affecting health ${ }^{(24,25)}$.

Flavanols can be found in cocoa as well as various other dietary sources as wine, tea and fruit ${ }^{(25)}$. The intake of monomeric flavanols is mainly attributable to chocolate and green tea ${ }^{(28-30)}$. Of the total amount of flavanols in chocolate, 34 to $37 \%$ are monomeric flavanols ${ }^{(27)}$. In grape seeds extracts this amount is approximately $25 \%$ with (-)epicatechin being almost half of these monomeric flavanols ${ }^{(31)}$.

\section{The claim}

In the opinion the claimed health effect is attributed to monomeric flavanols as epicatechin, leading to specific conditions of use of the claim: the claim can only be used on cocoa products containing at least 34 to $37 \%$ epicatechin. When the claimed health effect would be solely attributable to these monomeric flavanols, from a chemical perspective it would be preferable to specifically define these flavanols instead of using this generic term. This would give rise to the possibility of other products containing $34-37 \%$ monomeric flavanols (in their total flavanol content) to be allowed to make a similar claim. 


\section{$\boldsymbol{\beta}$-glucans}

Four health claims on the effects of $\beta$-glucans naturally present or added to foods are authorised for use in the EU: two Article 13.1 claims and two Article 14.1(a) claims, as described in table $1^{(7,32,33)}$. The source of $\beta$-glucan is specified in either the wording of claims or the conditions for use and is supposed to be either barley or oats.

Table 1. $\beta$-glucan health claims.

\begin{tabular}{|c|c|c|}
\hline $\begin{array}{l}\text { Type of } \\
\text { claim }\end{array}$ & Suggested wording of claim & Conditions \\
\hline Art 13.1 & $\begin{array}{l}\text { Regular consumption of } \beta \text { - } \\
\text { glucans contributes to } \\
\text { maintenance of normal blood } \\
\text { cholesterol concentrations. }\end{array}$ & $\begin{array}{l}\text { Food bearing claim must contain } \\
\geq 1 \mathrm{~g} \text { of } \beta \text {-glucans from oats, oat } \\
\text { bran, barley, barley bran, or } \\
\text { mixtures of these sources per } \\
\text { quantified portion. } \\
\text { Information must be provided that } \\
\text { the beneficial effect is obtained } \\
\text { with a daily intake of } 3 \mathrm{~g} \text { of } \beta \text { - } \\
\text { glucans from oats, oat bran, barley, } \\
\text { barley bran, or from mixtures of } \\
\text { these beta-glucans. }\end{array}$ \\
\hline Art 13.1 & $\begin{array}{l}\text { Consumption of } \beta \text {-glucans } \\
\text { from oats or barley } \\
\text { contributes to the reduction of } \\
\text { the glucose rise after a meal. }\end{array}$ & $\begin{array}{l}\text { Food bearing claim must contain } \\
\geq 4 \mathrm{~g} \text { of } \beta \text {-glucans from oats or } \\
\text { barley for each } 30 \mathrm{~g} \text { of available } \\
\text { carbohydrates in a quantified } \\
\text { portion. } \\
\text { Information must be provided that } \\
\text { the beneficial effect is obtained by } \\
\text { consuming the } \beta \text {-glucans from oats } \\
\text { or barley as part of the meal. }\end{array}$ \\
\hline Art 14.1(a) & $\begin{array}{l}\text { Oat } \beta \text {-glucan has been shown } \\
\text { to lower/reduce blood } \\
\text { cholesterol. Blood cholesterol } \\
\text { lowering may reduce the risk } \\
\text { of (coronary) heart disease. }\end{array}$ & $\begin{array}{l}\text { Foods which provide } \geq 1 \mathrm{~g} \text { oat } \beta \text { - } \\
\text { glucans per qua may use the claim. } \\
\text { Information must be provided that } \\
\text { the beneficial effect is obtained by } \\
\text { a daily intake of } 3 \mathrm{~g} \text { of oat } \beta \text {-glucan. }\end{array}$ \\
\hline
\end{tabular}


Table 1 (cont.). $\beta$-glucan health claims.

\begin{tabular}{|l|l|l|}
\hline $\begin{array}{l}\text { Type of } \\
\text { claim }\end{array}$ & Suggested wording of claim & Conditions \\
\hline Art 14.1(a) & $\begin{array}{l}\text { Barley } \beta \text {-glucans have been } \\
\text { shown to lower/reduce blood } \\
\text { cholesterol. High cholesterol is } \\
\text { a risk factor in the } \\
\text { development of coronary } \\
\text { heart disease. }\end{array}$ & $\begin{array}{l}\text { Foods which provide } \geq 1 \mathrm{~g} \text { barley } \beta \text { - } \\
\text { glucans per quantified portion may } \\
\text { use the claim. } \\
\text { Information must be provided that } \\
\text { the beneficial effect is obtained by } \\
\text { a daily intake of } 3 \mathrm{~g} \text { of barley } \beta- \\
\text { glucan. }\end{array}$ \\
\hline
\end{tabular}

\section{$(1 \rightarrow 4)(1 \rightarrow 3) \beta$-D-glucan}

Glucans are non-starch polysaccharides found in various plants, algae and fungi ${ }^{(34)}$. These soluble dietary fibres consist of glucose polymers, linked by different glycosidic bonds between the monomers ${ }^{(34)}$. Glucans vary highly in structure, due to differences in e.g. position and distribution of glycosidic bonds or molecular size ${ }^{(34)}$. The $\beta$-glucans considered in these claims are linear mixed $(1 \rightarrow 4)(1 \rightarrow 3)$ linkages $\beta$-D-glucan (figure 3$)$, which are mainly found in plants as part of the cell wall of the bran ${ }^{(34,35)}$. Mixed $\beta-(1 \rightarrow 4)$ $(1 \rightarrow 3)$ linkages indicate that the polymers are built of blocks of two up to four glucose units linked by $\beta-(1 \rightarrow 4)$ bonds (approximately $70 \%$ of the mixture), generally separated by $1 \beta$ - $(1 \rightarrow 3)$ linked glucose molecule (approximately $30 \%$ of the mixture) ${ }^{(35,36)}$.

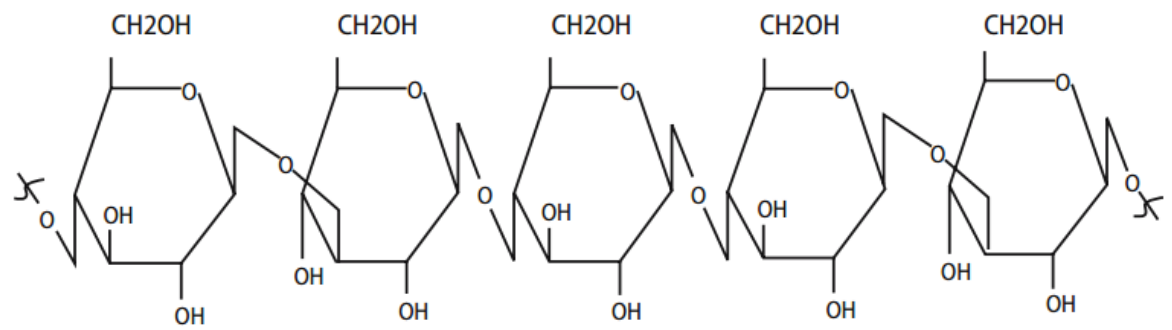

Figure 3. $\beta$-glucan with mixed $\beta-(1 \rightarrow 4)(1 \rightarrow 3)$ linkages.

The health effects of $\beta$-glucans (reducing serum cholesterol levels and post-prandial glucose rise) are ascribed to various physical properties as water solubility, viscosity 
and gelation properties. These properties are influenced by structural aspects of the molecule such as the molecular weight, the ratio of tri- to tetramers and the ratio of $\beta$ $(1 \rightarrow 4): \beta-(1 \rightarrow 3)$ linkages ${ }^{(34,37)}$. The dietary fibres form a highly viscous solution in the gut, encapsulating bile acids in the meal bolus. These bile acids become inaccessible for reabsorption, requiring increased bile acids synthesis to replenish the decreased amount of bile acids. Such synthesis leads to decreasing concentrations of circulating $(\mathrm{LDL})$ cholesterol ${ }^{(36,37)}$. The formation of viscous bulk also delays the rate of nutrient absorption, resulting in lower post-prandial glucose peaks in the blood ${ }^{(38)}$.

\section{The claim}

Various studies showed differences between the molar ratio of tri- and tetramers of $\beta$ glucan and subsequently their insolubility ${ }^{(39)}$. Increasing the ratio of tri- to tetramers led to an increased rate of gel structure development ${ }^{(39)}$. These structural properties are suggested to lead to specific physical effects, implying that this ratio of tri- to tetramers is important for the elicited health effects of $\beta$-glucans. The ratio of $70 \%$ $(1 \rightarrow 4)$ to $30 \%(1 \rightarrow 3)$ links is established in $\beta$-glucans from oats and barley. However, not this apparent important ratio but the specific source of $\beta$-glucans is specified in the claim. Defining this ratio in the claim could increase the possibility to use a claim on $\beta$ glucans from other sources, which do have similar ratios and can subsequently give rise to comparable physical effects.

\section{Discussion}

Under the NHCR the EC approved various nutrition and health claims following an assessment of their scientific substantiation by EFSA. The first criterion in EFSA's assessment procedure is the definition and characterisation of the active ingredient ${ }^{(6)}$. The defined active ingredient is generally associated with the food item carrying the claim. However, as exemplified with the analysed health claims, the functionality of the bioactive component does not depend on the source in which it has been 
characterised. In other words, from a chemical perspective it would be preferable to build the claim exclusively on the bioactive rather than on the food item comprising this bioactive.

\section{The analysed claims}

The discussed Article 13.1 claim on olive oil polyphenols defines hydroxytyrosol and its derivatives as the responsible bioactives. Literature agrees upon the beneficial effect of hydroxytyrosol, because of its prominent amphiphilic antioxidant characteristics ${ }^{(18)}$. In the claim however the active components are generalised into 'olive oil polyphenols', where it is in the conditions of use standardised upon the specific amount of hydroxytyrosol in the mixture.

As described in the opinion on this health claim, most research on hydroxytyrosol has been performed with olive oil containing hydroxytyrosol ${ }^{(8)}$. Although this justifies linking hydroxytyrosol to olive oil, the effects of hydroxytyrosol from other sources should not be ignored immediately.

The Article 13.5 claim on cocoa flavanols identifies epicatechin as bioactive responsible for the claimed beneficial health effects. When this health effect would also be attributed to specifically epicatechin in the wording of the claim, next to the conditions of use, new claim possibilities would arise for other products containing this bioactive compound. Next to increasing the opportunity to use epicatechin in food products, the transparency upon the real active ingredient would be increased, in this case epicatechin and not the broad category of cocoa flavanols and in the claim discussed in the section 'Olive oil polyphenols' the effect would be attributed to hydroxytyrosol instead of olive oil polyphenols.

In the case of the Article 13.1 and 14.1 (a) claims on the health effects of the dietary fibre $\beta$-glucan substantiating evidence was found for the effects of $(1 \rightarrow 4)(1 \rightarrow 3) \beta$ glucan on maintaining cholesterol levels and lowering the glucose rise. The positive health effects are specifically attributed to the ratio of the tri- to tetramers, as found in $\beta$-glucan from oats and barley ${ }^{(36,38)}$. However, the ratio of these $\beta$-glucans in other 
cereals is not known. When this ratio would have been studied in other sources of $\beta$ glucan by focussing on the chemical composition of the bioactive ingredients, more information would have been available on the potential effects of other cereals. Transparency of the claim and its functional ingredient could be increased by specifying the ratio of $\beta$-glucans in the claim.

\section{Type of claim and scientific substantiation}

These examples indicate two elements which influence whether the active ingredient is linked to a specific food component or food matrix in the authorised health claims: (i) the type of claim considered; and (ii) the substantiating evidence available and delivered in the dossier.

Within the NHCR three types of health claims are defined: (i) Article 13.1 claims: general function claims which imply a health benefit based on generally accepted scientific evidence; (ii) Article 13.5 claims: new function claims which imply a health benefit based on newly developed scientific evidence, where the opportunity is given to request protection of proprietary data; and (iii) Article 14.1 claims: claims on (a) the reduction

of disease risk, describing the positive effect of consumption on a risk factor of a disease or on (b) children's development and health ${ }^{(2,4)}$.

In the assessment procedure of the Article 13.1 claims on both olive oil polyphenols and $\beta$-glucans, all generally accepted scientific evidence is required to be considered. In case of an Article 13.5 or 14.1 claim however, the claim is assessed through a specific question. This can lead to the interpretation becoming as narrow as the question itself: when the presented evidence is based only on the active ingredient in a specific matrix, an Article 13.5 or 14.1 claim is likely to include this matrix in either the conditions of the claim or in the claim itself ${ }^{(40)}$. This is seen in the Article 13.5 claim on cocoa flavanols, in which epicatechin is the bioactive responsible for the health effect. The studies however all focussed on cocoa flavanols containing 34 to $37 \%$ monomeric flavanols, and not on epicatechin from other sources. 
When the generally accepted scientific evidence to substantiate an Article 13.1 claim is only focussed on the bioactive within a specific matrix as hydroxytyrosol in olive oil polyphenols, it is reasonable to focus the claim or its conditions on the active ingredient within this matrix. However, such a general function claim should give rise to the opportunity of using the bioactive from and in other matrices as well. The food industry would be less restricted in using existing as well as new claims, thereby stimulating innovation $^{(41,42)}$.

Next to increasing the opportunities for food industrials to innovate with these welldefined bioactive components, claims also become more transparent by defining the specific bioactive. Thereby understanding of consumers on health enhancing effects of bioactive ingredients and the effects of nutrition on health might increase. By allowing broader use of more unambiguous claims, consumers will be exposed to more nutrition information and gain more experience with claims, which is suggested to lead to increased relevance of such claims ${ }^{(43,44)}$. From a chemical perspective it would therefore be preferable to focus research on health effects of food on specific bioactive ingredients. As depicted in figure 4, this would subsequently lead to transparent claims on bioactives instead of vague food item claims. 


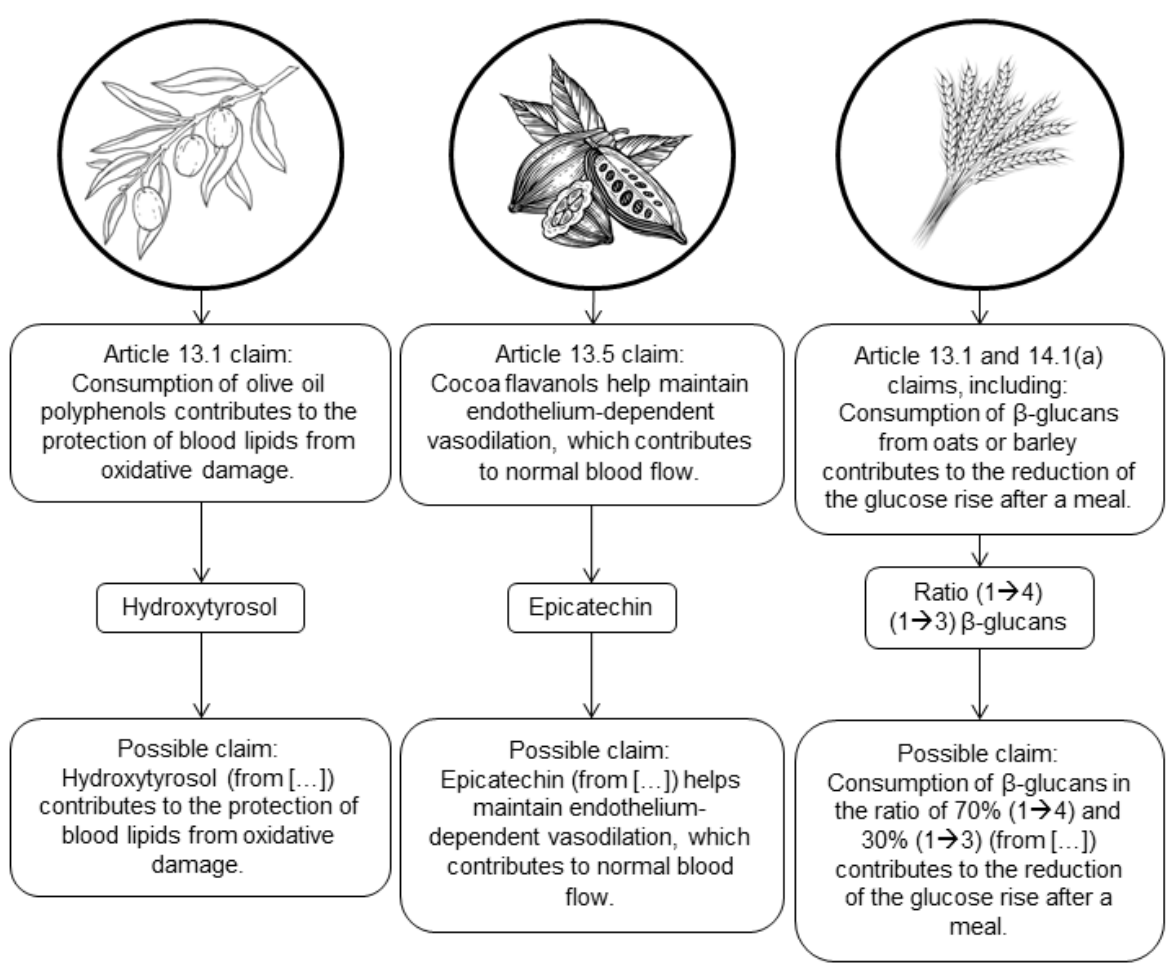

Figure 4. Claim possibilities when focussing on bioactives.

\section{Conclusion}

From a chemical point of view it would be advisable to standardise an active ingredient to the real bioactive substance such as hydroxytyrosol in the case of olive oil polyphenols. Authorising the claim for olive oil polyphenols based on its hydroxytyrosol contents narrows the possibilities for using hydroxytyrosol in other products while the name of the authorised claim is too generic, possibly leading to consumer confusion. Therefore standardisation of a health claim via one bioactive ingredient could enhance the opportunities to use such an ingredient in different products. When health claims are based on the bioactive constituent without having to be linked to a specific source, claims could be more valuable for both the industry 
and consumers by stimulating innovation and increasing their relevance. Therefore characterisation and defining the active ingredient should be central in the health claim. 


\section{References}

1. Hoad D (2011) Scientific Method and the Regulation of Health and Nutritional Claims by the European Food Safety Authority. Bull Sci Technol Soc 31, 123-133.

2. De Boer A, Vos E \& Bast A (2014) Implementation of the nutrition and health claim regulation - the case of antioxidants. Regul. Toxicol. Pharmacol. 68, 475-487.

3. European Commission (2000) White paper on food safety. COM 719.

4. European Parliament and Council of the European Union (2006) Regulation (EC) No 1924/2006 of the European Parliament and of the council of 20 December 2006 on nutrition and health claims made on foods. OJ L 404 49, 9-25.

5. Gilsenan MB (2011) Nutrition \& health claims in the European Union: A regulatory overview. Trends Food Sci. Technol. 22, 536-542.

6. EFSA NDA Panel (2011) General guidance for stakeholders on the evaluation of Article $13.1,13.5$ and 14 health claims. EFSA Journal 2135, 1-24.

7. European Commission (2012) Commission Regulation (EU) No 432/2012 of 16 May 2012 establishing a list of permitted health claims made on foods, other than those referring to the reduction of disease risk and to children's development and health. OJ L 13655 , $1-40$.

8. EFSA NDA Panel (2011) FSA NDA Panel (2011) Scientific Opinion on the substantiation of health claims related to polyphenols in olive and protection of LDL particles from oxidative damage (ID 1333, 1638, 1639, 1696, 2865), maintenance of normal blood HDLcholesterol concentrations (ID 1639), maintenance of normal blood pressure (ID 3781), "anti-inflammatory properties" (ID 1882), "contributes to the upper respiratory tract health" (ID 3468), "can help to maintain a normal function of gastrointestinal tract" (3779), and "contributes to body defences against external agents" (ID 3467) pursuant to Article 13(1) of Regulation (EC) No 1924/2006. EFSA Journal 2033, 1-25.

9. Li A-N, Li S, Zhang Y-J, et al. (2014) Resources and Biological Activities of Natural Polyphenols. Nutrients 6, 6020-6047.

10. Hu T, He X-W, Jiang J-G, et al. (2014) Hydroxytyrosol and its potential therapeutic effects. J. Agric. Food Chem. 62, 1449-1455.

11. Storniolo CE, Roselló-Catafau J, Pintó X, et al. (2014) Polyphenol fraction of extra virgin olive oil protects against endothelial dysfunction induced by high glucose and free fatty acids through modulation of nitric oxide and endothelin-1. Redox Biol. 2C, 971-977.

12. Widmer RJ, Flammer AJ, Lerman LO, et al. (2014) The Mediterranean Diet, its Components, and Cardiovascular Disease. Am. J. Med. 128, 229-238.

13. Klonizakis M, Alkhatib A \& Middleton G (2014) Long-term effects of an exercise and Mediterranean diet intervention in the vascular function of an older, healthy population. Microvasc. Res. 95, 103-107.

14. Bast A \& Haenen GRMM (2014) Nutritional antioxidants - it is time to categorise. In Antioxidants in Sport Nutrition, pp. 17-38 [Lamprecht M, editor]. Boca Raton, Florida: CRC Press - Taylor \& Francis Group.

15. Achmon Y \& Fishman A (2015) The antioxidant hydroxytyrosol: biotechnological production challenges and opportunities. Appl. Microbiol. Biotechnol. 99, 1119-1130. 
16. Fernández-Mar MI, Mateos R, García-Parrilla MC, et al. (2012) Bioactive compounds in wine: Resveratrol, hydroxytyrosol and melatonin: A review. Food Chem. 130, 797-813.

17. Torres de Pinedo A, Peñalver P \& Morales JC (2007) Synthesis and evaluation of new phenolic-based antioxidants: Structure-activity relationship. Food Chem. 103, 55-61.

18. Rietjens SJ, Bast A \& Haenen GRMM (2007) New insights into controversies on the antioxidant potential of the olive oil antioxidant hydroxytyrosol. J. Agric. Food Chem. 55, 7609-7614.

19. Yuan J-J, Wang C-Z, Ye J-Z, et al. (2015) Enzymatic Hydrolysis of Oleuropein from Olea europea (Olive) Leaf Extract and Antioxidant Activities. Molecules 20, 2903-2921.

20. De Bock M, Thorstensen EB, Derraik JGB, et al. (2013) Human absorption and metabolism of oleuropein and hydroxytyrosol ingested as olive (Olea europaea L.) leaf extract. Mol. Nutr. Food Res. 57, 2079-2085.

21. Trujillo M, Mateos R, Collantes de Teran L, et al. (2006) Lipophilic hydroxytyrosyl esters. Antioxidant activity in lipid matrices and biological systems. J. Agric. Food Chem. 54, 3779-3785.

22. Gordon MH, Paiva-Martins F \& Almeida M (2001) Antioxidant Activity of Hydroxytyrosol Acetate Compared with That of Other Olive Oil Polyphenols. J. Agric. Food Chem. 49, 2480-2485.

23. European Commission (2013) Commission Regulation (EU) No 851/2013 of 3 September 2013 authorising certain health claims made on foods, other than those referring to the reduction of disease risk and to children's development and health and amending Regulation (EU) No 432/2012. OJ L 235 56, 3-7.

24. Aron PM \& Kennedy JA (2008) Flavan-3-ols: nature, occurrence and biological activity. Mol. Nutr. Food Res. 52, 79-104.

25. De Pascual-Teresa S, Moreno DA \& García-Viguera C (2010) Flavanols and anthocyanins in cardiovascular health: a review of current evidence. Int. J. Mol. Sci. 11, 1679-1703.

26. Donovan JL, Lee A, Manach C, et al. (2002) Procyanidins are not bioavailable in rats fed a single meal containing a grapeseed extract or the procyanidin dimer B3. Br. J. Nutr. 87, 299-306.

27. EFSA NDA Panel (2012) Scientific Opinion on the substantiation of a health claim related to cocoa flavanols and maintenance of normal endothelium-dependent vasodilation pursuant to Article 13(5) of Regulation (EC) No 1924/2006. EFSA Journal 2809, 1-21.

28. Arts IC, Hollman PC \& Kromhout D (1999) Chocolate as a source of tea flavonoids. Lancet $354,488$.

29. Song WO \& Chun OK (2008) Tea Is the Major Source of Flavan-3-ol and Flavonol in the U.S. Diet. J. Nutr. 138, 1543S-1547S.

30. Manach C, Scalbert A, Morand C, et al. (2004) Polyphenols: food sources and bioavailability. Am J Clin Nutr 79, 727-747.

31. Weseler AR, Ruijters EJB, Drittij-Reijnders M-J, et al. (2011) Pleiotropic Benefit of Monomeric and Oligomeric Flavanols on Vascular Health - A Randomized Controlled Clinical Pilot Study. PLoS One 6, e28460. 
32. European Commision (2011) Commission regulation (EU) No 1160/2011 of 14 November 2011 on the authorisation and refusal of authorisation of certain health claims made on foods and referring to the reduction of disease risk. OJ L 296, 26-28.

33. European Commission (2012) Commission regulation (EU) No 1048/2012 of 8 November 2012 on the authorisation of a health claim made on foods and referring to the reduction of disease risk. OJ L 2 310, 38-40.

34. Synytsya A \& Novak M (2014) Structural analysis of glucans. Ann. Transl. Med. 2, 17.

35. Skendi A, Biliaderis CG, Lazaridou A, et al. (2003) Structure and rheological properties of water soluble $\beta$-glucans from oat cultivars of Avena sativa and Avena bysantina. J. Cereal Sci. 38, 15-31.

36. EFSA NDA Panel (2009) Scientific Opinion on the substantiation of health claims related to beta glucans and maintenance of normal blood cholesterol concentrations (ID 754, $755,757,801,1465,2934)$ and maintenance or achievement of a normal body weight (ID 820,823 ) pursuant. to Article 13(1) of Regulation (EC) No 1924/2006. EFSA Journal 1254, $1-18$.

37. Lazaridou A \& Biliaderis CG (2007) Molecular aspects of cereal $\beta$-glucan functionality: Physical properties, technological applications and physiological effects. J. Cereal Sci. 46, 101-118.

38. EFSA NDA Panel (2011) Scientific Opinion on the substantiation of health claims related to beta-glucans from oats and barley and maintenance of normal blood LDL-cholesterol concentrations (ID 1236, 1299), increase in satiety leading to a reduction in energy intake (ID 851, 852), reduction of post-prandial glycaemic responses (ID 821, 824), and "digestive function: (ID 850) pursuant to Article 13(1) of Regulation (EC) No 1924/2006. EFSA Journal 2207, 1-21.

39. Lazaridou A, Biliaderis C., Micha-Screttas M, et al. (2004) A comparative study on structure-function relations of mixed-linkage $(1 \rightarrow 3),(1 \rightarrow 4)$ linear $\beta$-d-glucans. Food Hydrocoll. 18, 837-855.

40. EFSA (2015) 'New function' health claims under Article 13.5 . http://www.efsa.europa.eu/en/topics/topic/article13-5.htm (accessed April 2015).

41. Moors EHM (2012) Functional foods: regulation and innovations in the EU. Innovation $25,424-440$.

42. De Boer A \& Bast A (2015) Stakeholders' perception of the nutrition and health claim regulation. Int. J. Food Sci. Nutr. 66(3), 321-328.

43. Van Trijp HCM (2009) Consumer understanding and nutritional communication: key issues in the context of the new EU legislation. Eur J Nutr 48, 41-48.

44. Dean M, Lampila P, Shepherd R, et al. (2012) Perceived relevance and foods with healthrelated claims. Food Qual Prefer 24, 129-135. 


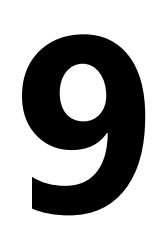

Summary and general discussion 
The main objective of the studies presented in this thesis was to elucidate the shift of nutrition and pharmaceutics in both effect and subsequent legislation. Chapter 1 introduces legislation upon nutrition and medicinal products and showed the shift of these concepts towards each other, by nutrition focussing on maintaining and improving health next to provide sufficient nutrients. Chapter $\mathbf{2}$ and $\mathbf{3}$ analyse the implementation of the nutrition and health claim regulation in the field of food products containing antioxidants. The enforcement strategies of national enforcement authorities throughout the European Union are reviewed in chapter 4. Chapter 5 reviews international pieces of legislation upon nutrition and health claims. The shifting perception of nutrition and medicinal products in effect are studied in chapter 6 and 7. Chapter $\mathbf{8}$ applies the nutritional and toxicological knowledge to the characterisation of active ingredients under the nutrition and health claim regulation ${ }^{i}$ (NHCR). The research presented in this thesis shows that it is necessary to scientifically unravel both the effects of nutrition and pharmaceutics as well as legislation surrounding these types of products to increase the clarity upon both.

\section{Main findings}

\section{The implementation of the NHCR leads to discussion on its effectiveness}

In chapter 2 the consequences of the implementation of the NHCR in the field of food products containing antioxidants or claiming antioxidant activity are analysed. The origin and the creation of the NHCR as well as the involvement of EFSA in the implementation of this legislative act are reviewed. The assessment procedure of the scientific substantiation of health claims is studied by analysing opinions provided by EFSA on this evidence provided for putative health claims. Three criteria are shown to

\footnotetext{
i Regulation (EC) No 1924/2006 of the European Parliament and of the Council on nutrition and health claims made on foods (Consolidated version 13 December 2014).
} 
be crucial in the health claim assessment by EFSA: (i) the food or functional ingredient must be well defined and characterised; (ii) the claimed effect must be well defined and be physiologically beneficial; and (iii) a cause and effect relationship between intake of the food or functional ingredient and the claimed effect must be established. The described criteria are shown to have various implications for research focussed on substantiating health claims. These implications however do not all seem to fit nutrition research as it is currently executed. The definition of health is highly debated, leading to the development of new methodologies to assess the effects of dietary components on health. This should be taken into consideration in assessing the scientific substantiation of health claims. In the case of antioxidants specifically, the complexity of the mechanisms and actions of these bioactives has not been recognised by the evaluating criteria, nor by the methodologies used to assess antioxidant effects on health. A clear divergence in claim authorisation (with eight authorised claims) versus claim submission (over 200 claims on antioxidants were proposed) highlights this.

Chapter 3 analyses the perception of stakeholders (industrials, regulatory experts, nutritional scientists and consumer representatives) on the implementation of the $\mathrm{NHCR}$, to unravel the grounds of disproving the putative health claims on food products containing antioxidants or claiming antioxidant activity. Most health claims were considered to be refused based on the quality of the scientific evidence substantiating the proposed claims. The interviewed stakeholders attributed this to the use of scientific methods in substantiating evidence on which no general consensus had been reached, as well as a difference in expectations of submitting bodies and required criteria concerning the evidence in the assessment procedure. Three themes are identified on which the application of the NHCR should be improved: (i) enforcement; (ii) methodology in nutrition; and (iii) perceived impact of the NHCR on innovation, research, the market and consumers. The stakeholders are shown to have highly diverging perceptions, which gives rise to the question whether the NHCR in its current form is effective. The views expressed by the interviewed stakeholders on the 
different themes could be valuable in focussing the discussion on the NHCR in capturing health effects.

\section{Similar enforcement strategies for the NHCR throughout the EU are crucial for its effectiveness}

With the NHCR aiming to protect consumers against false or incorrect claims as well as establish a level playing field in the internal market for all food producers, enforcement of the regulation is crucial. European food regulations, as the NHCR, are required to be enforced by national authorities. Due to Regulation (EC) No 882/2004i, when controlling compliance with feed and food law requirements the national authorities are obligated to adopt a risk-based enforcement approach. Our analysis in chapter $\mathbf{4}$ however shows fragmented national enforcement practices. This is depicted by the development of 13 different guidance documents on the flexibility of wording and/or general compliance with the NHCR developed by 18 member states. In the meantime also diverging actions have been taken by member state authorities in correcting non-compliance, ranging from punitive measures as imposing fines to persuasive measures as naming and shaming. The NHCR is therefore currently shown to be unable to establish a level playing field. We call for the development of an EUwide approach in enforcement to ensure fair competition in the internal market.

\section{The global landscape of nutrition and health claim legislation is highly divergent}

The European legislation on nutrition and health claims is compared with international pieces of legislation dealing with these types of claims in chapter $\mathbf{5}$. Thereby we depict the global diversity in approaches and envisioned ways to optimise procedures from a scientific perspective. Pieces of legislation of 28 jurisdictions are reviewed. Three

\footnotetext{
ii Regulation (EC) No 882/2004 of the European Parliament and of the Council of 29 April 2004 on official controls performed to ensure the verification of compliance with feed and food law, animal health and animal welfare rules (Consolidated version 30 June 2014).
} 
prominent differences are discerned, concerning (i) the classification of different types of nutrition and health claims and their permitted use; (ii) variations arising in the (premarketing) authorisation procedures; and (iii) the use of the scientific minority opinion in substantiating claims. Although various studied approaches displayed positive aspects in their regulation of nutrition and health claims, no optimal approach has been identified to be implemented yet. It would be preferable to permit similar types of claims throughout jurisdictions and to permit the use of emerging evidence in the substantiation of claims that have lower probability to mislead consumers (as nutrition claims), with requiring pre-marketing approval for claims having higher impact. By harmonising these aspects globally, improved pieces of legislation could be developed that stimulate industrial efforts concerning functional foods and enhance the opportunity for consumers to use health-enhancing products.

\section{The interactions between foods and medicinal products have either positive or negative effects}

The shifting perception of the roles and effects of nutrition and medicinal products are studied in chapter 6 and 7. By evaluating the potential positive effects elicited by dietary components on chronic inflammatory lung diseases in chapter 6, we demonstrated several components that can decrease inflammatory markers in the lung and thereby improve lung function in patients. Taking into account the number of weighed articles in this literature review, n-3 PUFAs and vitamin E seem to beneficially influence both inflammatory and immunological markers as well as lung function of patients suffering from chronic inflammatory lung diseases. Many other dietary components show only small or no effects on inflammation and/or lung function, although the number of weighted studies is often too small for a reliable assessment. The potential beneficial influence of various dietary components on chronic inflammatory lung diseases might lead to improved quality of life of patients suffering from these diseases. We conclude that optimal dietary elements might reduce the required amounts of anti-inflammatory treatments, thereby decreasing both side effects and development of resistance. 
In chapter 7 the adverse events occurring due to concomitant intake of healthenhancing products and drugs that were reported to the Netherlands Pharmacovigilance Centre Lareb are studied. With the increased popularity of food supplements and herbal products, the risks of interactions occurring between prescribed drugs and these bioactive products increase. The 55 notified adverse events are suspected to be caused by the concomitant intake of bioactives and drugs. Most of these suspected interactions seem to occur during the metabolism of xenobiotics or in the pharmacodynamics stage. Where legislation is seen to distinct food and medicine, legislation concerning these different bioactive products is less clear-cut. This can only be resolved by increasing the molecular knowledge on bioactive substances and their potential interactions. Thereby potential interactions can be better understood and prevented on an individual level. By considering the dietary pattern and use of bioactive substances with prescribed medication, both health professionals and consumers will be increasingly aware of interactions and these interactive adverse effects can be prevented.

\section{Characterisation of functional foods and ingredients should be based on their bioactive constituent}

The first criterion in the assessment procedure of EFSA in reviewing scientific substantiation of health claims under the NHCR is the definition and characterisation of the active ingredient responsible for the claimed health effect. In chapter 8 we analyse three health claims in which the active ingredient responsible for the health effect is directly connected to a specific food item containing this bioactive, either in the wording of the claim or in the specified conditions of use. Since the bioactive itself is held responsible for the health effect, the association of the food item with the bioactive component is not always justifiable. Two elements were shown to influence whether the bioactive ingredient would be linked to a specific food component: (i) the type of claim considered, differing between generic health claims (Article 13.1 claims) and new function health claims (Article 13.5 claims); and (ii) the substantiating evidence available and submitted in the dossier substantiating the proposed claim. We argue 
that it would be preferable to chemically define the active ingredients for subsequent use in standardising the real bioactive substance in the claim. Along these lines, claims can be based on a bioactive constituent without the necessity to connect the claim to a specific matrix. Thereby health claims become more transparent upon the active ingredient that elicits the proposed health benefit, which makes the claims more relevant to both the industry and consumers. Therefore characterisation and defining the active ingredient should be central in the health claim assessment.

\section{Implications and suggestions}

\section{The consumer's perspective}

As described in the studies within this thesis, the focus of nutrition shifts more to the enhancement and maintenance of health, touching upon the application of medicinal products. The difference between both types of products is thereby narrowing. Consumers are seen to be more interested in maintaining and increasing their health by using more products as vitamins and dietary supplements or other health and wellness products, products for which growth is predicted in most European countries in the upcoming years ${ }^{(1-3)}$. Health consciousness of consumers is especially highly correlated to their interest in functional products ${ }^{(4)}$. The health-consciousness of consumers is not only shown in the expanded sales of health products, it is also exemplified by the popularity of the information on the Internet concerning health and healthy foods. Consumers thereby try to increase their knowledge on health and bioactive substances ${ }^{(5)}$. The elevated importance of health is however also suggested to lead to increased uncertainty of consumers on health ${ }^{(6)}$.

The increased availability of information and increased amount of products lead to new opportunities for consumers in managing their health, as exemplified in chapter 6 and 7 on the combination of nutrition and medicinal products. Where in some cases combining different products can elicit beneficial effects on health as described in 
chapter 6, chapter 7 depicts the risk of combining bioactive substances without professional advice. This demonstrates the need for health professionals as doctors, dietitians and nutritionists to give truthful and personal information to consumers. With increased information about bioactives and bioactive containing products, consumers will be better able to make well-informed decisions. Stakeholders as the food industry, nutritional scientists and legislators are seen to respond differently to the consumer's demand for safety, trust and truth upon health and health enhancing products.

\section{The food industrial's perspective}

Producers of food products focus on the development of new products that carry effect claims, claims on their naturalness, carry logos or focus on other unique selling points as taste or price of the product ${ }^{(7,8)}$. Various studies on purchasing behaviour identified health as an important factor for consumers in buying food products ${ }^{(7,8)}$. The increased interest in bioactive ingredients as potential health enhancing products resulted in the development of various product categories, including not only food supplements, but also other categories as functional foods, nutra- and cosmoceuticals and foods for special use are increasingly found on the market ${ }^{(1,2,9)}$. The legal boundaries set by the legislator on the communication of health enhancing effects on e.g. homeopathic medicinal products and foods are challenged by industrials by repositioning these products as medical devices. This enables producers to carry claims on the products that are not allowed under the nutrition and health claim regulation ${ }^{(10)}$.

\section{The scientist's perspective}

Nutritional academics on the other hand focus on how the effects of nutrition should be tested, by discussing used methodology in assessing the effects on health and how health should actually be defined. The WHO definition of health as 'a state of complete physical, mental and social well-being and not merely the absence of disease or infirmity' was developed right after the Second World War in $1948^{(11)}$. Since this absolute approach did not result in a very practical definition, efforts have been made to develop a new definition of health recently ${ }^{(12)}$. An example of a definition more often 
used to define health is 'the dynamic ability to adapt'(13). This ability to adapt is also referred to as 'increased resilience': successful adaptation to adversity via recovering from the challenge and sustainability of the state of well-being ${ }^{(14)}$. This new definition is less static and more personal than the first definition Such a new definition of health also requires new measurements of health and health-enhancing compounds. Newly developed biomarkers and integrating the different (smaller) effects of one substance into one measure should be part of such approach ${ }^{(15,16)}$. The integration of pleiotropic effects of substances on health could also describe the effect of a substance as a 'risk on health': the higher the effects elicited, the higher the risk that the substance will show health enhancing effects ${ }^{(17)}$. The scientific community is however quite rigid in changing and accepting new definitions and subsequently new methodologies. Therefore the integration of these evolving concepts will take time; its applicability in legislation will take place in an even lower speed.

\section{The legislator's perspective}

As put forward in chapter 1 , historically nutrition and medicinal products were regulated locally. Legally a distinction has been made between nutrition, that focussed on supplying sufficient macro- and micronutrients and to alleviate hunger, with pharmaceuticals aiming to cure diseases or alleviate their symptoms ${ }^{(18,19)}$. Following various food scares in the 1990s, European food law was highly reformed and not only focussed on harmonising the internal market, but also addressed consumer interests $^{(20)}$. To regain the trust of consumers in both science and politics, independent agencies were established to advise on scientific issues and transparency was increased in the risk management process ${ }^{(20-22)}$. The reform of European Food Law also resulted in the development of new pieces of legislation as the NHCR, aiming to not only increase harmonisation but also to protect consumers from misleading by false and inaccurate claims ${ }^{(23,24)}$.

The NHCR was however developed without awaiting the results of the academic discussion on how health should be defined and assessed. As described in chapter 2 
and 3, only Terms of Reference were provided to the independent agency assessing the proposed health claims and the assessment procedure was not clear for bodies submitting health claims. The assessment procedure of generic health claims (Article 13.1 claims) resulted in the development of a positive list of authorised claims in the Annex of Regulation 432/2012 ${ }^{\mathrm{iii}}$. Within this procedure however claims describing health effects from botanicals used in foods were not included. The assessment of these health effects is still highly debated and often connected to the approach taken in medicinal products, where traditional herbal medicinal products are reviewed through the so called simplified procedure. This again depicts the shift of food products towards more health enhancing, medicine like products.

Where foods and medicinal products are seen to overlap in effect and law, the question arises whether regulating these concepts separately is still justifiable. The definitions of a medicinal product described in Directive $2001 / 83 /$ EC $^{\text {iv }}$ already take into account the concept of intended use: when either the presentation or the function of a product shows that it is aimed to treat or cure a disease, it automatically becomes a medicinal product $^{(25,26)}$. As described in chapter 7 , the definition of food is also based on the intended use by defining food as any substance or product that is intended or can be expected to be ingested by humans ${ }^{(27)}$. In the current market of health enhancing products these definitions however give rise to uncertainty in which category the

\footnotetext{
iii Commission Regulation (EU) No 432/2012 of 16 May 2012 establishing a list of permitted health claims made on foods, other than those referring to the reduction of disease risk and to children's development and health (Consolidated version 27 January 2015).

iv Directive 2001/83/EC of the European Parliament and of the Council of 6 November 2001 on the Community code relating to medicinal products for human use (Consolidated version 16 November 2011).

The definitions of medicinal product by function and medicinal product by presentation were amended by Directive 2004/27/EC of the European Parliament and of the Council of 31 March 2004 amending Directive 2001/83/EC on the Community code relating to medicinal products for human use.
} 
different types of products should fall. Focussing on the bioactive components of these different products and their mechanisms of action might result in more certainty.

\section{Future perspectives and advice}

This thesis describes the interactions between nutrition and medicine in effect and law and depicts the shift of nutrition in both effect and legal status towards a medicinal product. Where this gives rise to increased opportunities to treat diseases with less use of medicinal products, it is also seen to create confusion amongst consumers and increases complexity in law. With the involvement of a multitude of stakeholders in this process, an interdisciplinary approach is required to deal with all uncertainties surrounding this shift. We tried to unravel uncertainties and create understanding among all involved stakeholders as a first step in increasing the acceptance and effectiveness of functional foods and related legislation.

Although this research does not provide sufficient details to draw up new legislation upon bioactive substances and their commercial outings, we highlighted various elements that are important to be taken into consideration for medicinal and food law and more specifically the NHCR. The NHCR can be considered as an example of legislating before general consensus has been reached in the academic setting. A new definition of health can result in new methodologies to assess the multifactorial effects of nutrition, but also other bioactive substances. The use of emerging evidence in communicating health effects should be thoroughly discussed, as it can drive innovation and improve health of consumers. When these elements can be incorporated in legislation, enforcement should ensure the creation of a level playing field throughout the European Union. Increased knowledge upon effects of foods and pharmaceutical products should be used in legislation, leading to interactions between effect and law. 
The differences and similarities between nutrition and medicinal products as well as the various other product categories should be taken into consideration when drafting new legislation on nutrition or medicinal products. Although the different intermediate legal categories can result in the repositioning of products in the markets by industrials that are looking to use unauthorised claims on food products, more pieces of legislation might create a confusing and unclear situation for all players in the field. By reviewing active compounds as bioactives rather than focussing on the different legal categories, a new opportunity may arise to draft legislation that can stimulate innovation, protect consumers from false and misleading claims and ensure safety.

Unravelling the effects of nutrition on one hand and medicinal products on the other increases the clarity about what can be expected from the different types of products. Separating the legal concepts of food and pharmaceutics improves transparency upon the positioning of different health enhancing products. However, the increased understanding of both aspects separately helps to understand the other aspect: the effects of food and pharmaceuticals clarify their legal constructs and legal constructs of food and pharmaceuticals can help to show what effect can be expected. The interaction between effect and law is required to clarify both. When the legal concepts and the biochemical effects correspond more closely to each other, not only understanding of consumers on nutrition and pharmaceutical products will increase, also more possibilities to innovate will arise. 


\section{References}

1. Euromonitor International (2015) Vitamins and Dietary Supplements Market Sizes Worldwide Growth Forecast (2014-2019).

2. Euromonitor International (2015) Fortified/Functional Packaged Food - Worldwide Growth Forecast (2014-2019).

3. Schilter B, Andersson C, Anton R, et al. (2003) Guidance for the safety assessment of botanicals and botanical preparations for use in food and food supplements. Food Chem. Toxicol. 41, 1625-1649.

4. Landström E, Hursti U-KK, Becker W, et al. (2007) Use of functional foods among Swedish consumers is related to health-consciousness and perceived effect. Br. J. Nutr. 98, 10581069.

5. Dutta-Bergman MJ (2004) Primary sources of health information: comparisons in the domain of health attitudes, health cognitions, and health behaviors. Health Commun. 16, 273-288.

6. Crawford R (2006) Health as a meaningful social practice. Health: 10, 401-420.

7. Steptoe A, Pollard TM \& Wardle J (1995) Development of a measure of the motives underlying the selection of food: the food choice questionnaire. Appetite 25, 267-284.

8. Pula K, Parks CD \& Ross CF (2014) Regulatory focus and food choice motives. Prevention orientation associated with mood, convenience, and familiarity. Appetite 78, 15-22.

9. Euromonitor International (2011) Female Breadwinners - How the Rise in Working Women is Influencing Spending Patterns.

10. Euromonitor International (2012) Impact of New EU Regulations on Functional Food/Drink Claims (Part 3: Opportunities and Challenges).

11. World Health Organization (1948) Preamble to the Constitution of the World Health Organization as adopted by the International Health Conference. New York: World Health Organization.

12. Saracci $R$ (1997) The world health organisation needs to reconsider its definition of health. BMJ 314, 1409-1409.

13. Editorial (2009) What is health? The ability to adapt. Lancet 373, 781.

14. Reich JW, Zautra AJ \& Stuart Hall J (2012) Handbook of Adult Resilience. Spring Street: The Guilford Press.

15. Van Ommen B \& Stierum R (2002) Nutrigenomics: exploiting systems biology in the nutrition and health arena. Curr Opin Biotechnol 13, 517-521.

16. Weseler AR, Ruijters EJB, Drittij-Reijnders M-J, et al. (2011) Pleiotropic Benefit of Monomeric and Oligomeric Flavanols on Vascular Health - A Randomized Controlled Clinical Pilot Study. PLoS One 6, e28460.

17. Hanekamp JC \& Bast A (2008) Why RDAs and ULs are incompatible standards in the Ushape micronutrient model: a philosophically orientated analysis of micronutrients' standardizations. Risk Anal. 28, 1639-1652.

18. Menrad K (2003) Market and marketing of functional food in Europe. J. Food Eng. 56, $181-188$. 
19. Eussen SRBM, Verhagen $\mathrm{H}$, Klungel $\mathrm{OH}$, et al. (2011) Functional foods and dietary supplements: Products at the interface between pharma and nutrition. Eur. J. Pharmacol. 668, S2-S9.

20. Levidow L \& Carr S (2007) Europeanising advisory expertise: The role of 'independent, objective and transparent' scientific advice in agri-biotech regulation. Env. Plann C Gov Policy 26, 880-895.

21. Vos E (2000) EU Food Safety Regulation in the Aftermath of the BSE Crisis. J. Consum. Policy 23, 227-255.

22. Chalmers D (2003) 'Food for Thought': Reconciling European Risks and Traditional Ways of Life. Mod. Law Rev. 66, 532-562.

23. European Commission (2000) White paper on food safety. COM 719.

24. European Parliament and Council of the European Union (2006) Regulation (EC) No 1924/2006 of the European Parliament and of the council of 20 December 2006 on nutrition and health claims made on foods. OJ L 404 49, 9-25.

25. European Parliament and Council of the European Union (2001) Directive 2001/83/EC of the European Parliament and of the Council of 6 November 2001 on the Community code relating to medicinal products for human use. OJ L 311 44, 67-128.

26. European Parliament and Council of the European Union (2004) Directive 2004/27/EC of the European Parliament and of the Council of 31 March 2004 amending Directive 2001/83/EC on the Community code relating to medicinal products for human use. OJ L 136 47, 34-57.

27. European Parliament and Council of the European Union (2002) Regulation (EC) No 178/2002 of the European Parliament and of the Council of 28 January 2002 laying down the general principles and requirements of food law, establishing the European Food Safety Authority and laying down procedures in matters of food safety. OJ L $3145,1-24$. 
Samenvatting en algemene conclusie 
In het verleden werd er geen onderscheid gemaakt tussen voeding en geneesmiddelen. Zowel voedingsmiddelen als geneeskrachtige middelen werden gevonden in de natuur. In diverse culturen met traditionele geneeskunde wordt nog altijd geen fundamenteel verschil gemaakt tussen voeding en geneesmiddelen. In de Westerse wereld zijn beide concepten echter uit elkaar gegroeid: voeding is vooral gericht op het voorkomen van honger en het voorzien in benodigde macro- en micronutriënten, terwijl geneesmiddelen zijn bedoeld om ziekten te genezen of symptomen van ziekten te verminderen. Dit onderscheid wordt ook concreet gemaakt in voedings- en geneesmiddelenwetgeving.

In de ruim 200 jaar dat geneesmiddelen gereguleerd worden, is er echter wel een verschuiving te zien. Door de economische en technologische vooruitgang is voeding niet alleen meer belangrijk bij het voorkomen van honger. Inmiddels gebruiken we voedingsmiddelen ook om ziekten te voorkomen en de gezondheid te bevorderen. Hierdoor verschuift de definitie van voeding richting medicijnen. Een voorbeeld hiervan is de toegenomen interesse in en het gebruik van functionele voedingsmiddelen; voedingsmiddelen die positieve effecten op de gezondheid hebben die verder gaan dan de voedingswaarde van het product. Om met deze verschuiving van voedingsproducten richting geneesmiddelen om te gaan, is wetgeving ontwikkeld om bijvoorbeeld de beweringen die over deze functionele voedingsmiddelen gemaakt worden te reguleren; de Europese verordening inzake voedings- en gezondheidsclaims voor levensmiddelen ${ }^{i}(\mathrm{NHCR})$. Het onderzoek gepresenteerd in dit proefschrift laat zien dat het belangrijk is om zowel de effecten van voeding en geneesmiddelen als bijbehorende wetgeving op een wetenschappelijke manier te ontrafelen, om beiden ondanks de verschuiving van voeding en geneesmiddelen te kunnen begrijpen.

\footnotetext{
' Verordening (EG) Nr. 1924/2006 van het Europees Parlement en de Raad van 20 december 2006 inzake voedings- en gezondheidsclaims voor levensmiddelen (Geconsolideerde versie 13 December 2014).
} 


\section{Belangrijkste bevindingen}

\section{De toepassing van de NHCR leidt tot een discussie over de effectiviteit}

In hoofdstuk 2 zijn de consequenties bestudeerd van de toepassing van de NHCR bij voedingsmiddelen met antioxidanten. Hierin zijn de aanleiding van het ontwikkelen van de NHCR beschreven als ook de betrokkenheid van de Europese Autoriteit voor Voedselveiligheid (EFSA) bij deze wetgeving. Drie criteria blijken essentieel te zijn in de beoordeling van de wetenschappelijke onderbouwing van gezondheidsclaims door EFSA: (i) het voedingsmiddel of functioneel ingrediënt moet goed worden gedefinieerd en gekarakteriseerd; (ii) het geclaimde effect moet goed worden gedefinieerd en moet fysiologisch gunstig zijn; en (iii) een oorzakelijk verband moet worden vastgesteld tussen de inname van het voedingsmiddel of functioneel ingrediënt en het geclaimde effect. De implicaties van deze criteria, zoals het in vivo kunnen meten van het effect, zouden toegepast moeten worden in het onderzoek dat gedaan wordt om gezondheidsclaims te onderbouwen. Deze implicaties lijken echter niet allemaal toepasbaar op voedingsonderzoek zoals het nu uitgevoerd wordt, waarbij men nog uitgaat van de statische definitie van gezondheid en methoden gebruikt worden die daarbij aansluiten zoals de gerandomiseerde klinische studie. De huidige discussie rondom de definitie van gezondheid geeft aanleiding tot het ontwikkelen van nieuwe methoden om gezondheidseffecten van voedingscomponenten vast te stellen. Deze nieuwe methoden moeten meegenomen worden bij het beoordelen van de wetenschappelijke onderbouwing van gezondheidsclaims. In het specifieke geval van antioxidanten doen de gebruikte evaluatiecriteria en gewenste methoden om effecten op gezondheid te meten, geen recht aan de complexiteit van de mechanismen en effecten van deze bioactieve stoffen. Dit wordt benadrukt door het opmerkelijke verschil in het aantal voorgestelde claims (meer dan 200) ten opzichte van de acht claims die zijn toegekend.

In hoofdstuk 3 zijn 14 personen met vier verschillende invalshoeken (fabrikanten, wetgevingsdeskundigen, voedingswetenschappers en consumentenvertegenwoordi- 
gers) geïnterviewd, die in aanraking komen met de NHCR. Door middel van interviews hebben we geanalyseerd hoe deze belanghebbenden naar de toepassing van de NHCR kijken. Hiermee hebben we geprobeerd te ontrafelen waarom vele voorgestelde gezondheidsclaims op voedingsmiddelen met antioxidanten zijn afgewezen. De kwaliteit van het wetenschappelijke bewijs dat voorgestelde claims moest onderbouwen wordt gezien als belangrijkste reden voor het afwijzen van voorgestelde gezondheidsclaims. De geïnterviewde belanghebbenden wijten dit allereerst aan het gebruik van wetenschappelijke methoden waarover nog geen consensus is bereikt. Ook geeft men aan dat er een groot verschil was tussen wat indienende instanties dachten aan te moeten leveren als bewijs en hoe het bewijs uiteindelijk in de beoordelingsprocedure gewogen werd Hierbij hebben we drie elementen geïdentificeerd waarin de toepassing van de NHCR zou kunnen worden verbeterd: (i) de handhaving, (ii) de gebruikte methoden in voedingswetenschappen, en (iii) de visie op het effect van de NHCR op innovatie, onderzoek, de markt en consumenten. De belanghebbenden blijken zeer uiteenlopende opvattingen te hebben, waardoor de effectiviteit van de NHCR in zijn huidige vorm betwijfeld kan worden. De standpunten van de geïnterviewde belanghebbenden geven richting aan de discussie rondom de NHCR in het beschrijven van effecten op de gezondheid.

\section{Voor de effectiviteit van de NHCR zijn vergelijkbare nalevingsstrategieën in de gehele EU cruciaal}

Naleving is cruciaal om de doelstellingen van de NHCR te behalen: consumenten beschermen tegen misleiding door valse of onjuiste beweringen, maar ook een gelijk speelveld op de Europese interne markt te creëren voor alle levensmiddelenfabrikanten. Europese voedingswetgeving zoals de NHCR moet worden gehandhaafd door de nationale handhavingsautoriteiten. Als gevolg van 
Verordening (EG) 882/2004ii moeten nationale handhavingsautoriteiten bij het controleren van de naleving van (dier)voedingswetgeving hun handhavingsaanpak baseren op risico's. Onze analyse in hoofdstuk 4 laat echter zien dat de handhaving van de NHCR gefragmenteerd is binnen de EU. Dit wordt duidelijk door de 13 verschillende richtlijnen over de flexibiliteit van bewoording van claims en/of de algemene naleving van de NHCR die zijn ontwikkeld door 18 lidstaten. Intussen zijn uiteenlopende acties ondernomen door de nationale handhavingsautoriteiten bij het corrigeren van schending van naleving. Deze acties variëren van strafmaatregelen als het opleggen van boetes tot overredende maatregelen als 'naming and shaming'. Door deze fragmentatie is de NHCR momenteel niet in staat een gelijkwaardig speelveld te creëren. Wij pleiten voor de ontwikkeling van een EU-brede aanpak bij het handhaven van de NHCR om eerlijke concurrentie op de interne markt te waarborgen.

\section{Het wereldwijde landschap van voeding en gezondheidsclaims verordeningen is zeer divers}

De Europese verordening inzake voedings- en gezondheidsclaims voor levensmiddelen wordt vergeleken met internationale regelgeving rondom deze claims in hoofdstuk 5. We beschrijven de wereldwijde diversiteit in benaderingen en schetsen manieren om de procedures te optimaliseren vanuit een wetenschappelijk perspectief. Regelgeving in 28 jurisdicties zijn bediscussieerd, waarbij drie prominente verschillen aan het licht komen, namelijk: (i) de indeling en het toestaan van verschillende typen voedings- en gezondheidsclaims, (ii) variaties in (pre-marketing) vergunningsprocedures, en (iii) het gebruik van het wetenschappelijke minderheidsstandpunt in te onderbouwen claims. Diverse benaderingen hebben positieve aspecten, maar er kan er geen optimale aanpak geïdentificeerd worden in de huidige werkwijzen. Door wereldwijd een gelijke aanpak te kiezen voor deze drie aspecten kan wet- en

\footnotetext{
i Verordening (EG) nr. 882/2004 van het Europees Parlement en de Raad van 29 april 2004 inzake officiële controles op de naleving van de wetgeving inzake diervoeders en levensmiddelen en de voorschriften inzake diergezondheid en dierenwelzijn (Geconsolideerde versie 30 juni 2014).
} 
regelgeving worden ontwikkeld die fabrikanten stimuleert functionele voeding te ontwikkeling en consumenten meer kansen biedt om gezondheidsbevorderende producten te gebruiken.

\section{De interacties tussen voeding en geneesmiddelen hebben positieve of negatieve effecten}

Het verschuiven van de beleving van de rol en de effecten van voeding en geneesmiddelen wordt bestudeerd in hoofdstukken 6 en 7. In hoofdstuk 6 hebben we mogelijke positieve effecten van de inname van voedingscomponenten geëvalueerd bij chronische inflammatoire longziekten. We tonen aan dat diverse componenten ontstekingsfactoren in de longen kunnen verminderen en daarmee de longfunctie van patiënten verbeteren. Gezien het aantal gewogen artikelen in deze review lijken in het bijzonder omega-3 vetzuren en vitamine $\mathrm{E}$ zowel de inflammatoire en immunologische markers als ook de longfunctie van patiënten met chronische inflammatoire longziekten positief te beïnvloeden. Veel andere voedingscomponenten tonen weinig tot geen effecten op ontstekingen of longfunctie, hoewel het aantal gewogen studies vaak te klein is voor een betrouwbare beoordeling. De potentiële gunstige effecten van verschillende voedingscomponenten op chronische inflammatoire longziekten kunnen leiden tot een verbeterde kwaliteit van leven van patiënten. Door zulke voedingscomponenten te gebruiken, kunnen anti-inflammatoire en bronchodilatoire therapieën teruggebracht worden waardoor zowel bijwerkingen als de ontwikkeling van resistentie tegen deze medicatie afnemen.

In hoofdstuk 7 worden bijwerkingen tussen voedingssupplementen of kruiden en geneesmiddelen zoals die zijn gemeld bij het Nederlands Bijwerkingen Centrum Lareb bestudeerd. Door de toegenomen populariteit van voedingssupplementen en kruidengeneesmiddelen verhoogt ook het risico op interacties tussen voorgeschreven medicatie en deze bioactieve producten. Van 55 gemelde bijwerkingen wordt gedacht dat deze veroorzaakt worden door de gelijktijdige inname van bioactieve stoffen en 
medicijnen. Het grootste deel van deze vermoedelijke interacties lijken te ontstaan tijdens het metabolisme van de stoffen en bij de uiting van het effect. Waar in de wetgeving voeding en medicijnen als verschillende concepten worden gezien, is de wetgeving rondom de verschillende bioactieve producten minder duidelijk. Dit kan alleen worden opgelost door de moleculaire kennis van biologisch actieve stoffen en interacties te verhogen. Hiermee kunnen potentiële interacties beter begrepen en voorkomen worden.

\section{Functionele voedingsmiddelen en ingrediënten moeten gekarakteriseerd worden op basis van hun bioactieve bestanddelen}

Bij het beoordelen van de wetenschappelijke onderbouwing van een gezondheidsclaim onder de NHCR is het eerste criterium de definitie en karakterisering van de werkzame stof. Deze werkzame stof is verantwoordelijk voor het geclaimde effect. In hoofdstuk 8 analyseren we drie gezondheidsclaims waarin deze werkzame stof rechtstreeks verbonden is aan een specifiek levensmiddel met deze bioactieve stof. Deze verbinding wordt beschreven in de formulering van de claim of in de gespecificeerde gebruikscondities. De bioactieve stof zelf wordt echter verantwoordelijk gehouden voor het gezondheidseffect, waardoor de associatie met het specifieke levensmiddel niet altijd te rechtvaardigen lijkt. Wij laten zien dat twee elementen bepalen of de bioactieve stof in een claim als stof op zich wordt gezien of gekoppeld wordt aan een specifiek voedingsmiddel: (i) het type claim, waarbij het doorslaggevend is of het een generieke claim is (artikel 13.1 claim) of een claim is die gebaseerd is op nieuwe, en dus beperktere hoeveelheid wetenschappelijke gegevens (artikel 13.5 claim), en (ii) het beschikbare en ingediende wetenschappelijke bewijs voor de voorgestelde claim, waarbij vaak de koppeling met een specifiek voedingsmiddel gemaakt wordt in de uiteindelijke claim als dit ook gedaan is in de wetenschappelijke studies ter onderbouwing van de claim. Het zou echter onze voorkeur hebben om ingrediënten specifieker chemisch te definiëren, zodat de daadwerkelijke bioactieve stof benoemd wordt in de claim en diens beoordeling. Nu wordt in de gezondheidsclaims vaak een generieke term gebruikt of verwezen naar het voedingsmiddel als geheel, terwijl de 
bioactieve stoffen verantwoordelijk zijn voor het gezondheidseffect. Als deze stoffen chemisch gedefinieerd kunnen worden, hoeven de bioactieve stoffen niet meer gelinkt te worden aan een specifieke matrix. Zo wordt het transparanter welk ingrediënt het gezondheidsvoordeel beschreven in de claim veroorzaakt en wordt de claim relevanter voor zowel de industrie als de consument. Daarom zouden karakterisering en definiëring van de werkzame stof centraal moeten staan in het beoordelen van de gezondheidsclaim.

\section{Conclusie}

Bij het ontwikkelen van nieuwe wet- en regelgeving op voeding en geneesmiddelen zou rekening gehouden moeten worden met de verschillen en overeenkomsten tussen voeding en geneesmiddelen en de intermediaire productcategorieën die zich richten op gezondheid en gezondheidsbevordering. Hoewel fabrikanten de intermediaire categorieën van gezondheidsproducten zouden kunnen misbruiken bij het presenteren van hun product, creëert het ontwerpen van meer wetgeving op deze categorieën alleen maar meer onduidelijkheid bij alle spelers op de markt. Door in de beoordeling de bioactieve stoffen centraal te stellen in plaats van de rechtspositie van producten, kan er meer eenduidige wetgeving worden geformuleerd. Daarmee ontstaat de mogelijkheid tot het ontwerpen van nieuwe wetgeving, die zowel innovatie stimuleert alsook consumenten beschermd.

Door de effecten van zowel voeding als geneesmiddelen te kunnen ontrafelen, kan er duidelijkheid geschapen worden over wat men mag verwachten van de verschillende typen producten. Het scheiden van de juridische begrippen van voeding en medicijnen verbetert de transparantie over het positioneren van verschillende gezondheidsbevorderende producten. Toegenomen begrip van beide aspecten afzonderlijk helpt bij het begrijpen van beide aspecten: het effect van voeding en geneesmiddelen verduidelijkt hun juridische positie, waar de juridische positie van 
voeding en geneesmiddelen kunnen helpen om aan te geven welk effect verwacht mag worden. Deze interactie tussen effect en wetgeving vereist dat beiden verduidelijkt worden. Wanneer de juridische begrippen en biochemische effecten duidelijker met elkaar overeen komen, zal niet alleen kennis van consumenten over voeding en medicijnen toenemen maar zullen ook meer mogelijkheden ontstaan om te innoveren. 



\section{Valorisatie addendum}




\section{Relevantie}

Steeds meer mensen zijn op zoek naar manieren om hun gezondheid in stand te houden en te verbeteren, zonder direct medicijnen te nemen.. Door onder meer de ontwikkeling van functionele voedingsmiddelen, maar ook van vitaminesupplementen en kruidenpreparaten is het aanbod van producten die specifiek gericht zijn op het verbeteren van de gezondheid, sterk gegroeid. Hiermee wordt duidelijk dat voedingsproducten nu niet alleen meer gebruikt worden om honger te vorkomen, maar ook om gezondheid in stand te houden. Daarmee krijgt voeding steeds meer het karakter van een medicijn.

Om er uit te springen in het schap, wil een producent vertellen wat zijn product bevat (een voedingsclaim) of kan doen (een gezondheidsclaim). Maar om te voorkomen dat er effecten worden toegeschreven aan voeding, die niet waargemaakt kunnen worden, is wetgeving ontwikkeld om consumenten te beschermen. Deze Europese verordening op voedings- en gezondheidsclaims heeft als uitgangspunt dat de beweringen die op een product of in de reclame voor een product verschijnen, gebaseerd moeten zijn op wetenschappelijke gegevens.

Aangezien iedereen eet, wordt een ieder ook blootgesteld aan zulke voedings- en gezondheidsbeweringen op voedingsproducten. Daarnaast proberen consumenten bewust hun voedingspatroon te optimaliseren middels super foods, nutraceuticals en voedingssupplementen. Het onderzoek gepresenteerd in deze thesis, over claims op (functionele) voeding en de combinatie van (functionele) voeding en medicijnen, is dan ook van belang voor zowel consumenten als bedrijven.

\section{Doelgroepen en activiteiten}

Het onderzoek gepresenteerd in dit proefschrift laat zien dat consumenten de claims kunnen gebruiken om zichzelf te informeren over de effecten van voeding. Daarnaast blijkt dat het interessant kan zijn om (functionele) voeding te gebruiken bij ziekten, al 
brengt het combineren van medicatie met bioactieve stoffen, uit bijvoorbeeld voedingsproducten, ook risico's op bijwerkingen met zich mee. Dit onderzoek laat zien dat er nog veel valt te verbeteren bij het informeren van consumenten over voeding.

Daarnaast bevat dit onderzoek ook informatie voor de voedingsindustrie en professionals in de gezondheidszorg. Het wordt duidelijk hoe de voedingsindustrie om kan gaan met de voedings- en gezondheidsclaims verordening en welk onderzoek benodigd is om te voldoen aan de hierin gestelde eisen. Nieuwe kansen in het combineren van voeding en medicijnen worden geïdentificeerd. Bovendien identificeert het hier beschreven onderzoek een onderliggend probleem: de concepten van voeding en medicijnen verschuiven, waarmee de rechtspositie van deze typen producten onduidelijk is geworden. In deze thesis worden handvaten aangereikt om de overlap tussen voeding en geneesmiddelen te ontrafelen door middel van een moleculaire benadering. Zo'n moleculaire kijk op stoffen geeft: (i) heldere wetgeving (omdat de beoordeling stofgericht is); (ii) duidelijke claims (wat doet de stof); en (iii) innovatiemogelijkheden (de stof kan in diverse producten worden toegepast en duidelijker worden getest).

\section{Innovatie}

Dit proefschrift beschrijft diverse onderzoeken waarbij voedingswetenschappelijke kennis gecombineerd is met juridische inzichten. Een dergelijke interdisciplinaire aanpak, om trends en ontwikkelingen in voedingswetgeving te beschrijven en te analyseren, is nog niet vaak gekozen. Deze innovatieve manier van onderzoek doen biedt dan ook de mogelijkheid de verkregen inzichten direct toe te passen in een bedrijfssetting. Hiermee zijn de resultaten van dit onderzoek realistisch en toepasbaar. 


\section{Planning \& realisatie}

Het beschreven onderzoek laat zien dat de markt van producten met gezondheidseffecten sterk in beweging is. Zulke trends worden vaak gevolgd door het ontwikkelen van wetgeving. Dit onderzoek beschrijft de noodzaak om de wetgeving omtrent voeding en medicijnen aan te scherpen. Door in deze thesis wetgeving en effecten gelijktijdig te bestuderen, is het mogelijk geworden de concepten van voeding en geneesmiddelen zoals we die nu kennen aan te passen aan deze tijd. 


\section{Dankwoord}


Tot ongeveer drie jaar geleden had ik nooit gedacht te willen promoveren, maar wat ben ik blij dat ik deze stap heb genomen. Voor de totstandkoming van deze thesis ben ik dan ook een heleboel mensen dank verschuldigd, zonder wie dit proefschrift er nooit was geweest.

Allereerst een woord van dank aan mijn fantastische promotoren, Prof. Dr. Aalt Bast en Prof. Dr. Ellen Vos. Het blijft een mooi verhaal hoe ik in de zomer van 2012 aanschoof op de afdeling Toxicologie voor een stage bij een bedrijf en uiteindelijk eindigde als 'hobby-aio' op de afdeling. Aalt, bedankt voor het vertrouwen, de kritische gesprekken, de goede ideeën, de cadeautips en het nooit aflatende enthousiasme! Ellen, waar het voor mij zeker in het begin nog wel eens lastig was de juridische insteek te begrijpen, heb je me altijd geholpen om dit beter te interpreteren en te omschrijven. Bedankt voor je kritische blik en inspiratie!

Daarnaast wil ik graag de mensen die meegewerkt hebben aan de verschillende onderdelen van mijn onderzoek hartelijk bedanken: Dr. Florence van Hunsel (Lareb), Dr. Geja Hageman en Miriam Urlings. Florence, bedankt voor de prettige samenwerking in het inzicht krijgen in meldingen over interacties tussen voeding en geneesmiddelen. Bedankt voor het aandragen van de data en de uitleg over de interacties. Geja, bedankt voor het aanreiken van het interessante onderzoek waar we ons artikel op hebben kunnen baseren. Ik vond het erg fijn om hierin met je samen te kunnen werken. Miriam, bedankt voor je hulp bij het opzetten van de workshop in oktober 2014 en voor de samenwerking bij zowel Inprofood als bij de verschillende artikelen. Heel veel succes met je PhD!

Ook een woord van dank aan een ieder die meewerkte aan de interviews, die veel inzicht gaven in het gebruik van de wetgeving en daarmee inspiratie opleverden voor het gehele onderzoekstraject. Nathalie Baltus, nogmaals bedankt voor je hulp bij het uitwerken van deze interviews en natuurlijk bij de organisatie van het symposium in 2013. Ook mijn stagiairs, Wouter van der Worp en Sadaf Edalat, bedankt voor jullie inzet en harde werk tijdens jullie stages. Veel succes met jullie carrière! 
Graag wil ik ook op deze plaats de leden van de leescommissie hartelijk danken voor het beoordelen van mijn thesis. En mijn proefschrift had er niet zo mooi uit kunnen zien zonder Karel Klerks: bedankt voor het ontwerpen van de kaft!

Onderzoek doen is natuurlijk leuk, maar het is nog veel leuker als je het kunt delen met fijne mensen. Daarom wil ik hier alle collega's van de afdeling Farmacologie \& Toxicologie bedanken. Hoewel ik qua onderzoek soms een vreemde eend in de bijt was, ben ik blij dat jullie een poging gedaan hebben te begrijpen wat ik eigenlijk deed! Allereerst de aio's (hoewel ze niet allemaal meer aio zijn), dankzij wie ik me vanaf het begin af aan ontzettend welkom gevoeld heb op de afdeling. Bedankt voor alle gezellige koffiemomenten, pizza movie nights en heerlijke baksels! Erik, Daniëlle en Kristien, bedankt voor het fijne welkom toen ik net begon. Kristien, bedankt voor al je hulp bij het afronden van het boekje. Veel succes met jullie verdere carrière! Kevin en Agnieszka, veel succes met afronden en Agnieszka, enjoy your little family! Carmen, Misha, Charlotte, Timme, Quan, Mireille en Gesiele, net als de eerder genoemde aio's ben ik blij dat ik jullie heb leren kennen. Thanks for the nice atmosphere at the department and good luck with your projects! Matt, thanks for all the fun and crazy ideas, the pranks and I hope you still enjoy baking oranjekoek! Roger B, bedankt voor het organiseren van alle gezellige borrels en uitjes (samen met Misha, Leonie en vele anderen), maar eigenlijk nog veel meer voor de vroege koffie! Gertjan en Antje, bedankt voor jullie tips over onderwijs en Antje, bedankt voor al je hulp bij het doorlopen van mijn BKO-traject. Marie-Claire, bedankt voor het benodigde regelwerk, onder meer rondom mijn promotie. En natuurlijk ook Frederik-Jan, Roger G, Agnes, Agi, Jan, Lou, Daniëlle, Edwin, Guido, Marie-José, Thalita, Pieter en de collega's van farmacologie bedankt voor de samenwerking en fijne sfeer.

Twee mensen die ik iets nadrukkelijker wil bedanken zijn mijn paranimfen, Rianne en Lotte. Rianne, ik ben blij dat jij mijn kamergenootje bent geworden! Hoewel ons onderzoek en ook onze levens soms ver uit elkaar liggen, kunnen we elkaar goed begrijpen en ik ben blij dat we daar zo goed over hebben kunnen praten (naast alle 
andere dingen die voorbij kwamen ;)). Erg leuk dat jullie nu met z'n drietjes achter me staan! Lotte, wat fijn dat je naar Maastricht bent gekomen! Bedankt voor alle gezellige lunches, kopjes thee, avondjes eten en je eeuwige geduld. Meiden, bedankt dat jullie mijn paranimfen wilden zijn. Vanaf deze plaats nogmaals veel succes met jullie promotietrajecten, maar ik weet zeker dat het goed gaat komen!

Gelukkig was er naast het werken aan dit proefschrift ook tijd voor vele gezellige dingen met verschillende vrienden en vriendinnen. Ik kan pagina's aan jullie wijden, hoe blij ik ben dat naast de vele groepjes die nog bestaan (vanuit thuis, Wageningen, Venlo en Maastricht) ik nog persoonlijk contact heb met veel verschillende mensen die ik in de afgelopen jaren heb mogen leren kennen. Maar dat zeg ik net zo graag tegen jullie zelf onder het genot van een kopje koffie of thee, een etentje, een biertje of tijdens een feestje!

Last but not least wil ik nog een paar mensen in de schijnwerpers zetten, die daar meestal niet zo van houden. Heit \& $\mathbf{m e m}$, bedankt dat jullie er altijd zijn en dat ik wat er ook gebeurt - altijd terug kan. Ik ben blij dat jullie, samen met Wilmer \& Hilde (en Rinse en Hedser) en Jelke \& Elze, me altijd steunen, geïnteresseerd zijn, voorzien van (meestal) wijze woorden, kritisch meedenken en met beide benen op de grond houden. Dat zelfs Maastricht niet te ver is voor jullie dochter en kleine zusje kan ik ontzettend waarderen. Huub \& Mieke, eigenlijk kan ik hetzelfde over jullie schrijven: bedankt voor jullie interesse, raad en natuurlijk leuke (thema)vakanties! (Nu kunnen we wellicht een vakantie aan dit boek wijden!) En lieve Frits, wat bin ik wiis mei dy. Ik zou pagina's vol kunnen schrijven over hoe dankbaar ik je ben voor al je wijze woorden, je steun en je eeuwige vertrouwen (ook als ik dat zelf even wat minder had). Maar ik ben vooral blij dat, hoe ver weg ook, je altijd dichtbij bent. 


\section{Curriculum Vitae}




\section{Curriculum Vitae}

Alie de Boer was born on March 30th 1989 in Heerenveen, the Netherlands. In September 2007 she enrolled in the bachelors programme Nutrition \& Health at Wageningen University and started the masters programme Health Food Innovation Management of Maastricht University in 2011. During her internship at the department of Toxicology at Maastricht University, she analysed the implementation of the European nutrition and health claim regulation in the field of food products containing antioxidants. Meanwhile, Alie was trainee of the European project 'Inprofood' at the Faculty of Law of Maastricht University. After graduating, she started in September 2013 as PhD student at the department of Toxicology at Maastricht University. Here she studied the interactions between (functional) foods and pharmaceutics with a special focus on claims and legislation. Alie collaborated with various parties including Lareb (Netherlands Pharmacovigilance Centre) as well as the Eatwell programme of Maastricht University. In these two years she organised a symposium entitled 'Voedings- en gezondheidsclaims: wat zijn de mogelijkheden voor u?'in October 2013 and the workshop 'Inclusive Food Research Programming and Implementation' in October 2014. She participated in different workshops and attended congresses such as the European Food and Feed Law Congress in 2014. In December 2014 she also obtained the Dutch University Teaching Qualification. 
List of publications 


\section{Full papers}

De Boer, A., Vos, E., Bast, A., 2014. Implementation of the nutrition and health claim regulation - The case of antioxidants. Regulatory Toxicology and Pharmacology 68, pg. $475-487$.

De Boer, A., Bast, A., 2015. Stakeholders' perception of the nutrition and health claim regulation. International Journal of Food Sciences and Nutrition 66(3), pg. 321-328.

Khan, S., Timotijevic, L., Newton, R., Coutinho, D., Llerena, J., Ortega, S., Benighaus, L., Hofmaier, C., Xhaferri, Z., de Boer, A., Urban, C., Strähle, M., Da Pos, L., Neresini, F., Raats, M. M., and Hadwiger, K., 2015. How is 'innovation' understood? Cognitive framing among actors involved in the funding of food and health research across eight European countries. Food Policy (in press).

De Boer, A., Bast, A., 2015. International nutrition and health claim legislation. Food Policy 55, pg. 61-70.

De Boer, A., Urlings, M. J. E., Vos, E., Bast, A., 2015. Enforcement of the nutrition and health claim regulation. European Food and Feed Law Review 5/2015.

De Boer, A., van de Worp, W. R. P. H., Hageman, G. J., Bast, A.. The effect of dietary components on inflammatory lung diseases - a literature review.

Submitted.

De Boer, A., van Hunsel, F., Bast, A.. Adverse food-drug interactions. Submitted.

De Boer, A., Urlings, M. J. E., Bast, A.. A bioactive is a bioactive is a bioactive: active ingredients should be leading in health claims on functional foods.

Submitted. 


\section{Abstracts}

De Boer, A., Bast, A.. Ten factors that influence the perception of the NHCR - the case of antioxidants. NUTRIM day, December 2013, Maastricht, the Netherlands

De Boer, A., Urlings, M.J.E., Vos, E., Bast, A.. Enforcement of the nutrition and health claim regulation. NUTRIM day, December 2014, Maastricht, the Netherlands 
